\title{
Accountability and responsibility : the influence of organisation design on management accounting
}

Citation for published version (APA):

Roberts, H. J. E. (1993). Accountability and responsibility : the influence of organisation design on management accounting. [Doctoral Thesis, Maastricht University]. Datawyse / Universitaire Pers Maastricht. https://doi.org/10.26481/dis.19930609hr

Document status and date:

Published: 01/01/1993

DOI:

10.26481/dis. $19930609 \mathrm{hr}$

Document Version:

Publisher's PDF, also known as Version of record

\section{Please check the document version of this publication:}

- A submitted manuscript is the version of the article upon submission and before peer-review. There can be important differences between the submitted version and the official published version of record.

People interested in the research are advised to contact the author for the final version of the publication, or visit the DOI to the publisher's website.

- The final author version and the galley proof are versions of the publication after peer review.

- The final published version features the final layout of the paper including the volume, issue and page numbers.

Link to publication

\footnotetext{
General rights rights.

- You may freely distribute the URL identifying the publication in the public portal. please follow below link for the End User Agreement:

www.umlib.nl/taverne-license

Take down policy

If you believe that this document breaches copyright please contact us at:

repository@maastrichtuniversity.nl

providing details and we will investigate your claim.
}

Copyright and moral rights for the publications made accessible in the public portal are retained by the authors and/or other copyright owners and it is a condition of accessing publications that users recognise and abide by the legal requirements associated with these

- Users may download and print one copy of any publication from the public portal for the purpose of private study or research.

- You may not further distribute the material or use it for any profit-making activity or commercial gain

If the publication is distributed under the terms of Article $25 \mathrm{fa}$ of the Dutch Copyright Act, indicated by the "Taverne" license above, 


\section{ACCOUNTABILITY AND RESPONSIBILITY}

The Influence of Orga nisation Design on

Management Accounting 
CIT.DATA KONINKLIJKE BIBLIOTHEEK, DEN HAAG

Roberts, Henri Johan Eduard

Accountability and responsibility : the influence of organisation design on management accounting / Henri Johan Eduard Roberts. - Maastricht : Universitaire Pers Madstricht. - III.

Thesis Maastricht. - With ref. - With summary in Dutch. ISBN 90-5278-082-X

Subject headings: management accounting / organisation theory / sociotechnical systems design.

Produktie: Corien Gijsbers

Druk: Datawyse I Universitaire Pers Maastricht 


\section{ACCOUNTABILITY AND RESPONSIBILITY}

\section{The Influe nce of Orga nisation Design on Management Accounting}

\section{PROEFSCHRIFT}

ter verkrijging van de graad van doctor aan de Rijksuniversiteit Limburg te Maastricht, op gezag van de Rector Magnificus, I'rof. mr. M.J. Cohen, volgens het besluit van het College van Dekanen, in het openbaar te verdedigen op woensdag, 9 juni 1993 om 14.00 uur

door

Henri Johan Eduard Roberts

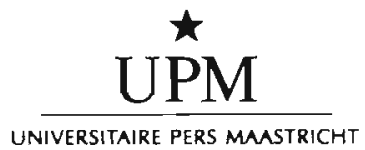


Promotor:

Prof. dr. J.F. den Hertog

Beoordelingscommissie:

Prof. dr. W.F.J. Buijink (voorzitter)

Prof. dr. J.M. Pennings

Prof. dr. J.H.R. van de Poel

Prof. dr. H. Schreuder

Prof. dr. L.U. de Sitter

Prof. dr. J.A.M. Theeuwes (TU Eindhoven) 


\section{Table of Contents}

Acknowledgements vii

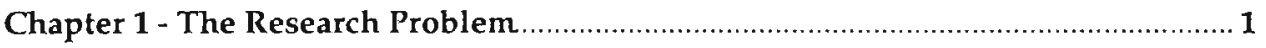

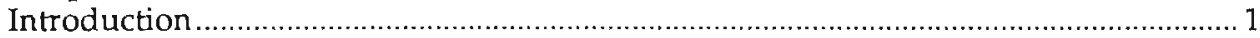

The Changes in Competitive Demands ........................................................................ 2

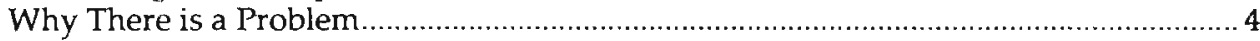

What Sort of Management Accounting is Needed .................................................. 6

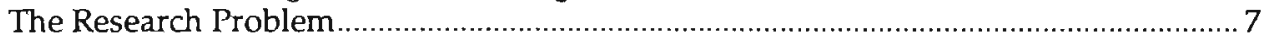

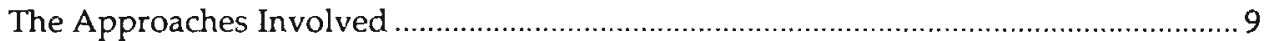

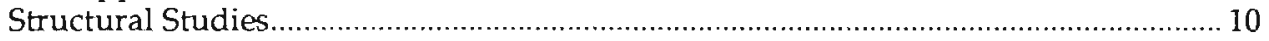

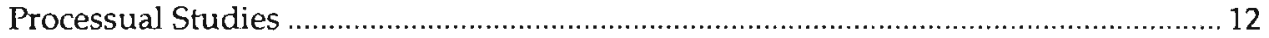

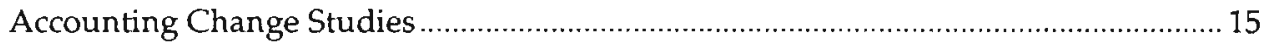

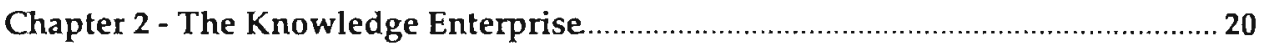

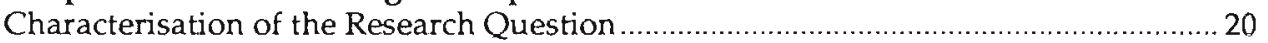

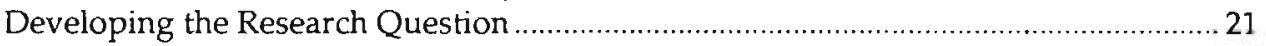

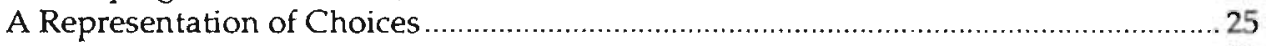

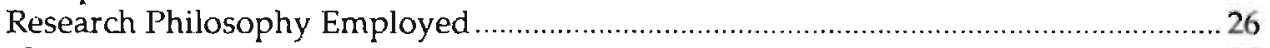

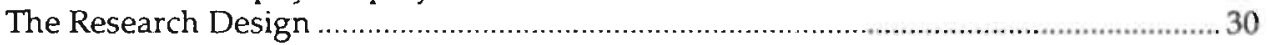

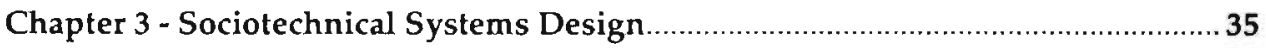

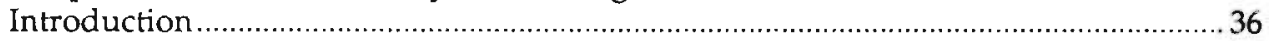

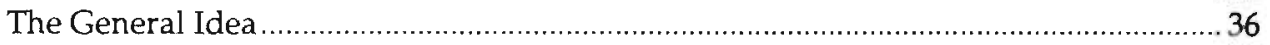

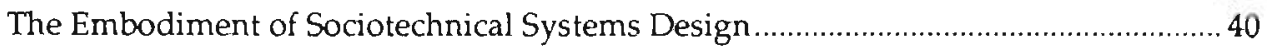

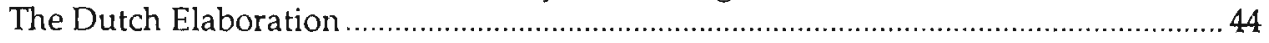

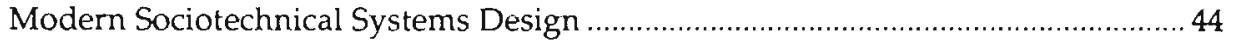

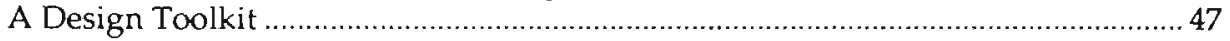

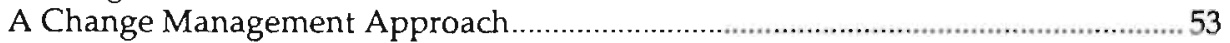

Chapter 4 - Case Van Nelle Tobacco/Rotterdam Plant ...........................................57

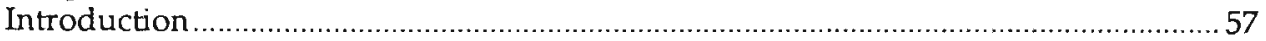

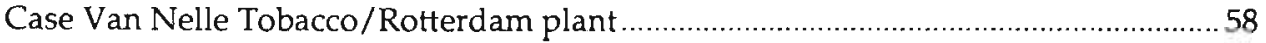

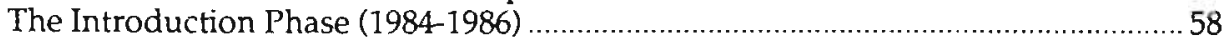

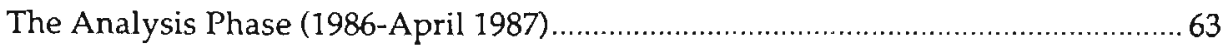

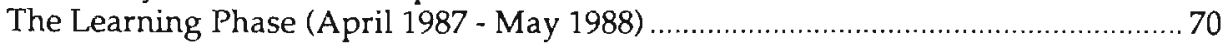

The Control and Information Structures ........................................................ 72

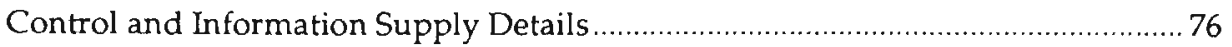

The Relationship with the Management Accounting System

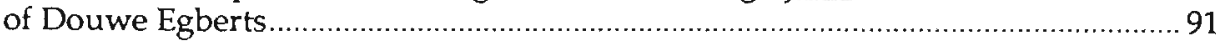




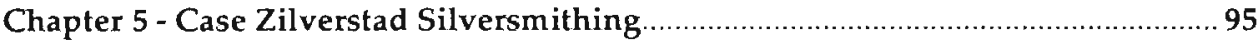

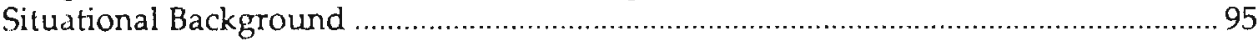

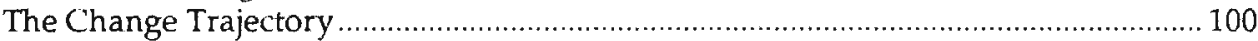

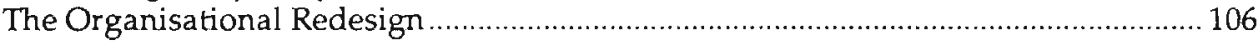

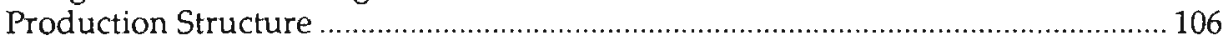

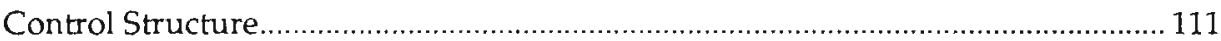

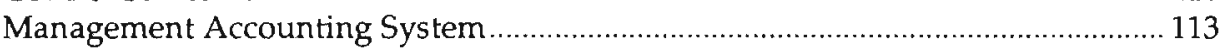

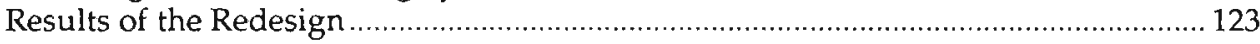

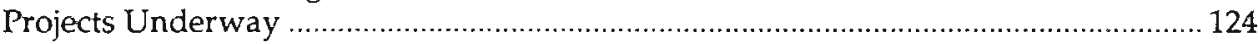

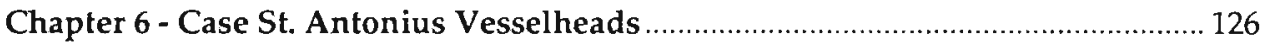

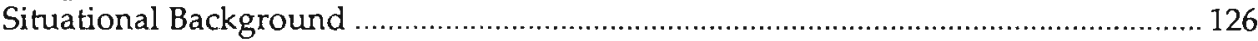

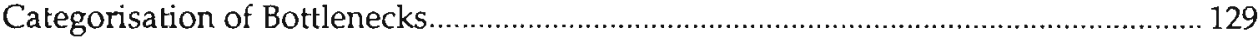

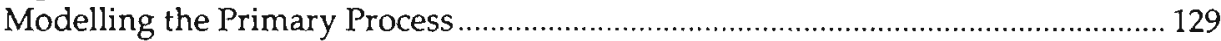

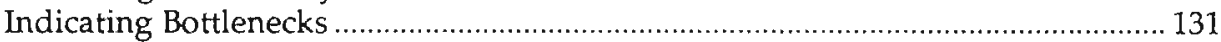

Relating Bottlenecks to Organisation Structure............................................... 132

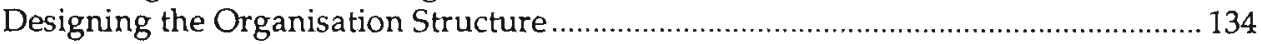

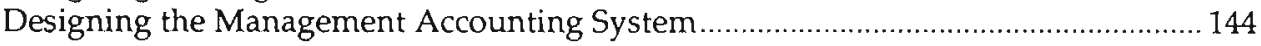

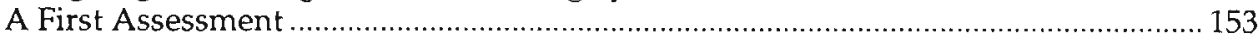

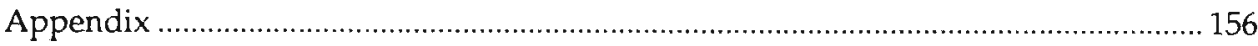

Chapter 7 - Case Analysis and Cross-Case Comparison ...................................... 158

Grounded Analysis of Van Nelle Tobacco/Rotterdam Plant ................................... 159

Grounded Analysis of Zilverstad Silversmithing ............................................... 173

Comparison of Van Nelle and Zilverstad ............................................................ 184

Grounded Analysis of St. Antonius Vesselheads ................................................ 188

Comparison of Van Nelle, Zilverstad and St. Antonius ........................................... 198

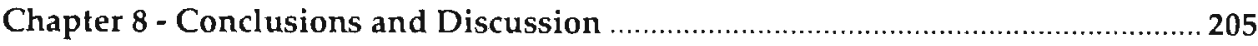

Organisation Design and Management Accounting Design -

Simple Organisations Make Simple Administrations ............................................. 211

Accounting and Learning Organisations ............................................................. 218

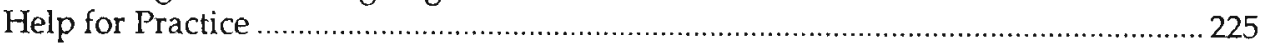

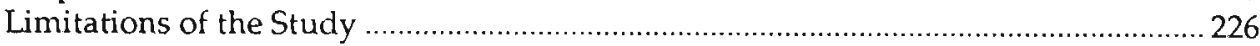

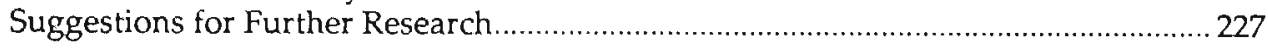

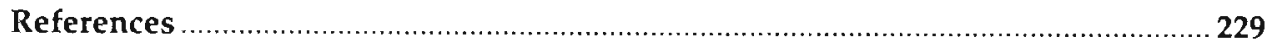

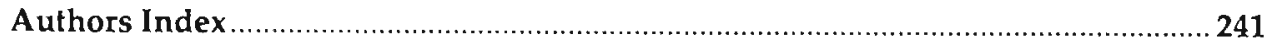

Nederlandse samenvatting - Summary in Dutch ................................................. 243

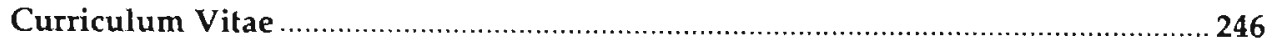




\section{Acknowledgements}

The preparation, executing and writing of a research study looks like a one-person affair, as only one name is mentioned on the cover. Nothing is farther from the truth. It is a multi-person event, involving many people in various roles.

First of all, my friends of the Technology, Work and Organisation (TAO) team at the Maastricht Economic Research institute on Innovation and Technology (MERIT): Friso den Hertog, who was as much a guide as a friend when confronted with the frequent questions of "how now?" The good atmosphere he created within the team was happily continued by my colleagues Jan Cobbenhagen and Ed van Sluijs, with whom I had research-related as well as many research-unrelated discussions. Moreover, the secretarial staff that supported the team were really the people that maintained the good working atmosphere on a day-to-day basis: Corien Gijsbers and Lori Mees wert always there to help (see the high-quality outline of this study) and we also had a lot of fun. Also, they provided the necessary corrections to my usage of the English language and turned it into something that could be understood by persons other than myself.

Having a good team of friends at your side in itself will not produce a research study if there is not an equally encouraging research topic. It was the many people I met 'out there' that gave life and contour to what I was trying to find out. Therefore, I would like to thank Rik van Sonsbeek and Toine Domensino of Van Nelle Tobacco/Rotterdam for their very clear and insightful accounts; it was their explanations that provided the insight that further guided my research activities. Furthermore, I would like to thank Messrs. Arne and Arie Pluut, and Klaas Teeuwen of Zilverstad $B V$ for their unrestrained help and cooperation in showing me how to turn a small company into a frontrunning business. Last but not least, I would like to thank Raymond Cordewener and Cor Jansen of St. Antonius for the many hours they spent explaining things to me and the kilos of information on how to redesign and manage a high-tech business in a competitive European market. Having met them and listened to them helped create much of my research excitement and convinced me of the qualities of Dutch managers.

Next, there are the many people that made things pussible. First of all, the consultants of KOERS Consultancy BV, Mieke van den Oetelaar and Frank Verschuur. They provided access to the above-mentioned companies and added a lot of refreshing perspectives and insights acquired from their long consultancy experiences to mine.

The Technology, Work and Organisation programme committee provided the funding and institutional framework for this study. The joint efforts of the participating Dutch ministries of Education \& Sciences, of Economic Affairs, and of Social Affairs \& Employment have created a unique research programme that is now beginning to reap its first benefits. 
I would like to thank my colleagues of the University of Limburg and, especially, the accounting section of the Business Department for their tolerance with me and with my preoccupation with topics that were often very unrelated to their own ways of thinking and research.

I would like to thank The Staal Stichting 1966 for their support in funding the publication of this study.

In conclusion, I thank my wife Ellen Krijnen. Without her presence and support, this study would not have been completed and I would not have become the happy person I am right now.

Hanno Roberts

Madrid, March 1993 


\section{The Research Problem}

Chapter 1 deals with the research problem, its background, and its theoretical positioning. The organisational design model underlying management accounting has changed. Organisation design is moving away from Tayloristic functional grouping, specialised tasks and is making a distinction between thinking and doing. The organisation design that is gradually appearing is that of flow-oriented organisations with flat structures and using a team approach and integrated tasks. Management accounting is also required to accommodate this new organisation design and must reconvert itself accordingly. It is argued that studying this rematching is best accomplished by field study research of transition situations in practice. The focus of this study is directed at the comparison of previous and present organisation designs as well as the concurrent change in the management accounting systems designs. It is concerned with the following questions: Is there a particular redesign logic in management accounting systems and what is its connection with the redesign logic of the organisation? And does redesign involve the adaptation, renovating or invention of traditional management accounting instruments? The research problem is positioned in organisational research in accounting. This study contains both a structural and a processual perspective on action, and its level of analysis is the organisation.

\section{Introduction ${ }^{1}$}

Since the early 1980s, competition between firms has changed. Authors like Porter $(1980,1985)$ tended to follow an intensified reflection on the competitive posture and ambitions of firms. His framework for competitive strategy did not only distinguish between cost, focus and differentiation strategies, but also pointed out the competitive forces of consumers, suppliers, new entrants, substitute products and existing organisations within the industry. Suddenly, firms seemed to realise that they were living in a world in which they were surrounded by competitive advantages and disadvantages. They had to line up their affairs and decide where they competitively stood, and what action to take to improve or to defend their position. 
The upsurge in attention for Japanese management practices amplified the feeling, especially in the U.S., that established management tools and routines were lagging behind and had to catch up. The Japanese produced better and cheaper automobiles, microelectronics and audio equipment; they even wiped out the rest of the world in cameras and motorbikes. And they were successful wherever and whenever they started to compete! Customers massively wanted high-quality products that were made to their personal demands and immediately available. It led to the 'discovery' of the new competitive parameters of quality, flexibility and innovativeness (Bolwijn, 1988; Bolwijn and Kumpe, 1987, 1990; Roberts, 1990), almost at the same time that firms began to realise that competition was both global and could be coming from such forces as suppliers and product substitutes. Companies now had to adopt a far more comprehensive business approach as well, including all 'new' competitive forces and parameters.

\section{The Changes in Competitive Demands}

With competitive awareness growing fast and industries beginning to lag, the tendency arises to copy successful competitors, i.e., asking questions as to how the Japanese run their organisations. Many studies of management were initiated, usually relating to one of the competitive parameters of quality, flexibility, timeliness or innovativeness. The high performance on quality of Japanese companies played an important role in their first competitive successes. The concept of statistical in-process quality control formed the basis for a systematic approach in organising for quality performance. Such methods as quality circles, a high level of industrial and process engineering, various forms of on-line feedback in manufacturing and stepwise product improvement were found to be of importance.

Customisation was considered a part of product quality, usually expressed as 'fitness for use': The customer decides whether the product fits his needs. Tying its design as much as possible to these needs will make him a prospective customer for a long time. Product quality thus defined, resulted in a crystallisation of markets, and with it came an opportunity to execute a focus or differentiation strategy. Customisation introduced a large product variation and, consequently, a large number of small production batches. To combine both a large product variety and economies of scale, advanced manufacturing technologies such as Flexible Manufacturing Systems (FMS) and Computer Integrated Manufacturing (CIM) provided help. These highly automated and computerised systems enabled firms to design, engineer, plan, manufacture and deliver products with a high level of customisation. The large number of product/customer specifications are stored by the computer, which can, for example, use this information at any time to control manufacturing operations. Also, switching operations from one product to another is done automatically by the computer, rendering a much more flexible organisation in terms of production capabilities and customer demands.

With quality properly taken care of, the process control of Japanese companies was sophisticated enough to use it as a tool. A tool for another goal: the timeliness of their processes. Competing on time indicates the use of a time consumption resource model throughout the value chain of the organisation, including both suppliers and customers (Stalk, 1988). Using it, first of all means excluding the 
time wastes within the value chain. As these wastes are eliminated, a start can be made with reducing actual time consumption; standardising operations on a time basis. This model is fully represented in the Just-In-Time (IIT) philosophy: at (production) control system based on the customer "pulling" the product out of the company instead of having the product 'pushed' to him from inventory, thus reversing the idea of upstream and downstream product flows (Boons and Roberts, 1990). Inventories in JIT systems are considered a waste of resources, because they slow down the flow (rest time) and add no value to the product (value adding is considered equivalent to operating time). As a result, throughput time, capacity utilisation and volume turnover will increase, generating profits (and losses) faster.

Hand in hand with an increase in timeliness goes an increase in product flexibility. If one is able to rapidly develop, manufacture and market products, the product follow-up can be considerably increased. As soon as product Mark-I is marketed, it can be evaluated on its customer satisfaction and profit potential. This information is input for redesigning a Mark-II, tying it again closer to customer satisfaction. In this respect, computer-aided technologies not only increase the rate of product turnover but also improve pre-market testing, using Computer-Aided Testing/Design. Innovations can therefore be developed quicker, with the market place less serving as a final evaluation of its success ('economies of speed'; Bertsch, 1989).

The above developments in quality, timeliness, flexibility and innovativeness have also radical consequences for the design of the organisation and the management of the human resources. However, these implications are not always recognised. Many organisations continue on the same footing, introducing new approaches and technologies to an organisation based on a Tayloristic design. This Tayloristic organisation design has all the characteristics of a machine bureaucracy (Mintzberg, 1979). It maintains:

1) a sharp distinction between staff and line functions, coinciding with a distinction between thinking and doing;

2) a functional classification, grouping sort to sort, its application including R\&D;

3) a strong hierarchy; and

4) an extreme splitting up of tasks.

The accounting response to this Tayloristic model is the consideration of labour as being a cost. For example, accounting can very well handle line functions, that is, the doing part of doing and thinking: direct labour costs. The thinking part of doing and thinking disappears into diffuse overhead categories which, until recently with the emergence of Activity-Based Costing, could be made managerable only with considerable difficulty.

Nevertheless, more and more firms come to the conclusion that the new competitive parameters only flourish in a certain type of organisation. This other organisation design is a far cry from the Tayloristic mode of organisation. Its characteristics are:

1) bringing staff and line (thinking and doing) back together; 
2) a flow-oriented production;

3) a flat organisation structure;

4) integrated tasks, up to the level of maintaining a team approach, including R\&D.

In this organisation model, labour is conceived of as an asset rather than a cost. Labour stands for human resources providing the very competences of the organisation. Accounting, however, has not been able yet to comply with this new type of organisation model. Moreover, the accounting representation of intellectual assets (R\&D and all other sorts of expertise) as well as Human Resource accounting never did get off the ground, and is as yet not included in regular accounting reporting.

Recent studies by Adler (1986, 1988), Adler and Helleloid (1987) and Jaikumar (1986) corroborate the characteristics of this new model. For example, in his studies of the implementation of flexible automation, Adler notes that human resource management issues were the major stumbling blocks for successful implementation (1988, p. 48). Jaikumar, in his study of the highly different productivities of flexible manufacturing systems in Japanese and U.S. firms, relates this low productivity in U.S. firms to the lack of accompanying changes in the organisational model. Especially the management of 'intellectual capital' instead of equipment, and the focus on decentralised and multi-skill, multi-disciplinary team work are major features of this new organisation model.

\section{Why There is a Problem}

It was Robert S. Kaplan who cued the reflections on the management accounting discipline and what it still has to offer to firms facing the competitive world described above. In the book Relevance Lost: The Rise and Fall of Management Accounting (Johnson and Kaplan, 1987), he questioned whether management accounting was as useful as it was in early 1900, when it was developed. Using historic analysis, he showed that most of the present-day accounting instruments and concepts were products of the then prevailing business situation: A world characterised by price competition with low-tech factories turning out large volumes of standardised products. Production economies of scale ruled the accounting concepts. Large volumes meant low costs and therefore improved price competition.

To get these large volumes, highly centralised and functionally specialised organisations were established in order to promote maximum efficiency. Frederick Taylor's 'scientific management' methods were used to split up processes as much as possible and divide labour into specialised functions providing further economies of scale. When processes could not be split up any further - i.e., when one single task content was assigned - operating standards were set. Originally, these standards were set to provide information for planning the work flow, but soon they were used to control costs, comparing standards with actuals and intervening when variances got 'out of control'. The first (standard) cost system was born. Also, as a consequence of the maximal division of labour, a massive and bureaucratic organisation structure was required. Each further process desaggregation was complemented with an additional control level. 
The different units and divisions had to be controlled on their performance, both in terms of volume and in profit. At the same time, control based on one-dimensional cost standards such as material or labour, proved insufficient to capture the multiple number of activities contained in a single division. A problem which arose because a multi-activity division was run as a mere sum of various singleactivity departments, measured by operational efficiencies such as costs per unit, operating ratios and inventory turnover (Johnson and Kaplan, 1987). To coordinate internal resource flows (materials, labour, equipment) budget systems were created. With the introduction of budgets, the concept of responsibility centres was implicitly introduced also. By means of the budget, the various managers of the single-activity departments could be grouped into a coherent multi-activity operating unit, aligning departmental goals with overail goals.

Furthermore, in order to grow, these multi-activity firms had to rely on outside capital. It resulted in an increased emphasis on management of capital resources as shareholders wanted a (high) return on their investment. Consequently, this led to an internal emphasis on capital returns as well, for example by employing Return-On-Investment (ROI) performance controls. Also, to increase further economies of scale, firms started to vertically integrate with suppliers and buyers in the business column. Usually, a large firm had no extensive knowledge of the specifics of the wholesale or raw materials business, so decision making, control and coordination had to be brought to the places where expertise was located. With the help of the tools of budgets and financial performance controls, such delegation could be adequately handled.

The large hierarchic organisations which existed around the 1920s and 1930s were thus managed and controlled by information on their respective efficiency and consequent profitable return on capital investment. The measurement systems put up to do this were largely constructed by engineers having a keen eye for the manufacturing processes of the organisation. This stage of managerial control Kaplan calls the era of cost management.

It was followed by an era of cost accounting, in which financial reporting for capital market requirements gained additional influence. In this era, financial accounting procedures took the lead in structuring internal financial management. This was because more elaborate cost management systems could not pass the cost-benefit test: They were too expensive given the lack of cost-efficient information-processing technology. The present availability of information technology, however, has witnessed an increase in more elaborate cost management techniques, e.g., the Japanese techniques of value engineering, cost tables and functional analysis (Tanaka, 1989; Yoshikawa, Innes and Mitchell, 1989, 1990). With the dominance of financial accounting procedures came also a switch in disciplinary focus, since auditors and financial accountants were more inclined to use economic methods to attach activities to products, rather than engineering methods (Johnson and Kaplan, 1987). 


\section{What Sort of Management Accounting is Needed}

Traditional. views on how to structure and control organisations operating in a radically changed competitive environment are presently only challenged in practice. For instance, textbooks gave, and still give, an implicit view of organisations in functional terms (Emmanuel, Otley and Merchant, 1990; Horngren and Foster, 1987): A representation of organisations which is still based on the historic notion of a maximal division of labour, grouping similar functions together in departments: lathes with lathes, tooling with tooling and material handling with material handling. But also engineers in the Engineering department, marketeers in the Marketing department and accountants in the Finance \& Accounting department. Sometimes, grouping appears under a business unit or product division label but at lower level, the functional distinctions appear again.

However, with the change of the competitive arena, organisational conditions are more and more found to diverge from conventional notions implied in textbook techniques and instruments. Inter-disciplinary development teams that follow the product's full life cycle, integrated tasks, Just-In-Time production, team-based jobshops - all changes that come in from practice and challenge longstanding views. For example, textbooks as yet do not discuss how to build an information system based on time consumed, or how to install flow performance measures instead of resource consumption measures, or manage production based on product attributes. Nor do textbooks discuss controlling for organisational learning or how to structure organisations on the basis of a minimal division of labour, using multi- or inter-disciplinary teams. Input from practice will have to supply adaptations, improvements and perhaps even innovations of conventional textbook representations and solutions.

Traditionally, accounting instruments and the internal bookkeeping system from which it gets its information input are one-dimensional. It registers financial transactions. Transactions regarding quality, flexibility or timeliness cannot be captured in this one dimension if translated to financial terms. As a result of this translation, many explanatory variables useful for managerial decision making are lost in the translation process. The only one variable that conventional accounting systems recognise as causing variations in cost behaviour is volume. That is the historical upbringing of management accounting systems; more or less input of products, capital, materials or human effort means lower or higher costs ${ }^{2}$. Parallel systems are usually needed in order to make translation to the financial accounts possible. For example, improved customer service will be measured by a reduction of the number of complaints. This, in turn, will probably result in lower warranty costs, thus creating a whole world of inferences, assumptions and estimations which allows for heuristics, rules-of-thumb and personal information systems.

Moreover, one-dimensional financial logic will sometimes work contrary to improved decision-making and management of the business. For example, using capital budgeting methods as Discounted Cash Flow (DCF) to allocate funds to projects, is mainly based on expected cash returns and outlays. Or, as Hayes and Garvin (1982, p. 77-78) put it: 
“... Less obvious benefits from increased worker skills and capabilities, new products, and a different cost structure are harder to document in advance and so do not fit neatly into a present-value analysis. In fact, to counteract this bias against modernisation, some companies are experimenting with a "sunset law" for capital equipment, under which a piece of equipment is automatically replaced at the end of a predetermined period unless a special review process decides otherwise."

The heuristic of using a "sunset law" is apparently felt necessary to prevent financial logic of dominating decision making. In itself, it says that financial information does not capture the complexities of practical decision making. Kaplan. (1986a, p. 174) exemplifies the same argument in his notion that

"... the existing financial accounting systems signal short-term increases in accounting profits while firms decrease their economic wealth by foregoing investments in their long-term information and productive capital."

He goes on to point out to what he feels is the way back to more relevant management accounting:

"... Effective managerial accounting systems must reflect the value-crealing; activities, of companies: in operations, in marketing and sales, and in product and process development. In particular, they cannot be developed and maintained in isolation from the organisation and technology of a company's manufacturing processes. If substantial changes are taking place in manufacturing processes, the management accounting systems must also change if they are to provide relevant information for managerial decisions and control. " (p. 174)

In other words, improve the representation of organisational reality and practice in the accounting system. However, how much adherence to this plea is justified, it is a continuation of the historic trend Kaplan himself signalled, called 'management by the numbers' (1987, p. 126). It does not make accounting more organisational, it just makes organisations more accountable; the underlying processes are still reduced, this time to better numbers (Ezzamel, Hoskin and Macre, 1990).

A more substantial approach would be to intervene directly into the processes that cause the accounting numbers instead of improving the numbers game. Accounting, and especially cost accounting, can still play a rolie but this tinne with a strict. awareness of the one-dimensional financial expression of activities. Supplementing it with nonfinancial operational information can continue to support the role of accounting in business management.

\section{The Research Problem}

The type of management accounting that is to link up better with the 'new' organisation facing the 'new' forms of competition has not yet fully arisen from practice. Several research studies have, however, started to indicate what would be the outline of such a management accounting system (Berliner and Brimson, 1988; Capettini and Clancy, 1987). Equally important, it became clear in the process of these studies, that as yet very little field research had been done regarding 'common practice': What methods and instruments are used and how do they relate to company and business characteristics? (Theunisse, Kerremans, Dyck and Van Overloop, 1988; Bennett, Hendricks, Keys and Rudnicki, 1987; Howell, Brown, 


\section{Chapter 1}

Soucy and Seed III, 1987; Boons and Roozen, 1992). Alternatively, little was known as to how to position existing practices: What could be conceived as 'worst' or 'best practice'. Only recently, as management accounting field research is receiving increasing attention in publications, a few 'best-practice' studies emerge. However, most of these studies are relating to relatively limited subject areas as, for example, the accounting implications of JIT production systems, or the allocation of corporate overheads (McNair, Mosconi and Norris, 1988; Johnson and Loewe, 1987; Harrison, Holloway and Patell, 1990).

Typically, these studies point at the diminishing relevance of the logic inherent in the use of 'economies of scale' (costs decrease as output increases). Economies of scale are the fundamental concept between the two main cost typologies we know: direct versus indirect costs, and fixed versus variable costs. Direct and indirect costs relate to the cost causality criterion; directly attributable or indirectly attributable to the production process presumes that the process is a given, a ceteris paribus condition. If the process itself changes, as is the case with advanced manufacturing technology, causality should be reexamined on its characteristics. Other process representations, other causality concepts or other cost typologies can be the result. Similarly, the fixed versus variable distinction relates cost behaviour to a firm's output; if costs do not proportionally vary with output, they are (semi) fixed. Here, output is again considered as being tied to economies of scale, i.e., volume is the only given variable put forward by the economic model. Whenever 'economies of scope' (costs decrease as variety increases) exist, management accounting procedures are having difficulties as they are dominated by an 'economies of scale' model of the organisation.

Other organisational models as implicitly introduced by advanced manufacturing technology ('the knowledge household'; Jaikumar, 1986), Just-In-Time production ('the time-coupled household'; Stalk, 1988) or global competition ('the network organisation'; Miles and Snow, 1986) disrupt with the economies of scale concept in management accounting. In other words, the (economic) mass production model of the organisation underlying present management accounting is moving away from business reality: The various logics of business and accounting seem to be in discord. Re-establishing a more contingent relationship between competitive context, organisation management and the design of the management accounting system is the research goal of this study.

In more operational terms, this rematching is best observed in transition situations in practice, where organisations change their internal accounting system. Motivations and design respectively should reflect the transfer in logic; i.e., the former and present factual use of management accounting systems as they are redesigned for contemporary competitive circumstances. The comparison of both situations should show us how the switch in market demands is met and, especially, how this switch influences the design logic of the management accounting system, thus leading to the following research questions:

1) Is there a certain redesign logic to be noticed in management accounting systems?

2) Is there a connection with the logic inherent in the design of the organisation? 
3) Are traditional management accounting instruments adapted, renovated or replaced by totally new instruments?

Before starting to answer these research questions, two preceding conditions should be made clear. First of all, answering these questions implies a pled for a certain type of management accounting research: The use of empirical field research, working upward from field observations towards more general conceptual and theoretical frameworks. Consequently, this includes methodologies and research designs which suit such field research approaches, uplifting field observations to analytical and theoretical knowledge. Generally, these methodologies and research designs are already familiar from disciplines such as organisation theory, sociology and psychology. It then becomes a matter of creative application to have them fit the management accounting research agenda. In Chapter 2, methodological issues will be discussed further.

Second, we need a theory for framing and putting into perspective the results from accounting field research. Not only as a map of the territory in terms of the research questions and methodologies used, but also theory to develop the research findings in terms of its wider interpretations. For example, in this particular study, the wider frame of reference is accounting's organisational context, i.e., its underlying organisation design model. It is tried to link up with preceding organisation design research in explaining the findings and indicating further directions for research.

In the next sections, the territorial map of accuunting research is sketched, including its inherent type of research methodology. It is concluded by discussing the direction and type of research the management accounting discipline is heading towards.

\section{The Approaches Involved}

The approaches involved fall under the heading of organisational research in accounting. Obviously, these theories are imported from organisation theory and can be typified along two dimensions: the level of analysis and the perspective on action (Dent, 1986). The first implicitly points at the definition of what an organisation is: Is it based on interacting individuals joined in coordinated efforts to advance their rational or irrational self-interests (micro-level analysis), or is an organisation part of a wider, environmental context with various countervailing forces determining its structure and behaviour (macro-level analysis)? Especially useful for accounting research in this respect, is the built-in notion of aggregation. Organisational processes take place at various levels in the organisation: measurement, reporting on and acting in these processes tend to follow the aggregate accountability structure - building from limited towards organisation encompassing responsibilities. Accounting information explicitly parallels this pyramid. Therefore, changes in responsibility or, in general, organisation structures supposedly should be reflected in the aggregated accounting information supply. However, what is lacking is a meso-level in the analysis. Groups in management and production, whether they are full organisational functions such as the Marketing department or team-based modes of organisation (Mintzberg's adhocracies, 1990), 
seem to fall in between. They are either reduced to a straightforward aggregation of individual behaviours or to a watered-down version of little full organisations within the organisation'. As a result, dynamics present at meso-level run the risk of being overlooked.

The other dimension is formed by the perspective on action. It pertains mainly to how one thinks people behave; programmed by a thorough analysis of preferences, goals, alternatives and available means, or heuristically, basing themselves on highly individual perceptions, experiences and beliefs (Van de Poel, 1986). An important consequence of this split is the type of research which can be related to it: rational behaviour is far more easy to transform to formal models than irrational behaviour. Once one has the input from practice to build a formal model, there will be no need to return; rationality is reconstructed and a start can be made with optimising it from behind a desk ('arm's length data'). On the contrary, a less rational perspective is far more difficult to put down into models. The dynamic, ever-changing nature of it necessitates constant study, using both concepts and meanings supplied by the researched subject ('immersion in the field'). This is not to say that irrationality is quite the opposite of rational behaviour; instead, as Dent states, irrationality can be conceived as fluid rationality, transiting continuously as it is influenced by experiences, beliefs and negotiations.

Using the two dimensions mentioned above - level of analysis and perspective on action - a matrix can be created, depicting the organisational research streams in accounting (Figure 1.1).

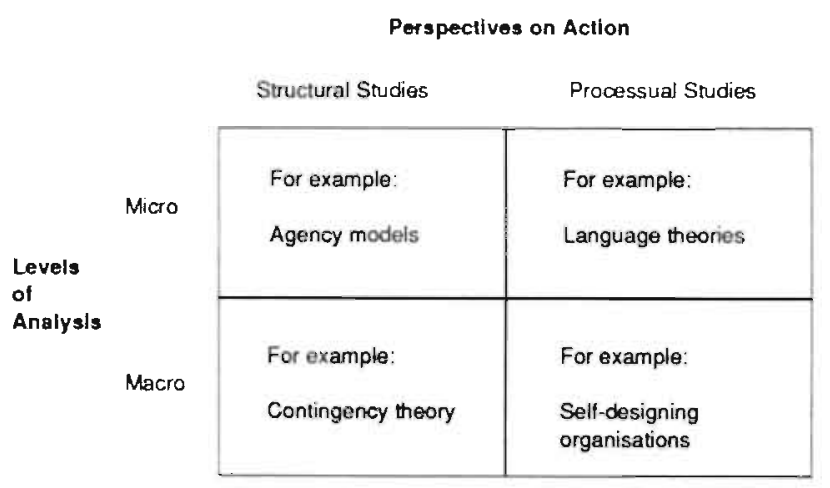

Figure 1.1 Classifying organisational research in accounting (Dent, 1986, p. 146)

The classification has no intention of narrowly defining research as to whether it belongs to just one type of research. Research can very well not be fully classified as it belongs in two or more cells, or tries to merge types of research. Similarly, the rational and 'less rational' sides of the matrix can be interpreted as research 
streams dominated either by studying organisational structures or organisational processes.

\section{Structural Studies}

Structural studies look at organisations as instruments for goal attainment. Organisations are considered static and stable, consisting of formal attributes which can be observed, modelled and predicted. As a consequence, structural studies lonk at accounting as an objective toolbox, performing technical analyses on organisational attributes and supplying inputs for control and planning of the organisational entity. For example, structural studies address questions like: What are the differences in organisations' planning and control systems, and: How do they systematically relate to contextual variables as technology or strategic posture? They try to develop contingency theories presuming to find a 'fit' between organisational effectiveness and variables such as strategy, structure and systems (Porter, 1980; Mintzberg, 1979; Ginzberg, 1980). If such a fit could be found, it would prescribe the most effective constitution of an organisation as it simply has to get in gear with the various contextual variables.

Contingency theory in accounting draws on the first appearances of contingency theory in general, which were concerned with organisational structures (Lawrence and Lorsch, 1969). The accounting version employs the line of argument that different structural configurations, as a result of contextual factors, lead to different accounting systems (Bruns and Waterhouse, 1975; Gordon and Miller, 1976; Gordon and Narayanan, 1984). More recent studies also investigated the role of strategy and control as explanatory variables as they are found to take the same importance as structure (Govindarajan and Gupta, 1985; Govindarajan and Fisher, 1990; Flamholtz, 1983; Flamholtz, Das and Tsui, 1985).

Contingency theory, however promising, has not resulted in conclusive empirical evidence; conclusions are fragmented because they relate only to narrowly defined relationships and relationships itself are found to be weak. Also, it is criticised from a behaviouralistic point of view; managerial or human discretion can mediate the relationship between external and internal factors. Human intervention can stop, slow down or affect any action or information implied by a contingency relationship. The concept of contingent 'fit' between two or more factors therefore rules out other than mechanistic and objectively modelled behaviour (Van de Ven and Drazin, 1985). Moreover, organisation participants can truly exercise their discretion to promote the fit between structural and accounting arrangements. The intervening effect of discretion therefore can halt, promote or even reverse causality between contingency variables: What causes what becomes unclear. In other words, increased organisational effectiveness may not be the outcome of appropriate choices of external factors and internal arrangements but, instead, a precondition to choose certain internal configurations.

Another consequence of discretionary behaviour is that it clearly shows that only formal properties of the organisation are included. As patterns of behaviour can only be impartially captured by formal models of structures and information, be- 
haviouralistic contingencies that do not have a formal representation are left out and implicitly considered nonexistent (Ford and Schellenberg, 1982).

Furthermore, most of the studies are focused at departmental level, which makes it hard to generalise results to organisational level. This argument is amplified when considering the need to specify relevant facets of the accounting system at various organisational levels: What is crucial at operational level may be of little importance at strategic level. Aggregating or disaggregating research findings can therefore not only be hampered by a lack of consistency across organisational levels, but also by a lack of equal level weight of researched factors.

Finally, although contingency studies may result in a clear understanding of how accounting and information systems designs are matched with external factors (Galbraith, 1977), it does not add to know-how on their instatement. Contingency studies may identify and classify accounting systems, but they do not help to understand how (matched) designs grow and what arguments are used in their evolution; a processual outlook has to complement its explanation (Dent, 1986).

In this particular study, it is tried to combine both the formal and the behavioral contingencies in researching organisation design and management accounting systems design. The main tool in this respect is the organisational design method used in all three researched cases, the Dutch elaboration of SocioTechnical Systems Design (STSD). It is this approach that provides an integrated design approach, meaning that it is consistent across all organisation levels, and starts off its design with the external competitive circumstances of the organisation (see Chapter 3 for a discussion of STSD).

\section{Processual Studies}

In contrast, processual studies view organisations as dynamic clusters of meanings, symbols and rituals. Goals and instruments are constantly open to change and (re)negotiation, and organisational participants each contribute a fluent part in this mixture of meanings and rituals. In other words, cognitive processes lie at the heart of this stream of study. They are the basis for routine and nonroutine behaviour and as such bring about stability and security to participants. The (non)learning organisation can either use it for reducing complexity to proportions it can handle or for barricading itself against change. Consensus on meanings and beliefs is needed before even to start talking about changes in organisations and accounting systems. Again as a consequence, accounting is thus far more viewed as an organisational language, providing categories for interpretation rather than an objective toolbox, and conveying meaning and common perceptions of what is going on. It follows that an accounting systems design - which decides what to measure, to report and to appraise - is a prime language medium and therefore crucial to the management and unity of the organisation. Accounting's role is thus considered to be more concerned with analyses of processes and interactions between people, than with the formal-analytic attributes of the organisation as, for example, leader/subordinate or principal/agent relationships. 
Processual studies on the organising of accounting (behaviour) have a strong focus on the execution of actions and on system properties. In particular, they look at managerial relationships and what specifically constitutes those behavioural relationships. For example, a large part of processual studies are concerned with control: how it is actually exercised, what dynamics certain control types bring about and how control links up with accounting systems (Hofstede, 1968; Jönsson, 1982; Birnberg, Turopolec and Young, 1983). Precisely the 'how' and 'what' questions asked make processual studies important inputs for improvement of accounting models of the firm. How things are expected to be done and how it actually turned out are in fact implicit variance analyses, extending the (learned on the job) repertoire of accounting mechanisms and classification typologies.

\section{Management Control}

The processual study of management control is twofold. It relates to the technical design of controls as well as how they are used in getting a desired response from people. In other words, both the system and the actor are to be controlled (Van Aken, 1978). Accounting controls in this respect have to compete with many other forms of control, e.g., action or personnel controls (Merchant, 1985). The formal accounting system underlying accounting controls is thus just one of many systems in an organisation; the formal information provided by it can easily be distorted by social and political processes.

Three general streams of processual studies can be distinguished:

1) one stream observing the actuation of various controls;

2) a stream concerned with the control of the resource allocation process; and

3) a stream focusing on the role of accounting in processes of organisational change (Dent, 1990).

The actuation type of studies are generally the strongest in their behaviouralistic outlook and involve accounting in a contest for control between organisation members (Argyris, 1952; Hopwood, 1974). Studies of the control of resource allocation processes, the second stream, objects to the rational and analytical image those processes have. These studies point out the highly political game-playing involved, with the various players taking different roles as the quest for funds evolves over time (Wildavsky, 1975; Jönsson, 1982). Not surprisingly, the accounting instrument most prominent in the control of the resource allocation process is that of budgeting. It is the most organisational of all accounting instruments: Budgeting draws on both the organisation chart as well as the chart of accounts in its inputs, thus making it the main instrument for responsibility accounting. The budget is formally defined as "... a quantitative expression of management objectives and a means of monitoring progress towards achievement of those objectives" (Polimeni, Fabozzi and Adelberg, 1991, p. 375). For accountants, budgeting is usually coupled to standard costing, which is to indicate the costs per unit instead of the total costs. Standard costs as well as budgets therefore provide financial benchmarks which are periodically determined as to carry over normative behaviour to the operational levels of the organisation. Setting norms in itself is a highly complex process, because it has to take into account both the consistency with the strategic plan as the characteristics of the operational processes which are to attain these norms. The non-analytic aspects are topping this 
since people can disagree with a norm and its implicated behaviour, or fail to undertake desired actions, for example when they lack direction, motivation or abilities. 'Good' control systems design therefore rests upon a two-tire approach: the analytical norm setting and the behavioural consequences.

To have actual behaviour coincide with what was expected/planned, behavioural problems can either be avoided, or they can be tackled by employing more than one type of control. Avoidance, in turn, can be counteracted by automation (machines do not behave unpredictably), by centralisation (less people involved means less disturbance), by risk sharing (putting a premium on desired behaviour) and by elimination (detaching from the activities to be controlled or, in other words, create control-free areas).

When it is chosen not to avoid the control problems, a composite control type can be created spanning all areas in which behaviour can manifest itself. The ingredients of the mix may be threefold: results, action and personnel controls. Results controls are typically based on accountability in a cybernetic fashion; they build on historical measurement, feedback and rewarding planned behaviour. They implicate defining the dimensions along which results will be measured (e.g., quality, timeliness), set performance standards, measure objectively along those dimensions, and provide clear-cut and understandable (negative) rewards. This is the control type most common in accounting, i.e., in budgeting and standard costing. Action controls are less mechanistic as they work on the constituting parts of expected behaviour - its actions. They come in three subtypes. First, a preventive form, making certain actions difficult or impossible to execute ('behavioural constraints'), for example by means of passwords or identification cards. Second, an observant form, monitoring one's activities and correcting them ('pre-action review'), for example by using formal expenditure approvals or direct supervision. And, third, an action-accountability form consisting of indicating the limits of acceptable actions, check the actions executed and punish deviations as, for example, in the forms of work rules and codes of conduct. Finally, the type of personnel controls spans the social end of manifested behaviour. It is either based on individual self-control, or social control by the group that people want to belong to or virtually belong to. Instruments are basically of a Human Resource Management kind: selection and placement of people, training programmes, team building or creating a distinct work culture (Merchant, 1985; Emmanuel et al., 1990).

The above control types and their subsequent accounting instrumentation are all based on the underlying assumption of stability. Production processes are fully known in their operations, decisions taken have well-anticipated consequences and people behave in a predictable and correctable manner. In other words, organisational activities are programmable and causality is known. Therefore, programmable activities can be expressed in predictive models that are universally applicable. In contrast, reality is unprogrammable, but still are accounting, control and organisational concepts and techniques declared to be of suitable use. Usually, an unprogrammable reality is stylised in terms of increased uncertainty and generic reactions to it (Den Hertog and Roberts, 1990). Accounting techniques thus try to incorporate uncertainty in their modelling by introducing various probabilistic techniques, scaling decision maker's risk preferences or adding risk mark-ups to their calculations. Consistently, however, it is based on program- 
mable causation principles (Dermer and Lucas, 1986); decision makers are believed to continue to act rationally in optimising their goal function, weighing alternatives which can be easily delineated and picked from the empiric.

Similarly, organisations are conceived as well-bounded and manipulable entities employing means that can be neatly grouped and coupled to ends. As a result, organisations are believed to react in general to uncertainty by adopting appropriate strategies of concentration and diversification. Concentration can take the form of horizontal or vertical integration and ensures a dominant market position. Economies of scale, market power and other economic aspects of synergy are the results. Diversification spreads the organisation across many relatively unrelated activities and, thus, reduces the dependence on a single product, market or industry. Both strategies reduce the possible impact of unprogrammable events outside the firm. The consequence, however, is that the organisation becomes bigger and bigger and that the initial functional structure can no longer cope with the increasing amount of complex internal transactions. Divisions or business units are created, reorganising the firm into several smaller-sized organisations each tied to a specific product market combination. With this organisational desaggregation, a simplification of the coordination of activities and a coupling of various degrees of uncertainty to the units is obtained (Ezzamel et al., 1990). Subsequently, each unit translates its external environment into the design of its organisation and, accordingly, into its accounting system design (i.e., the contingency approach). In summary, the processual study of management control relates to the organisation design model used. In other words, an organisation design logic underlies the management accounting system design, indicating that the design focus of this study has some preceding research to build on: the processes and systems of managerial control.

\section{Accounting Change Studies}

Research on adaptations of accounting systems to organisational structures is scarce. As organisations change in their intertwined structures and processes, the matching accounting design has to react. In this respect, the word accounting innovation' is sometimes used to indicate the way in which the reaction will unfold: Will it take the form of adapting traditional accounting systems and techniques to specific elements in the new environment? Will it complement accounting instruments with instruments from other areas? Will it result in another choice of the accounting system configuration or will take the form of virtually innovating accounting techniques and methods?

Thus far, two lines of thought can be distinguished: One, directed at the mere practical and instrumental role of accounting in change processes, and the second, taking a far more functional perspective addressing accounting as a technical toolbox for the improvement of the effectiveness and efficiency of the changing organisation.

The instrumental role of accounting in bringing about organisational reform is either occupied with it being a 'language' in the change trajectory or creating conditions of possibility for reform (Dent, 1990; Hopwood, 1987). As stated earlier, 
accounting creates a financial 'reality' on top of organisational processes and actual practice. In doing so, it sifts out elements of that practice, groups, labels, aggregates and, finally, uses them as inputs for decision making, control and planning. This rework process has the aura of being objective and neutral, a craft practised by well-trained professionals. Nevertheless, sieving practice like this imposes a strictly normative view on organisational reality. Only the events that have strict and direct economic visibility (i.e., can be expressed in costs and benefits, investments, resource consumption, etc.) pass through the accounting loophole. Once passed, they are supplied to decision makers based on what is needed for making 'good' decisions or exercising 'good' control, all in line with what is considered 'best' costing practice: A conception alternatively based on how an organisation is supposed to function. If organisations themselves are changing, wilful or not, the 'neutral' concepts underlying management accounting are affected.

There is expectedly another conceptional model in play of how the organisation is supposed to function. For example, lateral and flow-organised firms are still supplemented with accounting information aggregated on the basis of centralised, vertical conceptions of the organisation; information flowing bottom-up to the decision maker at the top of the pyramid and decisions flowing back top-down (Hopwood, 1985). It thus highlights aspects of organisational processes which are no longer particularly relevant as the organisation design has changed. As a result, outmodelled accounting systems direct management attention to the aspects that have not changed, which can be an ever-diminishing basis as organisations change even faster. Loss of process control itself may be an indicator as to whether the accounting practices employed by that particular firm are still relevant. Hopwood (1987) has depicted this line of argument as follows:

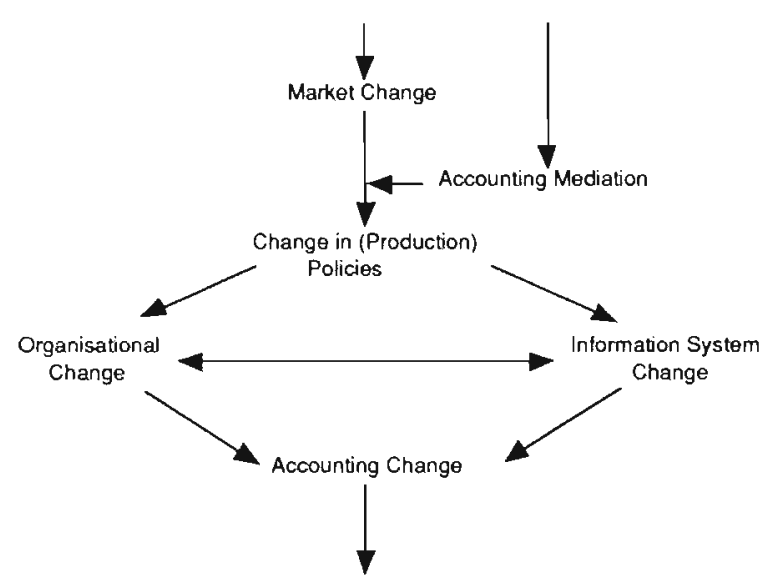

Figure 1.2 Accounting both as change agent and changed subject (Hopwood, 1987, p. 222)

As accounting changes, it provides another regime of economic visibility and calculation to management (Hopwood, 1985, 1990; Theeuwes, 1988a, 1988b). Leaning 
on this 'new' framework of representation, managerial decisions can create additional changes in organisational processes and policies requiring accounting to make subsequent changes as well, thus making the circle round again. Conditions for the possibility of change are therefore themselves a product of 'accounting (not) in motion'. What makes accounting 'move' in the first place does not always have to be stated in terms of design, structure or processes. Strategies, external shocks or industrial life cycles can all very well be the first cue for change (see the case studies in Chapters 4,5 and 6). What is most important, however, is the idea that accounting is embedded in and configured with an array of very diverse organisational functions and events. Or, as Hopwood (1985, p. 232) puts it:

"... When seen in such terms, accounting is involved with much more than directly facilitating managerial action. It is concerned with making visible and thercby governable the detailed work processes of an organisation. It provides for both aggregating and disaggregating organisational actions and outcomes - a powerful tool in the hands of organisational managers. It is involved with the establishment of a language of organisational motive, with rendering into the domain of the economic important aspects of the physical and task reality of the organisation. And it is quite centrally involved in the construction of operational concepts of accountability, responsibility, and even performance which play a significant role in the creation of a manageable organisational regime."

Adversely, the functional perspective of accounting change builds on its technical instrumentation and improvement of organisational management. Its capacity for representation of organisational processes is only limitedly questioned. Organisational economy, efficiency and effectiveness are seen as goals in themselves, independent from accounting representations. Accounting change here is identical to restoring user relevance in a technical sense. Better calculations imply better decisions, better decisions cause higher efficiency and effectiveness which, finally, result in 'more economic' organisations and market transactions.

The most prominent of this type of technical accounting innovators is Robert Kaplan of Harvard Business School. Not only has he started the discussion on accounting relevance, but he also takes an active part in innovating the toolbox himself. Johnson and Kaplan (1987) see two main areas where reassessment is most needed - cost management and performance measurement. According to Kaplan, 'good' cost management will always have to meet two objectives: facilitate process control and compute product costs. In his view, process control information ideally requires a financial process control system for each individual process, resulting in a number of separate cost control systems.

Product cost systems have yet other design requisites. As a process control system should employ a minimum of cost allocations relating to the controllability criterion (i.e., a manager is only responsible for the cost he can virtually control), product cost systems on the contrary do require representing the full resources consumed by the product, Kaplan states. Compared to financial accounting requirements with its neat periodic reporting cycle, process control systems will have to follow the cycles of the process - be it hourly, daily, weekly or monthly. The same goes for product costing: a reporting cycle is needed which follows the life cycle of the product as it progressively and digressively consumes resources. As a result, the objectivity of the information involved varies. Process control systems will involve a minimum of cost allocations, rendering better measurability and objectivity than conventional product cost systems. 
Furthermore, management accounting system users vary largely in their information demands. Process control systems prominently address production managers, plant staff and operation supervisors while product cost information is of prime importance to marketing and product managers or business unit management, as they have to decide on the product mix depending on the relative product profitability. Therefore, many cost systems are needed instead of just one system mainly orientated towards external reporting, each tied to their own purpose (Johnson and Kaplan, 1987; Kaplan, 1988).

Performance measurement is another toolbox reassessment problem. The time frame of financial accounting requirements obstructs insight into organisational performance, e.g., profit incurrence. According to Kaplan, matching revenues with costs for discrete quarterly periods will lead to a large proportion of prior and present expenditures being included in period cost, while at the same time, the benefits of these expenditures will be mainly realised in future periods. This point is aggravated by the increasing importance of a firm's intangible assets, such as human expertise, work experience, customer and personnel loyalty and production know-how. They are essential to the earning capacity of the firm but are not included in performance reports. Kaplan therefore points out the need to develop nonfinancial indicators for measuring manufacturing performance, and capturing the essence of quality, productivity and new product performance. Especially the case of new technology makes the development of nonfinancial measures even more urgent (Kaplan, 1983, 1984b, 1986b).

Both notions of accounting from a functional and a behaviouralistic perspective are seldom integrated. Only the research of Jönsson (1987, 1988, 1990) can be named. It ties the functionalistic problems signalised by Kaplan to the specific organisational setting. In his research, shop floor employees are asked to develop their own local information system for process control, building on their expertise of production processes. Gradually learning from the local problems encountered, links are made with the centralised accounting system and units upstream and downstream of the product flow. The elements of decentralisation of responsibility and trust, organisational learning and the emergence of local information systems build on a large number of operating statistics. As a result, the bottom-up design point of view engenders a strongly participative management accounting system.

To innovate management accounting requires a return to the organisational setting. Conceptualisations nor theoretical models alone will suffice for adapting internal accounting systems to the new organisation model. It requires going out into practice - observing, learning and understanding the rationales behind the construction of systems as they are continuously shaped by their users. Each case adds a little to understanding how accounting and organisational life are matched. With each case, insights grow and with that, the possibility of theory building and practical help. Or, as Dent puts it (1986, pp. 163-164):

"... These interpretations of accounting in action may indeed be subjective. As argued before, they are best seen as stories. but they are illuminating stories opening up alternative appreciations of accounting practice. They portray accounting as it is played out in a dynamic world of drama and vitality. In comparison ... the issues uncovered here are both more subtle and more 
immediate. Qualitative methods of processual analysis are as yet, perhaps, underdeveloped. But gradually in the organisation literature in general, and the accounting literature in particular, experience of qualitative research is being acquired, and new understandings are emergent."

\section{Notes}

1 This research study was made possible by the department of Accounting of the Faculty of Economics and Business Administration of the University of Limburg, Maastricht, The Netherlands, which I would like to thank for their longstanding cooperation and support. Funding of this study was generously provided by the Dutch programme on Technology, Work and Organisation (TAO) - a multi-year, multi-disciplinary research and diffusion effort sponsored by the ministries of Economic Affairs, Social Affairs, and Education and Sciences - of which it was part of the accounting research line.

2 The input-output modelling of the firm has tried to enlarge the number of independent variables by pointing out various other activity drivers. Notable in this respect is the work of Staubus (1971, 1990). However, German cost theory seems to have made better progress in bringing these models closer to reality as the works of Gutenberg (1951) and Heinen (1983) show. See also Schoenfeld (1990) for an English introduction to their works. 


\section{The Knowledge Enterprise}

This chapter discusses how this study evolved and how the research design and methodologies were used. It is argued that any research endeavour can be conceived of as a knowledge enterprise, especially when it explores unknown research territories trying to develop new knowledge. The research question was developed after a pilot study. The focal point is the relationship between changes in the structural organisational design and the resulting changes in the management accounting design. This involves looking at two disciplines in an iterating approach: Organisation Theory and Management Accounting. It is tried to bring these two together in both research approach and research design by using a bridging strategy and a creative application of grounded theory insights and procedures. Since no existing body of literature and research was available, and because answering this research question is conceived to be best researched by field study, the research design is of mixed origin. The design is legitimated by arguments from policy research (Majchrzak) and combines the case study approach of Yin with the grounded theory procedures of Strauss and Corbin for its analysis.

\section{Characterisation of the Research Question}

In general, almost every research project forms part of a knowledge enterprise. A research endeavour is a reaction to preceding work and further extends it. In undertaking this endeavour, the researcher hopes that others will follow suit and that his work will be greeted by responses from other researchers. In this way each research project forms part of a larger knowledge enterprise. A knowledge enterprise is the accumulation of interrelated research activities by which a specific body of knowledge is built up, maintained, used and adapted. Roethlisberger (1977) sketches the knowledge enterprise in organizational sciences as a cyclical process, going back and forth between clinical practice, and the generation of scientific knowledge (see Figure 2.1).

The researcher himself decides upon which enterprise he wishes to contribute to. $\mathrm{He}$ also chooses his position within the knowledge enterprise - he chooses his 
own track. This can be a relatively safe track, deriving hypotheses from a well-established and ripe theory which can be tested with well-defined and accepted instruments. However, his choice of a certain track can also include the building of a new theory, based on observations and experiences from practice. In that case, little is established prior to the start of the research. Thus, theory and methodology do not provide a firm anchoring point. Even the research question can be very vague. Moreover, when progressing with the research, it can become clear that the research question is incorrect and requires a restatement. This choice was at the basis of this study.

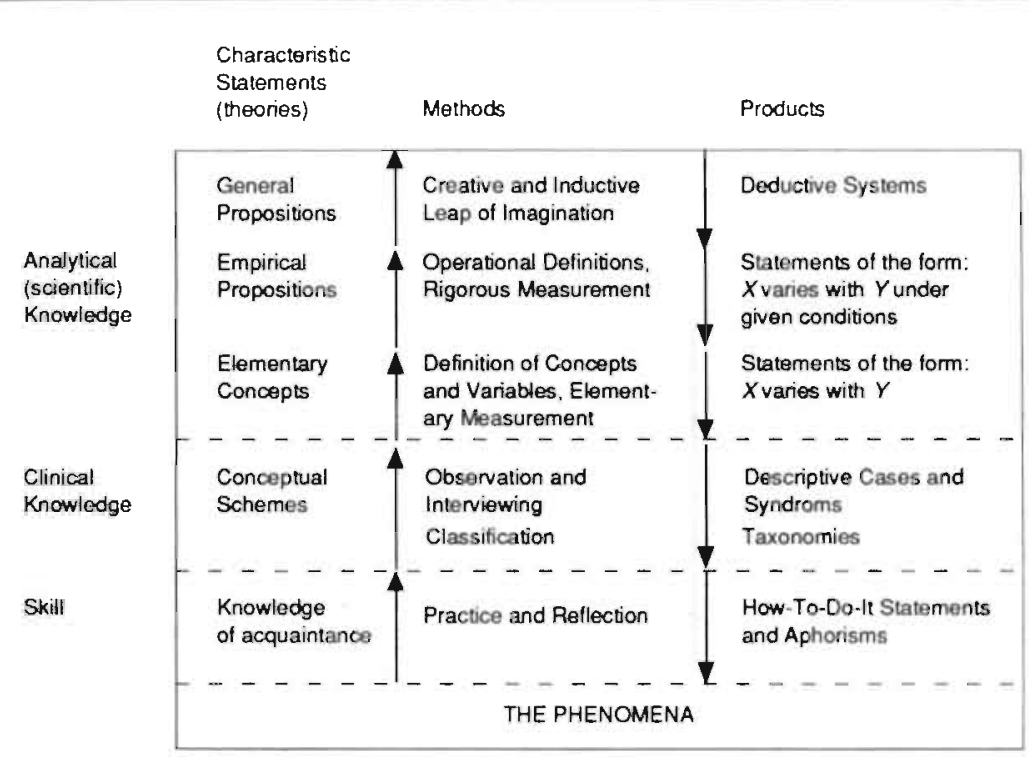

Figure 2.1 The knowledge enterprise (Roethlisberger, 1977, p. 393). The upward arrows indicate the development of knowledge, the downward arrows the practice of knowledge

\section{Developing the Research Question}

Kaplan and Johnson signalled the problem of inadequate management accounting answers to the problems of the present competitive environment. However, they did not supply any new theory, possible solutions or clear suggestions for research efforts. The initial intention of this study was to focus on the advanced manufacturing technology that allegedly caused many of the management accounting problems. The expectations were that organisations employing flexible manufacturing systems would encounter managerial accounting problems and, consequently, would find creative solutions to deal with them. This was the goal of the research study that had been formally approved. Its research question was as vague as the expectation of fresh solutions from practice: Is Kaplan's problem recognised in practice and how are management accounting systems subsequently changed? With this research question, a conscious choice was made to start a new 
knowledge enterprise, one that could hardly build upon any previous work. In other words, there was a knowledge gap.

The project began with a pilot study whose function was (1) to become acquainted with the field, (2) to fine-tune the research question and (3) to provide the basis for a choice of methodology for the main research study. Entering the field, therefore, with an open mind and with few preselected views for consideration was regarded as the best route. Additionally, it was felt that no research question could be formulated without some notion of what was going on in practice. "Field reconnaissance" provides this feel for the matter while at the same time acquiring the vocabulary used in the field.

According to preceding research, the most dominant sector in applying new manufacturing technology were the electrotechnical, metal and metal-processing industries (Kaplan, 1985; Howell et al., 1987; Innes and Mitchell, 1988; Theunisse et $a l ., 1988$ ). It is to those industries that our attention was turned (see Table 2.1 for a summarised overview).

Table 2.1 Summary outline of companies involved in the pilot study

(Company names have been disguised for contidentality reasons.)

\begin{tabular}{|c|c|c|c|c|c|c|c|c|c|c|c|}
\hline Company & HerA & Aare & HatC & Meid & Kinge: & BloF & Airs & VerpH & Stelf & Antow & Ruitk \\
\hline $\begin{array}{l}\text { Person } \\
\text { Interviewed }\end{array}$ & $\begin{array}{l}\text { Generai } \\
\text { Manager }\end{array}$ & $\begin{array}{l}\text { Production } \\
\text { Manager }\end{array}$ & Controller & $\begin{array}{l}\text { Chief } \\
\text { Engineer }\end{array}$ & $\begin{array}{l}\text { General } \\
\text { Manager }\end{array}$ & $\begin{array}{l}\text { Production } \\
\text { Engineer }\end{array}$ & $\begin{array}{l}\text { Production } \\
\text { Manager }\end{array}$ & $\begin{array}{l}\text { Production } \\
\text { Manager }\end{array}$ & $\begin{array}{l}\text { Chlet } \\
\text { Englneer }\end{array}$ & $\begin{array}{l}\text { Production } \\
\text { Managef }\end{array}$ & $\begin{array}{l}\text { General } \\
\text { Manager }\end{array}$ \\
\hline $\begin{array}{l}\text { Main } \\
\text { Procluct } \\
\text { Line }\end{array}$ & $\begin{array}{l}\text { Sheot } \\
\text { Iron }\end{array}$ & $\begin{array}{l}\text { Âgri- } \\
\text { cultural } \\
\text { Machinery }\end{array}$ & $\begin{array}{l}\text { Bakery } \\
\text { Machinery }\end{array}$ & $\begin{array}{l}\text { Electro- } \\
\text { technical } \\
\text { Appliances }\end{array}$ & $\begin{array}{l}\text { Machinery } \\
\text { for the } \\
\text { Bulding } \\
\text { Industry }\end{array}$ & $\begin{array}{l}\text { Machinery } \\
\text { lor the } \\
\text { Borting } \\
\text { Industry }\end{array}$ & $\begin{array}{l}\text { Alcondi- } \\
\text { tioning } \\
\text { Equipment }\end{array}$ & $\begin{array}{l}\text { Packaging } \\
\text { Machinery }\end{array}$ & $\begin{array}{l}\text { Central } \\
\text { Heating } \\
\text { Equip- } \\
\text { ment }\end{array}$ & $\begin{array}{l}\text { Sheel } \\
\text { lron }\end{array}$ & $\begin{array}{l}\text { Cannery } \\
\text { Machinery }\end{array}$ \\
\hline $\begin{array}{l}\text { Typo of } \\
\text { Technology } \\
\text { Employed }\end{array}$ & $\begin{array}{l}\text { CAD } \\
\text { CAPP }\end{array}$ & $\begin{array}{l}\text { CAD } \\
\text { CNC. }\end{array}$ & CNC & $\begin{array}{l}\text { CAD } \\
\text { CNC }\end{array}$ & CNC & CAM & $\begin{array}{l}\text { CAD t } \\
\text { CAE }\end{array}$ & CAD & $\begin{array}{l}\text { CAD } \\
\text { CAM }\end{array}$ & . & . \\
\hline
\end{tabular}

CADi - Computer Alded Design

CAPP $=$ Computer Aiderd Production Planning

CAE = Computer Alded Engineering

$\mathrm{CNC}=$ Computer Numencal Controlled

CAM = Computer Alded Manutacturing

The results of the pilot study were not at all what was expected. Virtually all firms reported not having any management accounting troubles in implementing or using their new manufacturing technologies. Conventional accounting techniques were used (standard costing, pay-back, budgeting) and standard operational procedures were not altered. The only two items mentioned were relatively remote from accounting - they concerned 'organisational troubles' in implementing advanced technology and problems with getting the necessary information for investment decision making. When asked about the precise nature of these 'organisational troubles', most answers fell into the following categories:

- more difficult production planning;

- fitting in with existing equipment;

- production layout and;

- training problems of operators. 
Training programmes were expensive and, once completed, the scarce number of operators tended to leave for better-paying positions at other plants and firms.

To follow up on these unexpected results, three additional interviews were conducted. All interviewees were employees of the largest electronics company in The Netherlands and an acclaimed frontrunning technological company. Interviews were held at two separate facilities. Typically, both plants made extensive use of CNC and CAD technologies and experimented with an elementary form of CAM. Also, both plants had a wide variety of nonstandard products and were forced to face outside competition in their own internal order bidding.

However, the additional interviews confirmed the original findings: The firms faced unexpected problems in acquiring the necessary financial information for investment appraisal, and problems with fitting in technological innovations in the existing organisation. At this particular point, it was clear that the technological angle to the organisational context / management accounting relationship was inconsistent. The pure organisational aspects seemed to be more important. Therefore, the research study was faced with a serious choice: Continue on the chosen track, which would result in a considerable shift in research target and design, or preserve the goal of researching accounting change, but taking a different angle this time? Continuation implied tracing the reasons why the research question was not acknowledged. In itself, this required switching over to a different knowledge enterprise with less accounting and more technology diffusion aspects. Accounting would only be involved as a distant characteristic of production management. Nevertheless, following this route was a less uncertain research activity since the research question could be related to an existing body of literature on technology diffusion, and contacts with research sites were already present. Also, the first exploratory research phase could be maintained and no rerouting would be necessary.

The alternative involved re-examining the initial research question and starting all over ${ }^{3}$. However, arguments supporting this choice were far more challenging, relating to the earlier choice of an accounting knowledge enterprise. As a result of the pilot study, attention was drawn to the role of organisation measures. As organisation measures are the reflection of a larger organisation design framework, organisation design was selected as angle of analysis ${ }^{4}$.

The next step was to look for a field situation where both organisation design and management accounting systems were involved, i.e., an organisation renewal case, and where the same questions could be asked as in the pilot study: Is there a management accounting problem if the organisation finds an alternative to the classical model of mass production, and which creative solutions to these problems are conceived? Such a case was found in the Van Nelle Tobacco/Rotterdam plant. It was found through the help of a consulting company that specialises in organisation renewal: KOERS consultancy. The first case by the consulting organisation was on full target, and constituted a sort of voyage of discovery, mapping the new territory and providing many insights, illustrations and data material. 


\section{A Representation of Choices}

What was known at this point was that it concerned an interface situation, sitting in between the disciplines of organisation theory and management accounting. The second item was that the specifications of the research question should be practice-generated - the voice of the field was to guide us. And, finally, the focus was on the functioning of the organisation as a whole, not just one factor influencing one or two other factors. Moreover, it was known in very broad terms what knowledge was in demand (organisationally oriented management accounting practices and concepts) and what knowledge could be supplied (very little, as present field research mainly related to specific accounting instruments).

Conducting research into two disciplines simultaneously leaves little room in which to manoeuvre; there is a stone wall between the objective and the methodology to get there (Reisman, 1988, p. 219). In addition, two different disciplines have two dissimilar research traditions or modus vivendi in how to perform research. The most familiar research venue taken is usually an incremental one, called a "rippling strategy" by Reisman (see Figure 2.2). It implies taking what is known, and subsequently developing an extended model, solution or theory adding an extra dimension, while staying in the same type of problem domain. Examples for the accounting field are the extensive research lines in budgeting (Birnberg et al., 1990), agency theory (Baiman, 1982) and decision making (Lewis and Libby, 1982).

Thus, bringing two disciplines together into the research objective requires a bridging strategy in performing research. Nevertheless, the issue remains how to achieve bridging of the strategies. The approach taken up in this study is to borrow knowledge from another discipline and apply it directly; Reisman calls this the creative application strategy.

Back to the field, the case of Van Nelle Tobacco provided the situation where organisation design and management accounting systems were simultaneously addressed. This case supplied the insights that determined our research approach. The very first contact with the production manager showed that there was indeed a management accounting problem and that a creative solution had been found to solve it. Also, the production manager was willing to cooperate in the research study and provide full access to people and information.

Following this eye-opening contact, further research decisions were made. The first concerned the research methodology. The research design was to use case studies. In each case, the focus would be on causality (what happened as a result of what) and the chronological description of the chain of events. Also, the individual case study format was first developed in the Van Nelle case, describing the organisational change process, the previous and present organisation designs as well as the transformation of the management accounting systems. This format was later also used in the other case studies. The second decision was to develop a method of case analysis based on the procedures of grounded theory. The third decision was to specify the research question as to addressing the linkage between the organisation design and the subsequent management accounting systems design. Thus, the research question adopts a design-oriented focus. The topic of organisa- 
tion design was further exemplified by the use of SocioTechnical Systems Design (in this book referred to as STSD), an integral design approach based on systems theory and providing a large number of design instruments and practices. The specifics of STSD will be further discussed in Chapter 3. Finally, it was decided to replicate the analysis in two other cases, giving specification and detail to the content of the initial findings and building up the first elements of a theory regarding the integral design of organisations and management accounting systems.

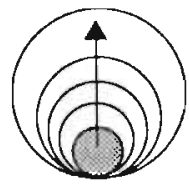

Rippling strategy

$\bigcirc=$ Domain of problem charactenstios

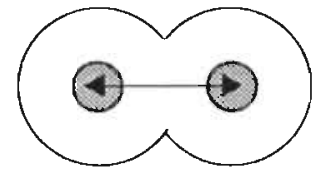

Bridging strategy

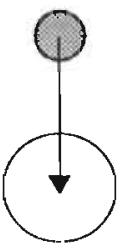

Creabive application strategy

Figure 2.2 Research strategies in the management sciences (Reisman, 1988, pp. 216-218)

With the help of the consulting organisation, two more case studies were found where an identical process of organisational and accounting renewal had taken place, and where the managements were willing to fully cooperate in the research study.

In terms of the research study, organisation design as performed by STSD had the advantage that it was well specified, handing over ample concepts and labels to clearly map the context of the management accounting system of each case. Moreover, STSD does not address the matter of management accounting design in itself, indicating that the focal point of this study was relatively untouched by STSD concepts and open for research. The latter point related to our earlier knowledge entrepreneurial choice for trying something new and unconventional, away from the little steps forward and rippling research strategies that are commonly found.

An identical choice, away from the rippling strategy, is represented by our set-up of the research design. The initial field study of Van Nelle instigated our use of 'grounded theory' as the creative application used in bridging the organisation and accounting disciplines. The research design will be discussed in more detail below.

\section{Research Philosophy Employed}

Researching the linkage of the organisation design with MAS design embraces a design-oriented view. Implicit in this type of research is the question of how the 
study results can be used to improve these designs. A full definition of design-oriented research is not available but it can be depicted by its assumptions (Den Hertog and Van Assen, 1988). First of all, design-oriented research is prescriptive in the end - it must provide a knowledge base for better designs, not in terms of general tools but rather in terms of better insights underlying better choices. Second, as the name indicates, it is directed at the design process, including diagnosis, intervention and effect phases of the process. Design orientation means an integral focus on the design and implementation trajectory, and it is not limited to (monodisciplinary) parts of the design process. Third, design-oriented research is scientific but not in terms of rigourous statistical and experimental modes of research (Argyris, 1980). It is concerned with knowledge acquisition about well-conceptuated interventions in human systems (Morgan, 1983; Van Maanen, 1983) and obtaining 'stronger answers from weaker methods'. Fourth, it is directed at the organisation as a whole. This "Gestalt" approach states that organisations are not accumulations of parts but rather comprehensive entities, adding up to more than the summed energy of its constituting parts. From this, it follows that design-oriented research is multi-disciplinary. Finally, design-oriented research occupies itself with prevention. Conceivable consequences are considered in advance and not corrected afterwards when they appear. However, these five functional demands of design-oriented research do not provide the instruments for conducting design-oriented research. These instruments were found in a combination of case study research and grounded theory procedures while the legitimation for performing design-oriented research was found in policy research.

Policy research is defined as "... the process of conducting research on, or analysis of, a fundamental social problem in order to provide policy makers with pragmatic, action-oriented recommendations for alleviating the problem" (Majchrzak, 1979, p. 12). Here, 'fundamental' means that it addresses broadly defined research questions that have multiple facets and a variety of consequences for large groups of people. In terms of the research problem, policy research would view management accounting as having a 'coping problem': Managers in practice cannot financially counter the changes in the competitive environment. Hence, their policies break adrift and organisations start to wander in terms of loss of financial process control.

Clearly, according to Majchrzak, policy research is highly contextual in that it interacts with or is responsive to the study user. In an iterative manner, problem definition and interim results are confronted and discussed on the basis of the study user's conceptualisation of the subject. The intimate tie with the user results in a constant interchange between information and the concept(s) wherein the information can be framed. As no concept is available, new concepts or approaches can be generated or, at least, the limitations of available concepts become more clearly delineated. Furthermore, interaction with the user of the policy options implies that policy research is an inductive, empirically based approach. Even more so, it is grounded in practice with a large role for empirical, daily-life events.

In this aspect, it rolls over to the 'grounded theory' approach of Glaser and Strauss (1967). A 'grounded theory' approach inductively builds on the observation of the phenomenon studied: 
"... it is discovered, developed, and provisionally verified through systematic data collection and analysis of data pertaining to that phenomenon. Therefore, data collection, analysis, and theory stand in reciprocal relationship with each other. One does not begin with a theory, then prove it. Rather, one begins with an area of study and what is relevant to that area is allowed to emerge" (Strauss and Corbin, 1990, p. 23).

The use of 'grounded theory' in this study is inspired by the type of knowledge enterprise. This research study is attempting to formulate the initial theoretical insights where no theory has yet become available. It does this by relying on field observations and case studies. This material has to be analysed and compared in a systematical way in order to provide valid conclusions. Grounded theory provides the systematic procedures and well-developed framework of analysis to perform these analyses.

The basic assumption of 'grounded theory' is that discoveries and the development of new theory in the social sciences, as in the natural sciences, are the result of observations:

\begin{abstract}
"Grounded theorists share their [natural scientists'] conviction that the usual canons of "good science" should be retained, but require redefinition in order to fit the realities of qualitative research, and the complexities of social phenomena that we seek to understand." (Strauss and Corbin, 1991, p. 249)
\end{abstract}

Observations are viewed as the raw material 'filling in' new concepts and developing new theory ('obtaining conceptual density'). Relationships between concepts and phenomena grow from iterating between theorising and observation. Gradually, insights are 'dense' enough as to provide a cohesive theory about a phenomenon. Such theory should meet the criteria of fit, understanding, generality and control. In other words, it should provide a comprehensible representation of reality and contain enough abstraction to be applicable to a variety of situations. Also, the theory should lead to an increased grip on the phenomenon - it should spell out the conditions for controlled actions towards the phenomenon.

In the previous pages, we gave a description of 'our' knowledge enterprise; what we wanted to add and why. It involves the building of a theory, followed by making observations, filling the concepts with observations and continuing to observe. In this way, dense concepts filled with data emerge. That is inductive re search - theory based on observations - and that is also grounded theory.

However, we also use replication logic in order to test the theory that was built up, i.e., we ask ourselves the question: do we find the same thing in the second and third cases as we did in the first case? Moreover, when we find more than we did in the first case, we adjust our theory and, consequently, perform deductive research. Nevertheless, this study is positivist research because it sticks to the empirical cycle of observing to build a theory and then observing to test a theory. This study places strong emphasis on the building up of a theory, because (to date) there simply is no theory available.

'Grounded theory' follows a clearly systematic research methodology. It starts by formulating the research question. The research question marks out the phenomenon one wants to investigate. It is, however, not formulated stringently 
since it should allow sufficient flexibility and freedom for an in-depth study of the phenomenon from different angles. Also, the question is not just formulated but also posed to professionals from the discipline and from 'the field'.

On the basis of the research problem, the coding process starts. Coding forms the heart of 'grounded theory' as it unravels data, develops concepts based on those data and re-integrates the data again, this time based on new concepts. Following this sequence, coding can take on three forms: open coding, axial coding and selective coding.

Open coding unravels, closely analyses, compares, conceptualises and categorises data. Axial coding puts together the open-coded data, but this time based on relationships between categories obtained from a coding paradigm. A coding paradigm is a model linking subcategories to a category in a set of relationships. This category of relationships denotes several elements: casual conditions, phenomenon, context, intervening conditions, action/interactional strategies and consequences (Strauss and Corbin, 1990, p. 99). Finally, 'grounded theory' is shaped by selective coding. It establishes a central category (i.e., the phenomenon around which theory evolved) and determines the relationships with the other categories. The final 'grounded theory' is then reflected in the story the researcher has to tell: the 'storyline'. The storyline analytically shows the process of conscious action to change a situation and the effects this action causes: the evolving sequence of events is 'the story' (see Figure 2.3).

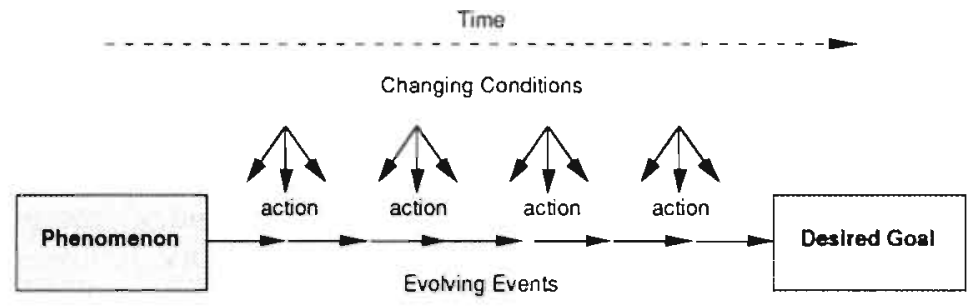

Figure 2.3 The storyline (Strauss and Corbin, 1990, p. 145)

The instrument of case study research was chosen for two main reasons. First, the research question relates to the context of management accounting system design: The focus is on the organisation as a whole and the relationships between systems inside that organisation. A case study can be defined as "... an empirical inquiry that: investigates a contemporary phenomenon within its real-life context; when the boundaries between phenomenon and context are not clearly evident; and multiple sources of evidence are used" (Yin, 1984, p. 23). Real-life context, unclear boundaries and multiple sources of evidence are all aspects that dominate the research question. Second, in testing theories related to organisations as a whole, one has to deal with a complex reality; one simply cannot manipulate and control conditions the way one wants it to be, let alone distribute research subjects (people, 
groups, organisations) at random across conditions. Therefore, one must look for research approaches that are as close to this ideal approach as possible.

Multiple case studies implicitly represent a replication logic in their design. Each case study provides additional insight into the phenomena studied, and, when analysing the various insights, a pattern or classification may arise. Where no theory is yet in existence, as is the case in this study, the convergent observations from each case study will provide a preliminary formulation of theoretical propositions. In other words, theory formulation is 'grounded' in empirical observation. The box 'Develop Theory' (see Figure 2.4) can thus be replaced by 'General Research Question'. Only after an initial multiple case study is completed, an attempt can be made to focus on 'grounded' theoretical propositions.

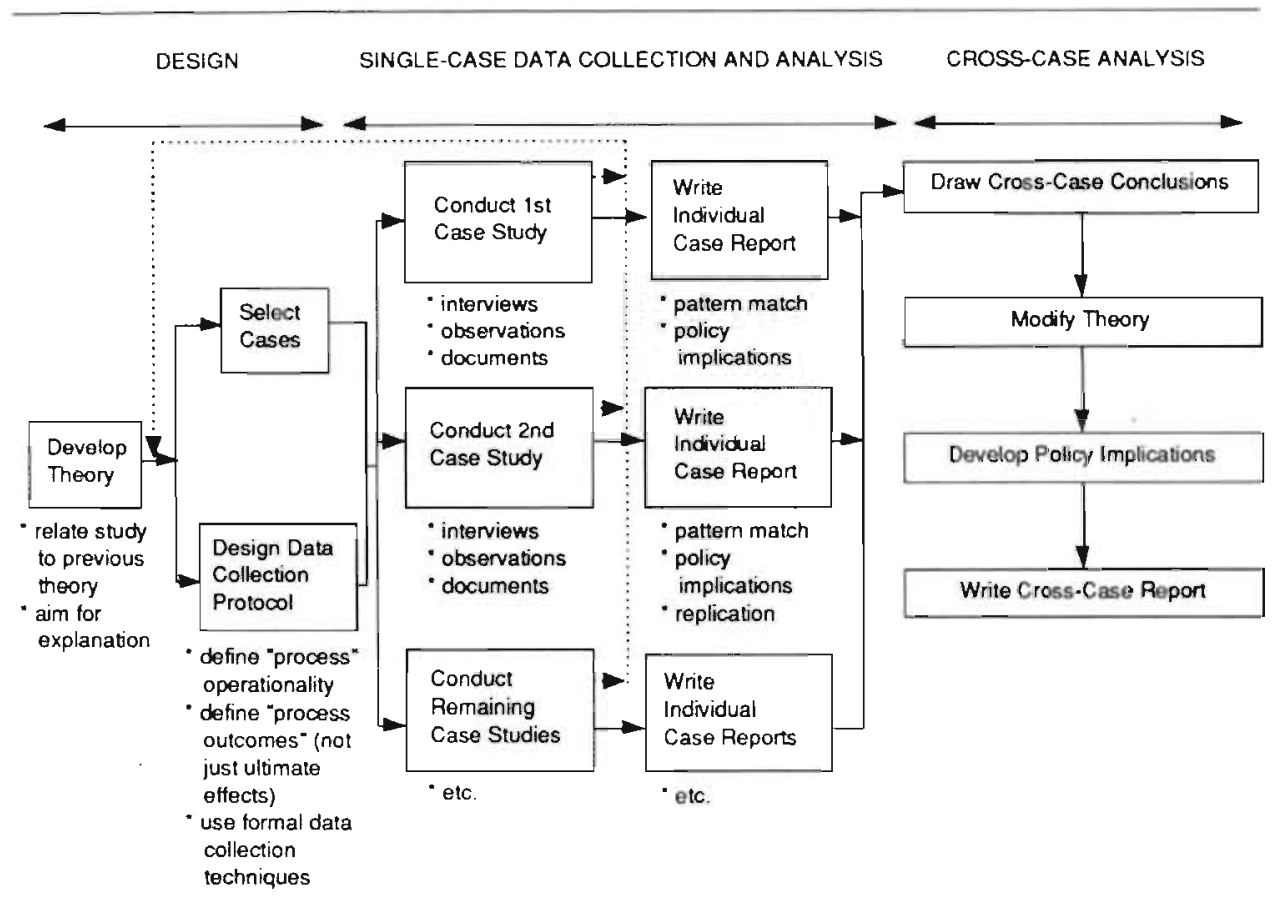

Figure 2.4 Case Study Research Design (Yin, 1984, p. 51)

Therefore, our research design is based upon two methods that each serve a double purpose: Case study research for the larger setup and replication of the study findings, and grounded theory for the development of theory on the basis of data and its procedures for analysing the individual case studies and making cross-case comparisons. The case studies serve the purpose of mapping the territory, i.e., performing exploratory research, while grounded theory procedures were used for lifting the observations up to a more conceptual level. In terms of the knowledge enterprise, it was tried to go from observed phenomena to analytical knowledge (the left side of Figure 2.5). 


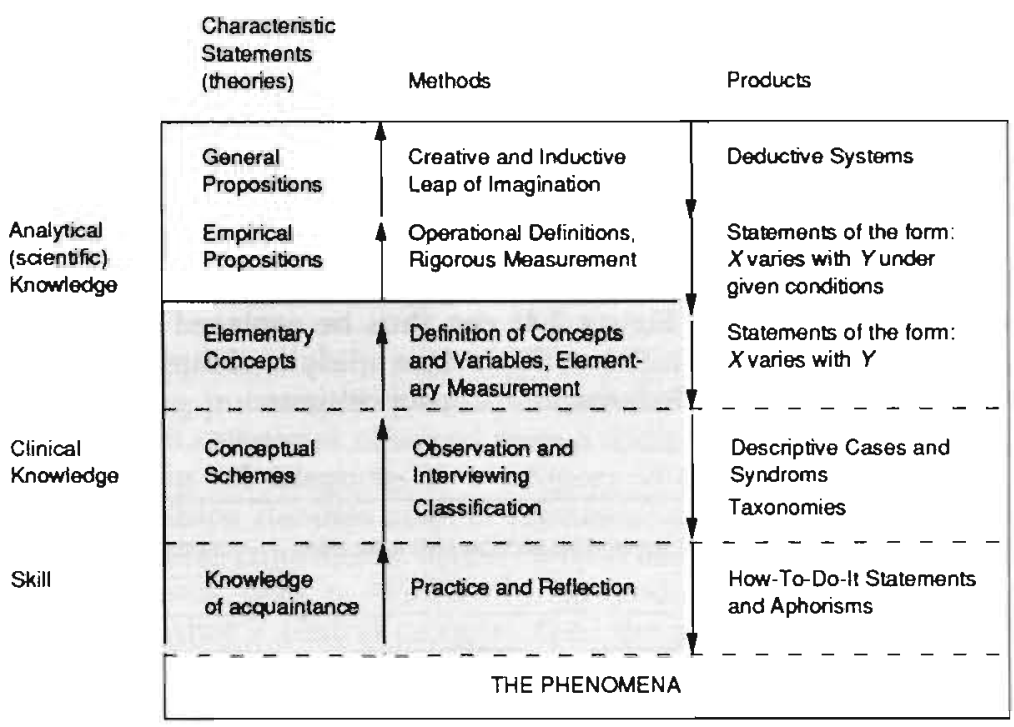

$=$ Domain of Exploratory Case Study Research

Figure 2.5 The Knowledge Enterprise (Roethlisberger, 1977, p. 393). The upward arrows indicate the development of knowledge, the downward arrows the practice of knowledge.

Case study research as proposed by Yin plays its role in the categories of skill (i.e., the application of techniques and methods) and in the category of clinical knowledge (Roethlisberger, 1977). Grounded theory procedures picks up in this stage and lifts the observations to the first stage of elementary concepts by way of its coding steps - by starting to make inferences on it and embedding findings in existing knowledge as they are found, defined and measured in other studies (see Chapter 8).

Thus, our knowledge enterprise is an enterprise both in terms of getting from $A$ to $B$ and in terms of the first attempts to develop missing knowledge concerning the links between organisation design and management accounting systems design.

\section{The Research Design}

The research design consisted of three phases. The first phase relates to the previously discussed exploratory study in which the research question was developed. The second phase relates to the first case study and establishes the individual format of analysis. The last phase relates to the data collection in two other case studies and the comparative analysis of the findings. 
The first phase - the exploratory study - consisted of interviews with mainly production managers, some general managers, and one controller. The high percentage of technical people interviewed was based on a clue provided by Kaplan, who stated that advanced technology was exposing the bulk of the management accounting problems. Therefore, technical people were supposed to be the first 'early warning indicators'.

Similarly, the companies interviewed were in industries where, according to the literature, the first advanced manufacturing technologies should be adopted, i.e., the metal-processing, machinery, and electrotechnical industries. Companies had been selected using the standard industry codes of the above three industries. Furthermore, only firms exceeding 100 employees were approached. This was done as an arbitrary measure of sufficient company size to sustain advanced manufacturing technology investments. Twenty-two companies were approached by mail and telephone, eleven of which agreed to be interviewed. The interviews themselves were conducted on a partially open format. The agenda was to introduce the goal of the research study and then ask questions regarding alterations made in management accounting procedures and calculations, changes made in the decision trajectory regarding capital investments, and other consequences of technological changes that were not included in the interview.

Phase two was dominated by the Van Nelle Tobacco/Rotterdam plant case study. As a result of the previous exploratory study, a field situation was looked for in which both the organisation design and management accounting design were changed. With the help of the KOERS consultancy company, the Van Nelle tobacco plant was approached. This organisation had just completed a full reorganisation of its entire structure as well as its processes through KOFRS assistance. The plant management agreed to cooperate and provided access to management and internal documentation.

The data material was acquired in three different modes. First, by extensive interviews of key personnel such as the plant manager, who was the main force behind the plant reorganisation, and the manager of production planning, who, together with the plant manager, conceived and managed the control and information system reorganisation. The interviews were between three to five hours in duration and involved several site visits. The interviews focused on explaining the many changes in organisation and accounting design, their motivation and lines of argument, the effects the changes had and what was to be expected in the near future regarding accounting design. Second, data analysis involved access to all project documentation and internal reports of the plant organisation. This information allowed for a chronological support of the interview data and supplied many examples of events and reporting formats. Third, data was acquired from KOERS. This proved to be very valuable because it provided an involved outsider's view. This type of data consisted of material from the consultant's archives as well as oral descriptions, putting into perspective the many data elements.

All interviews were tape-recorded and transcribed verbatim. Documentation and reports were placed into chronological order to describe the chain of events. The analysis of the data was performed in two steps. First, a comprehensive case description regarding both organisation redesign and accounting redesign was writ- 
ten and submitted for verification to plant management. After verification and the integration of a second round of comments, the case description was approved by plant management. Second, the approved case description provided the input for a grounded theory procedure analysis, using the three coding steps as described above.

The format of the case description is twofold. The first part is directed towards the organisational context and chronologically describes the causes and effects that preceded the management accounting redesign. This chronological description is categorised into a description of the organisation and its products and markets, the preceding organisation design, the change process events and the resulting redesigned organisation and work processes. Where possible, interview statements have been inserted to illustrate how events were realised and perceived, giving a more comprehensive flavour of the differing company cultures. The management accounting part of the case description is based on the reports used in the redesigned information and control systems. This was done for reasons of system overview as well as the positioning and use of various managerial accounting practices and instruments. In this part, the various instruments and reports are individually represented and discussed, both regarding their composition and their use. No attempt is made to relate these descriptions to insights gathered from other research or literature.

The last phase involved the data collection from two other organisations that completed a similar full reorganisation of both the organisation design and their management accounting design, based on identical reorganisation principles and approaches. These two organisations were also selected with the help of the KOERS consultancy company, which had also been involved in the two change projects. Data collection from these organisations, called Zilverstad and St. Antonius, a silversmithing firm and a producer of vesselheads, respectively, followed an identical method as was used in the case of Van Nelle. Once the organisations agreed to cooperate, extensive interviews were held with key personnel and extensive documentation was handed over. Again, all interviews were tape-recorded and transcribed in full. The comprehensive case descriptions were then fed back and complementary information was supplied by additional interviews and internal documents. Also, the individual consultants involved in each case study provided a great deal of additional information. The final case descriptions were then approved, and constitute the input for the next step of grounded analysis.

The comparative analysis of cases was based upon the individual grounded theory analysis of each case. In particular, comparison of the open coding and axial coding diagrams of each case was helpful in this respect; open coding was helpful for its reclassification of raw case material into more abstract categories that could be compared in a horizontal fashion with other such open-coded categories. Axial coding was especially helpful in that it provided a so-called axial pattern per case that could be compared. An axial pattern is a sequential pattern of characteristics with the characteristic being related to an open-coding category. In short, an axial pattern represents the main line of thought in a case study. Comparison of these patterns indicated the differences in motivation and choices made in the three cases in an identical situation of organisational redesign - the contextual motiva- 
tions for different management accounting system designs become clear, i.e., cause and effect on design level can be identified. The axial pattern also provided the main input to build up the storyline, which is the descriptive representation of the main line of argument.

\section{Notes}

3 Although events here may give the impression that they were evaluated on a strictly rational basis, there was considerable disappointment on the part of the investigator. The results of the pilot study became available after one year of hard work and preparation. As these results were totally unexpected, it was felt that this year had been nothing more than a total waste of time. For the next few months, little hope remained for continuation of the research project. Fortunately, becoming acquainted with his future wife did provide some unacademic incentives to proceed with the research effort. Thank you, Ellen.

4 The implementation of the TAO research programme provided the necessary vehicle for altering the accent of the research questions - from technology to organisation design (Van Sluijs et al, 1991). This research programme endeavoured to build up a knowledge base for the integrated (re)design of organisations. To be more specific, the aim was to conduct research into the consequences of changes in the primary and innovation processes of firms for a number of disciplines - industrial relations, personnel management and management accounting. With the emergence of this larger research framework redirection of the research question was not too cumbersome a burden. 



\section{SocioTechnical Systems Design}

This chapter explains the concepts, methods and toolkit of organisational (re)design as advocated by the Dutch elaboration of SocioTechnical Systems Design (STSD).

Organisations are viewed as architectures of relationships between internal subsystems. This architecture is designed as to minimise disturbance by providing sufficient opportunities for control of disturbances proportional to the probabilities of disturbances. The equilibrium between available control options and required control options determines both efficiency and effectiveness.

A short historical overview hands over the first insights into organisation design, which placed a strong emphasis on job design. The Dutch elaboration as proposed by the work of De Sitter greatly extends it with replacing functional concentration by transformational integration.

In transformational integration, an organisation is considered as being made up of a control and a performance function: control relating to the selection of relations to be performed, and performance relating to the realisation of these selected relations. Subsequently, a production and a control structure are distinguished which are based on seven essential structural design parameters: (1) functional concentration, (2) performance differentiation, (3) performance specialisation, (4) separation of performance and control functions, (5) control specialisation, (6) control differentiation, and (7) division of control functions. Parallelising and segmenting the product flow constitute the degrees of freedom for control structure design, which is based on selecting, allocating and coupling control cycles at all levels of the organisation. The design toolkit contains both design sequence rules as well as a change management approach. Organisational change is thus considered both a programmable (highly normative) design and a process greatly influenced by human behaviour. 


\section{Introduction}

As a consequence of the unexpected results from a preceding pilot study into the change effects of advanced manufacturing technology on management accounting, the focus of the study was shifted. Although a more thorough exploration of why no change effects were initially found would also provide an interesting study, it would signify stepping down from the topic of management accounting change and its cause(s). However, the preceding pilot study made one thing clear and that is the importance of organisation structures and processes. It is on this point we proceeded with the study.

Competitive pressure necessitates change, and one of the roads open to coping with change is to redesign the organisation. As organisation structures change, internal processes change with it, resulting in a whole new set of dealing with problems and approaching the market place. Furthermore, that organisation design influences management accounting is a commonly held opinion, but scarcely researched when it comes to determining what exactly are those influences.

A venue was found in an inspiring development called Modern SocioTechnical Systems Design (STSD). STSD represents a deliberate design logic which is systematically repeated and addresses the accounting structure as well. Because the logic surrounding the accounting system is identical, firms using STSD provide a good opportunity for performing research into the relationship of management accounting to its context. Moreover, its focus on the design of whole (accounting) systems instead of single elements or practices prevents limited explanations.

To take the STSD option, a well-structured and instrumented path is required. Interventions in structures and processes place demands on both the content of the redesign and the changeover process. Instrumenting it in just a technical sense falls short of the behavioural aspects which can easily overrun whatever effective and beneficial redesign one had in mind. STSD is basically a systems approach, paying attention to the interacting subsystems of the organisation. Its subsequent redesign toolkit as well as its change management approach relate to management accounting in their effects on existing information and control structures. But in order to properly assess the latter, Modern Sociotechnical Systems Design has to be discussed in more detail first.

\section{The General Idea}

The main point is that STSD is a structural approach to organising. Specifically, it is an open systems approach to organisations, considering that the organisation consists of a number of aspect systems and subsystems. The difference between the two is that subsystems relate to a collection of elements from the overall system, while aspect systems relate to a collection of relations between system elements from the overall system (Den Hertog, 1991). Accounting, for instance, is an aspect system, as well as Finance, Logistics and Personnel. When a number of relations (such as accounting, personnel and finance) are coupled to a number of elements (such as the job shops 1 to 6 , the shipping department and the order-taking 
department), one can speak of an integral approach. To prevent partial analysis and design, the parts as well as the relations should be integrally approached, visualising Modern STSD as the 'theory' of the architecture of relationships.

What 'Modern' STSD adds to traditional STSD consists of the following: a consistent concept of overall structure design going beyond working in task groups and the relatively narrow world of job design and work structuring, and a supporting design toolkit and change management trajectory specifically targeted at implementing Modern STSD. Both 'extensions' offer a theoretical link between the Quality of Work paradigm usually associated with classical STSD, and called the Quality of Organisation. Roughly speaking, the latter extends sociotechnical design principles to areas of the organisation other than the pure production function. More specifically, it adds design elements for obtaining flexibility, control, productivity and innovativeness (Groep Sociotechniek, 1987). Thus, 'Modern' STSD encompasses significantly more than just working in task groups and maintaining good working ('human') relationships.

Modern STSD is foremost directed at structures, it focuses on the architecture of connections between parts. An integral design configures relationships as well as parts - it addresses connectivity and content at the same time.

A more exemplifying discussion of what integral design is and does, can probably be best arranged by comparing it with the more traditional integral design proposed by Frederick W. Taylor. His design rests on the concept of functional concentration, which is repeated in every system relationship as well as in the content of every subsystem. Taylor's design approach rationalises the organisation into a division of executive tasks on the one hand and controlling and regulative tasks on the other, concentrating operational and managerial tasks in separated and spi. cialised departments (De Sitter, 1982). Bureaucratic support was organised along the same line of functional concentration: the grouping of identical capacities in supporting departments. However, functional concentration also results in separating and concentrating control and performance functions. In other words, operations become specialised, and so do management and control. They are allocated to different specialised support departments such as finance and accounting, production planning and scheduling and inventory control. Management and control are thus dispersed and allocated to various hierarchical organisational levels and aspect systems, i.e., disciplines.

However, as functional concentration connects all parts of the organisation to all orders (every order passes all or several functions) things will only be relatively simple as orders are more or less identical in content and only require various capacities to be attributed: that is, when it comprehends standardised mass production characteristics. The problem arises when orders acquire different characteristics. The order size varies per planning period from large to small batches and the order content becomes less standardised and varies largely in content as well. In a functionally concentrated structure, this will lead to a (very) high variety of orders each having to pass all parts of the organisation. In other words, an enormous crisscrossing of orders throughout the organisation will arise. This enormous variety creates an equally complex control problem. 
In order to solve this control problem one can follow two paths: allocate orders over different capacities or allocate capacities over different order flows. In the first option, one continues on the track of functional concentration, meaning the creation of specialised departments for order coordination and tracking (i.e., expediting), accumulation of large stocks and increases in delivery times, followed by an extensive use of large computer systems for production planning, which are installed at the Computer Support department, and establishing special coordinating units, task forces or matrix organisations.

Or, in the second option, one can shift the focus of integration: Changeover to flow-oriented production and integrate on the basis of transformational concentration. Therefore, integrative design is structural design (see Figure 3.1). A flow production is structured by differentiation of basic functions such as 'support', 'prepare' and 'make', identical to Tayloristic differentiation, but then they are transformationally concentrated instead of functionally concentrated. The same holds for control: No specialisation in process or flow aspects by different aspect systems such as monodisciplinary departments including accounting, personnel, production planning, but differentiation towards the basic control domains, i.e., the subprocess in the flow one is working on and responsible for. The basic value assessment underlying both integral design approaches is its belief in human capabilities. Taylor implicitly holds the belief that human capacities are limited, while STSD holds the belief that humans have almost unlimited capacities, which subsequently can be addressed by the organisation design surrounding them; see the STSD-based research on human resources management and industrial relations wherein this value issue is pronounced more explicitly (Dankbaar and Den Hertog, 1990; Van Sluijs, Van Assen and Den Hertog, 1991; Buitelaar, Dankbaar and Van Klaveren, 1991).

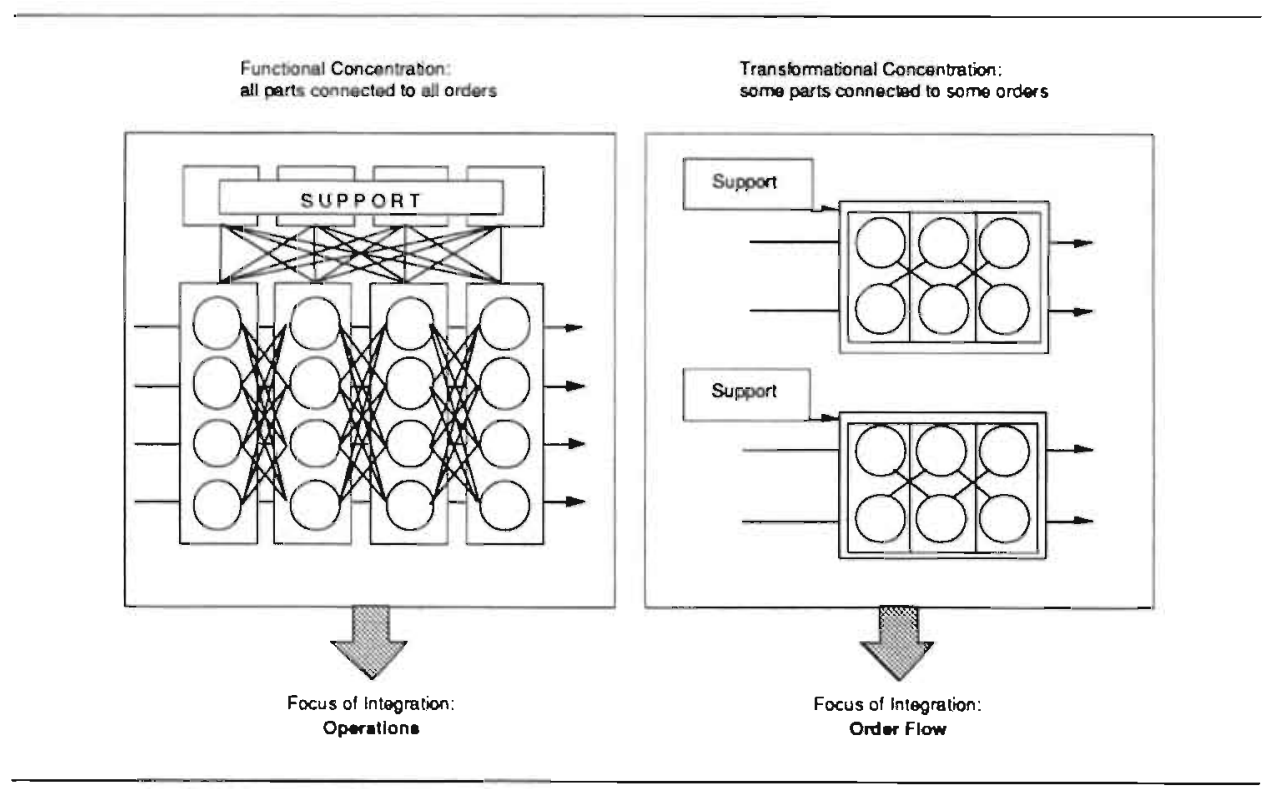

Figure 3.1 Integral design: functional concentration vs transformational concentration 
The above example indicates a two-way reduction of variety: External and internal. External variety is determined by the number of flows or operational trajectories required. On the other hand, internal variety is determined by the number of departments and work stations. To indicate the variety reduction accomplished by transformational concentration, consider the following calculations (De Sitter and Den Hertog, 1990). For external variety reduction, the functional organisation mode is structured by four flows which require 15 operational trajectories $\left(2^{4}-1=\right.$ 15). However, the transformational organisation mode requires only 6 trajectories $\left(\left[2^{2}-1=3\right]+\left[2^{2}-1=3\right]=6\right)$, therefore reducing external variety by 9 trajectories or $60 \%(9 \div 15=60 \%)$. A similar type of calculation can be made for the reduction of internal variety - in the functional organisation mode, four kinds of operations yield 24 possible sequences $(4 !=4 * 3 * 2 * 1=24)$. Each sequence can be produced by 256 different routings $\left(4^{4}=256\right)$; the total internal variety in operational trajectories thus amounts to 6144 possible routings $(24 * 256)$. The transformational organisation mode, however, leads to 384 possible routings per flow $\left(4 ! * 2^{4}=384\right)$, amounting to a total reduction of internal variety by 5760 routings or $93 \%$. The occurrence of external variety is mainly based on demand variation, i.e., changes in product mix and product volume demand.

This leads us to the method of integrative design, or how to structure flow-oriented production without losing control. Modern STSD has several well-elaborated design principles and strategies (i.e., the change management trajectory) which can all be reduced to one basic principle: that of Requisite Variety, also known as Ashby's Law (1952). It is the design criterion of systems controllability, and reads:

$$
\mathrm{C}=f \frac{\text { (opportunities for process variation) }}{\text { (variation required) }}
$$

It constitutes a ratio, coupling structural answers to variety (the nominator) to the latitude needed to cope with that variety within that particular structure (the denominator). A qualitative balance is obtained if the ratio equals 1 . That is, if there is as much structural latitude provided as needed. If there is provided more than needed (the ratio is $>1$ ), this surplus can be considered anticipating future variety. For instance, regarding the Quality of Work, i.e., at the micro-level, the ratio can be understood as a ratio of control capacity built into a task versus control capacity required. Or, in normal language, if the opportunities to solve problems are equal to what is needed to solve problems.

Furthermore, in order to improve organisational effectiveness one directs attention to the opportunities for process variation (nominator): How much effectiveness is permitted by the structure? An increase in effectiveness is an effect of structural measures, i.e., redesign. Alternatively, to improve efficiency, the variation required (denominator) is reduced. For instance, to continue the Quality of Work example, the required control capacity of a particular task is reduced if the number of recurring problems encountered in that task is also reduced. If the number of unusual, nonrecurring problems increases, so does the required control capacity. The employee needs more instruments to solve the unusual problems he encounters. Efficiency therefore increases when all the nonroutine variety is matched by 
problem-solving instruments. In terms of the above equation: if the ratio is 1, an organisation is both effective and efficient. An organisation is ineffective when the choice options for process variation are less than required (the nominator < the denominator). On the other hand, an organisation is inefficient, but indeed effective, when the structure provides ample problem-solving opportunities but there is relatively little need for it (the nominator $>$ the denominator).

A somewhat similar basic principle can be found in the work of Galbraith (1977). Together with Ashby, he follows the idea first proposed by Simon (1947) that organisations are to be conceived as information-processing institutions or systems run by humans who are plagued by a bounded rationality which does not allow them to make optimal decisions. Since then, complexity and uncertainty in decision making have generated a stream of research, contingently relating uncertainty and complexity to decision making (Thompson, 1967) and organisational design (Galbraith, 1973, 1977). Galbraith states that there is a balance between information-processing requirements and information-processing capacities. The difference between the two, if any, is caused by uncertainty as it necessitates greater amounts of information to be processed between decision makers. Organisational hierarchy then provides an adequate method to control for certain tasks. Uncertain tasks then require implementing a more organic and less hierarchic form of organising, thus relating the information-processing perspective to organisational design.

If the information-processing equation is not balanced, two design strategies can be operationalised for dealing with uncertainty: Reducing processing requirements through the creation of slack resources (e.g., excess capacity) and self-contained tasks (the job design predecessor of autonomous work groups), or enlarging the processing capacity through sophisticated information systems and improving lateral relations. However, Galbraith is one of the few researchers that depart the functional concentration point of view because he suggests lateral linkages or selfcontained tasks as design-oriented solutions.

\section{The Embodiment of Sociotechnical Systems Design}

The crucial experiment which marked the first light of Modern STSD lies in the study of Trist and Bamforth (1951) of the work organisation in the Elsecar coal mine in South Yorkshire in the United Kingdom (Van Eijnatten, 1991). Due to the short coal front in the Haighmoore seam, the new mechanised way of winning coal, called the 'long wall method', could not be used. Alternatively, Reg Baker, the Area General Manager of the area in which that particular coal front was found, developed what he called the all-in method. This work organisation consisted of so-called 'composite work groups': eight miners forming a small group which was responsible for a full cycle of coal extraction. At that time, it deviated largely from the generally held opinion that there was one best way of organising, which was determined by a combination of Taylor's scientific management concept and Weber's concept of bureaucratic organisation (Trist, 1981, cf Van Eijnatten, 1991). Equally significant were two other characteristics involved: the great reluctance of management to communicate Trist and Bamforth's findings, 
and the fact that the new work organisation form was developed independently from managerial directives or other higher set orders. Later in the development of sociotechnical systems design, the elements of management steering only in a very general mode (i.e., autonomy means almost full decentralisation of decision making) and of the diffusion and learning by others of sociotechnical findings and concepts established two main characteristics of 'Modern' sociotechnical design. Meanwhile, the field experiments (known as 'the Bolsover case'; Van Eijnatten, 1991 , p. 10) with the new work organisation proved highly successful: From other mines in North-West Durham it was reported that output was $25 \%$ higher, production costs were lower and absenteeism was reduced by $50 \%$, all compared to the traditional mode of work organisation (i.e., Tayloristic and functionally concentrated jobs).

Typically, the development of 'composite work groups' was constituted primarily to solve a problem: the mining of coal in such a fashion that the new long wall method' was retained. However, what was still lacking was a theoretical base of their findings. This is not surprising, as the contents of 'composite' versus 'traditional' work organisation were primarily described and explained. How to get from 'traditional' to 'composite' was not discussed, which essentially means that the expert proposes the new solution and convinces management and employees to apply the proposed solution (Den Hertog, 1992). A theoretical foundation of 'composite work groups' was therefore only implicitly present at first. Individual researchers, however, were influenced by the then emerging research stream of systems thinking resulting in the application of the holistic and open system view of organisations together with the concept of self-regulation. The holistic and open system view allowed them to consider both the whole coal-mining situation and the influence of the hostile and unpredictable environment in the coal mines. Self-regulation is particularly effective in this environment and all-round miners are required for that or, in other words, provide the 'requisite variety' as to the problems associated with environmental uncertainty (Van Eijnatten, 1991). Also, the application of the open system view to the production organisations led to the distinction of a 'sociotechnical system' consisting of a social and a technical component. Both components are independent in so far as they 'obey' the laws of natural science and the 'laws' of social sciences. They depend on each other because they need each other in fulfilling the production function of the firm, i.e., they are connected by heterogeneity. Typically, the economic aspect is not viewed as a separate system but only as a means of measuring the effectiveness of the entire sociotechnical system (Emery, 1972 cf Van Eijnatten, 1991).

Following the action research carried out in the British mines, empirical research on sociotechnical systems transferred to Norway as the Norwegian programme on Industrial Democracy (ID) was started up in 1962. Sociotechnical systems design would fit perfectly in this programme for its self-regulation design and decentralised decision making. Part of the Norwegian programme consisted of a number of exemplary projects, featuring the autonomous workgroup as the main design ingredient, in a wire-drawing mill, a paper pulp factory, an electrical appliances plant and a fertiliser plant respectively (Emery and Thorsrud, 1969, 1976; Bolweg, 1976). As projects followed one another in time, a transfer of lessons learned was possible and, as it showed, badly needed. 
The first project was carried out at the wire-drawing mill of Christiana Spigerverk in Oslo in 1964. Group work was introduced by the British-Norwegian research team, but the reward system and the non-involvement of local managers and mill employees posed serious difficulties to the control of the change process. After a year, the project was cancelled. A second project was started in February 1965 at the chemical pulp department of the Hunsfos paper mill in Kristiansand. This time, management and unions were extensively consulted and the change process was better controlled by phasing the project and having representative project groups installed for each phase. More importantly, the project really won impact at the moment the research team withdraw and management committed itself strongly to the new organisation mode. However, early 1967 the project came to an almost complete standstill as industry conditions worsened and managerial priorities shifted accordingly. A third project was started in December 1965 at NØBO's metal ware plant near Trondheim, this time directed at the introduction of autonomous workgroups at the product line level. All earlier insights regarding change and project management were applied. This project was turned into the show case of the ID programme and drew widespread international attention. Furthermore, as a new plant was built later, the sociotechnical production organisation was maintained. The fourth and final exemplary project was initiated in 1967 in a conjunctive approach wherein an old fertiliser plant was reorganised and a new fertiliser plant of Norsk Hydro in Porsgrun was designed. As in the other projects, it introduced group work supported by a training programme and a reward system based on group work. Both plants were fully organised in sociotechnical terms and became very successful (Van Eijnatten, 1991).

The Norwegian programme was of great significance as it provided many sociotechnical tools and shaped the change management approach of classical sociotechnical systems design (Bolweg, 1976). Two main lessons were learned. First, the overruling importance of participation and, second, as a consequence, the switch-over from content to process in sociotechnical design (i.e., the expert approach versus the facilitator approach).

Participation proved to be the only route which made the autonomous group structure last. Participation took the form of self-design which is basically shaped by an educational workshop in which concepts and tools are handed over to managers, shop stewards and employees together. This is followed by small design teams which redesign independent parts of the organisation - design teams are, again, of a mixed composition. Design teams are then brought together again for a discussion round of the various designs. Subsequently, in a plenary presentation, all revised designs are coupled and a first planning of the reorganisation is made. In the late seventies, a more general redesign approach was generated. It made use of a so-called search conference bringing together a broad selection of people (25 to 35) of various functions and levels from the organisation who develop possible and desirable scenarios for the organisation. In fact, it contains a strategic orientation on the environment of the organisation and the organisation's possibilities and limitations in that environment. Furthermore, a search conference fulfils the subsequent role of bringing people together in a learning situation and taking advantage of the future structure of cooperation. 
At first, change management was dominated by an expert approach. As it was the pioneering phase of sociotechnical systems design, it was believed that an expert model would guarantee the largest diffusion of sociotechnical ideas. Experts would, one believed, convince several firms to agree with sociotechnical experiments in their organisations and with the results they would yield, researchers could further prove that STSD really lived up to expectations. Information transfer in the literature, conferences, etc., would then lead to further diffusion. Also, the expert approach reflected the technical model of change at that time; after establishing the goals of the organisation, further specifications were derived and various alternatives weighed. The one alternative chosen then would be implemented and that is all there is to it. This linear, stepwise mode of operation can still be found back in the sociotechnical project management tool called the ninestep plan, which will be discussed below. However, the expert approach did not lead to the expected diffusion of ideas despite the success and international attention for the Norwegian experiments. Researchers and the parties involved in the ID programme therefore drew the conclusion that participation is not a mere condition for lasting change but the main substantial element of the change approach. It reduced the role of technical expertise radically. Expertise from now on was limited to the educational workshops and to the possible need for additional expertise explicitly expressed in the later stages of self-design (Den Hertog, 1992).

The sociotechnical tools that resulted from the British and Norwegian experiments led to (1) an improved change project management as implied in the ninestep design method, (2) a disturbance diagnostic tool called the 'variance control matrix', and (3) a series of job design principles for joint optimisation of the social and technical systems at individual and group level.

The nine-step method constitutes a classic sequence of action steps, familiar since the time Simon proposed it. It was applied to STS change projects by Emery and Trist (1978). Because of its linear logic, it is still used in many models for information system design (Van Reeken, 1990). What is interesting about the nine-step method, however, is that it implies a sort of project organisation, each project group tied to one or various steps in the method.

The variance control matrix is based on the concept of 'disturbance control' of Herbst (1959). It maps disturbances as to the locations where they are signalled and to where they are caused, which can be at two very different places in the organisation. Signal and cause then are brought together: At the location where the signal occurs, the cause should be controlled. Typically, its basic idea is to construct system boundaries around those places where signal and disturbance collectively appear. In this respect, the variance control matrix is a sort of process analysis.

The nine-step method then was wrapped around the variance control matrix: By using the matrix the process was analysed, and its subsequent redesign outcomes are then brought into a project organisation as constituted by the nine-step method (Engelstad, 1972).

Finally, the Norwegian experiments resulted in the formulation of structural propositions for joint optimisation. These principles distinguish between individual and group level. At group level, it is more explicitly attempted to couple 
work groups to overall organisation design, because it addresses larger issues such as communication and information, and requirements for personnel policy (Emery and Thorsrud, 1976).

The further diffusion of sociotechnical ideas and experiences to Sweden and the United States marked the start of various other experiments which are well documented and still have an significant impact on production organisation design (Whitsett and York, 1983; Agurén, Bredbacka, Hansson, Ihregren and Karlsson, 1984; Lawler, 1986; Auer and Rigeler, 1990). In the US, the sociotechnical idea was first renamed 'Quality of Working Life' (QWL) and later 'High-Performance Work Systems' (Vaill, 1982; Buchanan, 1987; Taylor, 1990; Moch and Bartunek, 1990). As these changes in labels already indicate, the diffusion of sociotechnical ideas and their application in a field situation thus evolve with the accents placed over time on certain elements of organisational effectiveness. Or, as Safizadeh (1991, p. 63) puts it "... But because the past solutions have reflected the environmental imperatives of the time in which they were proposed, their applications to a modern setting is problematic". The present accentuation of organisational flexibility and innovativeness do indeed add an extension to the original sociotechnical ideas as developed in the U.K. and Scandinavia in the 60s and $70 \mathrm{~s}$. The use of the adjective Modern to reflect the Dutch further elaboration of SocioTechnical Systems Design with an extensive design toolkit and a change management approach is no coincidence in this respect.

\section{The Dutch Elaboration}

\section{Modern Sociotechnical Systems Design}

As The Netherlands also had its share of classical sociotechnical experiments in the 60s and 70s (Van Beinum, 1963; Den Hertog and Wester, 1979; Allegro and De Vries, 1979), De Sitter was the first to critically review the original paradigms of classical STSD. The main points of his criticism include (Van Eijnatten, 1991): imprecise definitions of concepts, inadequate attention for the systemenvironment relationship, the overly emphasis on reducing the social system to a psychological entity, the incorrect system-theoretical distinction between social and technical subsystems instead of defining them as aspect systems and, finally, the inadequate separation of the analytical model (explaining existing production architecture) from the design model (shaping a renewed architecture). The next paragraphs on the Dutch elaboration of STSD are deeply rooted in the work of De Sitter (1989a, 1989b; Groep Sociotechniek, 1987; De Sitter and Den Hertog, 1990).

De Sitter's critique initiated the design of a new theoretical framework, which describes STSD as "The study of the manner in which structural parameters of organisation as a function of the division of work and technical instrumentation of a production system in a given environment, shape opportunities for the production of internal and external functions, and the application of this knowledge in this respect to the design of production systems" (De Sitter, 1989c, p. 13). Technical instrumentation here literally means technical equipment. The division of work indicates the separation, grouping, allocation and coupling of executive and 
regulative functions. Internal and external functions relate to system functions: Internal functions are, for example, procurement, manufacturing and sales, and external functions are transactions with respect to various markets such as the consumers market, the suppliers market, the governmental 'market and the capital market. As a shortcut for understanding, a function can be considered a transformation, translating an input into an output. However, this definition particularly stresses the interdependence between technical instrumentation and the division of work. The balance model implicit in this conceptualisation is worked out via the Law of Requisite Variety earlier mentioned. It focuses on the premise of 'requisite variety', stating that turbulence imputed by the variability of the environment can only be compensated for by a proportional capacity to control (Van Eijnatten, 1991).

Modern STSD, however, explicitly tackles the problem of the functional requirements in which modern production organisations must excel. The production concepts of today still build on the characteristics of the Tayloristic-bureaucratic concept of the organisation dating back more than 100 years ago. At that time, its organisational concept was based on integral thinking, relating structure to the division of labour. Since then, efforts have been directed at improving parts of the system (e.g., personnel, production, accounting) taking for granted the initial integral setup of the organisation. However, problems can be solved no longer without addressing the structural background of the strains between production systems and their socio-economic environments. All other answers not addressing this structural background will have the characteristic of providing 'more of the same'. What is therefore needed is a science of integral structural design: i.e., STSD becomes the architectural science of organisational structures (De Sitter, 1989c). The Modern sociotechnical point of view can thus be summarised:

"Production is embedded in a network of socioeconomic exchange between production systems and their respective environments. The external structure of a production system can be defined as the configuration of interactive relations with its environment. The internal structure describes the architecture of relations between the parts or elements of a system. ... It consists of a set of functionally differentiated relationships and their interactive outcomes. Outcomes with an external function are defined as outputs. Outcomes with an internal function are usually conceived as 'emergent' properties or 'condition changes' in the internal structure, such as changes in inventories, wear \& tear, changes in skill and knowledge, and changes in (or reinforcement of) current industrial relations as a function of learning processes. The multitude of functionally differentiated external and internal processes of exchange requires continuous adaptation and coordinating under ever-changing conditions.

The internal structure or architecture of a production system fosters or restricts the opportunities for effective and efficient control of the required coordination between functionally differentiated processes, which may interfere with each other and may impede each other's normative completion. The core of sociotechnical inquiry is therefore the analysis and identification of the external and internal structural parameters which together determine a system's disturbance probability and sensitivity with respect to a balanced production of internal and external functions in time." (translated from De Sitter, 1989b, p. 12)

Since STSD is being considered as the architectural science of organisational structures, attention must be paid to the following four design elements: 
- identification of disturbance criteria (i.e., what type of turbulence turns out to be a structural problem), which are called the 'functional requirements' of the systems to be (re)designed;

- identification of structural locations and sources of disturbance;

- identification of structural parameters related to the probabilities of disturbance and disturbance sensitivity, i.e., on what element(s) of design does turbulence reflect and what are the chances that this turbulence highly disrupts the overall organisation?;

- a study and formulation of structural design principles, indicating how to design aspect systems on the basis of insight into their dynamic interdependencies with respect to the basic requirement of balanced production of internal and external functions in time (De Sitter, 1989, p. 12).

From a design point of view, it thus became necessary to make a fundamental distinction between aspect systems, regardless of their function. Consequently, two basic functions in every purposeful, and therefore selective processes can be distinguished: control and performance. Control here means the selection of relations to be performed and performance relates to the realisation of selected relations.

This distinction is followed by a subsequent distinction regarding design methodology. It addresses the structure of three basic aspect systems (De Sitter and Den Hertog, 1990, p. 14):

- the Production structure, which addresses the grouping and coupling of performance functions;

- the Control structure, which addresses the allocation and coupling of control functions; and

- the Information structure, which is derived from the production and control structure and which addresses mainly design questions regarding technical matters such as sensing, coding, retrieval and transfer of control data. Basically, the information structure is nothing more than a technical elaboration of the two main production and the control structures.

As structural design implies changes in structural parameters, these parameters refer to the two basic structural aspect systems, i.e., the production and the control structures. These parameters have been well known for a long time as they represent the primary architectural characteristics of any structure. Designing and changing existing designs therefore always address one or more of the following parameters:

1. Functional concentration, which can take two extreme forms: all transformation coupled to all subsystems (concentration), or each transformation coupled to its own corresponding subsystem (deconcentration in parallel flows). This parameter usually sets the pace for all other structural parameters as it determines the freedom of (design) choice for all remaining parameters.

2. Performance differentiation, which refers to the separation of the prepare, support and make functions into specialised subsystems. 
3. Performance specialisation, referring to classical Taylorism as it splits up a performance function into a maximum number of subfunctions, which then are allocated to separate subsystems.

4. Separation of performance and control functions, which allocates a performance and a corresponding control function to different subsystems, i.e., an employee overseeing a group of similar lathes.

5. Control specialisation, which allocates the control of functional aspects to separated aspect systems, i.e., quality, maintenance, logistics, personnel, etc.

6. Control differentiation, which splits up control domains into separate control levels such as strategic, structural and operational levels.

7. Division of control functions, refers to the allocation of various functions from the control cycle (e.g., perceiving, judging, action selection) to separate subsystems (De Sitter and Den Hertog, 1990, p. 15).

The concept of structural parameters can be considered the link between a 'modern' sociotechnical paradigm as sketched above and its elaboration into a toolkit for (re)design. The latter is not only an extension of 'modern' STSD, but also an important body of knowledge representing design principles, design strategies and design sequence rules. It instruments STSD with a view of how to implement it, thus adding largely to the significance of sociotechnical design in daily practice. In other words, it supplements the explanatory function of how an architecture of structure determines the system's internal and external functions with a design function of how to obtain desired relations between internal and external functions. This design toolkit is discussed below.

\section{A Design Toolkit}

The design toolkit of Modern STSD consists of three main instruments in a hierarchy of decreasing abstraction: There are design principles, design strategies and design sequence rules. The design principles have the most general significance as they address the complexity of the systems. Systems' complexity is considered a function of, respectively, the number of system elements, the number of their external and internal relations and their variability in time (i.e., is a steady-state condition applicable?).

In Modern STSD terminology, an increase in complexity is related to an increase of disturbance probability and disturbance sensitivity. Seen from the structural point of view, disturbance probability is a function of the seven parameters mentioned above. The more separation and differentiation between control and performing functions, the more interfaces and, accordingly, the higher the probability of interferences: i.e., the probability that functions may interfere with each other. Thus, disturbance probabilities define the degree of requisite variety. On the other hand, disturbance sensitivity refers to the available options to reduce disturbances at the level of subsystems. If available options to absorb disturbances are less than required at their location of occurrence, the probability of disturbance transfer increases (see Figure 3.2). 


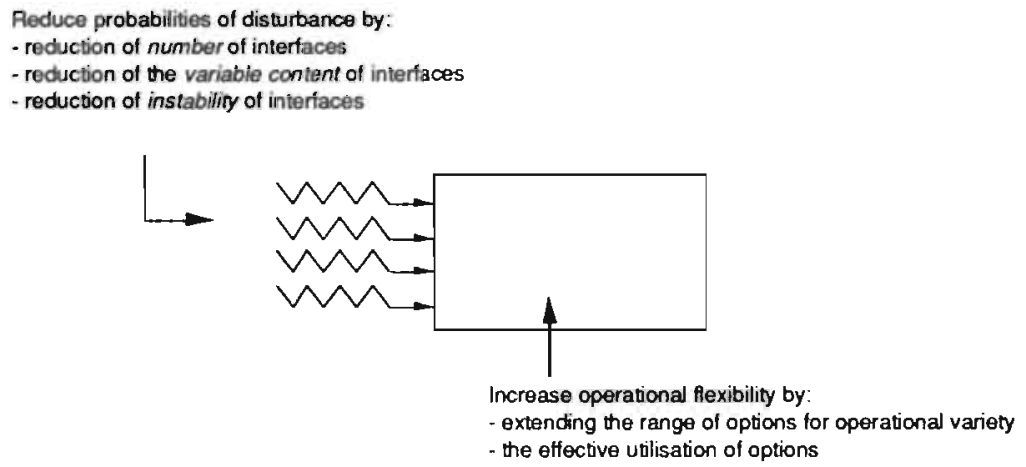

$\sim$ - disturbance working on a process segment

Figure 3.2 Relationship between complexity, disturbance and requisite variety

The basic integrative design principle is directed at establishing two goals: to reduce disturbance probability, and to reduce disturbance sensitivity. This can be obtained either by reducing impending variety or by increasing control capacity, in other words: by applying the Law of Requisite Variety discussed earlier. Applied to the two basic aspect systems of production and control structure it takes the form of (De Sitter and Den Hertog, 1990, p. 16):

controllability of the production structure $=f \frac{\text { (available means to vary performance functions) }}{\text { (variation required) }}$.

$$
\text { controllability of the control structure }=f \frac{\text { (control information available) }}{\text { (control information required) }}
$$

The design strategies serve both as analytical techniques and as the various applications of the design parameters. However, as design strategies are largely contingent upon the organisational setting, an equally large number of strategies are possible. Nevertheless, the following six strategies are the ones most commonly used, and therefore warrant attention as main design 'reflexes'.

Regarding the production structure:

* Parallelisation (entails parameter 1 - functional concentration)

* Segmentation (entails parameters 2 and 3 - performance differentiation and performance specialisation).

Regarding the control structure:

* Unity of time, place and action (concerns parameters 4 until 7 - separation of performance and control functions, control specialisation, control differentiation and division of control functions). 
* Bottom-up allocation of feedback loops (concerns parameter 4 - separation of performance and control functions).

* Uncouple feedback loops in time (concerns parameter 6 - control differentiation).

* Built-in feedback loops in every task (concerns all seven parameters).

The production structure design strategies can be considered design for flexibility. They are directed at the available means to vary the production process, while the control structure relates to the utilisation of those means.

The point of parallelisation is proven earlier where a process flow was deconcentrated (parameter 1) into two parallel flows, inherently reducing complexity by $60 \%$. Segmentation builds on parallelisation in its reduction of interfaces in the input-output chain. Interfaces are 'amplifiers' of internal variation sources. For instance, in the earlier example complexity was further reduced by $93 \%$. Parallelisation is directed at reducing external variety as caused by demand variation such as changes in volume demand and product mix. Alternatively, internal variety as countered by segmentation is caused by the number of performance operations, i.e., their subsequent number of necessary interfaces (see Figure 3.3). Segments are created by clustering performance operations that have maximal interdependence in their execution. In general, segments should contain operations that either show direct interdependence regarding sequence and balancing the flow of material or are dealing with quality, or form a cluster with joint input and output channels.

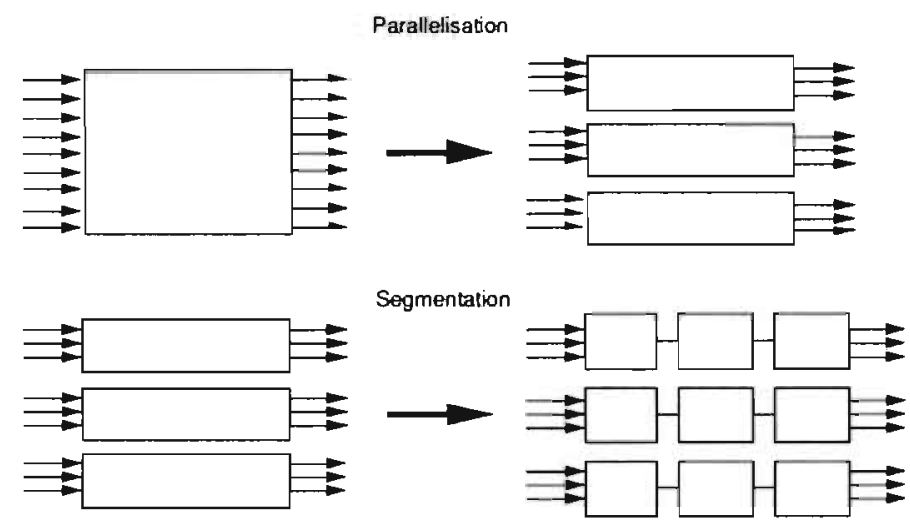

Figure 3.3 Simplifying by parallelisation and segmentation (separating order flows and, subsequently, separating process parts in the order llows; Van Amelsvoort, 1992)

Segmentation of performing functions are a first step towards a corresponding segmentation of support and preparatory functions, which thus form a fluent next step to the phase of control structure design. Parallelisation and segmentation result in less internal and external variety and use few interfaces which already im- 
ply an exponential decrease in required control. Therefore, most control problems are implicitly solved by the design of the production structure; what is left to design, builds on the concept of the control cycle or, as it is sometimes called, the feedback loop. This is the reason why the design of the production structure has to be taken care of first, i.e., the sequence rule discussed below. In other words, 'required control' is the linking factor between production and control structure design.

A control cycle consists of four interrelated functions: (1) sensing, i.e., perception of process states, (2) judging, i.e., evaluation per aspect, (3) judging again but now on an integrated basis of evaluated aspects, and (4) action selection, i.e., the choice of a controlling activity. The control cycle is independent of the control level. For instance, at the operational level operations are controlled on the basis of given norms. The structural level generates those norms on the basis of production, and control models on the basis of given organisational goals and, finally, the strategic level evaluates these goals given the environmental or market conditions. Control cycles therefore control variation at all levels of aggregation (micro, meso and macro). Control structure design is now directed at configuring the allocation, selection and coupling of control cycles in the production structure designed first (see Figure 3.4).

The design principle of unity in time, place and action relates to the availability of effective control information. The time between the two phases of occurrence \& perception and perception \& action upon a disturbance should be as short as possible. What links these two is the place of occurrence. Therefore, separation of the two phases and, thus, the control design principle of unity in time, place and action should be prevented. Implicitly, this design principle hands over criteria which determine what information is effective information: information should be reliable (correspondence between facts and perceptions), actual (time-span between occurrence and control action), complete (simultaneous measurement of current conditions) and relevant (affects probability of information distortion and severs learning processes involved in the mental modelling of processes). Each of these criteria can be related to the above-mentioned structural parameters. For instance, completeness relates to control specialisation (parameter 5) as it pertains to all aspect systems involved. Also, relevance relates to separation of performing and control functions and division of control functions (parameters 6 and 7) because it refers to the allocation of these functions to separate elements, i.e., individuals or machines. Separation of control information can thus block the transfer of learning 'on the job'.

Bottom-up allocation of control cycles is in itself an application of the structural parameter of control differentiation. In general, everything in an organisation can be controlled top down. However, by starting to allocate bottom up, a differentiation is made towards what control cycle is most appropriate at what control level. This is done by means of stepwise elimination. At micro-level (e.g., individual work stations) a first round of control cycle allocation is made. From the total set of control cycles, these control cycles are then eliminated and a step-up is made to the next control level. Consequently, at the meso-level, the next round of control cycles is allocated and eliminated from the total control set. This procedure is repeated up to the top level, where the last and most strategically oriented control 
cycles are allocated. For reasons of simplicity regarding the procedure, the mictolevel is operationalised to start at the level of segments or whole-task groups. Determination of the control range at segment level then works two ways: upward to the organisation's top level and downward into the group. Micro-level for the latter is the individual work station. Typically, in a structural architecture without parallelisation and segmentation there would be few starting points for allocating control cycles, since micro or meso-levels in the organisation are hard to distinguish.

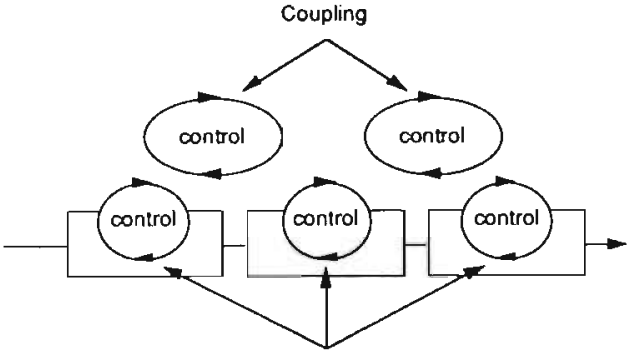

Allocation and Selection

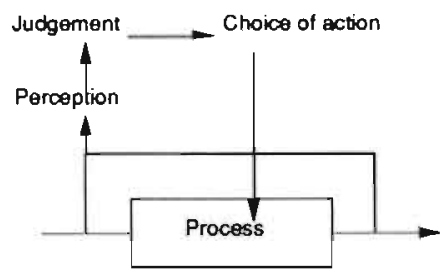

Figure 3.4 Selecting, allocating and coupling of control cycles and the control cycle concept (KOERS, 1989)

The design strategy of uncoupling feedback loops (control cycles) in time relates to the moment when external control transforms into internal control. Segments have various interfaces. Each segment's internal control cycle is coupled using a higher level external control cycle, which usually matches the existence of an interface. Typically, each segment's internal control would be substantially reduced if all preparatory and support functions were received at the same time. Therefore, instead of physically buffering those functions, it is the lead-time which defines their reception. This shows a strong similarity with Just-In-Time production systems, which primarily structure their processes on the basis of time consumption. Most significant here is the use of Kanban cards, which are control signals to the preceding segment that an input is required by the signalling segment. In other words, a kanban is a concrete depiction of control cycle coupling, i.e., an external control cycle transforming into an internal control cycle if the kanban is received and acted upon. The general idea supporting this design strategy is somewhat similar to stepwise elimination in allocating control cycles. It builds on a hierarchy of control levels (strategic, structural and operational) each having their control domain, which are separated by input or output interfaces, thus resulting in local control, interlocal and global controls. It therefore follows that the structural parameter of control differentiation is involved (parameter 6).

The last control design strategy, building in feedback loops in every task, is perhaps the most 'traditional' as it relates to the 'grandfather' of STSD: job design. It con- 
siders the individual work process as the smallest existing production organisation. This can be compared with traditional craftsmanship, where, for example, a cabinet-maker would purchase wood and make it into cabinet parts, build the entire cabinet, perform on-line quality inspections and sell it. The notion of individuals as mini-production organisations thus results in the application of all structural design parameters: a micro presentation of all production and control problems addressed above. The human mini-production organisation should therefore integrate all manufacturing, preparatory and support functions as much as possible. It also implies the appearance of external and internal variety encountered at individual level, which according to STSD should be met by an equivalent control capacity. A parallel can be drawn with the work of Emery and Thorsrud (1976) discussed earlier. They provided some task redesign principles which can be found back as elements of this later control design strategy, the main difference being the more extensive theoretical grounding and the present relationships with an overall design methodology. Accordingly, control capacity should regard all levels of control (strategic, structural and operational) in every task performed. If such a match occurs (variety versus control capacity), the quality of work is considered high. Also, the outcoming quality of work can be considered a function of the division of labour.

The design sequence rules direct the sequence in which the design steps should be taken - in fact, they constitute the production structure of change. The flow of change has to be managed in an orderly fashion, which demands a stepwise and project approach. When to take what steps is the subject of what is called the 'Integral Organisational Renewal' trajectory (see below). Part of that trajectory consist of the design sequence rules on what to design first or how to structure the (re)design itself.

As stated above, the production structure design sets a first framework, shaping the conditions for the control structure design and removing, at an early stage, some of the disturbance probabilities present. The control structure design repeats this streamlining process for the information structure design. A fully worked control design is a clear input on what control information is required where. It reduces the information structure design to a mere exercise in accommodating existing information requirements by a reporting flow and the formats of the individual reports. The main design sequence rule thus states that the order is: design Production structure first, followed by the Control structure and finalised by the Information structure design. In Dutch STSD jargon, this is referred to as the $P C I$ rule. Breaking with this rule, for example by designing new controls in an existing, given production structure, will have negative results, since the complexity of control is restricted by the surrounding complexity of the production structure. For instance, improvements in control by the introduction of information technology will increase disturbance sensitivity but will not increase coping options as they are defined by the production structure. Consequently, improvements in flexibility or timeliness will fail to materialise.

As indicated by the PCI rule, the design starts from the whole and ends at the smallest element. This requires that the first step, i.e., designing the production structure top down, is made by those having overview over the whole entity. This means that production structure design should start by identifying possible paral- 
lel flows and proceed by creating segments at the meso-level. Finally, task groups can be constructed at the micro-level. Alternatively, as follows from the stepwise elimination procedure for control cycle allocation, the control structure is designed bottom up. This bottom-up sequence starts upward from the (parallelised and segmented) production flow, which consequently allows for a modular architecture of control and a flexible stepwise implementation of a (newly or redesigned) control structure. The modularity involved thus provides options for limited (i.e., modular) improvements or changes as conditions so require. This may be the case in, for example, the introduction of production cell technology or Flexible Manufacturing Systems. These segregated interventions can have clear advantages in introducing changes slowly to the organisation and allowing people to gain experience and become familiar with various innovations. Again, all of it made possible by a flow-oriented organisation mode.

\section{A Change Management Approach}

The change management approach proposed by Modern STSD builds on the change experiences gained in Scandinavia and Dutch experiences with job design experiments that ran in the same time period (Den Hertog, 1978).

A number of lessons were learned from these projects and later incorporated into the change management trajectory. First, STSD should start at least at firm or plant level. Starting (re)design at lower organisational levels ignores the basic overall structures in which, for example, job shops have to operate. At lower organisational levels, the conditions for (re)design are already established and limit the degrees of freedom left for actual design. Second, involvement of employees in the redesign decision making was an essential condition for success. Employees here means everyone employed: all workers and all staff and management. However, participation per se is no guarantee for success (Den Hertog and Wester, 1979; Den Hertog and Wielinga, 1992). Design expertise is also needed in order to achieve an effective redesign. Both approaches try to control the change process in some manner but seemed to be incompatible. A simple question resulted: If both approaches are simultaneously required, how can we find a solution? An answer was found by combining the expert approach with the participative approach into a self-design approach: by making people design experts. This led to the introduction of change as an educational programme, which implies that organisation members have to be trained how to redesign their organisation themselves. The resulting change management approach was named Integral Organisational Renewal (IOR) and was established after various tryouts in several (re)design projects (De Sitter, 1981; Van Assen and Den Hertog, 1984).

Metaphorically speaking, the expert approach leans towards the engineering/machine metaphor, while the participative approach is rooted in the democracy metaphor (Morgan, 1986). Both metaphors were opposed to each other in their view on the change process. Fortunately, reconciliation was offered by integrating the two in a third metaphor, which is also endorsed by Modern STSD: the organisation as an educational system (Den Hertog and De Sitter, 1989). 
An IOR trajectory takes approximately two to four years; the exact duration is determined by the active involvement of all the employees which can lead to either 'fast' or 'slow' change. Nonetheless, it can definitely not be regarded as yet another 'quick fix' method to solve organisational problems. Also, as in the design toolbox, the IOR trajectory can be divided into six phases (Den Hertog and De Sitter, 1989; De Sitter and Den Hertog 1990). The first three phases are concerned with setting the mind for change and indicating the broad directions of a future organisation. The latter three phases are the actual design phases, including training, project management and the use of the design toolkit as introduced above (see Figure 3.5).

Awareness of need for change can be restated as 'without pain, no cure'. First, the organisation has to build up the feeling that "we can't go on like this": Low-exposure, low-risk experiments at the outskirts of the organisation have postponed fundamental choices and the firm has to (re)develop a sense of direction. Key items at this very early phase are top management leadership and ample resources (time, money). Top management here has to take the lead and must clearly know which problems are to be solved and what the outcome should be (Berg, 1986; Pasmore, 1988).

The Strategic Orientation Round formalises this feeling of discontent into a more specific analysis which serves several goals:

1) creating insight into the organisation's interrelations as a whole, thus precluding partial or monofunctional views to dominate;

2) providing a list of external demands to be met and an overview of the discrepancies and bottlenecks between present and future performance, based on classic strengths-weaknesses and opportunities-threats analysis (SWOT); and, most importantly,

3) carrying out the analysis itself by a group of people representing the organisation as a whole.

Usually, this group contains about twenty people from all functional areas, which can constitute a first base for renewal. Sometimes, a strategic analysis had already been carried out, leading to believe that this step can be skipped. However, it often turns out that the earlier analysis was performed by a small elite (staff) group. Repeating it, but now in a more representative group, usually benefits the quality of the analysis and the company-wide involvement.

Following the SOR, which sets the goals of the change effort, two further routes are taken, based on the question of what problems are structural and what problems are nonstructural. The division between structural and nonstructural problems also gives rise to the distinction between renewal and improvement activities. All activities that do not require fundamental changes in structure and can be taken care of immediately are considered improvements. Even so, they should be taken care of immediately, as it is a strong signal to the organisation that things are taken seriously and management is committed to change. The structural problems are matched with the external performance requirements drafted earlier, and thus a priority listing emerges. 


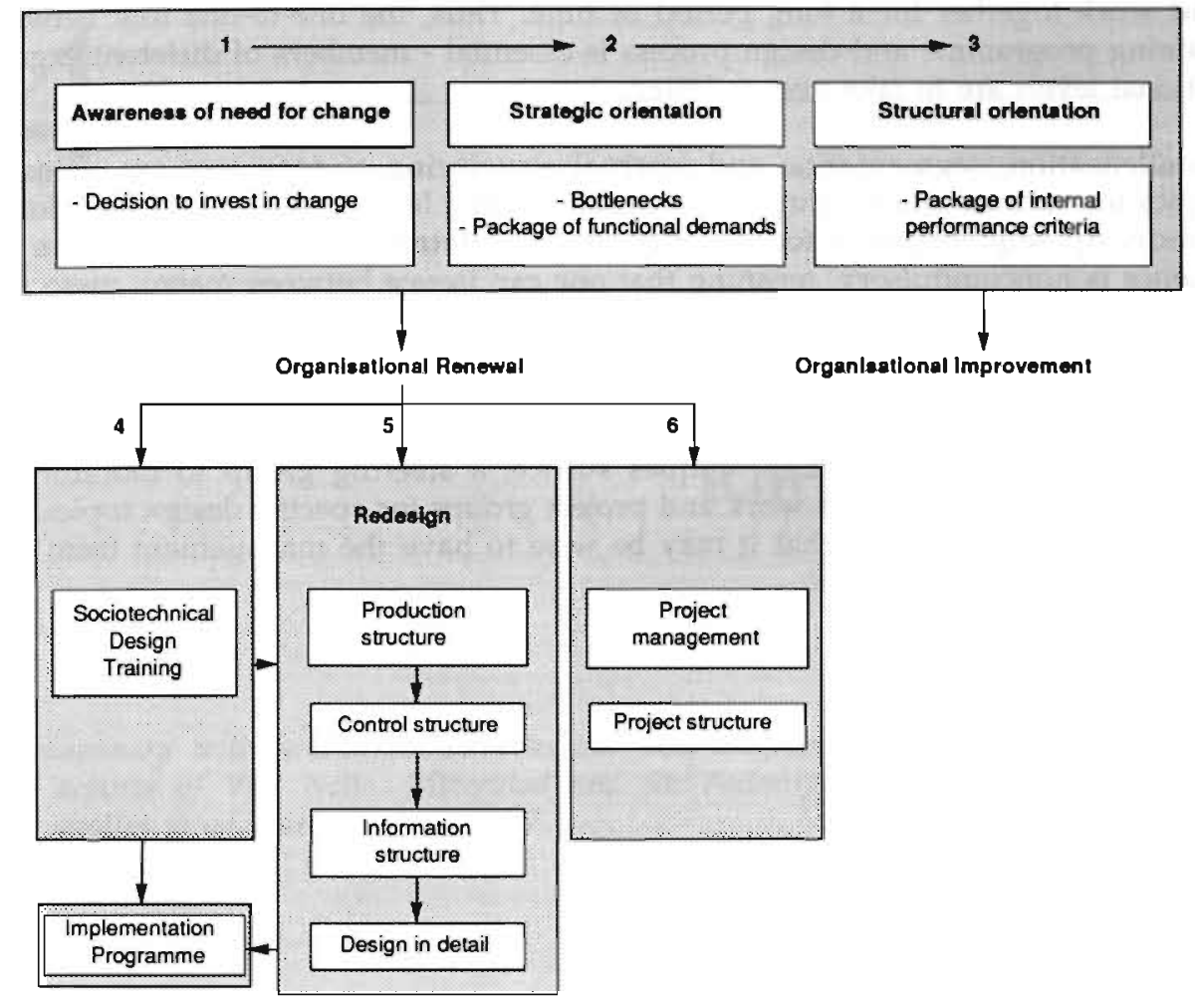

Figure 3.5 The Integral Organisational Renewal trajeclory (ct. De Sitter and Den Hertog, 1990, p. 27)

For 'disturbance stocktaking' (or bottleneck listing as it is usually called) as well as for strategic analysis, various training courses are available and have been adapted to the organisational levels involved. The final outcome of this mind-set phase is a document stating the internal performance criteria that serve as an input for the subsequent design phase.

Change management is in fact self-design, using an intensive training programme as the vehicle for change. Organisational participants are taught how to analyse one's work organisation and how to make links with other functions and system elements. STSD design principles and methods are taught while steadily increasing the application of course assignments to the own organisation, thus moving from course work to training-on-the-job.

Typically, experience has shown that the dynamics created go far beyond merely transferring knowledge; the organisation is mobilised. Participants are listened to, and their opinions (i.e., self-design efforts) are taken seriously. Also, the training 
programme breaks through functional barriers as people speak the same language and work together for a long period of time. Thus, the one-to-one link between training programme and design process is essential - members of different organisatiunal levels are to take over redesign.

Parallelisation, segmentation and internal structuring of segments are redesign topics for various work groups at all organisational level, following the top-down, bottom-up sequence rule for production and control structure design. The sequence is noncompulsory, meaning that one can iterate between macro, meso and micro-levels to find the most fitting solution to the specific design problem. At the start of the actual design, there is just one group, designing the basic structure (parallelisation). As they are followed up by various other design groups, the need for coordinating and matching of the subdesigns implies project control. Conventional project management techniques suffice: a steering group to monitor the whole process, and various work and project groups for specific design topics. Experience here has shown that it may be wise to have the management team and the steering group coincide. 


\section{Case Van Nelle Tobacco/ Rotterdam plant}

No summary will be inserted here as the next chapters represent 'data' only: the case reports of Van Nelle, Zilverstad and St. Antonius. The analysis part of the case studies is addressed in Chapter 7.

\section{Introduction}

This is the first of three case descriptions. Each case description provides the only input for further analysis and conclusions. Of course, the emphasis on what happened to the internal accounting system introduces a focused bias to the subject receiving the most attention. For instance, items regarding human resources and personnel are mentioned only in so far as they relate to the set-up of the 'new' accounting system. Also, key interview elements are inserted to illustrate why certain decisions were taken as well as to convey some of the different working atmospheres and cultures found in the organisations studied.

The three cases each step up in terms of size and complexity. The smallest organisation is Zilverstad BV, which produces silver products for the consumer and corporate gifts market. It employs 70 people with a balance sheet total of 6 million Dutch guilders. Second in size is St. Antonius, producer of vesselheads for the industrial market. Employing 140 people with a sales figure of 20 million Dutch guilders and an added value of $63 \%$ (percentage of sales, 1989), it takes a mid-position between a small and medium-sized firm. The largest organisation is Van Nelle Tobacco/Rotterdam plant, which is a full production unit of the larger Sara Lee/D.E. corporation. It is the only organisation having no ties with family ownership. Also, being the daughter of a large U.S.-based multinational, it is the one organisation operating within a larger organisational framework. 
The cases are presented in chronology of report completion as this follows the build-up of our own insights of what was going on: Van Nelle first, followed by Zilverstad and, finally, St. Antonius. After the full case reports were drafted and formally approved by company management, no further changes were made in the descriptions. Case reports thus represent frozen moments in time, which means that, in some cases, there is an 'open end' at some of the (sub)story lines.

\section{Case Van Nelle Tobacco/Rotterdam plant}

When writing this first case history, the following approach was used: First, a description of the actual organisational change is given. It is shown how this organisational change furthers the changed control system and, consequently, how the redesigned control system resulted in an adaptation of the management accounting system. The case description follows events chronologically with most of the attention being paid to the last stage of the organisational renewal process - the redesign of the management accounting systems (MAS).

\section{The Introduction Phase (1984-1986)}

The Van Nelle organisation consists of five divisions headed by a holding company: VNIEM, Food Services, the Sweets division, Kennedy and De Erven de Weduwe J. Van Nelle (hereafter called De Erven). The VNIEM division is in charge of the sales in Belgium, the Food Services division services vending machine sales (mainly coffee), and the Sweets division contains the consumer brands Droste, Venz and Tonnema (candy and chocolate). In addition, the Kennedy division takes care of the tobacco sales in the United States.

Table 4.1 Core Financial Figures of Van Nelle Holding (Source: consolidated annual report, 1988)

\begin{tabular}{|c|c|c|c|}
\hline \multicolumn{4}{|c|}{ Core Figures Van Nelle Holding N.V. } \\
\hline in 1,000 Guilders & 1988 & 1987 & 1986 \\
\hline Net turnover & 513,000 & 495,929 & 626,654 \\
\hline Operating income & 36,398 & 34.797 & 29.360 \\
\hline E.B.I.T. & 19,959 & 15,240 & 10,433 \\
\hline Idem in $\%$ of net turnover & $3.9 \%$ & $3.1 \%$ & $1.7 \%$ \\
\hline Idem in \% of net assets end of the year & $16.2 \%$ & $16.1 \%$ & $12 \%$ \\
\hline Investment in fixed assots & 41,368 & 34,435 & 15,621 \\
\hline Depreciation & 20,698 & 16,774 & 17.051 \\
\hline Cash flow & 40.657 & 32,014 & 27.484 \\
\hline $\begin{array}{l}\text { Number of employees per } \\
\text { end of the book year }\end{array}$ & 1,520 & 1.404 & 1.297 \\
\hline
\end{tabular}

The De Erven division is the focus of the case study. This division accommodates the five product lines of coffee, tea, tobacco, rice and desserts. The Rotterdam to- 
bacco plant is the part of the organisation where the further case description will focus on (see Figure 4.1).

The Rotterdam plant produces hand-rolling tobacco in two versions, classified to pouch volume weights of 40 and 50 gram. Subsequently, each weight type can be turned into a large number of packaging variances according to the wishes of the customer. The packaging standard is a poly pouch wrapped in an extra plastic foil for conserving purposes. Thus, product differentiation consists of either the packaging (most of the variance) or the amount of tobacco that goes into the pouch.

Another important aspect of the Rotterdam plant is the building in which it is located. It was constructed in 1929 by Brinkman and Van der Vlugt, representing the architectural stream of New Construction in The Netherlands. A significant feature of the building is the abundant use of glass panels in walls and roofs. As a result of its architectural value, it is virtually impossible to make changes to the building, i.e., change its layout. Consequently, the number of production efficiency measures open to use, including limiting the costs of energy, are restricted.

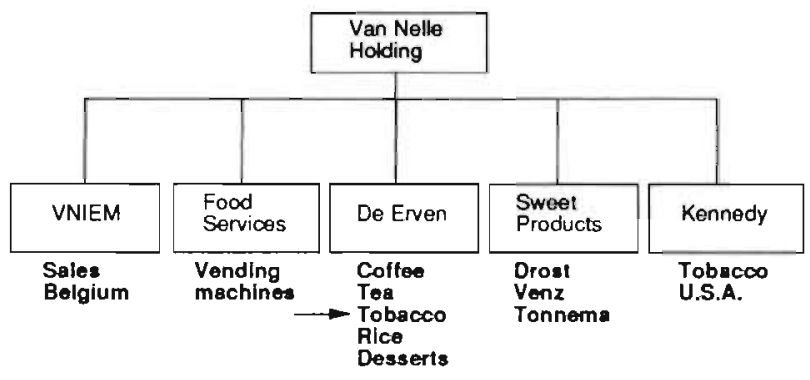

Figure 4.1 Organisation chart of Van Nelle in 1984 (Source: project documentation)

As a result of the lagging operating performance of Van Nelle Holding B.V. in 1984, then still a daughter company of the American firm Standard Brands, an organisational survey was held. From the survey, it appeared that the existing organisation was ill-adapted to the demands of a changing environment: it was inflexible, pigeon-holed, self-contained and it had high product costs. It was concluded that a strategic reorientation of the company was necessary. In addition, the American mother company stated the wish to desinvest, which led, in January 1985, to a management buy-out and independence for Van Nelle.

(plant manager) "... where the immediate cause resulted from that independence, in which you start to think, eh, like - how do we deal with it being an independent company? After the buy-out, you're left with skewed equity positions, your market position is going to play a role like - yes, how can we survive in the coming period, how do we become a company which can go public later on? That all played, of course, on the strong need to survive as a new and independent company. And to do so, to survive, you say like - well, a market-oriented organisation is needed, flexible and efficient. And how do you go about that, then? Initially by cutting out the 


\section{Chapter 4}

fat. So we had a reorganisation. That was in '85. The organisation was then subdivided into product groups."

After the buy-out, restructuring of the organisation was embarked upon energetically. Leading starting points were the following views derived from the earlier held strategic orientation round:

- Return entrepreneurship to the company - Van Nelle was to become dynamic, flexible, quality-minded and cost-conscious.

- From inward to outward-oriented - markets and customers provide the main orientation.

- The product first - it is the main strength in the strategic marketing process.

- The employees are the most important resource.

This policy statement resulted in the ensuing approach: to start with, a new organisation structure was developed, i.e., the cooperation structures were altered. Consequently, the willingness to work within the new structure was cultivated, using among other things, the slogan 'different collaboration means different thinking'. Finally, a project group to coordinate the change process and to guard the progress of the project was installed for the full duration of the project. It consisted of the managing director, the head of Personnel and the head of Quality Control.

The reorganisation started at the top of the organisation, at board room level, followed by a reorganisation of the business. At this moment in time, it was the management buy-out team that did the redesign. Later on - when training plans, management development and unions relations came into sight - the number of people involved in the redesign was extended, giving an important role to the (new and internally promoted) human resources manager. The new overall organisation structure came down to a first breakdown of functional concentration by reorganising into a product group structure with unit management instead of departmental management (see Figure 4.2).
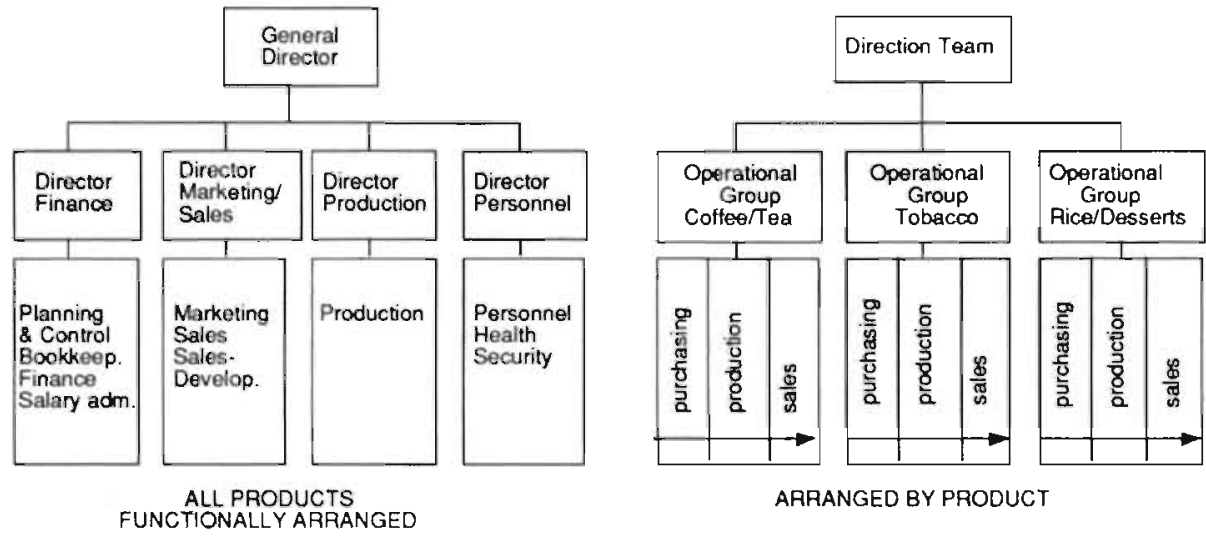

Figure 4.2 Ołd versus New Organisation Chart of Van Nelle - De Erven division (Source: project documentation) 
Division staff was relocated to the product groups as much as possible and put into the line structure. Also, tasks and responsibilities were maximally delegated in order to create integral work teams on all operational levels (minimal division of labour; see Figure 4.3).

Thus, entrepreneurship was being decentralised to the lower organisational levels, while at the same time, communication was improved and pigeon-holing broken down. The role of higher management in this new and flat organisation changed from expert and discipline control to a more strategic control.

(plant manager) "... So that means that we, the Operational Team, made a long-term plan, a strategic plan, in which you looked three ycars ahead; this happened in a discussion, of course, with General Management. Like: where are we heading for with Tobacco, where are we heading for with Coffee and Tea? And on top of those plans, which you have to specify every year into a business plan, came a yearly plan containing further details, and an implementation plan. On all those plans, you were evaluated. That is something else than a functional control which, for examplc, a production manager uses for his shop managers. They (production and shop manager, HR) are far more functionally occupied, like - you have to do this or that. No, this is control on results, on plans. Thus, you develop implementation plans, and at the end of the year one looks at what has been realised. As, for example, it is said in discussing the performance of Tobacco, more has to come out, then the organisation had to work in such a way that the Direction Team should ask the Operational Team the question - well, we don't want $20 \%$ return but $22 \%$, how do you go about that, the three of you? Not like when the commercial director says to the market group leader - cut 2 million from your advertising budget. That's the wrong attitude."

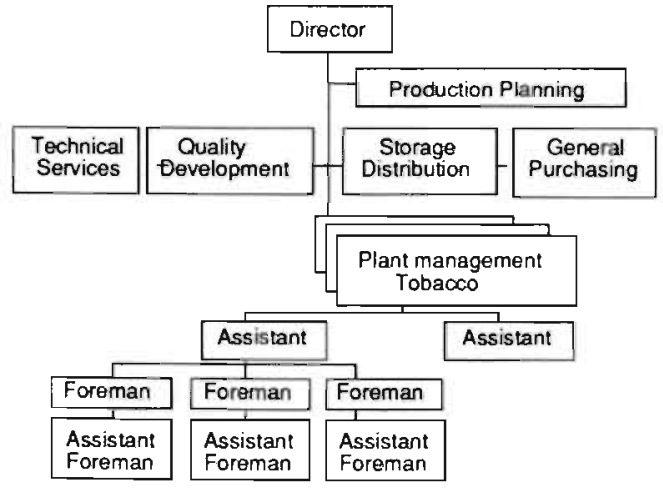

Od Production Organlzation Siructure

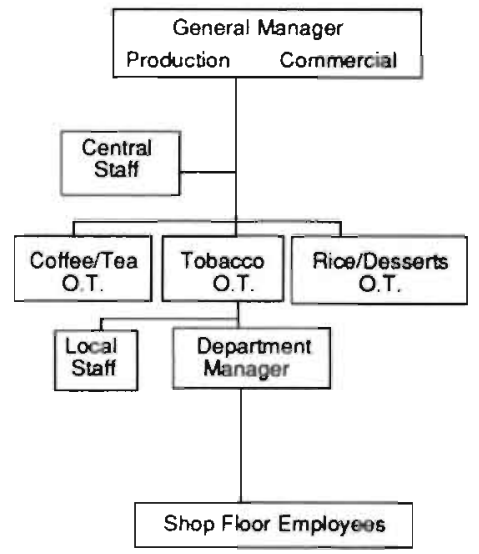

New Production Organization Structure

Figure 4.3 Old versus New Production Organisation Structure (Source: project documentation)

After the business was reorganised, a process of training and management development was started. To this end, the 'Unfreezing - Moving - Refreezing' phase model was used. Two methods were used to instrument the model: 
1) Training programmes, with a goal of 'pointing noses'. The training programmes provided an instrument for change as well as establishing unity in communication and terminology.

2) A management development plan directed at strengthening and training existing management. Part of this plan was that the works council representatives were much more involved and listened to than before. Moreover, it led to bringing in young and new management, as management that could not change was internally transferred. Setting up this plan was helped by the strong presence of a new human resource manager.

The training programmes were organised by an external consultancy company, KOERS B.V., which also supplied the consultancy and process facilitating activities for the latter change phases. The courses were tailored to the specifics of Van Nelle's strategic reorientation, emphasising the differentiation between the various organisational levels (see Table 4.2 for a specification of the training programmes).

(plant manager) "...Well, then there is that new organisation with operational teams, and you're asking yourself - how do we get this organisation functioning ? It always starts with those .. A lot of people are transferred to new positions. I myself became plant manager, new market group leaders entered; a market group leader was quite a new thing for Van Nelle. So then you have to start working on the awareness process of those people. General Management itself - how do they control such a thing as an Operational Team? Operational Team - how does it function, what is your control input, how are you being evaluated, what are your responsibilities? The development of thinking patterns and your own role in that new organisation. And all that, we accomplished, here, mainly by training programmes."

\begin{tabular}{|l|c|c|l|}
\hline & $\begin{array}{c}\text { Number of } \\
\text { Participants }\end{array}$ & Duration & Subjects \\
\hline $\begin{array}{c}\text { Operational } \\
\text { Team }\end{array}$ & 9 & $6 \times 2$ days & $\begin{array}{l}\text { Process Innovations } \\
\text { Products/Technics } \\
\text { Cooperation } \\
\text { Leadership Styles }\end{array}$ \\
\hline $\begin{array}{l}\text { Middle } \\
\text { Management }\end{array}$ & 65 & $5 \times 2$ days & $\begin{array}{l}\text { Leadership Styles } \\
\text { Individual Skills } \\
\text { Working with Groups }\end{array}$ \\
\hline Staff & 13 & $6 \times 2$ days & Cooperation O.T. - Staff \\
\hline
\end{tabular}

Table 4.2 Training Programme Outline (Source: project documentation)

After concluding the training haul, the training programmes were evaluated in mid ' 86 during an executive meeting with OT, staff and middle management. Among other things, it appeared that the willingness to change had indeed im- 
proved but the 'old' pigeon-holing and inward-bound behaviour was still lying dormant. The explicit personnel policy of mutating the employees who were unwilling or unwanting to change, resulted after three years (1988) in the fact that $30 \%$ of middle management either held other positions within the company, or had left the company.

During this period of reorganisation and getting the new overall organisation to work, the unions were explicitly involved. The new top management team much improved relations with the unions and the company's central works council, both at top and middle management levels. This improved relation kept on lasting during the time when 150 employees were to find another job, partly as a demand of the financers of the buy-out to structurally cut cost. Together with the unions, a social plan was constructed to the benefit of the employees, involving the help of an outplacement office in finding other work.

\section{The Analysis Phase (1986-April 1987)}

When the awareness process, the learning of new skills and the uniformity of the internal language on the basis of system theory were completed, a further start was made by filling in the new overall organisation structure (the moving phase). A choice was made to separate the organisation in a production and a nonproduction part. For the production part, the first matter of importance was the remaining explication of the production structure. Criteria were the earlier formulated strategic goals of quality improvement, better process control and product cost reduction. Attention would especially be paid to the critical, problem-solving and customer-oriented actions of the nonproduction employees.

At this moment in time, several motivational instruments were tried out to 'wake up' the organisation. Not all of these instruments were equally functional to this goal. The instruments encompassed a programme especially designed for the enhancement of so-called Quality of Actions and its influence on the performance of the organisation. Several other activities for the entire personnel were used in addition to this campaign, such as the publication of a Quality Indicator, the presentation of a monthly Quality Award and the declaration of 1987 as The Year of Quality. Evaluation of the quality programme in a workshop-type mode by the employees showed it was considered afterwards as a major contribution to the process of learning how to cooperate and of cultural change, despite the fact that people saw it more as learning techniques, and the activity itself petered out. However, this signified the first occasion were the entire personnel was addressed.

This first campaign was followed up in 1988 by a more comprehensive programme under the name of Actual. It was directed at the three topics of presence \& approachability, customer orientation and performance orientation. Executive meetings were periodically held in order to obtain commitment and unity in mind-set (pointing noses). Supporting this campaign was the awarding of individual and theme group prizes.

Restructuring the production structure was also based on the earlier mentioned goals of quality improvement, better process control and product cost reduction. To attain those goals, an improvement of effectiveness and an increase in effi- 
ciency and flexibility were regarded as means. In reality, this meant an integral approach to the respective qualities of organisation, work and working life by which the change process should reach the shop floor.

(plant manager) "...Well, that is how it has been sold within the organisation from the start on: the goal is product cost reduction. And to get to a better control. Control of your organisation but also control of your product quality and then, finally, from your control because only when you control your quality you can start improving on it. So that as a goal. We said - well, a means to reach that goal, for example, product cost reduction, that is to improve on your efficiency. Thus, the means to attain all that is working on all three because when you use an integral approach of those three qualities, it will lead to, and that is what I also explain elsewhere in the organisation, to cost reduction. If you're working with a fixed number of pcople and you take care of the effectiveness - more people think about the who and why of things; how do I explain then the effects it can have on efficiency? A well-informed group acting fast, flexibility of course, and that's how I make clear that we're returning, at the end, to our goal using this approach. Well, and that's how it's been told in the organisation."

Consequently, for the redesign of the production structure a stepwise action plan was made by which an integral approach of the three Qs could be attained. Basically, redesign was accomplished in three general phases, starting out from an encompassing training programme in redesign instruments and concepts. It was then followed by an analysis of the organisation (see also Figure 4.4 below) and concluded by the final redesign.
THE CHANGE PROCESS
1. Wish for Improvement - The Why
2. Assigning the Design Requirements
3. Analysis of the Present Situation
4. Analysis of the Control Needs
5. Designing the Organization Structure
6. Taking the Design Decision
7. Making of the Execution Plan per Task Group
8. Implementation
9. Try-out Period
10. Evaluation $\longrightarrow$ Improvement

Figure 4.4 Redesign Action Plan (Source: project documentation)

The improvement of the quality of work at De Erven's aimed at the working conditions as well as the contents and the execution of the various jobs. Working conditions were approached by means of a S.T.A.P. analysis. This SocioTechnical Analysis of Production organisations has a twofold target: the first is to incite a discussion on possible improvements in the working organisation, and the second is trying to raise the point of strengths and weaknesses in the job fulfilments of the persons concerned. It thus provides data on the formal as well as the informal 
working organisation in a structured manner. Main points in this S.T.A.P. information supply round were (see also Figure 4.5):

- job extensiveness and regulating capacity within the job

- available slack

- working interfaces

- participation

- information

- working conditions

S.T.A.P. steps

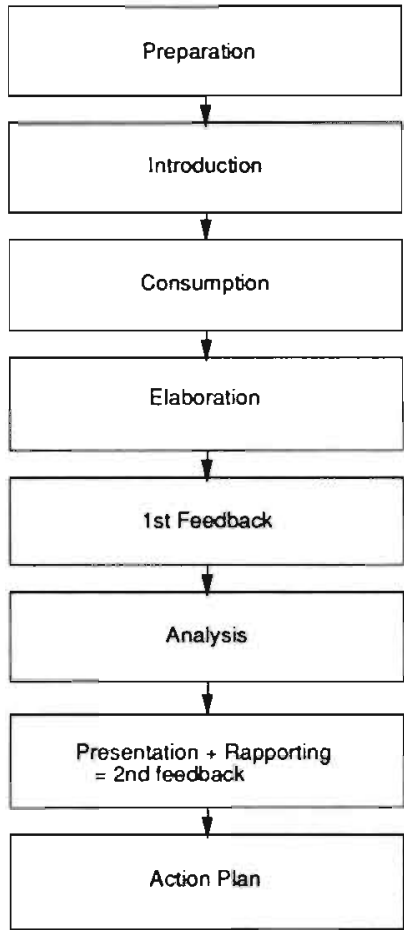

Management

Group

Individual

Change Possibilities

Management + Group

Change Direction

Figure 4.5 S.T.A.P. Plan (Source: project documentation)

A part of S.T.A.P. was to provide budgets for the improvement of working conditions.

(plant manager) "... And the STAP analysis, that is a SocioTechnical Analysis of Production organisations. It was carried out by Philips, once, so we could draw from their experience - how do you do such things? And then, here, internal, as a random test, we interviewed a lot of people; how they thought about their jobs, the job content. In short, the quality of work but 


\section{Chapter 4}

also the working conditions. And then we said to ourselves - there are quite a few remarks on the working conditions which were experienced as being not very good or less pleasant. Then we said to ourselves - we have to show that we're being serious about the responsibilities and that we actually are willing to do something. So this is what we do - we tackle the working conditions, anticipating what they will have to do later on. Namely, those task groups, uh.. those departments will be transformed into task groups with their own budget responsibility."

The budgets were handed over to the departments to manage; they could spend them at their own good will. As a result, the employees put confidence in the project and were motivated while in the same stretch, some of the most troublesome experienced working conditions were tackled. The S.T.A.P. budgets consist of yearly amounts per employee and are still part of the (annual) task group budgets.

(head Production Planning) "... Improvement of working conditions, STAP is 375 guilders per year per person, standard for each task group. That is an item with which they can do as they please. The Variant group, for example, had airconditioning installed in the coffee room because in Summer it got very hot and sticky in there. I mean, top-executive boardrooms here don't even have airconditioning, but that group has, so everybody is looking rather surprised at it, and says: How can that be? Even the Board doesn't have that but you can do whatever you want with it, as long as it improves working conditions."

The approach of the quality of work aimed at integrating internal relations on one common denominator and linking up with the earlier training programmes on management (leadership styles) and communication.

Finally, quality of the organisation was attained by a transition towards a flat organisation structure and an overall reduction of all ranks and positions leaving a limited number of functions. Therefore, the clarity and visibility created within the organisation made fast communication possible. Restructuring the quality of working life was being completed by stressing clear mutual relations.

As first site for the production structure changeover, the Rotterdam tobacco plant was selected. Main reasons were the relative absence of manufacturing disturbances at Tobacco Rotterdam, and the sheer size of the plant, which was supposed to make effects clearly visible. When successful, other product groups such as rice and desserts would follow suit in restructuring.

What the production redesign was actually going to look like was being established by the project group IKZ Tobacco (IKZ stands for Integral Quality Management, "Integrale KwaliteitsZorg" in Dutch). Eight staff members of Van Nelle, among them the production manager of Tobacco and the Head of Quality Control, and two advisors of KOERS participated in this project group. External counselling had been "... limited to a minimum and concentrated on passing on concepts and instruments, and structuring the design process itself" (IKZ report). This IKZ report also provided the main building stone for financial support of the banks for this round of organisational changes.

In the training programme itself, the integral approach to organisational change and how to work in and with a task group structure were explicated (see Figure 4.6 for an overview of KOERS' participation in the change trajectory). KOERS was invited to participate in the redesign process after the favourable experiences with their training programmes. 
The above-mentioned project group was deliberately composed of people who were supposed to implement the redesign later on. The working method of this group is explicitly integral in approach, i.e., the production organisation has been well devised, "... starting as much as possible from functional requirements, this way of assessing what is desirable and possible from within the existing situation" (IKZ report).

(production manager) "... Well, and what is written here (the IKZ report) is, of course, a description of how to structure your organisation, and an explanation of what items you have to be aware of and why, such as defining your system boundaries. And yes, the largest part of this report consists of the analyses we made to obtain a clear insight into the process and to be able to rearrange it. Look: assortment analysis, packaging analysis; all part of it, of course."

The contents of the report cover the points two to five of Figure 4.4:

- assigning the design requirements

- analysis of the present situation

- analysis of the control needs

- designing the organisational structure.

Design requirements contained four main demands:

1) double the number of product variants in the future;

2) no new small-batch product variants in tobacco preproduction in the near future;

3) an increase in (new) small-batch packaging variants at the lowest possible costs, together with an efficiency improvement and a volume increase of both standard packagings and of a number of selected variants; and

4) an optimal tobacco quality.

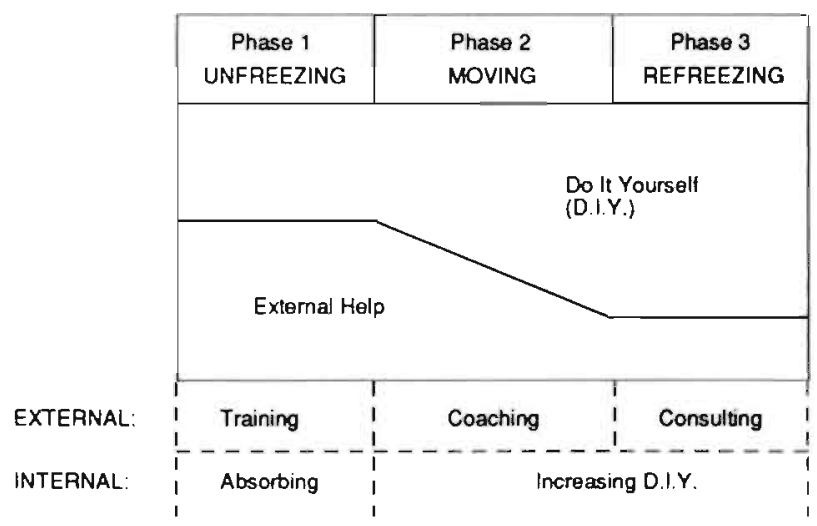

Figure 4.6 Participation of KOERS B.V. in the Change Process (Source: project documentation) 


\section{Chapter 4}

Not only the design requirements were taken into account but also the results of the S.T.A.P. analysis (part of the quality of working life track) and the general strategic starting points of Van Nelle. Quality of working life was mainly used in terms of improvement of working conditions, employed by management to indicate that it was taking participation and employee involvement seriously ${ }^{6}$. The analysis of the present situation (the existing production process) aimed both at locating the dominant process flows and the particular operations which were driving performance - where is value being added. It resulted in Production being modelled in terms of homogeneous and differentiable process elements. The analysis of the control requirement came next. It focused on establishing the necessary control and support activities regarding technology (maintenance), product quality (standards, inspection) and process information. Typically, it consisted of installing control capacity into the tasks of the Technical Service and Production Planning departments, within the task groups themselves and, finally, in setting up the future personnel structure (i.e., institutionalising control capacity).

The IKZ report, which was handed to the Board of Directors in April 1987, recommended to rearrange the tobacco factory according to a task group structure (see Figure 4.7).

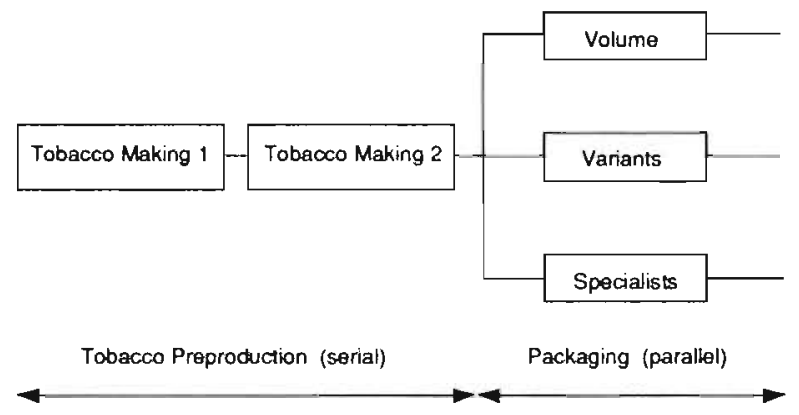

Figure 4.7 Task group Structure Van Nelle Tobacco Production (Source: project documentation)

The approval of this recommendation in May 1987 marked the end of the project group IKZ Tobacco and the beginning of the detailed execution of the plan in and by 'the line'.

\section{Intermezzo}

What are the characteristics of a task group at Van Nelle's Rolterdam plant?

A task group is the smallest organisational unit and is comprised of between 4 and 20 persons. Criteria concerning the size of the group are: large enough to draw on personal skills, to produce complete product parts and to attain set goals. The group is small enough to make group decisions and to have a clear sight on decisions taken and goals attained.

The tusk of a task group consists of carrying out a clearly recognisable set of activities, which as such constitute complete or relatively independent process elements within the overall 
production process. Activities comprise not only production activities but also preparing (making ready of materials), regulating (carrying on and off materials), controlling (scrap) and supporting activities (cleaning). Criteria for bounding a process element are: existence of many internal interfaces inside and few external interfaces outside the process element, a distinguishable contribution of the process element to the end product, a clearly visible and measurable performance of the process element and the presence of a possible natural pause following the process element.

The task group is responsible for performance, with the task group leader boing responsible for the functioning of the task group as a team. He is not a boss coordinating work, but a coordinator of made and kept agreements. His own tasks are in the field of information supply, working conditions and long-term planning.

The remuneration structure is attuned to working in task groups - group achievements - and is clear to everybody. Differences in remuneration are possible if clear and acceptable to the group, and remuneration should encourage leaming capacity.

In this case, therefore, the functions have been divided into five categories, each with its own job content and separated into executing and controlling activities (see Table 4.3); jobs are cumulative, which means that within the task group a member can 'leam his way' towards a more encompassing and higher paid function category.

Table 4.3 Function Structure and Classification (Source: project documentation)

\begin{tabular}{|c|c|c|c|c|c|c|}
\hline \multirow[b]{2}{*}{ Function } & & \multicolumn{5}{|c|}{ Supportung and Controlling Activites } \\
\hline & $\begin{array}{l}\text { Executive } \\
12345678\end{array}$ & $\begin{array}{l}\text { Technical } \\
123456\end{array}$ & $\begin{array}{c}\text { Logistics } \\
1234567891011\end{array}$ & $\begin{array}{l}\text { Quality } \\
1234\end{array}$ & $\begin{array}{l}\text { Maintenance } \\
1234\end{array}$ & $\begin{array}{l}\text { Innovative } \\
123\end{array}$ \\
\hline $\begin{array}{l}\text { Operating } \\
\text { Specialist A }\end{array}$ & $x \times \times \times \times \times \times x$ & $x \times \times \times \times x$ & $x \times \times x \times \times \times \times \times \times \times$ & $x \times x \times$ & $x \times x \times$ & $x \times x$ \\
\hline $\begin{array}{l}\text { Operating } \\
\text { Specialist }\end{array}$ & $x \times \times \times \times \times \times \times$ & $x \times \times \times \times x$ & $x \times \times \times \times \times \times \times \times x-$ & $x \times x \times$ & $\times \times \times$. & $x \times x$ \\
\hline $\begin{array}{l}\text { Machine } \\
\text { Operator A }\end{array}$ & $x \times \times \times \times \times \times x$ & $x \times-x \times$. & $\cdots \times \times x-x \times \cdots$ & $x \times x \times$ & $x \times \cdots$ & $x x$. \\
\hline $\begin{array}{l}\text { Machine } \\
\text { Operator }\end{array}$ & $x \times \times \times \times \times \times x$ & $x \times \cdots x$ & $\cdots x \times \cdots x \cdots$ & $x \times \times x$ & $x \cdots$ & $x \cdots$ \\
\hline $\begin{array}{l}\text { General } \\
\text { Production } \\
\text { Employee }\end{array}$ & $-\times \times \times \times \times \times$ & $\cdots$ & $\cdots \times \ldots \ldots$ & $-x \times-$ & $x \cdots$ & $\cdots$ \\
\hline
\end{tabular}

$x=$ tagk element in that specific tunctional lovel and lor that specific activity category

Control capacity within a group links up with multi-skill competence and ranges from priority setting in production planning and delivery to dealing with complaints and the distribution of work orders. Conditions for such flexibility are the presence of an adapted layout and an atmosphere of cooperation.

Effectiveness of working in task groups is guaranteed by a fixed number of employees per group. common goals and tasks, and the fact that the group itsclf can indeed attain these goals.

Efficiency is guaranteed by more people actually thinking about how to carry out production activities - it is no longer a matter for higher management only - which improves yields and working methods and reduces waste/scrap (product quality).

Flexibility is increased by the mere existence of a well-informed group acting fast on matters like sickness/leave, market fluctuations and technical malfunctions. 


\section{The Learning Phase (April 1987 - May 1988)}

After it had been decided to start working in task groups, five task group leaders were appointed. With them and the production manager, an implementation plan for each 'task group to be' was composed.

(production manager) "... The next phase is when you say - well, if the Board approves, it's also Okay with us, then you get the green light to change the organisation, and the first thing you do is appoint persons who are going to be responsible for a task group. So we first appointed task group leaders, task groups only existed on paper at that time, and we told them - you're responsible. As a departmental manager you say what needs to be done, but task group leaders they do no longer say what has to be done but they have to take care of the functioning of the task group as a whole, and that all the control means are built in right there and in such a way that people themselves can take care of the work being done. That's, of course, a completely different point of view of how to deal with your men as a manager."

Each implementation plan used the same systematic approach: first, a description of the task group in terms of goals, task areas and system boundaries (the process element). Next, the personnel capacity by way of a training flowchart indicating which number of employees (quantitative) are on what functional level (qualitative), accompanied by a training time-ladder which served as a basis for the task groups training plan to scale up the learning capacity of the group (see Figure 4.8). Part of it was also a listing of present function levels and task elements.

\section{FLOW DIAGRAM TRAINING TOBACCO MAKING 1}
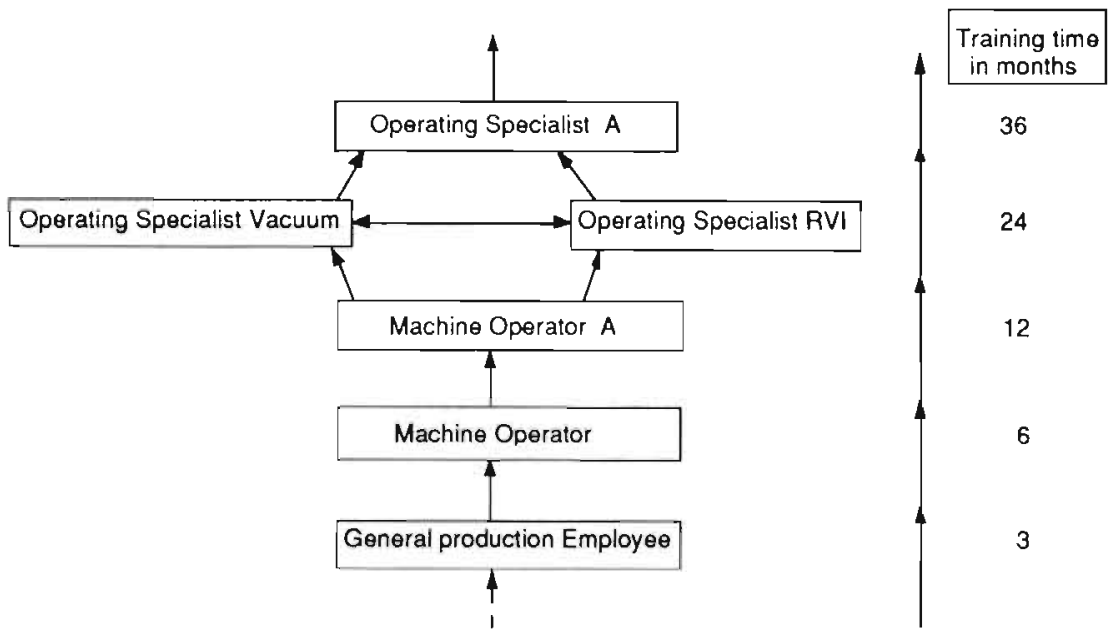

Figure 4.8 Tralning Flow Diagram (Source: project documentation)

It served as the basis for the function classification to be made - the number of functions was reduced accordingly from 40 to 5 . The target was to reach the same amount of function levels for each task group. The task element contents of each 
function level differ per task group, but the insight into and clarity of personnel and remuneration structure increased considerably.

Finally, each implementation plan contained a listing of the desired support from other departments, for example, Production Planning or Personnel, specifically describing goal, sort and format of the support. The implementation plan for each task group essentially stated what a task group would have to look like in terms of activities. A detailed description of control capacity per task group was not formally made but instead emerged on the way.

(production manager) "... Because we said - we will select the organisation, we will select the structure, we'll go for it and then we will, together with the task groups themselves, gradually definc their wishes. And that's what we developed, slowly but surely, while having started already. But none of this is mentioned in reports and so on. It is ingrained by now, in the regular reports we draw up at Production Planning."

A preparation period was installed before starting to work with task groups. During this period, all task groups became budget centres, future task group leaders took courses in budgeting and time management, and the surrounding departments and disciplines were being informed on the forthcoming changes. Furthermore, the financial reports and the overall production budget were converted to the task group structure. A start was being made with the priority items on the wished support lists of each task group.

(production manager) "... Already beforehand, you're assigning people to their task groups. Task group leaders are presenting themselves more and more as such in their regulur work instead of being the department manager. Of course, you don't change your organisation from one day on to another; you're doing so during the preceding normal daily routine of things, because the good things, you start with 'm right away."

The official date for the whole operation to start was set on September 1, 1988. On that date, everything, both in formal-administrative and in operative terms, had to start at once. The significance of that date was mainly contained in the signal it sent to the other departments - from that date on things had to be done differently.

(production manager) "... Because if you say already at the beginning of the year - September 1st, is when we'll start working in task groups, then it will start officially; the accounting department will know the new financial system has to operate from that day on. So, in reality, that date is, of course, a date on which nothing much changes for Production itself."

The time between September 1, 1988 and January 1, 1989, was considered a trial period. Specifically, its goal was to get used to the new situation within and outside the task group and to detect and resolve any problems brought about by the new situation.

A major rupture in the change process was the takeover in May 1989 by Douwe Egberts (D.E.), a daughter company of the American Sara Lee corporation. Douwe Egberts is about three times the size of Van Nelle in terms of sales, personnel and balance sheet total. Culturally significant, however, is that Douwe Egberts was the lifelong competitor of Van Nelle on the markets of coffee and rolling tobacco. Typically, the Dutch market shares for coffee and rolling tobacco of the two merged companies now reach between $60 \%$ and $70 \%$. 


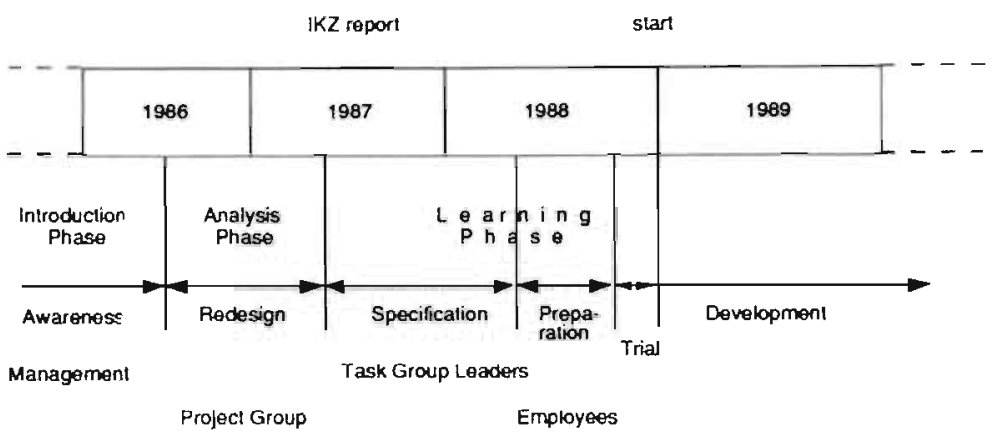

Figure 4.9 Time path change trajectory (Source: project documentation)

As a result of the merger, almost all change projects were frozen and, later on, some were suspended. For Tobacco, the merger signified the end of the operational group structure. It was merged with the Tobacco division of Douwe Egberts and three new companies were created under the heading of a new Tobacco division, named Douwe Egberts - Van Nelle. This daughter company accommodates both the Tobacco division's headquarters as well as the former tobacco production sites of Van Nelle and D.E., called Tobacco and Production company respectively, thus not changing much in the actual day-to-day operation of the plants.

Instead of by an Operational Team, Tobacco is now headed by five functional directors each with a functional portfolio - Production, Commerce, Purchasing, Finance \& Administration and Personnel \& Organisation.

For the specific operation of the Rotterdam Tobacco plant, the merger resulted in another change in reporting flow: the production manager reports disciplinary to the Production Director of the division. All other upward information supply was to be organised according to company rule of Sara Lee, the D.E. mother company. The task group structure as well as the locally developed information formats were left alone as a consequence of the positive experiences with working in task groups (see further on in this chapter). At the same time, it was decided that for the next three years (until 1992) no structural changes were to be made in the Rotterdam or Meppel tobacco plants.

\section{The Control and Information Structures}

After the overall organisation structure had been changed top down, the control and information structures were changed simultaneously and coherently. The control structure is specifically tied to autonomous work or task groups. Basic control principle, which is repeated at every control level, is that what can be controlled locally, should be controlled locally. Typically, this explicitly implies the delegation of control upward as well, which is contrary to conventional reasoning 
that focuses on a maximum of delepution downwards. Basically, it comes down to a replication of the task group design to a higher level in the organisation. For example, this meant that the staff-line relationships and the factory-business unit relationships are refocused on what expertise and control decisions are needed at line/factory level. Concretely, it resulted in an integration of staff functions in the line at both business unit and plant levels. Furthermore, the Operational Team (business unit management) pulled back from plant affairs and obtained control regarding the coordination of the various business functions, which were previously handled bilaterally at plant level between the various departmental managers. The difference between functional business unit management and Operational Team management became very clear when Douwe Egberts reinstituted the former functional system, thus stopping the application of the task group principle at business unit level.

The control domain of each task group is linked to the five function levels present within each task group. Each function consists of several task elements with its contents stepping up from task elements with an operating content to task elements with a more supporting and controlling content. When all five functions are represented in one task group, the task group is considered to possess the highest possible control domain. In other words, it can perform all functions and is therefore called 'autonomous', 'complete' or 'whole', depending on the jargon the organisation prefers.

At a higher aggregation level, control of the task groups themselves takes place using three reports (see Figure 4.10):

1) the labour productivity report;

2) the machine efficiency report; and

3) the period report.

The production report underlies and is the main information carrier for these three reports. The period report is a concise report per task group in which the actual labour productivity, machine efficiency and occupancy rate are contrasted respectively to the norm productivity, the budgeted machine efficiency and the budgeted occupancy rate. The norms originate from the yearly capacity and occupancy calculation. The task group budgets are also derived from the yearly production budget. Both production budget and capacity and occupancy calculation make up the performance standards with which the actual performance is measured and compared. Typically, production budget and the task group budgets are the only reports in which financial figures appear.

In the 'old' situation, the period report did not exist and the two reports on task group level were only available in a primitive format to the Personnel and Technical Services departments. Production control was administrated only by the overall production budget and the basic production report. Other control instruments did not have an administrative representation nor were paralleled in the information flow by some sort of reporting mechanism.

Two more differences were the reporting frequency and the feedback to shop floor employees. In the old system, reporting took place monthly. In the new system, it 
takes place weekly and it can be organised, if the wish or need should arise, on a daily basis. Every week, the labour productivity and machine efficiency reports are also sent by Production Planning to the task group leaders. The machine efficiency report is split out a second time into individual machinery. The efficiency per machine compared to its norm efficiency is weekly reported in a diagram, which is also stuck to the bulletin board of the task group for the employees to see how they performed the week before.

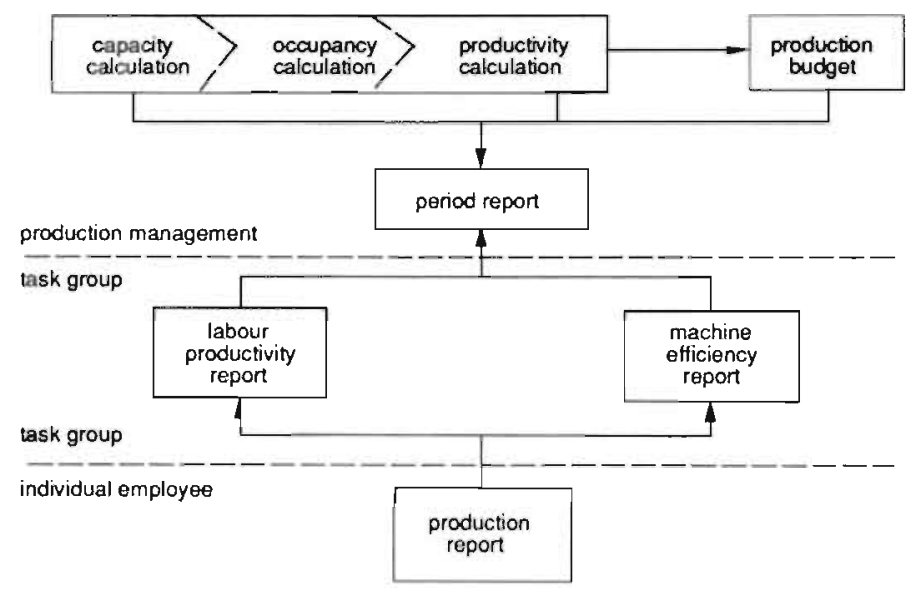

Figure 4.10 Reporting System Van Nelle Tobacco (Source: constructed using internal documentation)

(head Production Planning) "... well needed within the task group, to distinguish what kind of work quality has been done. An operator controls the machine and so he can affect the efficiency all right. So that's why we're saying - we look at it per individual machine. That's feedback from Production Planning of the information they write down on the production report."

The various reports (the task group information supply) were developed in the following order: first the budget and capacity calculation were adapted and standardised to task group operations. Next, the machine efficiency report was perfected - rebuilt to individual machine and different machine stoppage categories after which the adaptation of the labour productivity report was started. Finally, the period report was developed in order to follow task group performance on an overall basis of norm productivity. Thus, the information supply progressed evolutionary and simultaneously top down from the (financial) production budget and bottom up from the production report, all in close cooperation with the task groups. The main directive in this evolutionary growth was the goal of adequate cost control, using the operational control parameters of man and machine hours. 
An integrated report in which all relevant plant information was brought together in one format did not exist. However, there was/is a monthly Management Information System (MIS) report compounded by the Planning \& Control (P\&C) staff department and intended for all line managers and the Executive Board. The MIS report presents a monthly actual versus budgeted summary and cumulatively over the year of core figures specified to market group (see Figure 4.11).

The role of the central Planning \& Control staff department regarding the Rotterdam tobacco plant is one of financial information processor and controller of submitted financial reports going from department manager to division and higher up. Special studies or other products of the P\&C expertise are not in great demand by Tobacco. The development, for example, of the residing reporting system is largely done by a local team, consisting of the production manager, the head of Production Planning and the task group leaders.

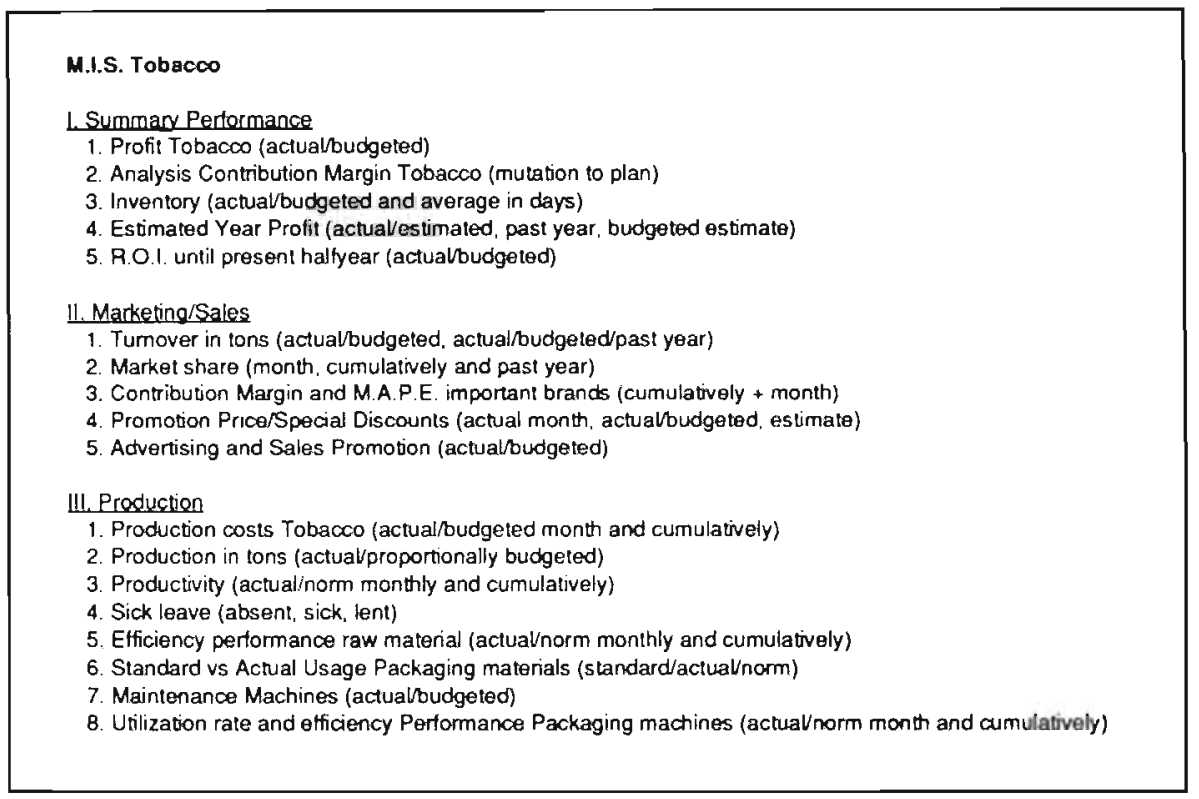

Figure 4.11 Contents MIS report (Source: abstracted from internal report)

Other reports or feedback instruments are mere technical or registrative by nature. For instance, the reports on behalf of the e-hallmark (a guaranteed and government controlled norm for the filling of packages), the waste reports and the registration of temporary employees. As for systematic structure, these reports are not altered after the organisational change otherwise than for automating their processing.

An extra use of the task group system was found in the field of product development and concurrent development cost control. The design of the packaging task groups is such that it allows a product to be 'passed on' when it progresses in its 
product life cycle. For instance, when a new product is still in its experimental stage, it is manulactured in the specialists group. All labour-intensive packaging and rarely manufactured articles are concentrated in the specialists group, which makes it the most experienced group. They are used to small batches (test series) and complicated packaging requirements and also are able to carry over their experiences with the new product to subsequent task groups. In fact, it is a sort of 'process prototyping'. Once familiarised with the technical machine and other manufacturing conditions, the man hour costs and machine hours costs can be established and, consequently, a reasonably appropriate production cost estimate becomes feasible. When the product is a success and larger batches have to be manufactured, the variants group can take over. The variants group is positioned in between the specialists group and the volume group in terms of volume, product variety and changeovers. Production in the variants group indicates further focussing of productivity and efficiency standards and a consequent increase in cost control. Eventually the volume group can take over production when the product is in its maturity phase.

(head Production Planning) "... If we wished to introduce a new product in our assortment, it first will be produced in the specialists group in an experimental stage, usually small series, nil-series. After some time, we know what the machine adjustments are, we know how the material behaves, the final orders for packaging materials are placed. If it's a hit, the decision is taken - we put it in our assortment as an inventory product, manufacturing it by the variants group. If it becomes an A-brand and it's put in as a main brand article, the volume group can start producing it."

The combination of task group configuration and product life cycle can result in an accurate product management with accompanying accuracy in cost control. It has to be noted, however, that tobacco is a mature product in a mature or even decaying market, which intrinsically makes it a product for an expanded and spun out control system.

\section{Control and Information Supply Details}

Successively discussed in the next five sections are the construction of the production budget and the respective control reports. A comparison with the former information supply system will be made wherever possible, accentuating differences and growth towards the present system. Finally, the relationship with the (functional) Management Accounting System of Douwe Egberts will be discussed.

The Capacity and Occupancy Calculation and the Production Budget

The start of the budgeting process is the capacity calculation for the next fiscal year, July to July. The capacity is calculated per task group but is, for the most part, identical for each calculation. Fixed start data are:

1. general starting points;

2. volume to be produced.

Item 1 indicates the maximal staffing capacity. Changes in, for example, shift, vacation periods, unpaid leave, etc, are being entered here in the calculation. In the former situation those figures were input from Production Assistance, at present it is Production Planning. Item 2 is input from the market groups, in the new merger situation it probably will be the product managers who are the source. This 
is also the only data item which comes from outside Production, all other information is coming from Production Planning.

Besides the identical data for each task group, there are also data which only change in the long run - they are connected to the machines and packaging lines present in the task group (see Figure 4.12):

3. number of machines/packaging lines in the task group;

4. standard required manpower;

5. attainable efficiency;

6. maintenance routine machines;

7. weight packaging unit/number of revolutions of the machine/number of packages per hour/machine output per hour;

8. specific task group information.

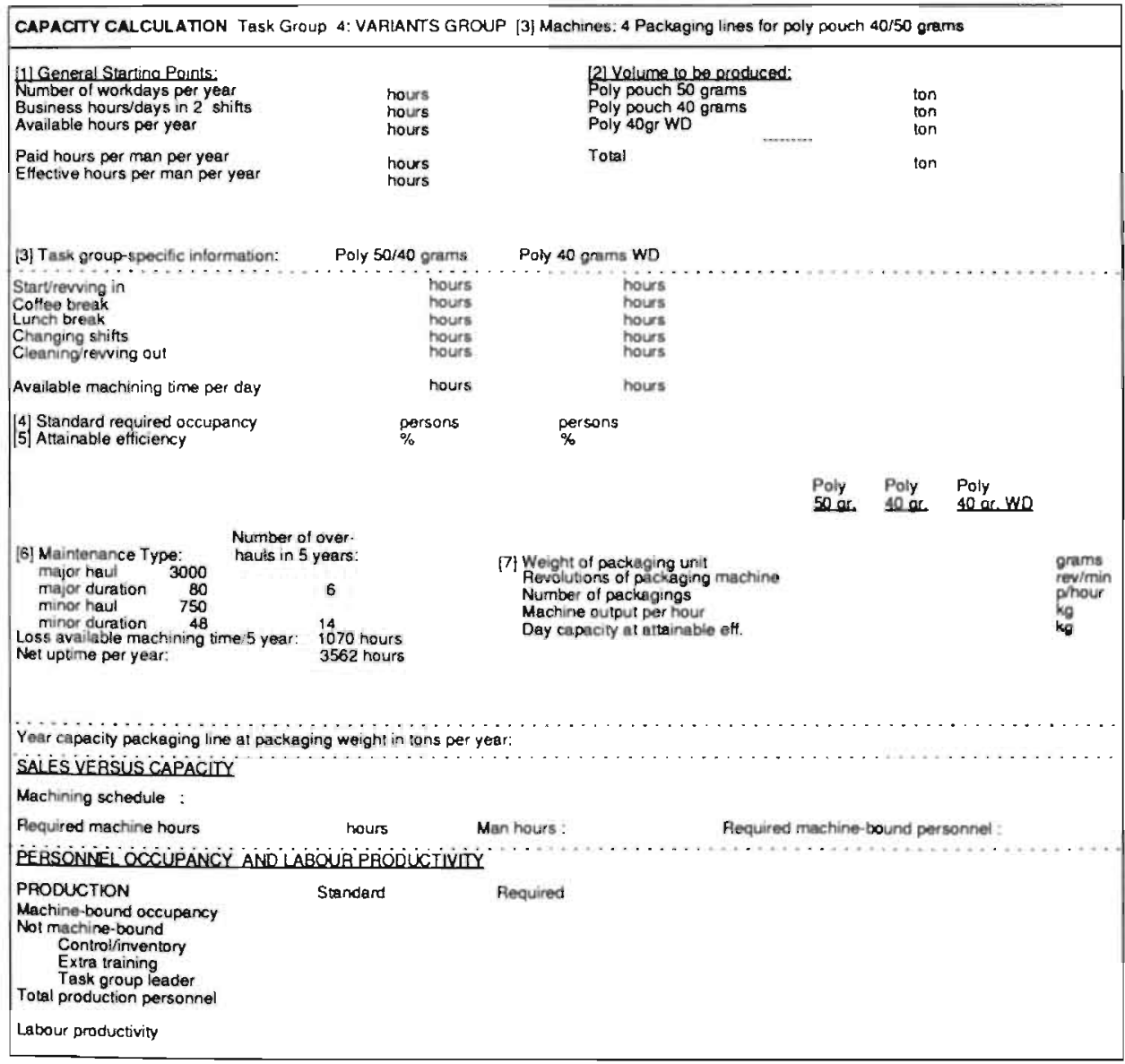

Figure 4.12 Capacity / Occupancy / Productivity Calculation (Source: regular internal report) 
Item 3 concerns the physical production capacity - (des)investments and layout changes are visible in this item. The standard required manpower (item 4) is the minimally required number of machine operators in the task group. It is related to both working methods and the mechanisation or automation of operations within the task group; every year it is established following discussions with the appropriate task group leader. Attainable efficiency (item 5) is the average percentual efficiency standard across all machines present in the task group, which is tied to the long-run average machine occupancy. This percentage is also established in close cooperation with the task group leaders and the production manager. Item 6, the machine maintenance routine, is a calculation to arrive at the total available net production uptime, using a deduction for major maintenance. The maintenance frequency is set by the head of the Technical Services department and is tied to the production hour volume. Item 7 applies to the technical relationships regarding the product weight and the machine output. If product weight is changed (for the existing machines only the aspect of weight counts) or technical improvements are installed in the machine (e.g., computerisation) the effects on machining schedule, man hours/labour force and labour productivity can be calculated by using the machine output. Finally, specific task group information (item 8.) comprises the allowed stoppage time of the machines. Part of this are the set-up and changeover time, cleaning and minor maintenance. The task group leader provides the information needed for the calculation of this item.

Due to the fact that the last two mentioned activities are performed within the task group, it results in a decrease in work for the Technical Services department. This extra work for the task group is performed without subsequent extension of performance standards for the task group.

(production manager) "... When starting the new organisation, the Technical Services department of Tobacco decided to do the machine maintenance. The occupancy rate standard which was then set for technical service operations remained much too tight to handle all the technical work. However, because we were starting with this project (the task group structure, HR) at which we said; maintenance belongs in task groups, I've never expanded the Technical Services department compared to its original manpower capacity. Coffee did expand, they now have a Technical Services department of about 13 or 14 men, and we're still on 8 . What we did is put in a lot of maintenance tasks, failure maintenance, changeover and so on, which is performed by the machine specialists, but what we didn't do was build in the required time in the operating standards of the capacity calculations. Therefore, the results you're now getting you can see for yourself; you do not have cost increases in the task groups although they're doing the maintenance, but you've a reduction of separable maintenance costs, on a yearly basis."

Using the items under 7. one can subsequently calculate the ratio day capacity at efficiency norm (see Figure 4.12). This is the multiplication of the specific task group ratio available machining time times machine output per hour times attainable efficiency. The final capacity ratio year capacity at packaging weight in tons per year is then calculated from the multiplication of this day capacity at efficiency norm with number of work days per year. This year's capacity ratio is then contrasted with the volume to be produced (item 2) from which the machining schedule (average machine occupancy over the year) follows. With the help from the machining schedule one can next calculate the required machine hours for that production volume: machining schedule times number of work days per year times available machining per day. From the required machining hours follow, via 
multiplication with the standard required manpower, the required man hours. This gross required number of man hours gets, after division by the effective hours per man per year, the required number of machine-bound personnel for that specific task group. With this number of 'direct' personnel one can establish a labour productivity standard. For that purpose, the number of direct personnel is increased with a number of 'indirect' personnel, i.e., not machine-bound personnel. The result is the desired occupancy rate per task group. Multiplication of this number with effective hours per man per year renders the total effective hours per task group. Division by the total volume to be produced per task group finally results in the labour productivity in kilos per man hour.

This interlocking system of ratios makes changes in basic assumptions such as, for example, in sales, machine efficiencies or man hours, easy to verify on their consequences for labour costs, occupancy rate or available capacity (see Figure 4.13).

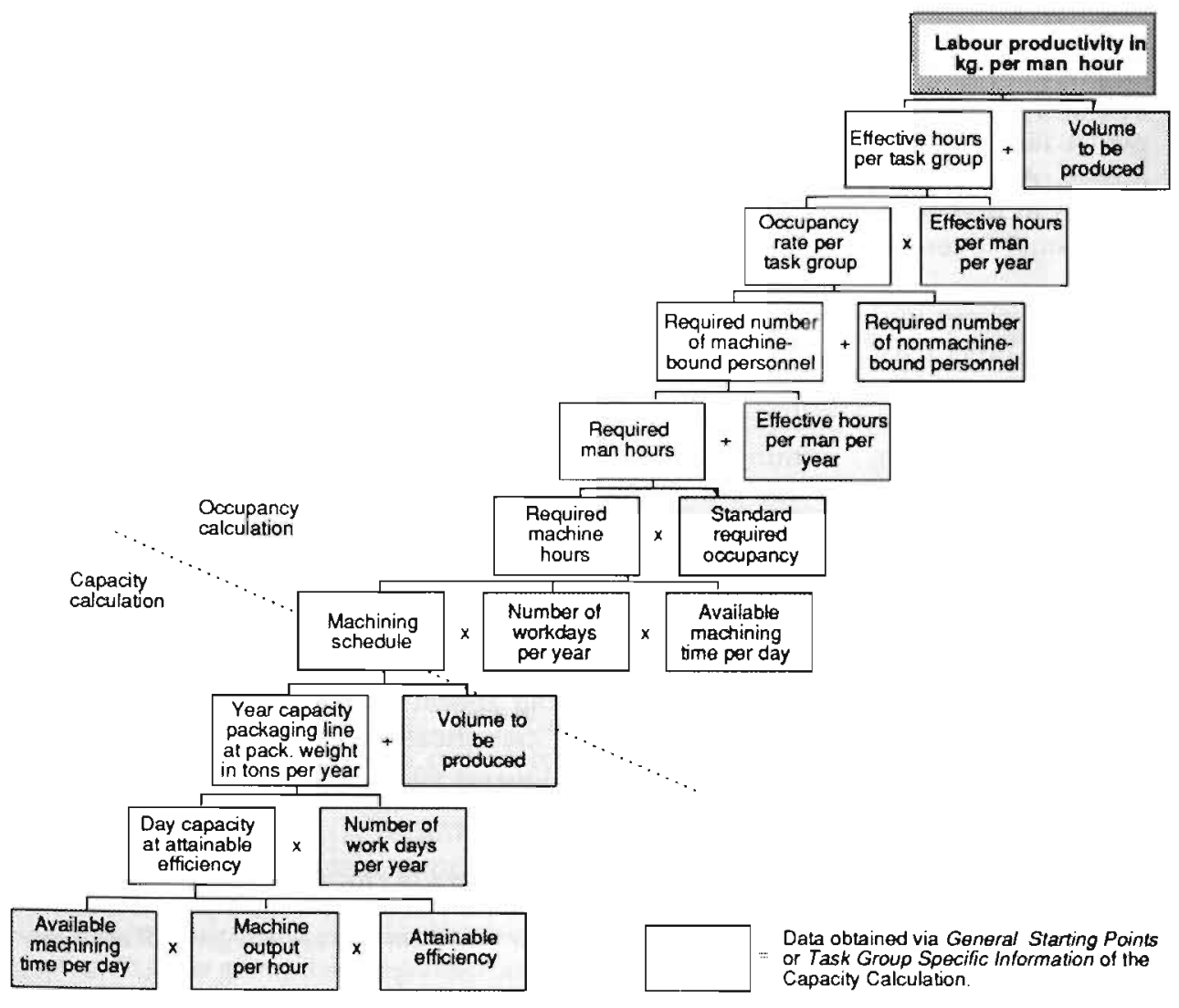

Figure 4.13 Linking Ratio Aspect of Capacity and Performance Calculation (Source: constructed using internal documentation) 
(head Production Planning) "... the capacity calculation is also a little spreadsheet-like. If there is a question such as - 40 tons extra production, what are the consequences for your occupancy rate? - then you simply alter your sales figure and you look at the bottom - has it got consequences for my occupancy? Well, in this case it stayed the same. Thus, you can simply give an answer as: it can be done, we have the slack."

The relation between capacity and occupancy calculation and the production budget of Tobacco is linked by the labour costs and the norm occupancy. Labour costs are split up into labour costs, restitution sick pay and external labour costs (temporary employees). The item of restitution sick pay is a benefit from the (Dutch) National Health Service Fund to the company for every sick employee; it is legally determined that employers make regular contributions to the Fund for each person employed. At the moment, the amount for restitution sick pay substantially diverges from the amount for external labour costs. It can be analysed per task group as to why these labour cost variances have developed. For instance, a comparison with the above-mentioned average number of vacant positions possibly indicates a structural occupancy problem in the task group, with possible consequences for the production budget or for total labour cost behaviour (see Figure 4.14).

The budget per task group is identically structured as the overall production budget. It falls entirely under the responsibility and controllability of the task group leader. An exception to the rule, the item depreciation hardware for the computer system in inventory control of Tobacco, is included in the task group budget. This is the only 'over-his-head' the task group leader will find on his budget.

The task group budgets contain a large number of items not related to production volume (direct fixed manufacturing costs). Contrary to traditional accounting practice, these costs are allocated and considered controllable by the task group leader. Costs that are indeed uncontrollable by the task groups but still fluctuate with production volume (e.g., printing costs of tax revenue tobacco stickers, additives, contracted-out production) stay out of the task groups and are booked in the production budget of Tobacco under the item various production costs.

For Production Management and Production Planning a similar budget format exists as for the task groups. The difference with the other (task group) budgets can be found in the presence of training costs, PC depreciation expense, business association contributions, software expense and the allocated overhead for the Management Information System. In terms of cost classification, it indicates that, in daily routine, the partition between direct and indirect costs coincides with the boundary line between task groups and management.

(production manager) "... But in fact I've only got the costs of Production Planning plus what transcends Tobacco. I definitely see those figures but I don't want them put on my cost summaries. In my controlling I've got nothing to do with them because you get it all allocated with some sort of allocation criterion, so that is not interesting enough for me to see. What we actually did do, that was the effect of course, was that we made almost all costs direct. I've got hardly any indirect costs - we haven't got an inspection service, no department for process control, no Technical Services department so large that cleaning is part of their job, because I made all those sort of costs direct." 


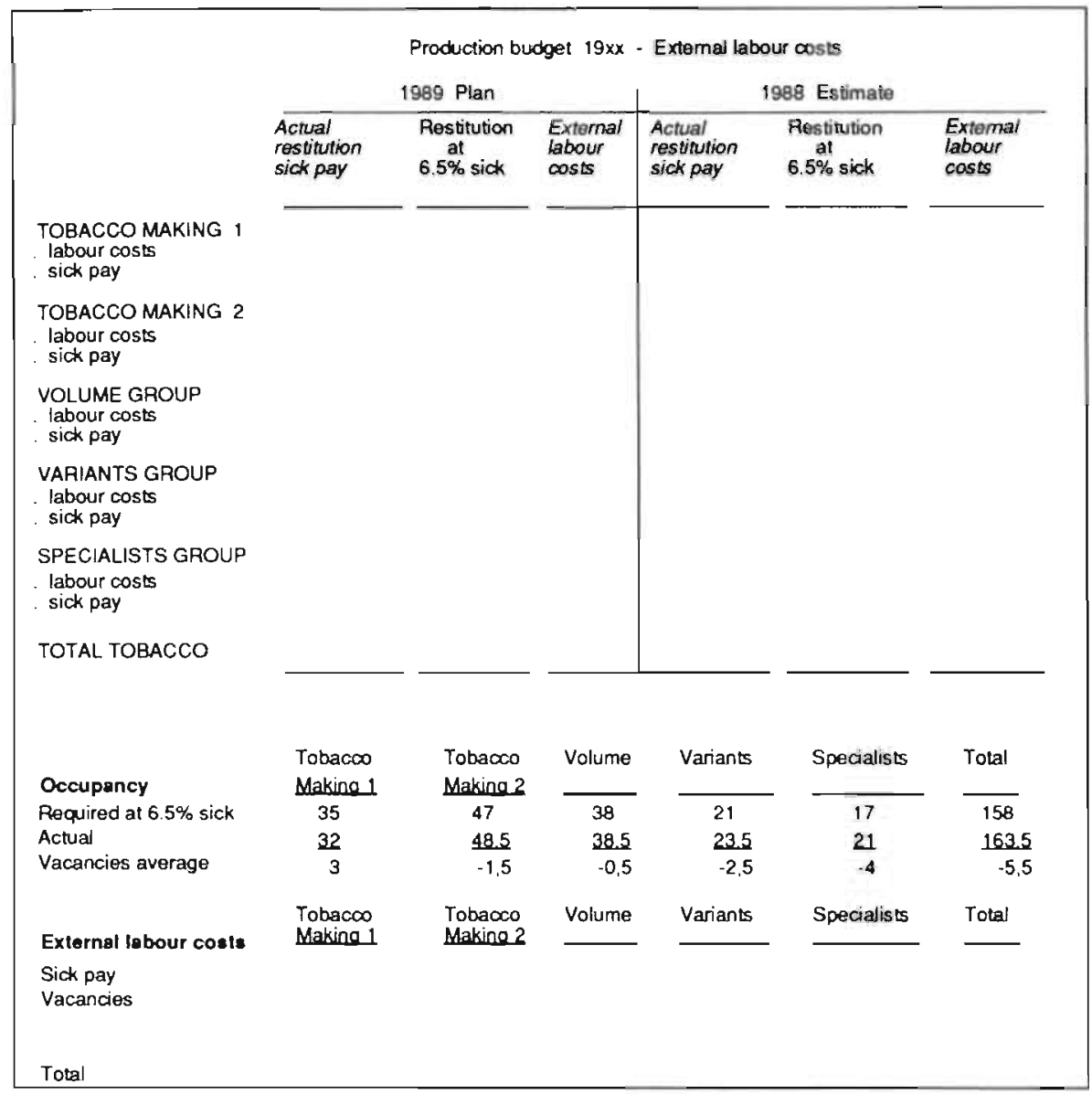

Figure 4.14 Production Budgel Tobacco - part on External Labour costs (Source: regular internal report)

The comparison between the present and the former structure can be made directly for the production budget of Tobacco. In the former structure, reports were made for the departments and organised in functional cost categories. In the new situation, task groups replace the departmental level and institure a new reporting denominator. Typically, it meant that the items direct labour costs, maintenance and various production costs were split up into their task group components and brought under task group responsibility (see Figure 4.15). Additionally, regarding major maintenance, the present production budget assigned machines and packaging lines to task groups. Within the task group, a further split could then be made into direct cost categories such as spendable hours and material and the costs of third parties (i.e., the Technical Services department).

(head Production Planning) "... And the budget as it was before, was about the same, but of course not split up. Look, you see Management, Production Planning, direct labour costs - bam! And that's what you don't see in here (new budget set-up, HR). And here you see Maintenance 


\section{Chapter 4}

Machines \& Inventory - well, that's all transferred to the task group. Various production costs - look at that amount! Well, we've been able to split up things nicely. So now you can control much better; you can see where costs are heading - in which task group are they, where are they? So this is the budget that the task group leader is responsible for. In this format, the monthly summaries are being reported - they (task group leaders, HR) can get it simply from the Bookkeeping department. And those costs, they'll find them all back and the sum is simply divided by twelve and entered. Then you get the budget they've spent, what the variance is and what the cumulative variance is. Well, that's how they can follow things."

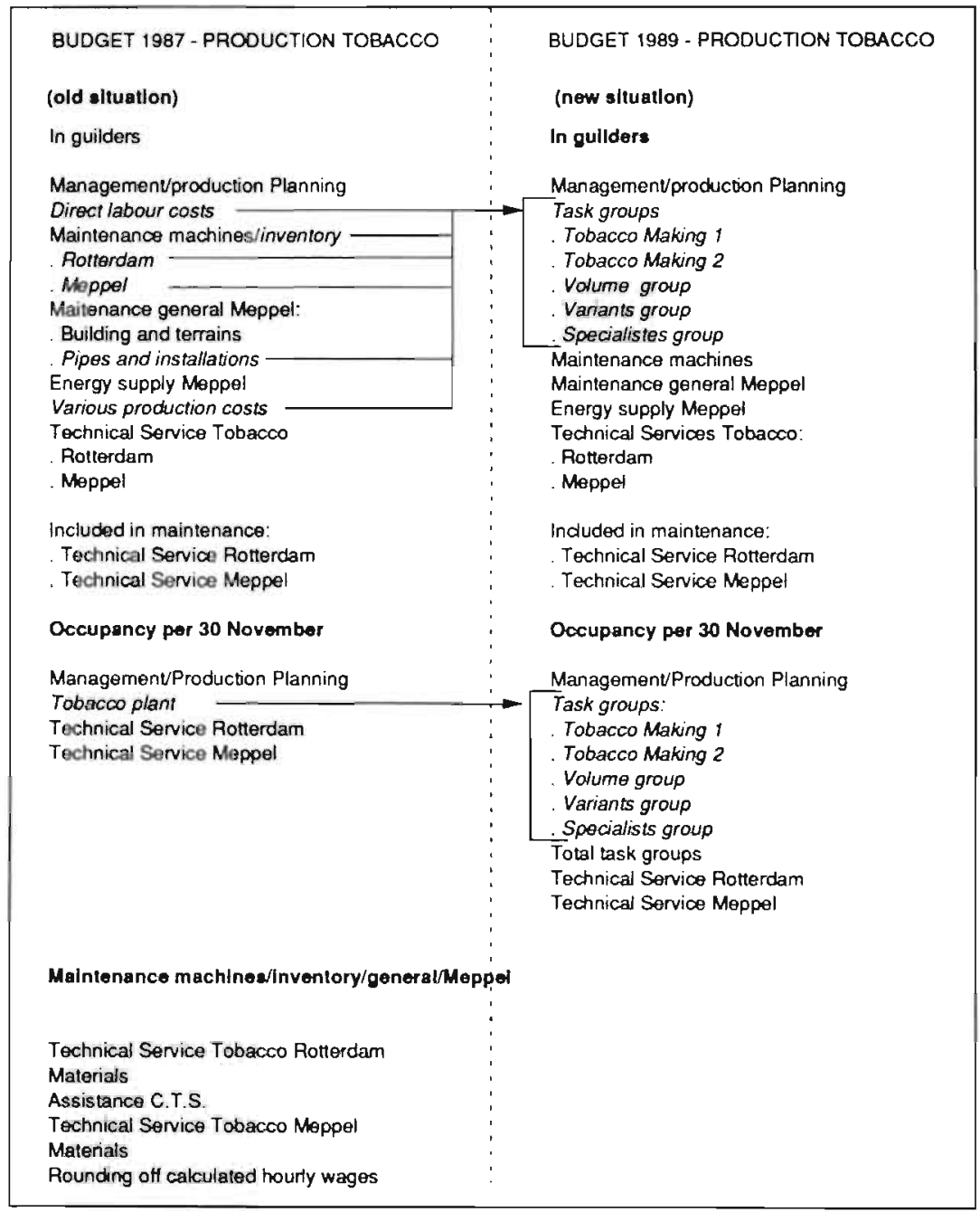

Figure 4.15 Old versus New Production Budget Van Nelle Tobacco (Source: regular internal reports)

Concerning the other formal changes in the management accounting system, there is the shift in budget centres and booking categories. Budget centres such as 
tobacco preproduction, tobacco packaging Rotterdam and packaging Meppel are changed over in the five task groups.

The booking category, direct labour costs, formerly contained a large number of budget items, as a result of which it was unclear what costs (fluctuations) originated from what place in the organisation. Presently, the entry flow is sort of turned around: from task group upwards it is being aggregated to production budget, which reflects the production organisation, and, finally, to cost category.

Furthermore, the capacity and occupancy calculation in the preceding situation differed from the new situation in three aspects:

1. the set-up or format of the calculation itself;

2. lack of explicit premises before starting to calculate; and

3. the goal for which it was used.

Formerly, the calculation was started from a sales estimate for the next three years, which was followed by balancing sales with capacity and arriving at an average machine occupancy rate (the present machining schedule). Not present were the standard setting items of effective hours per man per year and, via the allowed stoppage time of the machines (specific task group information), the standard of net available machining time per day. This relatively primitive approach led to inaccuracies in establishing the net available capacity.

With the former sales versus capacity comparison, it was also impossible to calculate the required labour need. The 'old' capacity calculation was mainly directed at early signalling of plant and manpower capacity problems - if capacity was not in accordance with estimated sales volume, actions had to be taken. The present goal of the calculation is, first, directed at setting the labour productivity norm per task group (i.e., a performance standard) and, second, at establishing the required personnel occupancy by function level (i.e., managing the human resources within the task group).

The main goal of the triplet capacity, occupancy and productivity calculation and the production budget, is cost control and, subsequently, signalling deviations from standard. Instruments to do so are, firstly, the task group budget and, secondly, the labour productivity and machine efficiency reports. In the production budget labour costs are of prime importance $(80 \%$ to $90 \%$ of direct costs are labour costs) - both budget reports serve as signalling device.

\footnotetext{
(production manager) "... We're steering, of course, on budget performance, and labour productivity - that's only to be able to explicitly define influences you notice in your labour costs. Let's say, you find a large deviation in the combination of labour custs and external labour costs. Then you will want to know where it stems from: Is it because the people no longer work so hard or in contrast, are they working harder? Or does it stem from the lagging of your machine efficiency, technical causes? And so you want to find explanations for deviations in your costs, go further in developing your reporting system."
}

The role of task groups in controlling costs is covered, for a large part, by both reports. Change proposals both from the task groups and management are primarily 
aimed at operational improvements that have quick and noticeable effects on the budget performance of a specific task group.

\begin{abstract}
(production manager) "... For example, a machining schedule for the vacation period. In the old days you were stuck with two shifts, but we said - we'll abandon the time principle a bit and look at the planning target; it has to be attained, and how you're going to manage - that's something for the task group itself. So, what does a group do? They have people start at half past ten in the morning, or at six; that's how they save on temporary employees. Those optimisations turn up again in your labour productivity."
\end{abstract}

More generally, working in task groups has become a (organisational) means in itself for generating cost improvement proposals that are already being tried out on their practical feasibility.

\begin{abstract}
(production manager) "... Well, and the improvements you finally hope to get, are often rather radical; you could hardly obtain such proposals in the situation in which we were previously organised, just in departments. And now, in task groups, you have people who live very close to their product assortment. Who live very close to their budgets; because someone on the shop floor just speaks with the task group leader and he is being made familiar with his costs, and what kind of effects it has and so on. But now you have task groups and the commitment of the people is much larger, anticipating proposals made by management much easier. On the other hand, they themselves come up with that sort of ideas and that's where you'll find your increase in labour productivity because they simply spend fewer hours. They start thinking about it all, and all within the normal routine of discussing how things are going."
\end{abstract}

\title{
The Period Report
}

The period report is a summary report, destinated for the task group leaders and the production manager of Tobacco. In it, the actual and the norm productivity and efficiencies are presented, which apply to both the task group and the whole of Tobacco. For the aggregate of Tobacco, actual man hour consumption is specified and a primitive product quality classification is added (see Figure 4.16).

The preproduction task groups (Tobacco Making 1 and Tobacco Making 2) do not contain an entry on efficiency and utilisation rate, which is due to the continuous process of tobacco making; it reduces the use for individual machine efficiencies. Matching machine efficiencies with utilisation rates (relation between machine uptime and available machining time) has another information value. It indicates the spread of production volume across the available packaging machines in the task group. A high machine efficiency and at the same time a low utilisation rate indicates that a 'good' machine is relatively 'under-operated'.

(head Production Planning) "... It often happened that, for example, a machine had an efficiency percentage of $90 \%$ while it had an utilisation rate of $20 \%$. Another machine with an efficiency rate of $60 \%$ has a utilisation rate of $80 \%$. So it implicates that they've been using a machine which was not technically Okay for almost a whole weck, and a machine which was technically all right, got utilised only very little. Well, those are simple analyses you can get like this (snaps his fingers) from the period report."

The utilisation rate itself does not add much extra information: A cumulatively low utilisation rate implies a machine overcapacity in that particular task group. As such, it supplies the same sort of (des)investment information as does the comparison sales versus capacity in the former capacity calculation. 


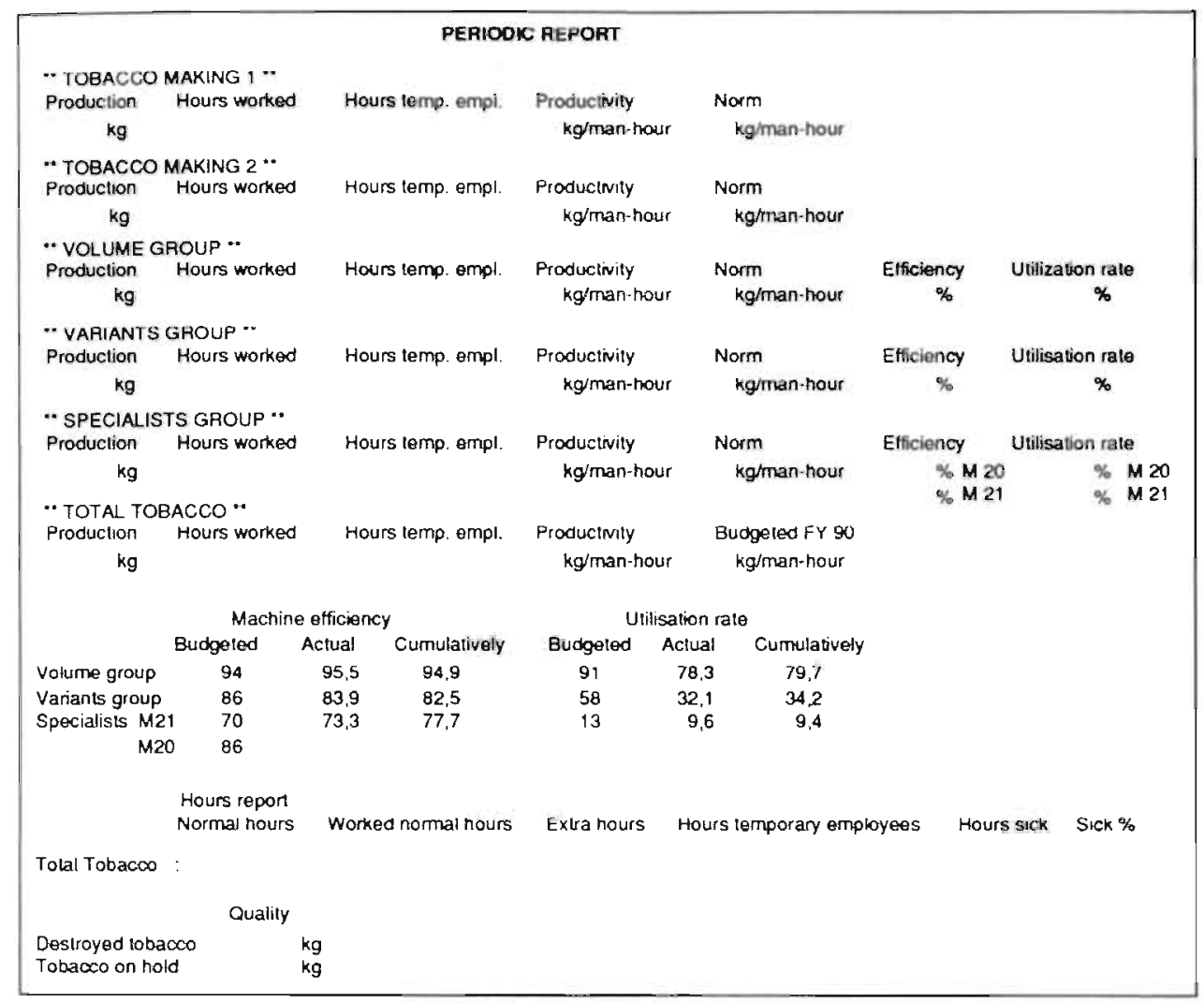

Figure 4.16 Period Report (Source: regular internal report)

(head Production Planning) "... Your utilisation rate can be low, you're allowed to know (laughs) that such and such machine has only been utilised for $25 \%$. It just implicates that you're having an overcapacity on machines. Nothing much is being done with that information. Each year we run into it - that we're having an overcapacity - but on the other hand, we say to ourselves, it works quite nicely. Yes, and if you got that alternative, if you have five machines standing there with an average machining schedule of two on a yearly basis, then you've got double."

The part at the bottom of the period report, which differentiates into destroyed tobacco and tobacco on hold, indicates quality costs: Tobacco returned from the market and internally rejected tobacco. Tobacco is 'on hold' if it is awaiting the decision whether it should be destroyed or reworked (i.e., re-blended).

\section{The Machine Efficiency Report}

This report covers one of the two main control parameters in the production of tobacco: the machine hours. With the collective use of efficiency standards and a variance analysis, a detailed control on machine hour capacity is carried out. Reporting is therefore organised according to machine (number) and not to task group. However, as it is known in which task group or plant (Rotterdam or Meppel) a specific machine is localised, a task group responsibility is easily uncovered. 
The Meppel plant (the volume task group) is where mass production with very few changeovers takes place, accompanied by high occupancy rates and machine efficiencies.

On the lowest aggregation level - the individual machine - actual production volume is matched with the maximum production volume possible in the available machining time of the machine, resulting in the machine efficiency percentage. This efficiency percentage is subsequently matched with the attainable efficiency norm from the capacity calculation, thus indicating slack in the standard setting and not in the virtual performance.

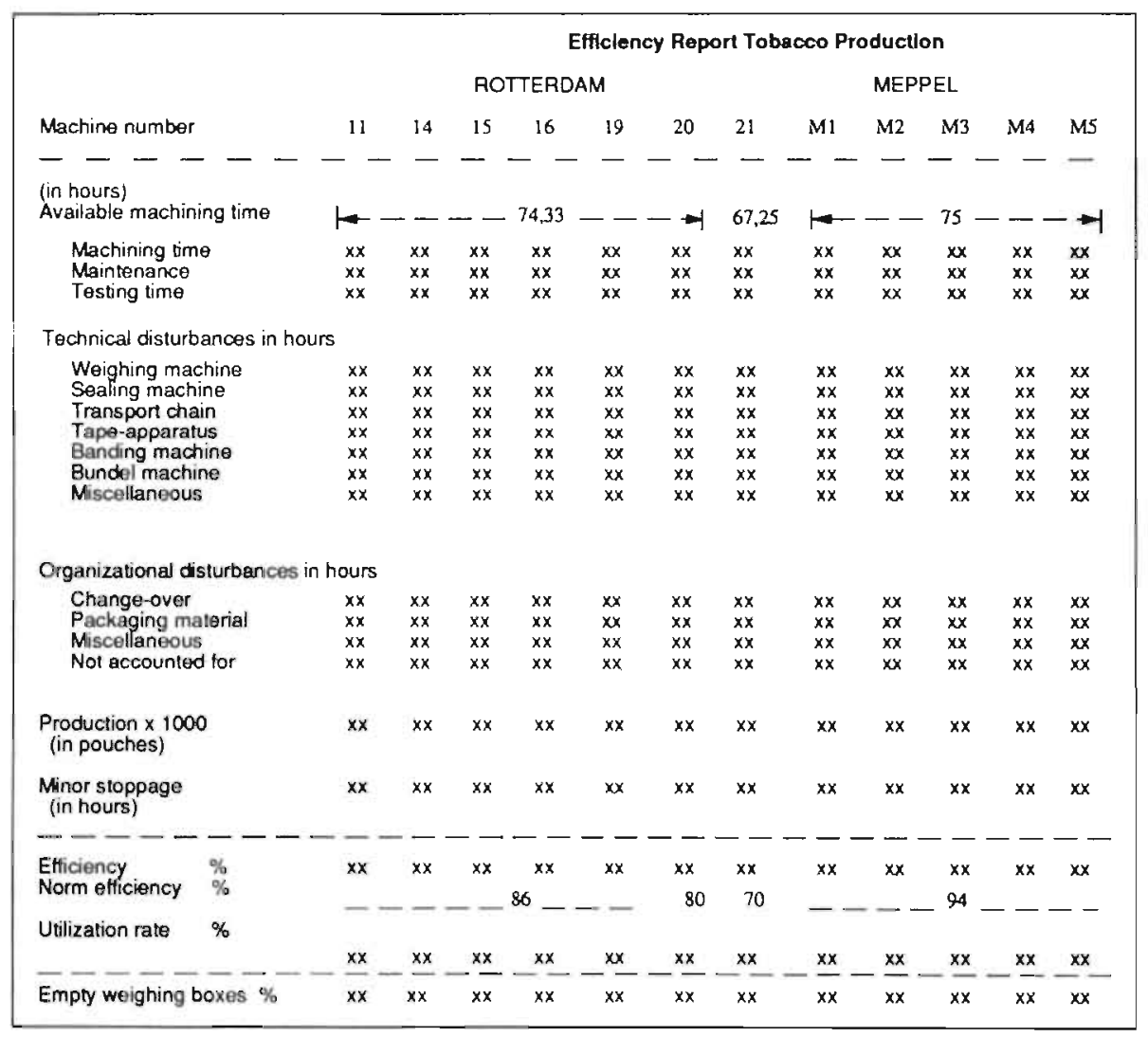

Figure 4.17 Machine Efficiency Report

To be able to analyse large variances and deviations on what caused them, actual machining time is led past two main stoppage categories in which possible process failures can be registered. Those categories are called technical disturbances and organisational disturbances. Technical disturbances are subdivided into categories of mere technical failures each related to a specific machine part. Except for the efficiency report, technical failures are also written down in the machine logbook. 
The Technical Services department can have a look in this logbook every major overhaul and see what the failure track record of the machine is. Organisational disturbances are not being caused by the machine, but are machine-related, explaining for organisational causes of machine setup and changeover downtime. The category of minor stoppage time is a residual category which remains after the completion of all other hourly variance analyses and contains only stoppage times less than five minutes.

The efficiency report (see Figure 4.17) can be read as follows: At the top is the yearly constant available machining time, including lunch and coffee breaks, and originating from the capacity calculation. Next, the actual machining time which comes from the machine clock card and is handed in with the production report. From the division of both figures results the machine utilisation rate at the bottom end of the report.

From the actual production volume on the report, an effective machining time can be derived: production $\div$ number of machine rotations (from the capacity calculation $) \div 60$ minutes. Effective machining time indicates how many machine hours are allowed to be consumed by this amount of production volume, and resembles the standard-allowed-actual comparison in management accounting textbooks. This effective machining time is deducted from the machining time on the clock card (actual machine hours for actual production volume) after which a variance results. The calculation of the effective machining time (machine hours allowed) is not represented in the report - this small calculation is made at Production Planning. This machine time variance is accounted for in the efficiency report in technical and organisational disturbance causes, as well as in empty weighing boxes. An empty weighing box originates when the packaging machine makes a rotation during changeover but does not package a product. What is left after this filtering of variances are the minor stoppage times.

Obviously, the efficiency report is strongly oriented towards (time) variance analysis. It is being used as a first-round machine disturbance analysis (vertically: what failure caused the most problems in this individual machine?) or machine part disturbance analysis (horizontally: for example, which machines are having problems with their sealing module?). This can trigger the Technical Services department to take action long before the formal machine overhaul cycle.

A second-round disturbance analysis employs the items miscellaneous and not accounted for in the category organisational disturbances. Just because these items collect every other disturbance that cannot be allocated to other causes, the presence of large numbers in these two items indicates something is going on.

(head Production Planning) "... an item miscillancous and an item not accounted for. So if we at Production Planning see things like - that isn't Okay, is not in correspondence with the clock card, then, well, if it's fifteen minutes or so, it is not worth the trouble to find out about it. If they are large ... yes, then we follow up. Miscellaneous, if you can't get rid of them under any other item for some reason. If they don't want to write it down or no personnel is around, there's no tobacco, somebody else made a mistake and caused a machine stoppage - well, those things can all happen. And for technical, the same thing." 
The predecessor of the efficiency report also had an efficiency calculation albeit not so detailed in its construction; it simply read available machining time + actual machining time. Moreover, the former efficiency report did not use categories such as technical and organisational disturbances and minor stoppage time, which are categories that only make sense when using effective machining time (i.e., allowable machine hours).

\section{The Labour Productivity Report}

The labour productivity report represents the second main control parameter within Tobacco production: man hour consumption. As the machine efficiency report is directed at increasing production efficiency by improving and controlling technological resources, so is the labour productivity report providing feedback on labour consumption. Labour productivity is once again reported per task group, and itemised by article number and its subsequent production quantity. A comparative summary containing all other task group labour productivities is only provided at the aggregate level of the period report.

The report itself is divided into columns for article number, article description, weight of the product, use of the sleeve-machine, production quantity and the number of man-minutes spent (see Figure 4.18).

\begin{tabular}{|c|c|c|c|c|c|c|c|}
\hline \multirow[b]{2}{*}{$\begin{array}{l}\text { Article } \\
\text { number }\end{array}$} & \multirow[b]{2}{*}{ Description } & \multicolumn{3}{|c|}{$\begin{array}{c}\text { LABOUR PRODUCTIVITY REPORT } \\
\text { Specialists group }\end{array}$} & \multirow[b]{2}{*}{$\begin{array}{l}\text { Total man- } \\
\text { minutes }\end{array}$} & \multirow[b]{2}{*}{$\begin{array}{l}\text { Norm } \\
\text { productivity }\end{array}$} & \multirow[b]{2}{*}{ Productivity } \\
\hline & & Weight & Sleoving & $\begin{array}{l}\text { Total } \\
\text { production }\end{array}$ & & & \\
\hline$\cdots \cdot 2$ & Training & & & 0 & $x x x x$ & 0 & 0 \\
\hline$\cdots_{4}$ & Pouring (soring out) & 1000 & & $x x x x$ & $x x x x$ & $x \times \mathrm{kg} / \mathrm{man}$ hour & $x \times \mathrm{kg} /$ man hour \\
\hline$\cdots_{6}$ & M2O sleeving, KLMCADI & 50 & $N$ & $x x x x$ & $x x x x$ & $x x \mathrm{~kg} / \mathrm{man}$ hour & $x x \mathrm{~kg} /$ man hour \\
\hline 06117 & DS SHAG IA $48 \times 100$ & 100 & $\mathrm{~N}$ & $x x x x$ & $x \times x x$ & $x \times \mathrm{kg} / \mathrm{man}$ hour & $x \times \mathrm{kg} /$ man hour \\
\hline 06202 & DS SPEC.AUT $12 \times 10 @ 50$ & 50 & $\mathrm{~N}$ & $x x x x$ & $x x x x$ & $x \times \mathrm{kg} /$ man hour & $x \times \mathrm{kg} /$ man hour \\
\hline 06206 & Onband. SO KLM & 50 & $\mathrm{~N}$ & $x \times x \times$ & $x x x x$ & $x \times \mathrm{kg} / \mathrm{man}$ hour & $x \times \mathrm{kg}$ man hour \\
\hline 06304 & DS H.ZW.AUT. $6 \times 10 @ 50$ & 50 & $\mathrm{~N}$ & $x x x x$ & $x x x x$ & $x \times \mathrm{kg} / \mathrm{man}$ hour & $\mathrm{x} x \mathrm{~kg} / \mathrm{man}$ hour \\
\hline 06308 & DS Onband. HZ KLM 20@5 & 50 & $\mathrm{~N}$ & $x x x x$ & $x x x x$ & $x x \mathrm{~kg} / \mathrm{man}$ hour & $x \times \mathrm{kg} /$ man hour \\
\hline 06320 & WELP H.ZW. 12×10@50 & 50 & $\mathrm{~N}$ & $x \times x x$ & $x x x x$ & $x \times \mathrm{kg} / \mathrm{man}$ hour & $x \times \mathrm{kg} / \mathrm{man}$ hour \\
\hline 26326 & DSH. ZW.15x10@40 & 40 & $Y$ & $x \times x x$ & $x x x x$ & $x \mathrm{~kg} / \mathrm{man}$ hour & $x \times \mathrm{kg} /$ man hour \\
\hline
\end{tabular}

Figure 4.18 Labour Productivity Report (Source: regular internal report)

The article description column also contains other human resource activities, such as training - the article number then uses a specific different code. An article number is not the same thing as a customer order; an order is being assembled in the Distribution Centre from the various batches coming out of the factory (the smallest denominator of finished product is a carton containing a standard amount of pouches).

Following the batch description, a weight indication is given because the capacity calculation and the physical machine production are constructed according to 
weight, and an additional entry is made in case the sleeve-machine is used. A sleeve-machine wraps a plastic sleeve around the tobacco pouch and is a highly disturbance-sensitive part in the production process (takes time to repair and, thus, can reduce labour productivity and machine efficiency). For the use of this machine, separate lower standards apply. Moreover, its deployment for a specific batch already provides a first explanation for possible unfavourable productivity variances. Actual productivity can subsequently be matched with norm productivity per article number.
(head Production Planning) "...In this manner, the task group leader can see: today I produced number 02627 , which is SQ without revenue band. I produced 12,000 pouches, they spent 1,000 man hours, results in a productivity of 9 kilograms per man hour, as opposed to a norm of 9.1 - Okay, I'm below the norm. He can see discrepancies, he starts asking and gets answers like - yes, we had to work with three temporary employees, it took much longer. Well, all those things he can simply extract from the report. And that he can do on a weekly basis, on a periodic basis. Also, holiday periods - how is my productivity behaving, with many temporary personnel, many vacation workers? Are we doing as we hoped for, how does it develop cumulatively? Well, that sort of information, that was never available before."

The norm productivity per article number serves as a means of control for the task group leader, although it is different from the labour productivity calculated in the capacity calculation. The latter is an indiscriminate productivity measure and serves to monitor aggregate labour costs. Summation of the total production column and dividing it by the number of task group members, results in a task group-specific productivity figure which is comparable with the one from the task group's capacity calculation, i.e., it is turned into a performance indicator at task group level.

\begin{abstract}
(head Production Planning) "... Then you don't specify by article number and they can see - am I on the norm which is also in the capacity calculation, this total norm? And he knows - if I'm above this, I'm probably having favourable labour costs variances. Do I stay behind cumulatively, then in time I'll have problems with my labour costs. That's always been the problem with budgets and budget control; as it is, for example, for those task group leaders. They've got a budget and await the year, those labour costs - it won't go wrong that easy. You don't go over your budget, only at the end of the year you go over your budget. And if you're not used to handling budgets then you have to learn. If you're over your budget al..ready after two months, you'll have to work damn hard to correct it for the end of the year."
\end{abstract}

In comparison with the past, the labour productivity budget on article level is almost entirely new. It originated out of discontent with the allocation of labour costs to products. The allocation criterion used was based on a norm productivity dating from a time-study that was conducted many years ago; it was applied to all product variants and task groups regardless of whether or not they required visibly more or less labour-intensive packaging. To straighten this out, the specialists group, with the largest variation in products, started registering labour time by article number.

(head Production Planning) "...Well, the specialists group, that is, of course, handwork, always has been a difficult factor, such as - What are exactly the costs of a bag-in-box? Bagsin-boxes are cardboard boxes, 200 gram packaging, which require a lot of operations. That article was introduced at one point in time and it has never been looked at, like: Can we produce this as low cost as we think? Aren't the manufacturing costs higher than the revenues? Why has that never been checked? Because our cost structure simply is like: I've got a task group, the specialists group for example, or 1 have the tobacco factory or hand packaging. And 
a norm productivity on the basis of time-studies applies. And, shall we say - 15.1 kilos per man hour is spent on bag-in-box for labour costs. So in the product cost calculation you have a portion for manufacturing costs, labour costs - 15.1 kilograms per man hour, 1 man hour costs 37 guilders, just fantasising, so if I sell 15.1 kilograms I spent 37 guilders labour costs for producing that amount. But is that really true? That's what we wanted to know once and for all; how much do we really deviate from that norm we apply in our product cost? For bag-in-box we were afraid it would be too much. Well, that guess came out right. And for other hand packagings we actually allocate too many labour costs. That is the reason why we needed to know rather badly, especially in the specialists group on article level, what precisely is spent on man hours per article. Well, and that is what you will find back again in the labour productivity report."

Later on, this time registration on article level was expanded to the other packaging task groups and it became a commonly used labour productivity report. However, the update of the product cost standards has not yet been formalised; a revision of labour cost absorption, therefore, remains to be done.

(head Production Planning) "... Next, in terms of calculations, it now is looked at on a somewhat higher abstraction level. Still, say per task group, we produce poly pouch 50 gram as the capacity calculation indicates. In that period, they've produced that much, spent that much on labour costs, so it is allocated to products proportionally to sales. And that is obviously incorrect, of course, because you don not know how it all relates. The allocation key is now according to sales and not according to man hours spent. But we have installed the options to allocate more precisely."

\section{The Production Report}

The present production report has replaced the former machine report in which unly machine stoppage was accounted for. The production report is the data carrier for both the labour productivity and machine efficiency reports. Together with the production report, the so-called clock card is handed in: a tabular round card divided into 24 hours on which it is recorded at what time and for what period the machine has been working. Clock card and production report are in fact a doubling of information: what is registered as a stoppage on the clock card has to be specified in the production report. For that purpose, a number of abbreviations are used (e.g., lunch break - LP, cleaning - SM). It also indicates what caused a stoppage by stating the relevant main machine group in the production line where the stoppage occurred (for example; bundling machine - BM, sealing machine - SM). The abbreviated note in the production report has to be accompanied by a full note in the machine logbook, intended for the Technical Services department. If the machine is still working when a disturbance occurs, it is not recorded on the clock card and only the production report will have to give the disturbance signal. The production report contains the following items:

1. task group and shift number (each shift fills in its own production report);

2. article numbers manufactured;

3. names of persons who operated the machine (including the one who fills in the report);

4. time account (per 5 minutes); and

5. machine number and date.

Similar to the machine efficiency report, the production report is directed at indicating disturbances in the manufacturing process; the visibility of the notes and the layout of the report (time-ladders, everything on one page) show at a single 
glance what has been going on. There is little text and uncomplicated filling in, which simplifies shop floor use.

The division into two control parameters (man hours and machine hours) takes place as early as in this first information acquisition round, which is at shop floor level. Processing, aggregation and availability in other types of information formats and reports are realised on task group (leader) level. The summary report finally reaches the highest production control level and contains the most aggregated operational information.

\section{The Relationship with the Management Accounting System of Douwe Egberts}

The takeover by Douwe Egberts had an impact on several aspects of the organisational redesign. First, an extra round of meetings and reports was needed - Van Nelle's new organisational set-up had to be explained and clarified to the DE management. For the structural and process changes that had already been implemented or started, it meant a sort of midterm economic evaluation. Positive yields thus far would, of course, signify a continuation decision of the project(s). We will come back to this subject later.

Secondly, it meant a change in the internal information system. Since Douwe Egberts (hereafter D.E.) is a subsidiary of the U.S.-based Sara Lee corporation, a corporate uniform information system was implemented, i.e., internal reports were standardised according to U.S. accounting practices. Therefore, the local information system of Van Nelle Tobacco Rotterdam with its own reporting formats had to change over to 'company rule'. Company rule resulted in reporting formats that are structured by resource categories and organised according to management functions. Additionally, reports are linked to a planning cycle based on progressing average performance figures.

The 'company rule' production budget implemented onto the task group situation uses the three conventional accounting resource categories (direct labour, direct manufacturing and fixed overhead). However, since the production budget of Tobacco Rotterdam is closely knit with the standard-setting capacity and occupancy calculations used for article/batch level production control, the request to draw up a departmental resource category-based production budget becomes an activity with little relevance to management and control of the manufacturing process itself.

Therefore, the steady-state type of information that Sara Lee/D.E. requires differs largely from the flow or process information that the information system of Tobacco Rotterdam supplies, and which is tightly linked to local production performance control.

The resulting linkage problems are being 'solved' by halting the vertical information flow to and from Tobacco at the system boundary of Tobacco. The production manager fills in the required corporate forms and maintains the task group (horizontal) reporting system for local production management and control. 
(production manager) "... Of course you get a terrible confusion of tongues and other difficulties by all this. But that's what we try to keep out as much as possible, since what we're saying is: reports we need for D.E., those corporate requirements, do not enter the factory. So they stay out of my organisation, the translation or the switch we make at Production Planning or I'll do it myself. We keep our own reporting system within the organisation so that we can continue working with them, and nothing is allowed to change that."

Obviously, budget control is familiar to D.E. However, they use budgets differently compared to Tobacco Rotterdam. The budget D.E. formulates is a volume budget based on steady-state resource information (this many people and this many machines makes so much capacity). In contrast, the task group budget of Tobacco Rotterdam informs the task group leader in detail on the production process, supported by the other two reports with their built-in variance analyses.

(head of Production Planning) "... We have got an AOP, Annual Operating Plan, which is a year plan, a budget. It states - Tobacco Preproduction: 130 men, Tobacco Packaging: 80 men, Process Engineering: 7 men, and a short outline of what they're doing. If you're budgeting like we do, you can hardly do head counts because what do you've to say at that time? You also control production by using temporary employees, so how to budget? It depends on your sales. If you've got a really busy period because sales go up, you hire more temporary employees. So that becomes problematic in your reporting."

The existence of two information systems at the same time results in linkage problems in control: The vertical and uniform system of Sara Lee is directed at the functional control of business units, a system level higher than plant level production control and in distinctive contrast with the local control principle of both task groups and operational teams. The plant's own information system is directed at the lowest system level (the shop floor) and has less to do with determining how many financial resources (budget) are tied down in what parts of the organisation; it provides process control. Linkage problems become clear on this local level when performance is evaluated by means of vertical capacity information.

(head Production Planning) "...We've put up a nice system; how we budget this, how we budget at all, how we determine our occupancy, how we calculate our capacities. And at D.E. they're doing that vcry simply. They don't budget labour costs but they're budgeting they're needing 130 men. We are controlling costs very explicitly. Because you budget, of course, your occupancy, but we're immediately linking labour costs and restitution sick pay and external labour costs to it. And with that application you have to control and stay on your budget, or stay below it."

Returning to the first item, the evaluation/(re)legitimisation of the change, a calculation was made based upon a comparison of the production budgets of ' 88 and 189 , both years in which task groups were already implemented and operating. The first estimate for ' 89 ('outlook 0 ') is an extrapolation of the ' 88 plan, which resulted in a savings of $16.5 \%$ on the total production budget. Corrected for volume and assortment changes, a final production budget saving resulted of approximately $5 \%$ for a period of nine months operating in a task group structure.

When measured using the new reporting system, considerably favourable labour productivities and labour cost results are found. As a result of these first and rough calculations of the economic profitability of the organisational redesign, a three-year freeze on interventions from D.E. management was installed for Tobacco Rotterdam. 
(head Production Planning) "...Well, the first hit we scored was by the increase in labour productivity: in ' $86-' 87$ and the first six months of ' 88 , it was stable at 20 kilos per man hour. Since the reports and working in task groups, it rose to 21.5 kilos per man hour. This was, of course, because you are producing with more efficient production schedules, so you can arrange things better, organise better, control better. On the other hand, because you produce more with less people, quite simple. [...] Well, the savings on labour costs, that is the rise in labour productivity; the first half year we had saved 350,000 guilders alone on labour costs, very concrete, from cost reports, in comparison with the year before. This is not something I concluded myself this way, it is worked out in cooperation with Planning \& Control, who manage and control the figures."

The main problems of this financial evaluation was that for certain cost and expense categories no historical references were available (the task groups had been operating for just eighteen months by then). Furthermore, it was unclear if certain effects were caused by the task group structure (no unequivocal causality) and, finally, specific industry/company characteristics eliminated some cost/benefit categories from the comparative calculations.

(head of Production Planning) "... We are now one year, one and a half year in operation in task groups and some costs you simply cannot measure yet because you haven't any historic reference material. We have, for example, savings on material losses but if they really have reduced, it is not yet known. You can see a decrease all right, but I do not dare to attribute that to task groups. You can, of course, think the other way around, saying - people get better motivated concerning their products and their work and sooner signal things taht are wrong. So, it could implicate very well an increase. [...] Then they talked about raw material inventories, that it could decrease since you're organising your production flow better, but apart from the fact that we are tied to seasonal purchases, you are always stuck with a 10 month inventory. And you do not bring that down by working more efficiently in your organisation. And manufacturing inventories are not being determined by cycle time but rather by standing time: before the tobacco can be packaged it has to stand for 24 hours, and also in preproduction. The total cycle time is thus, for $50 \%$, already fixed by standing time which by all means introduces a low yield."

Also, a cost-benefit comparison this selective does not take into account qualitative improvements such as increased flexibility or market orientation, which were goals from the very beginning of the organisational change as well as goals which focus on the whole of the organisation.

(head Production Planning) "... Market-oriented thinking must always be directed by the Marketing department or the market group and they of course have to be able to anticipate. And that has also been the most important conclusion of Berenschot (major Dutch management consulting group, $\mathrm{HR}$ ) in 1987, they did the Ingistics study, that a definite improvement appeared in the production organisation regarding flexibility."

For cost savings, a sort of opportunity cost argument applies because cost savings are mediated by less direct interventions, such as not hiring additional personnel for the Technical Services department since minor repairs and maintenance are done by the task group itself. The organisational decision to keep minor maintenance in the task group creates a cost alternative. However, listing and comparing both cost alternatives is possible in this specific situation, even if it is not supported by financial figures enhancing decision making.

Evaluating the whole change project beforehand using a cost-benefit or capitalbudgeting approach, has not been discussed at Van Nelle Tobacco Rotterdam. Typ- 
ically, the organisational and strategic arguments at that time were of such importance and magnitude that financial considerations were not raised nor was the necessity of such a preemptive evaluation felt.

(production manager) "... Well, if you want to decrease product costs, and that is what the explicit goal eventually is, then, yes, you think at that time - you cannot yet point out precisely beforehand what the effects will be on product costs. But this is a vision which has up untill now never, at least for me, been firmly proven. I'm thoroughly convinced of its success. Now I see it proving itself, but I didn't know that when I started with the whole thing. But then again, how much do you believe, when you get on with this all (= change project, HR), that it will have consequences for your product cost. And that conviction has to be there. With the ones who champion the project but also with top-management of course. That's all there is."

(head Production Planning) "... But okay, it is a global cost-benefit estimate. That has also been the reproach from Planning \& Control; that no proper analysis was made before so as to establish what the accompanying costs are and what the yield is going to be. Well, that is, of course, a little bit difficult when talking about organisational changes because it most of the time represents a philosophy such as "I'm convinced that it will lower my manufacturing costs", and that it will most certainly pay itself back in the long run, although it is hard to substantiate that. Most certainly because it is such an abstract affair. But now you have carried it through, so now you can start looking at it in financial terms."

\section{Note}

6 Although quality of working life usually assumes an industrial relations connotation, Van Nelle used it in a mixed sense: It is strongly related to labour and work conditions being the result of improved industrial relations (i.e., between employers and unions). 


\section{Case Zilverstad Silversmithing}

\section{Situational Background}

Zilverstad is a small-sized company which was founded in 1875 as one of the many silversmithing shops in Schoonhoven, a city dedicated to this one industry since medieval times. Its name, which translates as "Silver City", dates back to 1953. Prior to that, the family name was used, as still is customary for all other silversmithing shops in Schoonhoven. After the Second World War and, more specifically, during the seventies, severe competition from firms in the Far and Middle East resulted in a dramatic reduction in the local silver industrial activity. During the eighties, however, this trend was stopped by emphasising quality over low-cost production. And, as Zilverstad is the name-bearer of Schoonhoven's silversmithing tradition, this was reflected in the economic prosperity of Zilverstad. The upturn in events was amplified by a reinstatement of the traditional silver guild, St. Eloy, together with its quality standard, the St. Eloy Guild Mark. Together with the usual silver hallmark, it guarantees Schoonhoven craftsmanship and Zilverstad design.

Zilverstad is a family-owned and run company. The present two family members, brothers Arne J.P. Pluut (commercial executive) and Arie Pluut (production executive and engineer), have taken over the company from their father. Collectively, they constitute the Board of Management. The family ownership was reflected by the internal culture. People work their whole life for the firm, which, therefore, has little personnel turnover. Also, people are relatively well paid and receive a share of the profit. Labour conditions are good, mediated by the small community Schoonhoven, resulting in few labour and payment differences in the various local silver companies. Managerial control and decision making was of an enlightened autocratic type. The two brothers frequently consulted and discussed with key personnel on important decisions, but they were clearly the ones who actually made the decisions. No formal works council or some identical functional body is in place. The vision of the two brothers on labour affairs and human resources has always been based on a strong perception of social responsibility and 'taking care of your people'. 
The organisation is largely structured according to the product market (combination) with two functional departments, i.e., Procurement and Administration (see Figure 5.1).

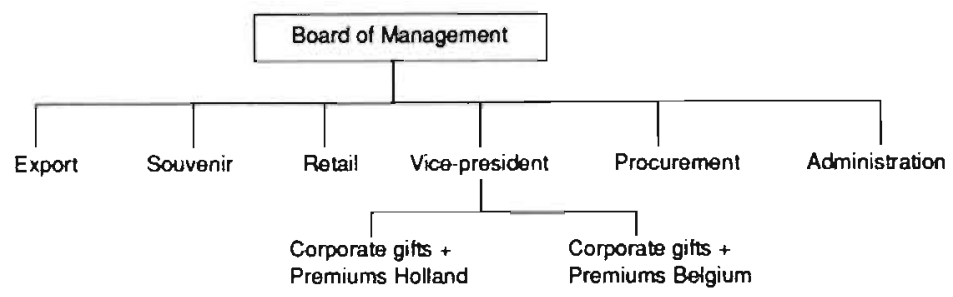

Figure 5.1 Former organisation chart (Source: internal brochure)

The craftsmanship tradition of Zilverstad can still be found in the three main product market combinations: premiums and corporate gifts, jewellery and souvenirs. The jewellery and souvenir lines are also exported; approximately $25 \%$ of sales are designated for export to 26 countries. The premium and corporate gifts markets are the fastest growing and most dynamic market, characterised by a large variety of design-to-order and customised products and a constant pressure for product rejuvenation and line development. Product quality, delivery time and technical capabilities are the main competitive parameters in this market. The jewellery and souvenir markets are in a more difficult position. The constantly decreasing number of jewellers, competition from alternative luxury articles (e.g., audio equipment and exotic holidays) and the hard monetary position of the Dutch guilder put a constant squeeze on sales. Again, quality and delivery time are important here, supplemented by the factors of a large product range and highservice level.

The common denominator of all the markets served is that they are characterised by high-quality, customised and small-batch production with short delivery times. The product mix consists of a large variety of different products, ranging from relatively inexpensive, easy to manufacture souvenir spoons to full silver, traditionally crafted candlesticks.

Two-thirds of the annual sales are from in-house production with the last onethird coming from wholesale activities. For the manufactured products, Zilverstad has all the required production facilities available. They range from tool shops and product development to the final finishing stage. The technology-in-use is dependent on the various craftsmanship domains, i.e., forging, casting, stamping, enamelling, engraving and electrogalvanizing, with the latter requiring the most technically advanced and complicated machinery. Most of the other crafts are inherently low-tech and high-skill manufacturing functions. Further manufacturing relationships exist with a fully owned enamelling job shop (since 1986), subcontractors in India and the Far East for low-cost, semi-finished products, and indepen- 
dent manufacturers in England, Germany and Italy for additional product specialities.

Zilverstad employs 70 people, has a Return On Investment (ROI) and an inventory turnover of about $18 \%$ and 5.5 respectively. Its balance sheet amounts to a total of 5.7 mln. Dutch guilders (all figures from 1990).

Initially, Zilverstad was specialised in just one manufacturing operation, i.e., stamping. In the 1970s, a limited number of standard products were made in large batches, mostly souvenir spoons, cheap nickel-plated ashtrays and cigar boxes.

(Commercial executive) "But our products were being copied in the Far East. Which meant it was over and out for us. We couldn't compete against this. We had to find a way to survive, it was as simple as that. We had to find alternative products and markets. We more and more started to manufacture products according to customer specification: high-quality products which allowed us not to compete on price alone. There is now, except for a basic assortment, almost no product left from our assortment of fifteen years ago."

From the 1980s onward, Zilverstad experienced an explosive growth. The number of employees doubled while the sales figures almost tripled. Also, various production techniques were acquired and used in manufacturing, for example casting and forging.

The success of the company necessitated a change as the company went from a pioneer phase to an organisation phase, increasing product diversity and production capabilities at the same time.

(Production executive) "... Orders came into the factory and, at some time, came out again but what happened in between we didn't know. In the factory everything was milling about, and there were bottlenecks in manufacturing. This was mainly caused by our own occupation with special customer orders, and therefore, with new and unknown products with all the quality and planning problems that went with it."

(Commercial executive) “We got delivery time problems in the years ' 85 -' 87 , also due to the fact that sales increased very fast. Our continuous need for a sufficient number of adequately trained personnel couldn't be kept up. The organisation didn't fit the fast growth. Furthermore, the market was changing rapidly and increasingly kept asking for shorter delivery times and higher product quality. It really became necessary to control quality in all phases of production. This is how, at the end of the eighties, the need arose to improve the structure of the company."

Traditionally, the production executive and the production manager acted as expediters once the customer telephoned to assure delivery time. Furthermore, the need for trained personnel continues to be important, focussing mainly on the jobs of toolmaker and stampmaker, which are highly qualified people and at the same time bottlenecks in the diversified product turnout. The added value of these people is located in the need to be creative in a different way; silversmiths are creative experts in certain operations, but tool and stampmakers are the creative architects of those operations. Appearance of this type of personnel shortage enforced thinking on personnel policy for the very first time. This bottleneck was approached in two ways: First, by starting internal training for tool and stampmakers and, second, by acquiring a computer system that could engrave stamps from an engravings database thus taking some routine work away. 
Complexity in production and a large variety of different products were to blame. Raw materials differ from silver or gold to brass, bronze and pewter, with having solid, enamelled or plated final products turned out. Additionally, each material has its own production process with many product-dependent individual manufacturing operations. For instance, galvanising is a complex operation and requires (knowledge of) the use of chemicals. Also, there are assembled products which combine two or more different production processes for each assembled part. Apart from all this, sales are highly seasonal with the largest volume being sold in the last three months of the year, i.e., Christmas and season gifts. To counter complexity and variety and to respond to quality-customised competition, high-grade product design and manufacturing technologies would possibly provide some answers. Unfortunately, the large product variety with its subsequent large number of machine changeovers make automation and even mechanisation of production a troublesome affair. In order for automation, and technological innovations in general, to succeed, it was felt that the organisation first had to be made fit for such changes. Only then can technological interventions be successful.

To the extent that the organisation was felt to be in need of direction, a business plan was made in 1986 by the commercial executive. Typically, the business plan focused mainly on the commercial aspects, as the Sales function was somewhat leaking away in terms of managerial control. Written in terms of the market, it dealt with, for example, product range, commercial targets, market developments and operational improvements in the sales department. In contrast, the Production function was thinking in terms of product types, e.g., spoons, business gifts, jewellery, etc. The business plan clearly indicated the need for intensified quality control in all production stages. It did not give any information yet as to how this could be achieved. The previous combined effect of both was that as long as the factory is fully occupied and sales sells it all, things are alright. The business plan signalled both a reversal in thinking (from the market inward to the organisation) and an awareness that insights into the present situations, and information in general, is important to the firm. It was not the first managerial effort towards planning and what things were expected to look like. This business plan, however, was much more thorough and detailed. And, more importantly, it was discussed with all staff members to ensure a shared agreement on targets, etc.

The business plan, however, did not prove to be satisfactory because of its limited focus, and the shopping for additional help was continued. This help was found in the form of the Dutch Contact Group for Employers in the Metal Industry (CWM in Dutch), of which Zilverstad was a member. The CWM offers various low-cost services to its members, including training courses and several types of business advice and consulting. By October 1988, the CWM introduced Zilverstad to the executive course on SocioTechnical Systems Design (STSD) for small and mediumsized companies. This course was taught collaboratively by the CWM and the Dutch Foundation for Quality of Work and Organisation (abbreviated into NKWO in Dutch); they later involved also a consultancy company, practising what they preached, called KOERS. The brothers Pluut and the head of administration returned with the impression that this could be what they were looking for and asked their key people to go and see what they thought of it. In February 1989, the production manager and two other production staff members completed a middle 
management course on STSD, and everyone came out very enthusiastically about the integral redesign ideas presented.

(Head of Administration) “... In fact, we have been looking for some time for the most suitable organisation format. For instance, we've been thinking about organising production to order size; large, medium and small orders. However, it proved no solution to our problems. In fact, we were confronted with the problem that Zilverstad both has products and production processes which are very specific and require specific solutions. To get a more comprehensive view on things, the two Board members and myself took the CWM executive course on Quality and Flexibility. Discussions with CWM employees and people of KOERS consultancy have led us later on in starting to think about flow-oriented manufacturing and homogeneous task groups. And since the reorganisation we had in mind had to be done integrally, three other employees subsequently took the middle management CWM course on Partaking in Renewal. After that, a start was made with the more specific filling in of the reorganisation."

The educational trajectory thus started with the two board members and the head of administration, followed by key people. The courses explained what system design was, how it was done and what the best way was to depict and describe organisational processes. At this moment in time (June 1989), a consultant of KOERS was introduced. Her main role was that of process facilitator, not of an expert, as she served to keep the project within the tracks set out.

A group of six people was again trained by this consultant, repeating the main design principles. This group consisted of the initial course participants: head of administration, production manager, two production staff members (the galvanising foreman and the foreman in charge of jewellery articles) plus the job scheduler, and the board secretary, also being export and import manager; i.e., four from the production department and two from nonproduction. The job of the design group was to do the general redesign. The highest rank present at all the design work group meetings was the head of administration. This was done deliberately since one of the goals of the new organisation was to bridge hierarchical distances and have the lower echelons get used to and acquire more responsibilities.

The project structure maintained a linking-pin model, with a steering group consisting of the brothers Pluut, the external consultant and the production manager (who had over 20 years of experience in the company) and the head of administration. The job of the steering group was to monitor progress and to make decisions. Actual redesign was in the hands of the design work group, as the Pluut brothers held the view that their main job was to just make the decision, nothing more. The installation of this design work group marked the formal start of the organisational change trajectory (August 1989).

Two different types of work groups followed up the general design of the design work group: A sales work group and various detailed design work groups. The sales work group, consisting of the commercial executive, market groups' sales managers and, to maintain the link with production, the job scheduler and the production executive, started mid 1990. Their job was to asses the commercial position of the firm by means of a SWOT analysis and propose measures to bridge the gap between desired and expected performance. Almost naturally, this flowed over into a strategic orientation round (SOR) as prescribed by STSD (SeptemberDecember 1990), the preliminary work of the SOR already being done by the business plan made earlier. 
Typically, the SOR was not initiated at the start of the reorganisation process but after the redesign decisions were made: i.e., not performed by the design work group before their general redesign of the organisation structure, but by the sales work group, accepting the new production structure as a given condition. This shift in sequence was primarily motivated by the condition of the internal organisation. First, a flexible production organisation was considered a neccessary condition before entering the market full-fledged with new strategies and commercial approaches. Second, since Sales proved itself in the sales growth of the 80s, it was not considered in urgent need of structural renewal. The SOR brought forward that a decision had to be made on what Zilverstad would look like in the 90s. Strategy was discussed in terms of market capacity, production and sales capabilities, and product range. Two strategic directions were considered: continue the present flexible organisation with its large and varied product range, or change towards an organisation with a clear image, having a relatively limited product range and market coverage. As for the implications for the organisation, it is not certain whether a flexible organisation can be supported in the long run, mainly for its cost consequences and the high organisational demands on Production. More important is the expectation that this option will cause the gap between the several market segments to grow since a focused strategy per segment will be needed, reflecting itself in a segmented sales organisation. The brand and company image strategy does not include this expectation, and seems to be preferred. However, this strategic discussion still continues as more and more information on Zilverstad's markets and organisational capabilities becomes available.

The second type of project group following up the design work group are the various production work groups. They zoomed in on the general design of their production segment and made a detailed design, paying special attention to interfaces (i.e., work flow boundaries). Typically, it involved all the members working in that specific production segment. Figure 5.8 shows such a detailed design made by the employees. These detailed design work groups were headed by the design work group participant under whose responsibility the specific part of the organisation fell. Meanwhile, the design work group was maintained for feedback and cohesion in the various detailed designs.

Therefore, the project structure unfolded simultaneously with the various redesign activities, their sequence and responsibilities coinciding: The redesign work group came up with the general design, then the upstream part (coupling job scheduling and production) was designed in detail, followed by the downstream part (coupling finished product and shipping). The end of the detailed design was marked by the completion of the control structure and information structure in December 1990. Halfway the detailed design, the sales work group was started up and an SOR was initiated.

\section{The Change Trajectory}

July 1989, the two board members, supported by the consultant, made a companywide presentation. It was outlined to all organisation members gathered, what the reasons for the change were, what was going to happen, and what generally would be their future role in the upcoming change process, explicitly stating their partici- 
pation and involvement. In this one big event, which was unequalled in the fir$\mathrm{m}$ 's history as well as in the fact that the board directed itself to all personnel, the upcoming change was openly laid out and discussed by the two brothers Pluut, showing their own commitment to the changeover.

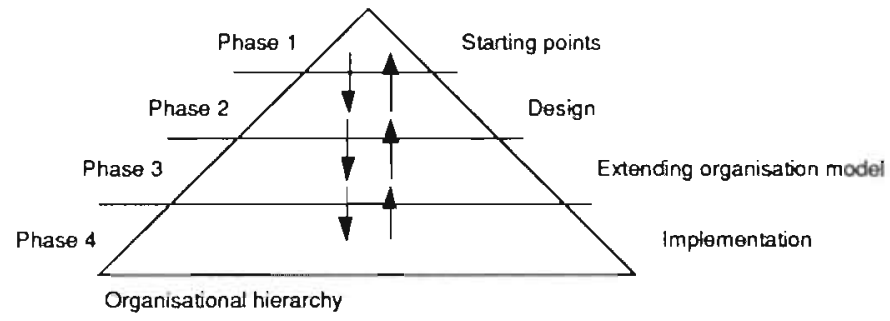

Figure 5.2 Phasing of redesign trajeclory (Source: project documentation)

The change trajectory started formally with the installation of the design work group and the concise rehearsal of the STSD design principles by the consultant (August 1989). As an immediate result, a phased approach to the change process was prepared, linking up with the project structure (see Figure 5.2). For example, phase 3 is where the above-mentioned detailed design work groups came in. Remarkably, the phased approach and the project structure related only to Production. Sales started up its own track later on.

Table 5.1 Full tasks per redesign phase (Source: project documentation)

\begin{tabular}{|c|c|c|}
\hline Phase 1 & $\begin{array}{l}\text { Formulating design specifications } \\
\text { Bottleneck listing }\end{array}$ & \multirow[b]{2}{*}{$\begin{array}{l}\text { Execulted by: } \\
\text { design work group }\end{array}$} \\
\hline Phase 2 & $\begin{array}{l}\text { Lock tor parallet liows in the production } \\
\text { Link fows to the pre-production and past-produdion trajectories as } \\
\text { much as possible } \\
\text { Determine in oullines all operational and control activities } \\
\text { Malch production and control strudure with design specifications, plus } \\
\text { make a choice (the Board enters the trajection) } \\
\text { Present new organtsation struqure to the entire company }\end{array}$ & \\
\hline Phase 3 & $\begin{array}{l}\text { Determine in detail operational and control activities of groupsunits } \\
\text { Determine (possbe) layout changes } \\
\text { Determine (possible) changes in lectnical equipment } \\
\text { List changes in intormation suppty \& demand } \\
\text { List the need lor training } \\
\text { Make an implementation plan }\end{array}$ & \multirow{2}{*}{$\begin{array}{l}\text { Expaced by: } \\
\text { work groups under } \\
\text { the design work } \\
\text { group }\end{array}$} \\
\hline Phase 4 & $\begin{array}{l}\text { Formulate group goals } \\
\text { Systematic problem solving } \\
\text { Situational leadership } \\
\text { Introduce work counselling } \\
\text { Training } \\
\text { Conflict management \& team building } \\
\text { Pertomance aporaisal }\end{array}$ & \\
\hline
\end{tabular}

The four-step approach consisted of the following main phases (see Table 5.1 for a more specific outline): 
- formulating design specifications \& categorising organisational bottlenecks (phase 1);

- actual design (phase 2);

- elaborating the organisation model (phase 3);

- implementing it, using an implementation plan (phase 4).

The design work group started off with listing bottlenecks or what was felt to be a bottleneck ('points of attention' and 'points of annoyance'; September 1989) and with formulating the design requirements (October 1989). In other words, it was stating the framework and boundary conditions for the upcoming design (see Figure 5.3).

(Head of Administration) "... That listing showed the way for the detailed final proposals. Those proposals have, to a certain extent, brought about a culture shock: Many things which were taken for granted, were suddenly discussed or abandoned."

The functional requirements are preceded by a short statement of General Company Goals, a sort of mission statement, which was unprecedented because it was the first time goals were explicitly stated and ratified. The functional requirements focus on structure, structure allowing for product quality, quality of work and functional integration. Furthermore, the explicit attention for the cost structure of each product market group is important: It states cost-structural targets simultaneously with the targets for delivery time and reliability and product quality, i.e., cost structure and performance are considered to be two sides of the same coin. Cost structure targets are, thus, norms for the overall accounting system to be designed, i.e., norms to be attained by means of rather than within the accounting system.

Bottlenecks were listed according to their system level and to whether or not they had a structural cause (September 1989). System level refers to the six subsystems making up the primary process at organisation system level; sales, preparation, production, storage, shipping and procurement. These six subsystems return in phase 2, where a process model of the existing organisation is made in order to establish interfaces and information flows between subsystems, employing the SADT/IDEF technique (see Figure 5.4). It forms the basis for the latter control and information structure design.

Nonstructural bottlenecks are then prioritised and serve as inputs for quick improvement actions. Structural bottlenecks are inputs for the subsequent redesign of the production structure. Apart from a structural/nonstructural and subsystem level listing, two other classifications were used: A strategy category, relating to bottlenecks which could only be solved by a change in policy or in managerial discretion. For most items, this classification coincided with a zero systems level, i.e., it was concerned with the organisation as a whole. Examples are the production order backlog on Zilverstad's own standard products compared to the immediate production of customer orders (system level 0 plus policy category), the recruitment of personnel in the absence of selection criteria and consultation with the foremen involved (system level 0 plus policy category), and the lack of time and attention for product development and product assortment (system levels 1 and 2, plus policy category). 


\section{General Compeny Goals}

- Sales spread across the various market segments (approx.): gift articles (export)

souvenirs

retail trade

premium/business gifts market
Market opportunities:

$30 \%$ growth, mainly export own products

$10 \%$ stable, on approx. $1 \mathrm{~m} / \mathrm{n}$.

$15 \%$ growth possible

$45 \%$ growth possible

- In order to operate successfully on the various markets, a wholly owned production of sulficient size per technology (foundry, presses). is needed. This means a size which can sustain a good market position per technology.

- Priority in choosing to make or buy is determined by:

- higher added value:

- own product as image;

- short delivery time possibilities.

- Profit maximisation is more important than sales growth.

- In building up the order position targets are:

a) a woll-utilized production capacity:

b) high-running whotesale articles;

c) supplementing sales with premiumbusiness gift artictes.

Functional requlrements for the executing and control atructure

- A structure that allows for the implementation of Total Quality Management.

- A structure in which a high quality of work is realised.

- A structure in which the qualities of all personnel are optimally realised, allowing people to develop involvement and/or motivation.

- A structure that allows for the integration of wholesale and production activities.

- A structure in which the sales activilies have to be integrated with the strategically set production capabilities and are nol autonomously directed at wholesale.

- A structure in which the procurement activities can have a clearly delineated position.

- A structure that, supported by the administrative department and computerisation, is controliable for the Board.

- A structure that allows for a clear and eflective consultation structure.

- A structure that allows for good planning

- A structure that improves communication between departments.

- A structure that prevents pigeon-holing.

- A structure that develops team spirit instead of creating little bosses' everywtere.

- A structure that allows for standards/norms in general.

\begin{tabular}{|c|c|c|c|c|c|}
\hline & & Retail & Souvenirs & Business/premium & Gifs/export \\
\hline Delivery time: & $\begin{array}{l}\text { Factory } \\
\text { Customer }\end{array}$ & $\begin{array}{l}0 \\
48 \text { hours }\end{array}$ & $\begin{array}{l}6 \text { weeks } \\
7 \text { weeks }\end{array}$ & $\begin{array}{l}6 \text { weeks } \\
6 \text { weeks }\end{array}$ & $\begin{array}{l}2 \text { weeks } \\
3 \text { weoks }\end{array}$ \\
\hline \multicolumn{2}{|c|}{ Delivery reliability: } & \pm 24 hours & \pm 1 woek & \pm 1 woek & \pm 1 week \\
\hline \multicolumn{2}{|l|}{ Quality $\overline{\mathrm{AB} / \mathrm{C} / \text { : }}$} & A & $\mathrm{B} / \mathrm{C}$ & AVB & A \\
\hline \multicolumn{6}{|l|}{ Cost structure: } \\
\hline \multirow{3}{*}{\multicolumn{2}{|c|}{$\begin{array}{l}\text { Acquisition } \\
\text { Whotesale/materiais } \\
\text { Processing costs }\end{array}$}} & 19 & 4 & 11 & 4 \\
\hline & & 67 & 25 & 44 & 44 \\
\hline & & 14 & 48 & 30 & 30 \\
\hline \multirow{2}{*}{\multicolumn{2}{|c|}{ Margin }} & 0 & 23 & 15 & 22 \\
\hline & & $100 \%$ & $100 \%$ & $100 \%$ & $100 \%$ \\
\hline
\end{tabular}

Figure 5.3 Functional requirements lor organisational redesign (Source: project documentation)

Bottleneck listing was most visibly used for starting up improvement projects, such as improving specific working conditions that have been annoying people for a long time, e.g., bad ventilation in the foundry as a result of plants growing on the roof of the shop. It involved considerable outlays on equipment such as hoods with extractor fans and flexible clenching arms. The production employees were invited to go to the trade fair and buy the equipment themselves. Apart from showing involvement and broadening the support base for the changeover, a beneficial effect was the improvement of communication. The various departments came into much closer contact than before, because they had to work together outside the daily routine. 

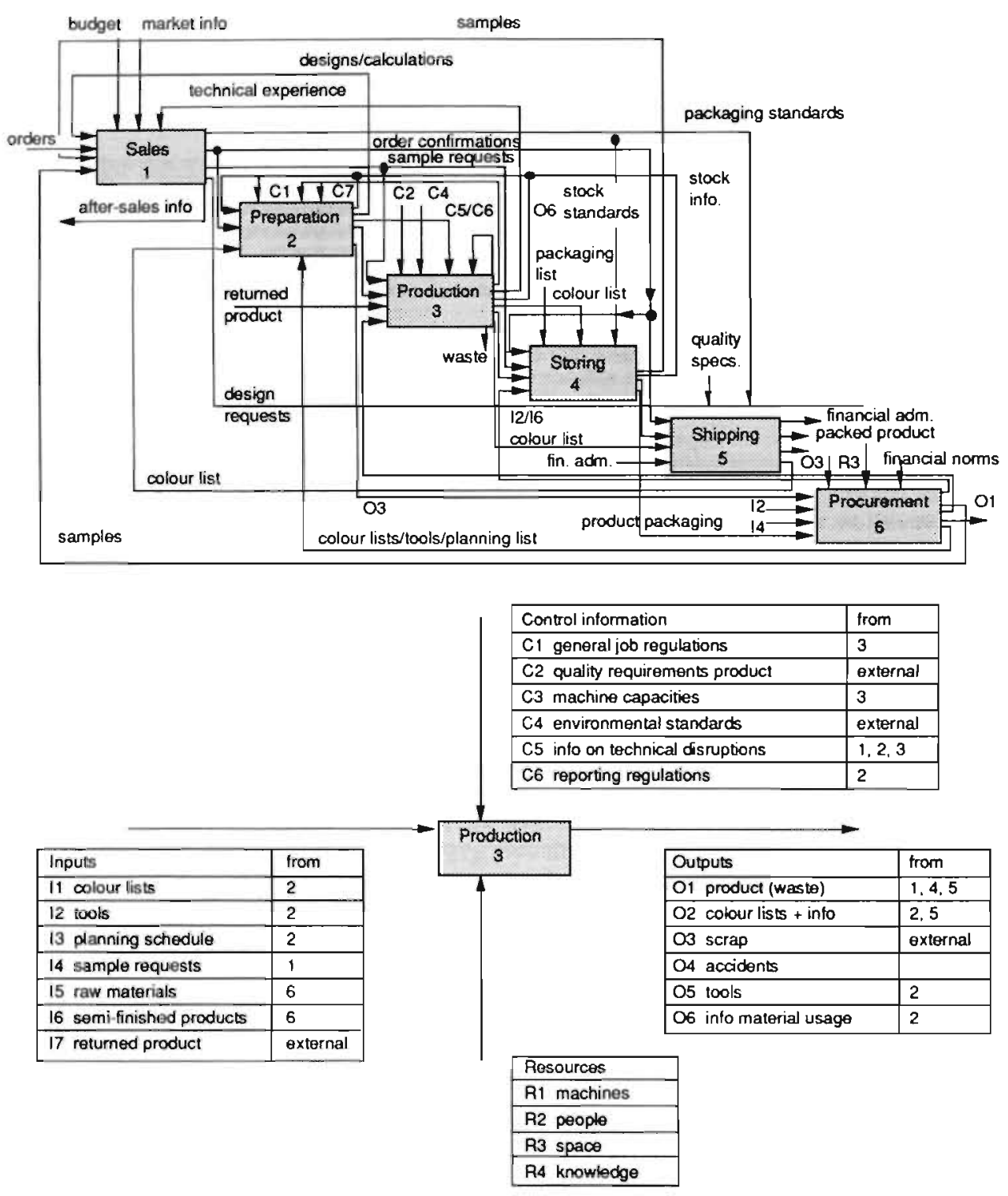

Figure 5.4 Model of primary process plus a SADT/IDEF subsystem exemplification (Source: project documentation)

By the end of 1990, a project structure was installed, the primary process was charted, analysed in terms of bottlenecks, and provided with functional requirements for the upcoming redesign, and the Board could be offered a general design. Meanwhile, some alternatives were considered on how to redesign production, for instance a structure according to batch size or according to manufacturing 
complexity, but none of these were found to be satisfactory. The main difficulty in choosing the best alternative was the delineation of tasks, because one of the goals was to improve interaction between the Sales department, which knows the signals from the marketplace best, and the Production department. In the final design offered to the Board, this point resulted in placing the warehouse under the responsibility of the Sales department.

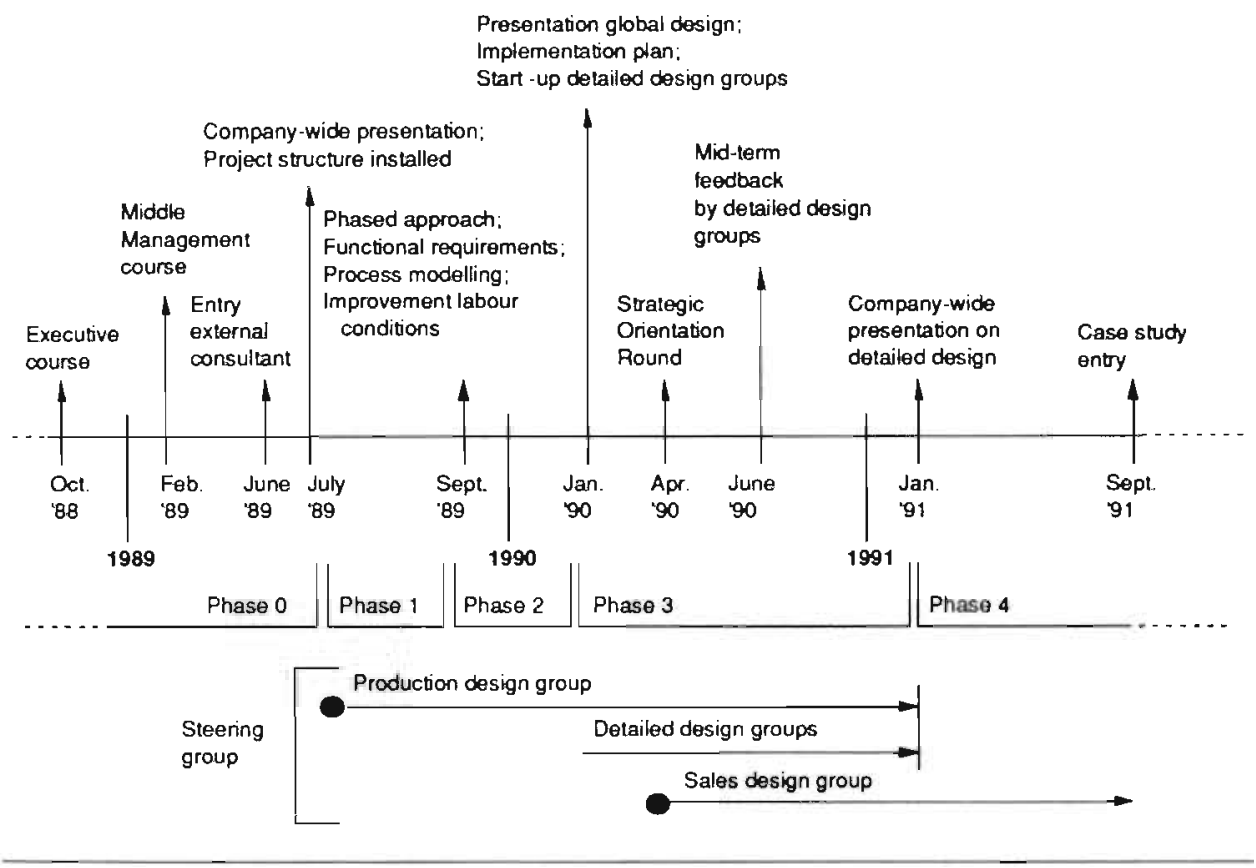

Figure 5.5 Timepath, main events and project structure ol organisational change

In January 1990, the general design was presented to the Board and approved. It marked the start of the detailed design work groups and extensive participation of all personnel. The design immediately resulted in an actual reform consisting of a primitive task group structure and flow-oriented production. The rest of the year 1990 was used to further refine this general design. Mid-term feedback implied the various work groups commenting on the assumptions and starting points employed by the overall design work group, thus providing a larger framework and a 'warming-up' on the design task. The linking-pin project structure was turned into reality as work groups were headed by the representative of that particular production part, who was also a member of the overall design work group. In fact, task groups turned out to become design work groups, thus bringing the change process 'into the line'. Design focus at this stage was on the upstream and downstream parts of the production process and on how linkages between parts could be established. This also included the first adaptations to the available control systems of, for example, inventory, order processing and registration. External assis- 
tance was provided here by consultants of the CWM, since Zilverstad was able to make use of their services at a reduced rate because of its membership. Typically, assistance was seldom called in; the state of affairs was regularly reported to the consultant from KOERS. Personnel acquired skills and knowledge at a high speed, doing things they had never done before: Providing feedback, making presentations, having meetings, and informing and relating to each other on how their design developed.

At the end of 1990, a detailed production design was ready and an implementation plan formulated. At the traditional New Year's reception in January 1991, the full design was festively introduced to all company personnel. Reactions of personnel were reserved, not negative nor resistant. Especially some of the jobs that had to be done in the task group were felt to be unpleasant, as they involved loss of status. For example, quality control is now done by the group itself, and it was something of a culture shock the first time a product was refused and returned to the responsible worker for additional treatment. In addition, nobody wanted to do the packaging as it was considered an inferior type of work. In other words, it took some time to get used to the full implications of autonomous work groups (in the first example, it was the woman that used to do the packaging who refused the product and returned it).

\section{The Organisational Redesign}

\section{Production Structure}

By January 1991, the final production structure was selected and ready for implementation. Based on the IDEF/SADT systems analysis, four autonomous task groups were formed. Three of them occupy themselves with manufacturing (blue, white and yellow), and one with the warehousing activities (green). The IDEF diagrams resulted in a general design which was handed over to the various work groups for detail and linkage (see Figure 5.6).

In fact, the warehouse group can be considered an 'inventory management group', since its task is to balance the wholesale and Zilverstad standard product inventories with demand. Its tasks include sorting, repackaging and order processing for wholesale products. The main reason for creating this group was, as it was experienced over time, that the wholesale and own standard products were overrun by the specialised customer orders. For example, the habit developed to manufacture standard products only when production slackened and there was time left, i.e., standard products filled the gaps in the production schedule. As a consequence, Zilverstad's own standard products were not available and often had an order backlog. In other words, Zilverstad was undercutting its own sales performance.

(Head of Administration) "... We deliver both on order and from stock. Then, it showed that customer orders always got priority over inventory orders. Because one order was for ourselves and the other just for inventory, it was never urgent. And you know, if things are not urgent, they don't get done. So if they have few customer orders, sales performance could drop. But if, in contrast, they produce on inventory when times are slow, that part of sales will be added to their performance since inventory and sales are the same thing. To them, it doesn't matter whether they deliver to the warehouse or to the customer: the internal transfer price values 
their sales turnover. So that's also a reason why you could say that they can influence sales; not directly, but indirectly all right."

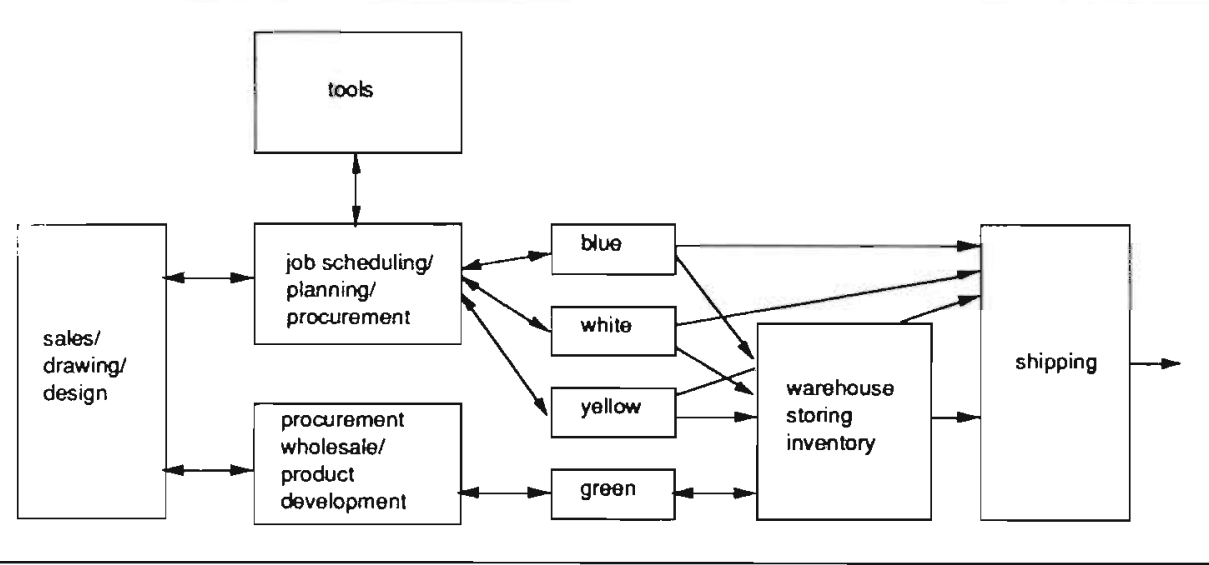

Figure 5.6 Global production structure design (Source: project documentation)

The warehouse group is separated from the factory and is placed directly under the Sales department. Presently, the warehouse group is treated in the production schedule as another customer, equalling both inventory and customer orders. The equal role of wholesale versus own products can also be derived from Figure 5.7: There are two inputs to the inventory function (the triangle in the picture) and the Sales responsibility domain embeds that of production.

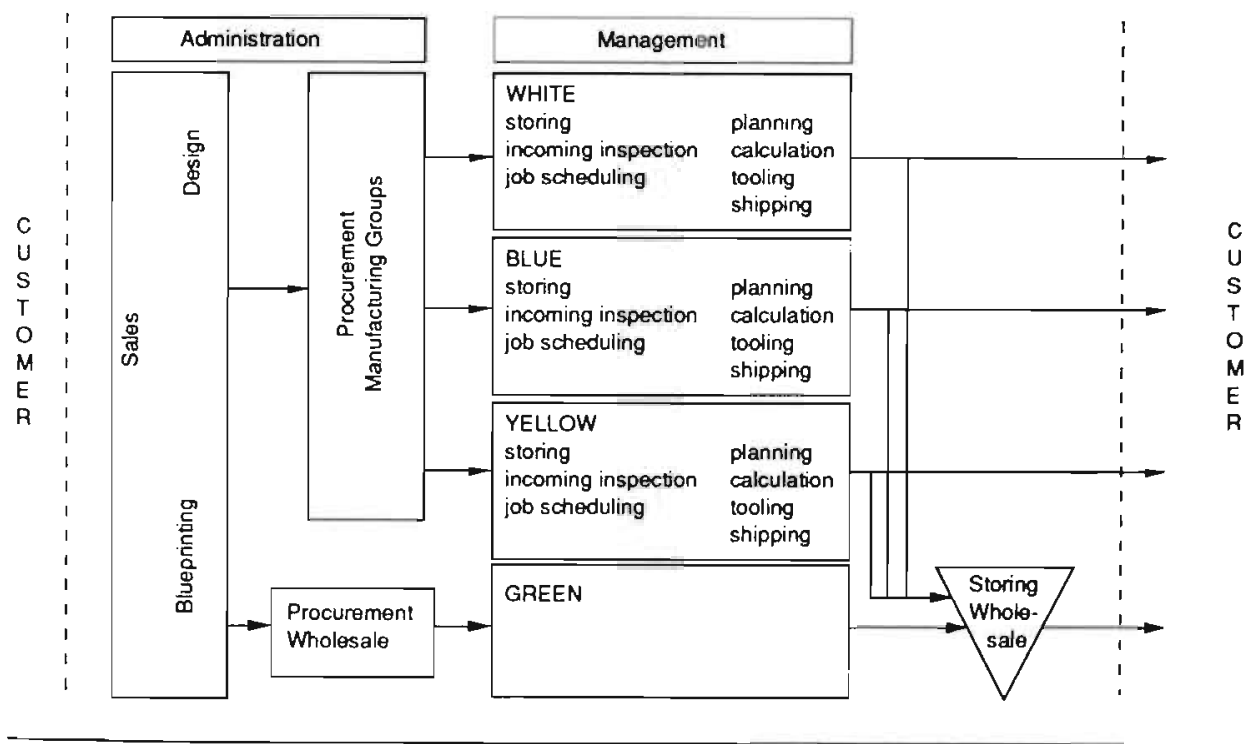

Figure 5.7 Production structure redesign (Source: project documentation) 
The detailed design of the production structure maintained the larger framework of the general design (see Figure 5.7). Comparison with the former production structure is impossible, as no production layout or process chart previously existed.

The 'White' group is made up of 14 people and manufactures so-called single products, i.e., products made out of one piece, and batch products, e.g., spoons and commemorative medals and coins. The 'Blue' group consists of 26 people and generally manufactures composite products in small batches, e.g., teacup holders and rattles for babies. The 'Yellow' group (see Figure 5.8) contains 8 people and also manufactures composite products in precious metal, in even smaller batches, e.g., silver miniatures, brooches and hallmark-quality decorative ware. This is the group where the fully experienced silversmiths are predominantly situated.

Several production typologies at the same time are available. From top to bottom, the order is in decreasing batch size: The White group manufactures the largest batches, mainly spoons, while the Yellow group manufactures the smallest batches, mainly jewellery. Next, the Blue groups has also input of semifinished products purchased in the Far East. The Yellow group is a full product manufacturing group and therefore has a somewhat different expertise buildup as well as a different way of working, including the craftmanships culture that accompanies it. Nevertheless, each production group is autonomous in terms of jobs: Planning, quality control and tooling are performed by the group (see Figure 5.8).

The detailed design is depicted for the Yellow group in Figure 5.8. It shows the operations contained within each task group, as well as its input and outputs.

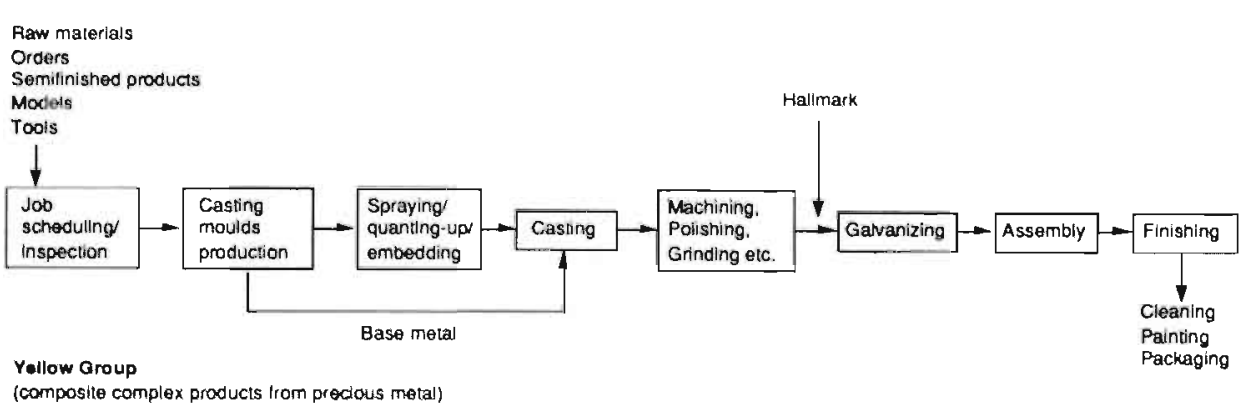

Figure 5.8 Internal organisation structure of a production task group (Source: project documentation)

Each group is headed by a group leader. Although circulating group leadership is intended, it is not as yet effectuated because there is not enough knowhow available in each group. Other than high quality and maximum employment of individual qualities, no explicit rotation target was mentioned in the preceding functional requirements. This was done deliberately, because its limitations were clear in advance. Some people do not want to rotate and view such demands as being 
threatening, while others simply do not have the capacities or qualificitions. Changes in the work included shared responsibility for tasks and the availability for various tasks. Group responsibility was the main argument used in the inferior packaging job example above - have all group members do packaging jobs. Availability, of course, is restricted to tasks requiring a short learning period on the job, learned from colleagues.

(Production executive) "Of course it is true that some difficult operations can only be performed by a few people who really know their business. It's hard to get other people to do this. You need time to enable all the people in a group to perform all sorts of operations. That's a next step in the process on which we're working right now. We're starting with training, job classification and all that sort of thing. Again, it's an example of taking up things we're able to handle. The process will never stop, you have to be inventive constantly."

Consequently, the task group structure resulted in a different responsibility structure in Production, replacing the functional foreman by flow-based units (see Figure 5.9).

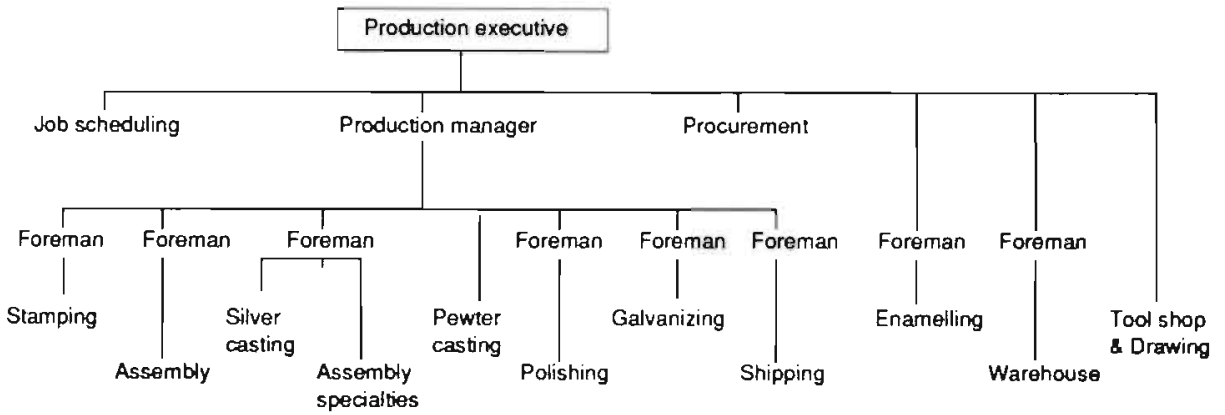

Figure 5.9 Former production organisation chart (Source: project documentation)

And the present chart of the responsibility structure:

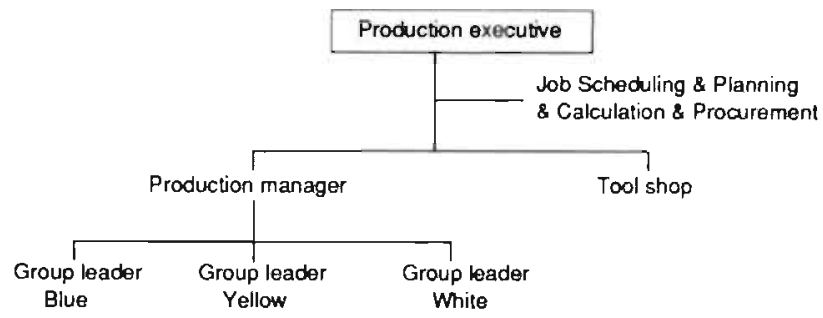

Figure 5.10 Present production organisation chart (Source: project documentation). The 'production manager' function is considered temporary and will eventually disappear. 
The drawing function is renamed 'design' and is coupled to Sales and brought upstream. Basically, because Sales generates the sample requests, Design has to draw and Production has to manufacture. Samples are important to convince the customer of the quality and appearance of the product and get him to confirm the order. The designer is located next to the job scheduler (which is a production staff function) in order to enforce preliminary planning and communication by proximity.

The task of higher management is to keep all groups together and have them act as one. For example, it is set up in such a way that a group which is low on orders assists another group. The 'assistance hours' are being registered and 'sold' to the demanding group using an internal transfer tariff.

\begin{abstract}
(Production executive) "Changing the organisation brought numerous other changes with it. The first one was the grouping of people. It meant a significant change for people. Previously, they worked on a manufacturing operation and now, they're working on a product. Work was something they did on their own in the past, and now they have to work together and in mutual agreement. This has to grow over time. For example, at the start there was clearly visible resistance to having meetings. People were saying to one another: "Do we have to go and sit around the table again; it'll cost me ages, all this blabbering." But by now, it has become clear to everyone what the use is of having regular meetings; one is able to say one's piece, people listen to you and problems get solved. Employees have far more responsibility in this group structure and it seems that they can handle it very well. A second important thing is that planning and job scheduling are made much easier and more precise. It improves your insight into the organisation and into the throughput of orders. You dare to look ahead, so to speak. Which was far more difficult in the earlier situation. A third point is that it is easier to deliberate on problematic matters. It improves with groups getting smaller. Solutions do come up quicker from a group. And because people are directly involved, they come up with workable solutions."
\end{abstract}

The overall organisation structure underwent a subsequent redesign. The former product market structure was replaced by a structure according to business function (see Figure 5.11), framing a combination of product market and task group typology.

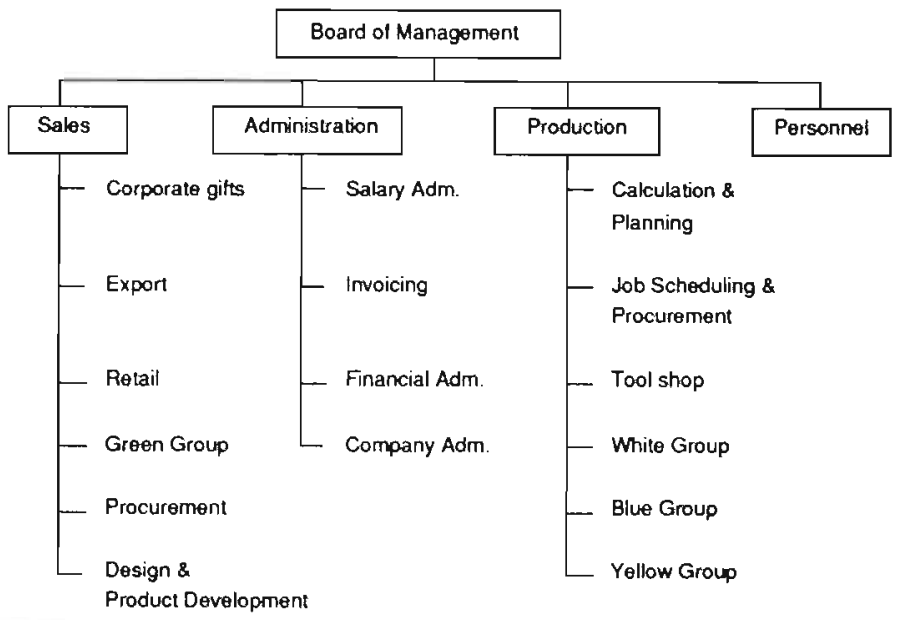

Figure 5.11 Present organisation chart (Source: project documentation) 


\section{Control Structure}

The control structure design can be seen as resting on two mutually supporting tracks, i.e., meetings and agendas. Both meetings and agendas form parallel links between the elements in the production structure (see Table 5.2). The primary process is supplemented with a combination of agenda-setting reporting forms and concurrent meetings in which this information is discussed. Three meetings annex forms support the business process:

- the sales meeting with the sales order ticket;

- the procurement meeting accompanied by the purchase order form, and

- the post-calculation meeting using the calculation ticket for agenda setting.

(Head of Administration) "... Well, you see, we make a difference between standard orders and special orders. And a special order always goes with a calculation ticket. If we make a product we've never made before or very rarely make, the group involved has to calculate it, meaning that they have to register the quantitative data. How many kilos of material do I use, how many hours does it take me, this department, that department and that operation take that much time, etcetera. Those data then go to Job Scheduling, which makes a proper calculation, tariffs get attached to it. As you have a new product, you have a new calculation. And consequently, it is put into a spreadsheet to have it available as a price when the product turns up again sometime in the future. Or if you manufacture it just once, it ended at that special order calculation; no further use is made of it."

Two other combinations of meetings and reports which are less related to the primary process are the product development meeting with its subsequent product development proposals, and the after-sales meeting which has filled orders as input.

Table 5.2 Control structure design (Source: project documentation)

\begin{tabular}{|c|c|c|c|c|c|c|c|}
\hline & Function & Goal & Inpul & Output & Agenda & Fraquency & Participants \\
\hline $\begin{array}{l}\text { Seles } \\
\text { Meeting }\end{array}$ & $\begin{array}{l}\text { Balance customer } \\
\text { demand with } \\
\text { manulacturing } \\
\text { supply }\end{array}$ & $\begin{array}{l}\text { To accept } \\
\text { sales } \\
\text { proposals }\end{array}$ & $\begin{array}{l}\text { Sales } \\
\text { proposals }\end{array}$ & $\begin{array}{l}\text { Realisable }(\mathrm{R}) \\
+ \text { nonrealisable } \\
\text { (non-R) } \\
\text { proposals }\end{array}$ & $\begin{array}{l}\text { Select, } \\
\text { priontize } \\
\text { and dacide } \\
\text { on } R \text {, non-R } \\
\text { and } R \text { ? }\end{array}$ & Woekly & $\begin{array}{l}\text { Sales reps } \\
\text { + all group } \\
\text { leaders }\end{array}$ \\
\hline $\begin{array}{l}\text { Procurement } \\
\text { Moeting }\end{array}$ & $\begin{array}{l}\text { Coordinate } \\
\text { purchasing } \\
\text { orders }\end{array}$ & $\begin{array}{l}\text { To purchase } \\
\text { elfectively } \\
\text { and efficiendy }\end{array}$ & $\begin{array}{l}\text { Purchase } \\
\text { proposals }\end{array}$ & $\begin{array}{l}\text { Purchase } \\
\text { ordars }\end{array}$ & $\begin{array}{l}\text { Select. } \\
\text { combine and } \\
\text { delivery ime } \\
\text { coordination }\end{array}$ & Woeddy & $\begin{array}{l}\text { Group member } \\
\text { + membet } \\
\text { Procusement } \\
\text { deparment }\end{array}$ \\
\hline $\begin{array}{l}\text { Post-Calculation } \\
\text { Meeting }\end{array}$ & $\begin{array}{l}\text { Enlarge } \\
\text { insight into } \\
\text { menutecturing } \\
\text { process }\end{array}$ & $\begin{array}{l}\text { Minimal costs } \\
+ \text { 'pure' } \\
\text { menulacturing } \\
\text { data }\end{array}$ & $\begin{array}{l}\text { Calculation } \\
\text { tickets }\end{array}$ & $\begin{array}{l}\text { Tested + } \\
\text { corrected } \\
\text { norns }\end{array}$ & $\begin{array}{l}\text { To evaluate } \\
\text { decisions. } \\
\text { correct yes/no } \\
\text { and how much }\end{array}$ & Monthly & $\begin{array}{l}\text { Manegement } \\
+ \text { group reps }\end{array}$ \\
\hline $\begin{array}{l}\text { Product } \\
\text { Development } \\
\text { Meeting }\end{array}$ & $\begin{array}{l}\text { Product } \\
\text { mix } \\
\text { management }\end{array}$ & & $\begin{array}{l}\text { Product } \\
\text { devolopment } \\
\text { proposal }\end{array}$ & $\begin{array}{l}\text { Mix } \\
\text { extension } \\
\text { of pruning }\end{array}$ & $\begin{array}{l}\text { To evaluate } \\
\text { proposals: } \\
\text { prune. take in } \\
\text { or don'l }\end{array}$ & Ouanerly & $\begin{array}{l}\text { Group reps, } \\
\text { Managomont } \\
\text { people kom } \\
\text { Sales and Design }\end{array}$ \\
\hline
\end{tabular}

Originally, it was meant to conduct the after-sales meeting as a separate meeting, but it turned out to be more effective to have it coincide with the sales meeting, which is more related to the primary process (Figure 5.12 ). The main reason was that improvement proposals go across functional boundaries. Since people from both Sales and from Production groups are present in the sales meeting, it could be 
coupled and simplified. The sales meeting was first created for internal communication between the four groups, but linking Sales to Production proved to be difficult:

(Commercial executive) "The only difficulty was to link up Sales with the factory. Of course, the thing we would have liked to do was to couple the sales representatives to each separate manufacturing group. But that's impossible, since a sales person can't just say to a customer when he is asked a question about products of a different manufacturing group: "I'm sorry, that's not my area of responsibility, you have to talk to my colleague about that." So we think it is necessary that the entire sales department knows about the complete product range. Meaning they would have to be knowledgeable about all products! An additional disadvantage is that the communication between Sales and the factory becomes less direct. We try to circumvent this by having sales meetings: people from Sales are present at this meeting with the Production groups. The weekly issue of orders is discussed there. As a result, a better understanding of each other's capabilities and impossibilities exists between the Sales department and the factory."

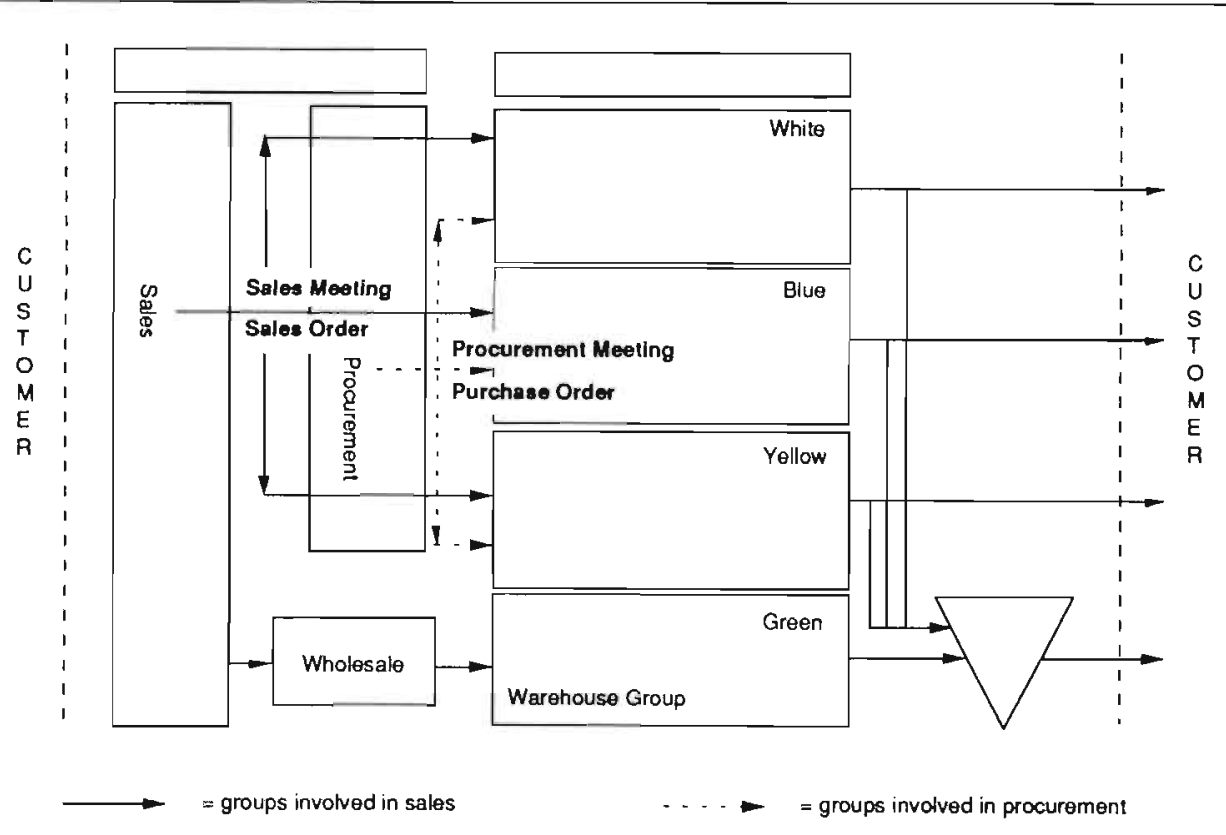

Figure 5.12 Controlling the order flow; linking Sales and Procurement to Production (Source: project documentation)

The goal of the after-sales meeting is to obtain insight into the customer's experience with the product so as to optimise and continue customer relationship. Management is also present at this meeting. The problems and improvement proposals that result from this meeting have somewhat the same function as the post-calculation meeting, which, however, is oriented more towards the business process, towards continuously improving organisational performance by solving incidental and structural market-oriented problems. 
A longer-term-oriented meeting, which requests the presence of board members, is the one concerned with product development and post-calculation (see Figure 5.13). Aptly referred to as the product development meeting and post-calculation meeting, they can be considered as a sort of control mechanism of both product mix composition and manufacturing costs. The product development meeting is held quarterly and discusses the various development proposals which are put forward on the product development ticket. If the product is technically and commercially feasible, it is supplied with a product specification and taken into the assortment.

The post-calculation meeting has the objective to enlarge insights into the manufacturing process. Management and group representatives discuss on a bimonthly basis the actual consumption of resources and the standards against which they are set. Calculation tickets are explicitly used to match standards with actuals and to come up with variances which are then used as input for discussion in the meetings. Discussing standards often implies discussing their own knowledge on how products are manufactured, i.e., results are improvement proposals based on cost efficiency. An alternative benefit which is targeted is the supply of up-to-date financial data for order bidding. Monthly discussion within the production groups of these calculation tickets is considered ideal but is at the moment of study not yet realised.

(Head of Administration) “... In the production groups, discussion takes place at management level. Which has to do with this being just a test year (= 1991); it is the first year we started with all this. We used the first couple of months to clean up the figures and to correct things which were not all right so that we can now work with the numbers. The next step is to have the figures discussed with the group leaders. And the step following that is indeed to discuss them within the group, but there are still some differences between people. Production people are even less used to dealing with figures than sales people. And that is not without significance. It has also something to do with education. The people in Production usually have vocational training only, or didn't even finish it. So you have to introduce things very slowly, otherwise people get jumpy or frightened."

After six months it was evaluated how the various new forms were experienced in daily practice. It turned out, according to the task groups, that no significant changes were needed. The layout of certain forms was changed, an additional form for warehousing was added and the job ticket used for scheduling and production operations was considered for integrating both commercial and technical product information. The specific comments and critiques received indicated, however, that the forms were used and understood in a production system by people not used to administration and documentation: It was something for the bosses to handle and they would know. Now, people speak up in detail.

\section{Management Accounting System}

The financial control system or management accounting system was put up in concordance with the information system, and therefore used the meetings and agendas as well. This regards all the meetings where group representatives are present, especially the post-calculation meeting since cost information is one of the primary inputs to this meeting (see Table 5.2). Although started as an outline, the accounting system gradually developed as the detailed task group design was implemented. It still is not finished nor is it expected to be ever finished; continuous improvement involves internal control systems as well. 


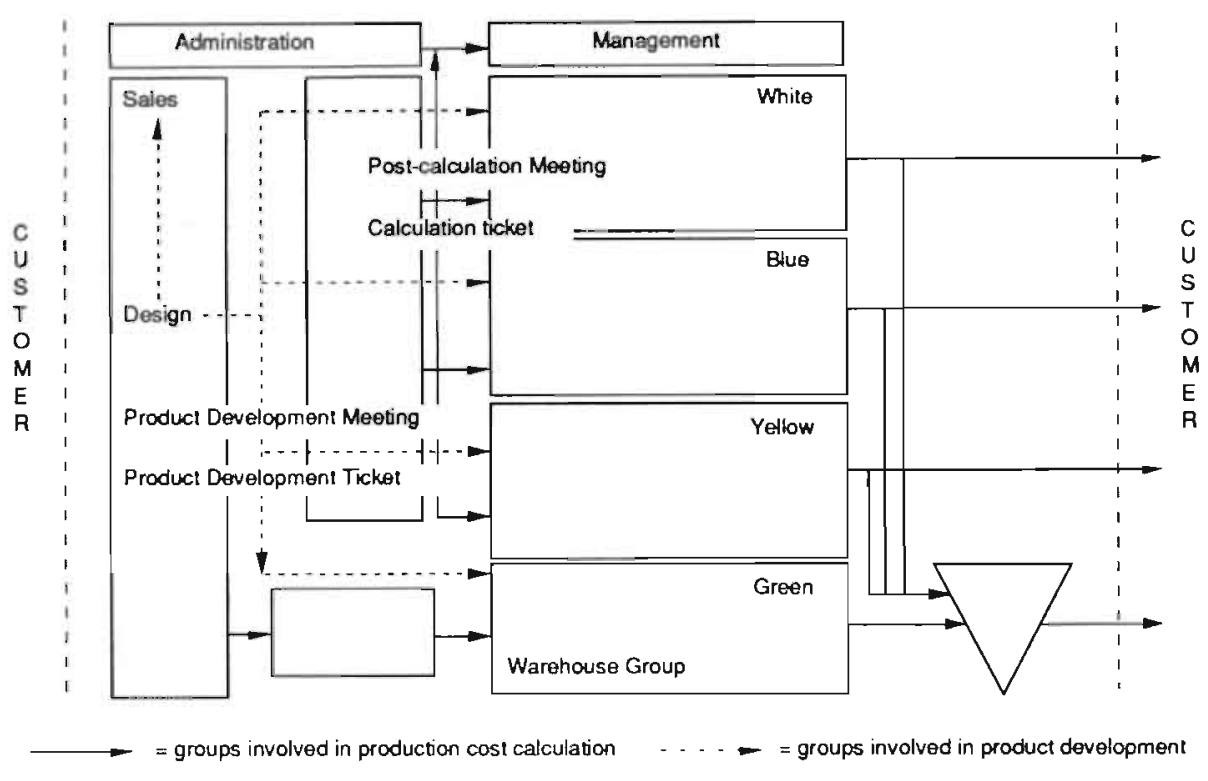

Figure 5.13 Controlling the order flow - linking Design and Administration to Production (Source: project documentation)

Compared to the previous internal accounting system, the present system is an upgrade as well as an extension of existing elements (see Figure 5.14). The toplayer of general ledger, and yearly and monthly budget is upgraded to the task group structure: Budgets, standards and tariffs are formulated on a task group denominator. The bottom-layer underwent a similar upgrading, rephrasing certain items in terms of task groups.

The mid-layer or group level in Figure 5.14 is where the main redesign effort is located. Previously, budgets where desaggregated only to functional departments as well as just to labour costs. Similarly, Sales was addressed as one diffuse department. The redesign therefore involved reconverting lump departmental budgets into desaggregated task group budgets, extending the budget content well over the labour cost item: Budgets are presently some sort of group Profit \& Loss statements, including detailed standards. As a result, budgets now serve also as planning devices in addition to their traditional control roles. The sequence of redesign followed that of the overall organisation design: Sales task group budgets were installed first, followed by those of Production. The linkage by an internal transfer price between the two was introduced last.

The overall management accounting system is a standard cost system based on budgeted standards and variance analysis. Standards for sales, inventory, transferred work and direct costs are set in the yearly master budget. Monthly reports at the organisational and task group levels match these budgeted standards with actuals. The net result is reported per group, both in financial numbers and percent- 
ages. It is also reported in a Direct Costing (DC) type format; a choice explicitly made to steer organisational behaviour towards margin optimisation rather than sales optimisation or net result optimisation (i.e., instigating a drive towards shcer volume or insightless cost cutting). The gross margin functions as a more stable behaviour modifier, because it takes account of the profit of an order relative to its sales price and its cost.

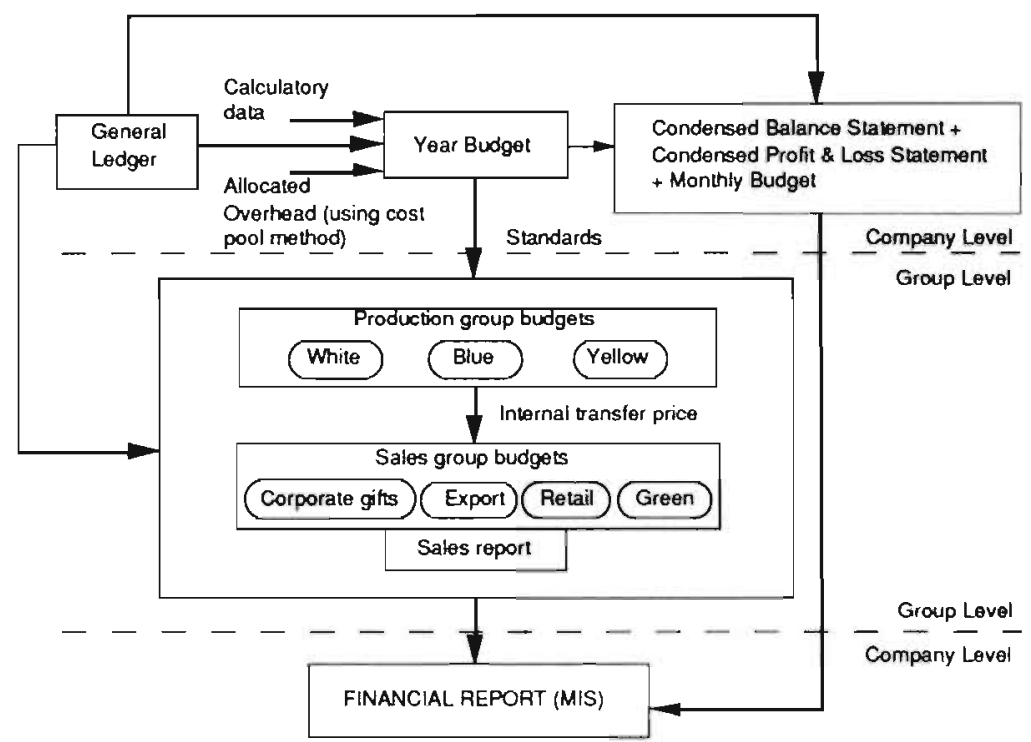

Figure 5.14 The Management Accounting System design (Source: constructed and approved, using regular internal documentation)

The root of the management accounting system is the yearly master budget. It sets the standards for both performance and costs, which makes it the building stone for the variance analyses used in steering at group level. Therefore, considerable attention is paid to constructing this control norm. Inputs for the budget construction are various calculatory data (e.g., depreciation and finance expenses, productive time) and the allocated costs using a cost pool table. Interesting in this respect is the role of the four production task groups as main cost objects: The task group is the central element in the financial control and information system. Manufacturing cost pools, which are organised by function in the process (e.g., stamping, casting or galvanising), are transferred into task group cost pools by the preceding production structure design; in other words, a functional organisation structure is replaced by a flow-based structure.

The general ledger feeds both the master budget and the group budgets; the production group budgets via the labour and material accounts, and the sales group 
budgets via labour, sales and administrative accounts. The use of task groups resulted specifically in the insertion of a group layer in the internal accounting system; it is 'sandwiched' between a top layer of precalculatory, ex ante standardised information and a bottom layer of ex post aggregated information. The top and bottom layer represents the company-wide information with a strong accent on traditional balance sheet and profit \& loss accounting information. In between, the control of results and the direct steering of processes is effectuated by a group-oriented reporting system.

The internal transfer pricing system linking up Production with Sales groups is a result of the flexibility design requirement. It fulfils three purposes: First, it measures output within the order flow so as to evaluate the manufacturing part of the process. Second, it provides production groups with standards for make-or-buy decisions that they have to make on whether or not to subcontract certain operations. Finally, the transfer prices are used as minimum costs in order bidding. Since Sales has to exist on the gross margin between factory sales price and full sales price, the transfer price hands them over a bottom-line figure on which they can break even. Sales does not use hourly rates themselves, they have to cover margin to make up their budgeted costs.

Management information is considered to be information at the organisation level spanning the full entity of the organisation. It makes use of balance sheet accounts which appear on reports at company level. The lower level budgets are to capture the manufacturing process in financial terminology, i.e., a vocabulary and disciplinary switchover within STSD.

The Head of Administration is the personified link between company level information and group level information, a distinction which is paralleled by the distinction between financial and management accounting information.

\footnotetext{
(Head of Administration) "On the basis of this budget (i.e., yearly master budget) the group budgets are constructed. And they are matched monthly with the costs and sales turnover of that particular month. So this is directed at management and group members, both actually, to have them communicate more with one another. It's an instrument really. The groups usually tell management they've had a really busy year and management for example says : 'it doesn't show from the figures'. It's usually an instrument to start discussing things since my experience is that financial information like this doesn't get used very often. You can beat about the bush a lot if you lack financial proof."
}

The cost pool table is used to obtain the tariffs used in order bidding and internal transfer pricing. Tariffs are applicable to both Production and Sales and are therefore called 'integral'. They are calculated based on labour cost per minute per task group. As customary when using the cost pool method, tariffs can be considered standard product cost elements. In fact, the use of the cost pool method matches a budget-controlled production since they are both standard cost system instruments.

Compared to earlier management accounting procedures, present use of the cost pool table reflects the task group build-up of the organisation instead of a split-up in functional departments. For instance, it resulted partly in allocating the toolshop and drawing department costs as part of sales overhead to be allocated to the 
various sales groups. With Sales being both directly responsible and accountable for customised orders, they absorb the cost of over-customisation (which results in excessive unique tooling and drawing).

Two other advantages over the existing method show. First, the calculation of tariffs for selting standard product costs is explicitly ticd to product movements between parts of the organisation. As each manufacturing task group has two tariffs, one internal for manufacturing and one for sales, it becomes possible to budget per manufacturing task group: The tariffs allowing for establishing the turnover of an individual task group. Therefore, individual task group output is always valuated, whether it is going via sales to the customer or to another task group for final operations. In other words, the performance of each process element (i.e., task groups) is available, not just the lump sum performance of the full process, resulting in better opportunities for process control and improvements.

(Head of Administration) "Well, the internal settlement of hours I already mentioned: It is taken into the group budget times the internal tariff. To give an example, in the Blue Group we make the assembled products, for example a baby rattle. But a rattle is stamped by the White Group: A rattle consists of two parts, both are being stamped, two cups which are soldered together. The product in a sense is made by the Blue Group, but the operation of stamping the two cups is performed by the White Group, so you have a sort of subcontracting. The White Group stamps and if they have to stamp something for the Blue Group, the internal transfer price is really turnover of White. And that's being taken care of in the sales of the group budget."

Second, sales performance of production groups can be more adequately judged as sales volumes are stated per task group (Figure 5.17). In other words, production output is also individualised in terms of what has been sold, tying production directly to the outside market. Therefore, market fluctuations and customer preferences are almost immediately felt by Production, setting their mind more to what happens outside the company.

The group budget is the most essential element in the financial control system since it is used by the group leaders to steer their operations (Figure 5.15). In this monthly group budget report, all cost items are included, not just those items which are assumed to be of relevance or discretionary to the group leader.

(Production executive) "Each group has its own budget. They're a kind of small companies within the company. And people run it like it is their own company. As a group, people say: We are responsible for our orders and that group has to take care of itself."

The key item on the budget report is gross margin. The two constituting parts of gross margin, sales and direct costs, are relatively controllable for the group leaders. Direct costs (mainly materials), contracted work and inventory mutation are directly influenced by work efficiency decisions regarding in-group job scheduling and contracting out some operations. Sales can only be indirectly influenced, either by balancing output by switching between manufacturing on order to manufacturing on stock and by manufacturing high-quality samples for the sales groups.

(Head of Administration) "For sales turnover, the group leader is depending on Sales. However, that's only relative. Previously, our philosophy was: Production cannot help it if they don't have anything to do. Because Sales is responsible for selling. But if you think a litthe bit longer about that, it becomes fairly relative. For instance, the Yellow Group performed very badly last year, not good at all. And in the beginning of the year, we received a large re- 


\section{Chapter 5}

quest for pendants. But it needed a sales sample to make it a full order. And because the Yellow group made a really nice sample, the order was awarded. So indirectly they can influence their sales turnover by tuning themselves to Sales, by empathising with what product a customer wants. Usually when Sales came up with a sample request, the reaction was - Not Sales again, they have to have one item of everything, that's troublesome. Samples are troublesome. But if you explain that you can only get orders if you make sharp quotes ... And when do you make sharp quotes? By adding a sample, or make a good blueprint. People no longer buy automatically. You have to show them something, convince them."

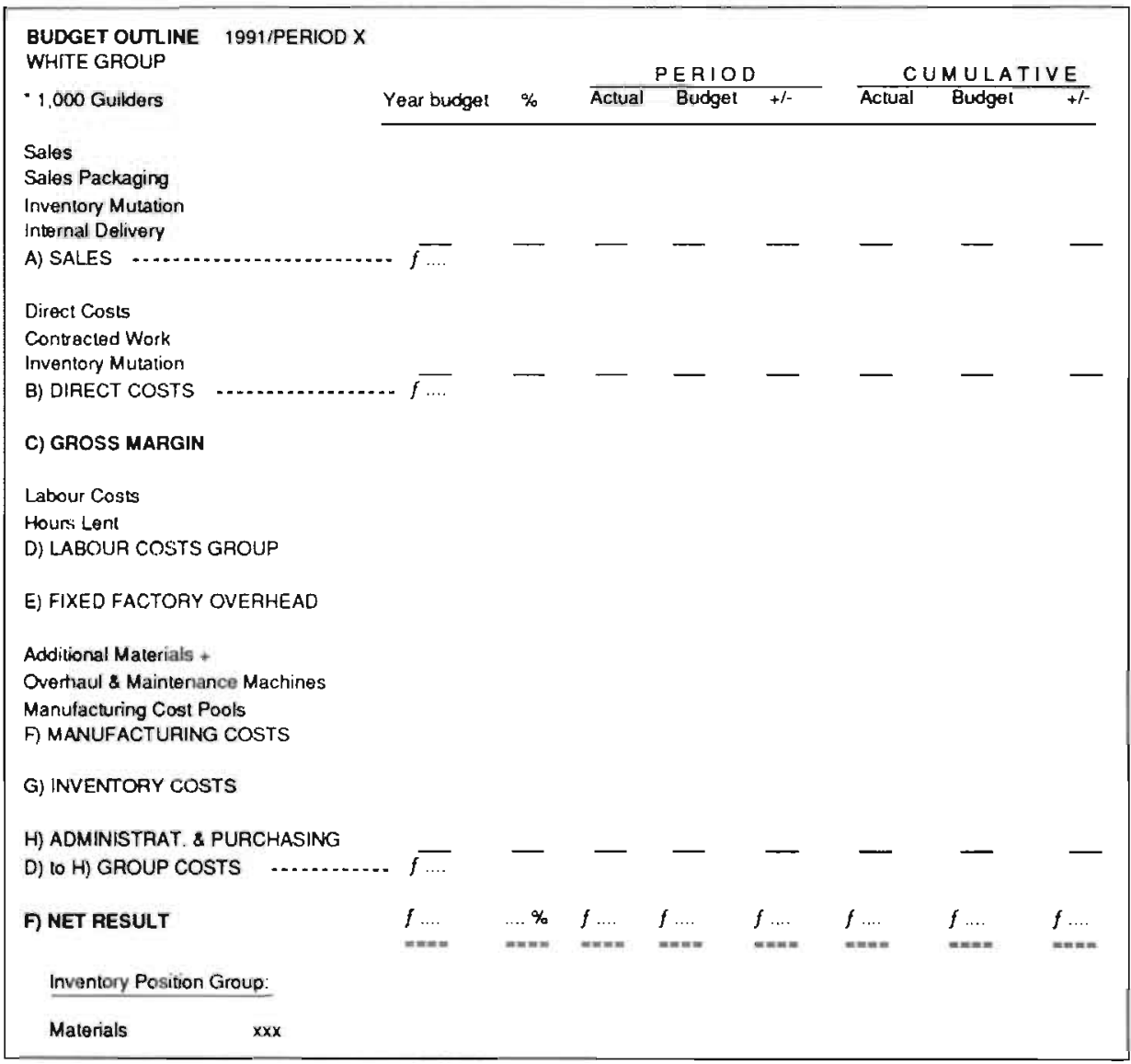

Figure 5.15 MAS design key item: the production group budget (Source: regular internal report)

The fixed costs, or group costs as they are called, are more long term. For example, group labour costs are fixed costs at group level. Suggestions for investments in equipment and machinery used in that group are reflected in this budget item. All other fixed costs are fixed at plant level and allocated using various indirect cost pool tariffs. Thus, budget build-up represents both discretionary annex controllable costs at group level and group performance in a direct costing format. 
Budgeted figures are matched with actuals, indicating variances per reported account both periodically and cumulatively (see Figure 5.15). Discussing variances is the explicit goal of the Post-calculation meeting taking place between and within groups. As indicated earlier, these meetings are structured around the Calculation Ticket which states the allowed and actual order costs in terms of materials, manufacturing time, scrap and waste.

The internal transfer price is a sort of 'factory sales price' bringing the order from Production to Sales and at the same time indicating a turnover performance per production group. The margin between the 'factory sales price' and the final sales price is indicative of the sales groups to steer their performance. The structure of the product cost almost runs parallel with the group structure: Manufacturing costs of an order can be easily traced to individual task group, including internal subcontracting, thus providing the means for cost control and performance measurement at order level.

(Head of Administration) "We start with the material cost which we then add up with the production hours used, we call the result the factory sales price. That's really the internal transfer price, groups have to be able to exist on that internal transfer price, they have to be able to manufacture within that cost. The next step is the gross sales price. And the difference between gross sales price and internal transfer price, that's the margin for Sales and that's what Sales has to live from."

For long-range planning the present instruments are the monthly sales and financial reports (Figures 5.16 and 5.17). They compare actuals with cumulatives as well as with periodic figures (last month and last year), both in percentages and in numbers. These reports are constructed at the company level and contain aggregate group performances.

(Head of Administration) "These (i.e., production and sales group budgets) are four respectively three periodic reports, and the monthly performances have to be in concordance, have to match the financial report. It would be rather strange if all groups would perform positively, and financially we would lose money; the connection would be lost. So it is done deliberately to control the coherence in performance. In fact, this control is established outside the formal book of accounts. But what is most important is that the end-of-the-year results are expected to be in line with the constituting results of the groups."

The sales report finalises overall group performance by presenting information based on the four production group formats but now solely indicating items such as sales, order backlog and various standards (budget, percentual, temporal; Figure 5.17).

Furthermore, in the sales report three article groups are mentioned separately: the article groups 2 and 3, silver-plated articles and packaging. Article groups 2 and 3 and the silver-plated articles are products made in the Blue Group, which is both the largest and, technologically, the most complex group. Separation of the three articles is done for two reasons: First, it is a historical demand from Sales to have them reported separately: Secondly, group 2 and 3 articles are fully manufactured while the plated articles are purchased as semifinished products elsewhere, with Zilverstad having only to perform the plating and finishing operations. Packaging is usually included in the product line and therefore the production group statistic, but for reporting reasons mentioned separately in the sales report. 


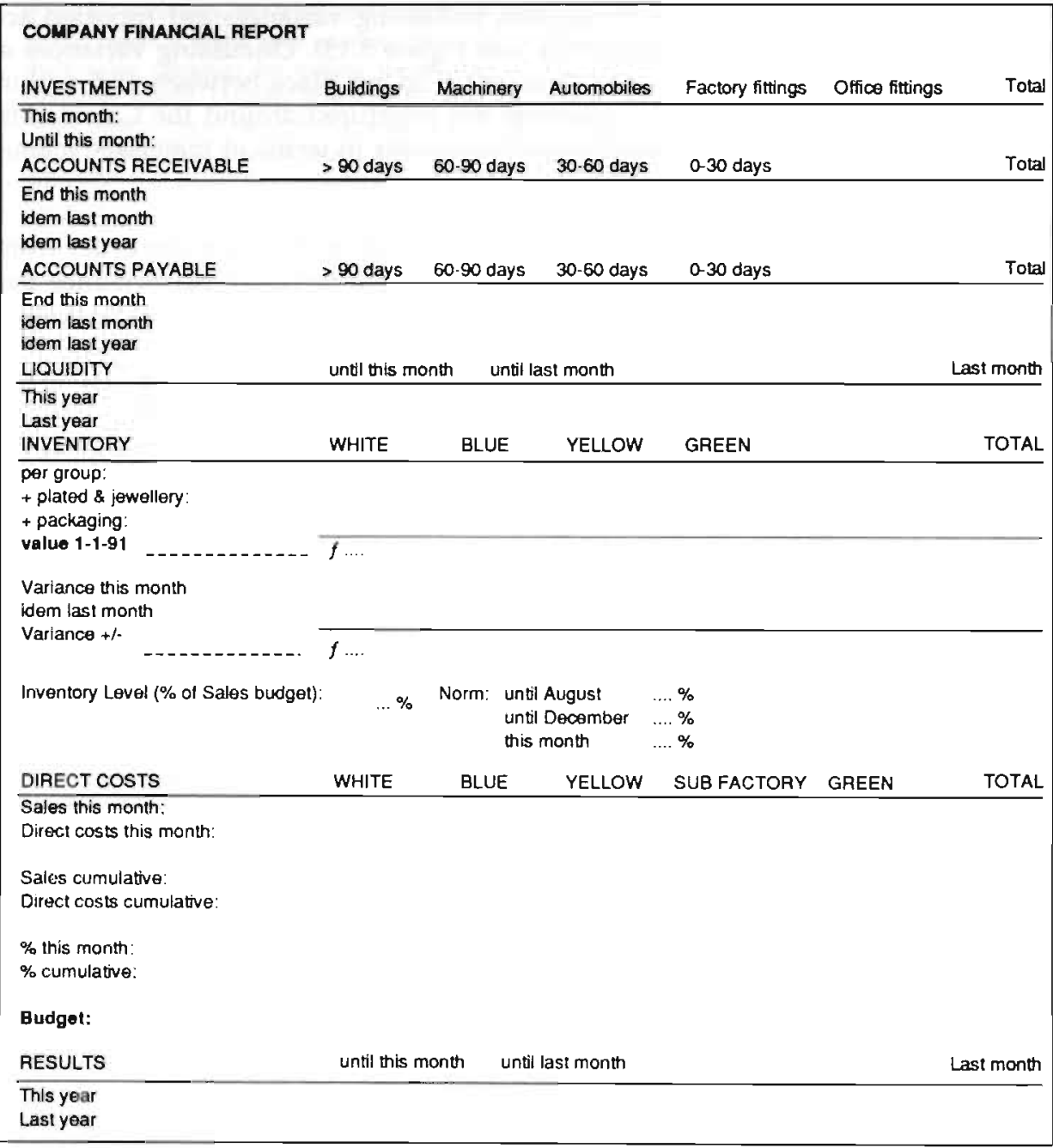

Figure 5.16 Company financial report (Source: regular intemal report)

The budget for a sales group is somewhat different in set-up than for the manufacturing groups (see Figure 5.18). It has an identical DC format and is reported according to product market combination: for corporate gifts, retail and export. A sales group largely coincides with a certain product market combination. Additional is the itemisation of gross margins per sales representative in each group as well as the inventory position which has become the responsibility of Sales (bottom-half of Figure 5.18). Sales groups also provide the basis for longrange product mix and business planning, being the organisational unit most familiar with the specific product market combination. 


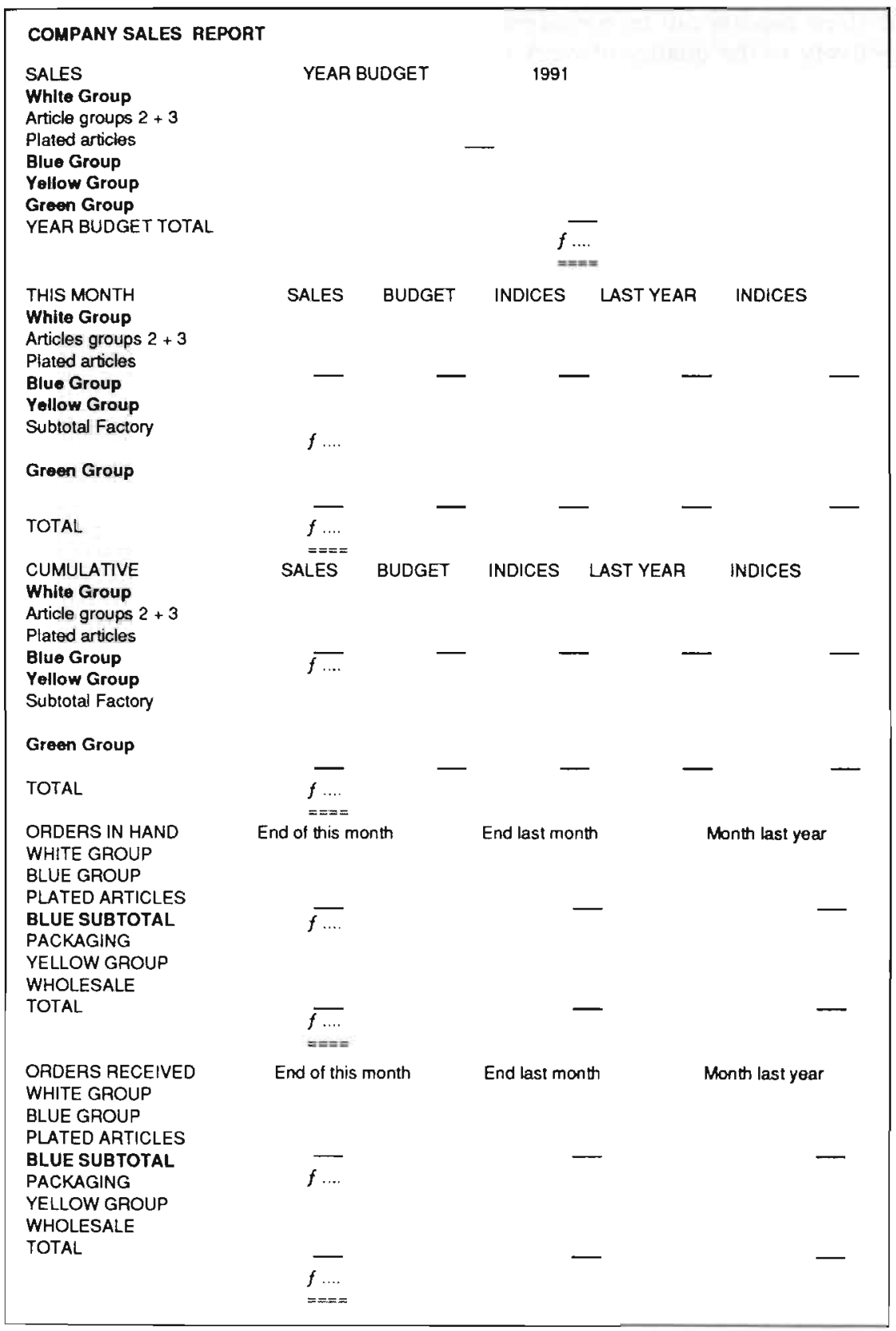

Figure 5.17 Company sales report (Source: regular internal report)

Additional operational information is reported stand-alone and in nonfinancial terms. It comprises such items as sick leave, delivery reliability and internal failure costs measured by the number of reversed sales bookings. In fact, all these 
stand-alone reports can be considered as quality cost information with quality tied respectively to the quality of working life and the quality of the organisation. The latter is more narrowly defined in terms of Just-In-Time performance, e.g., delivery reliability is measured by comparing the deviations in weeks (to the present and last year's figures) of the number of orders either delivered too late, on time and too early.

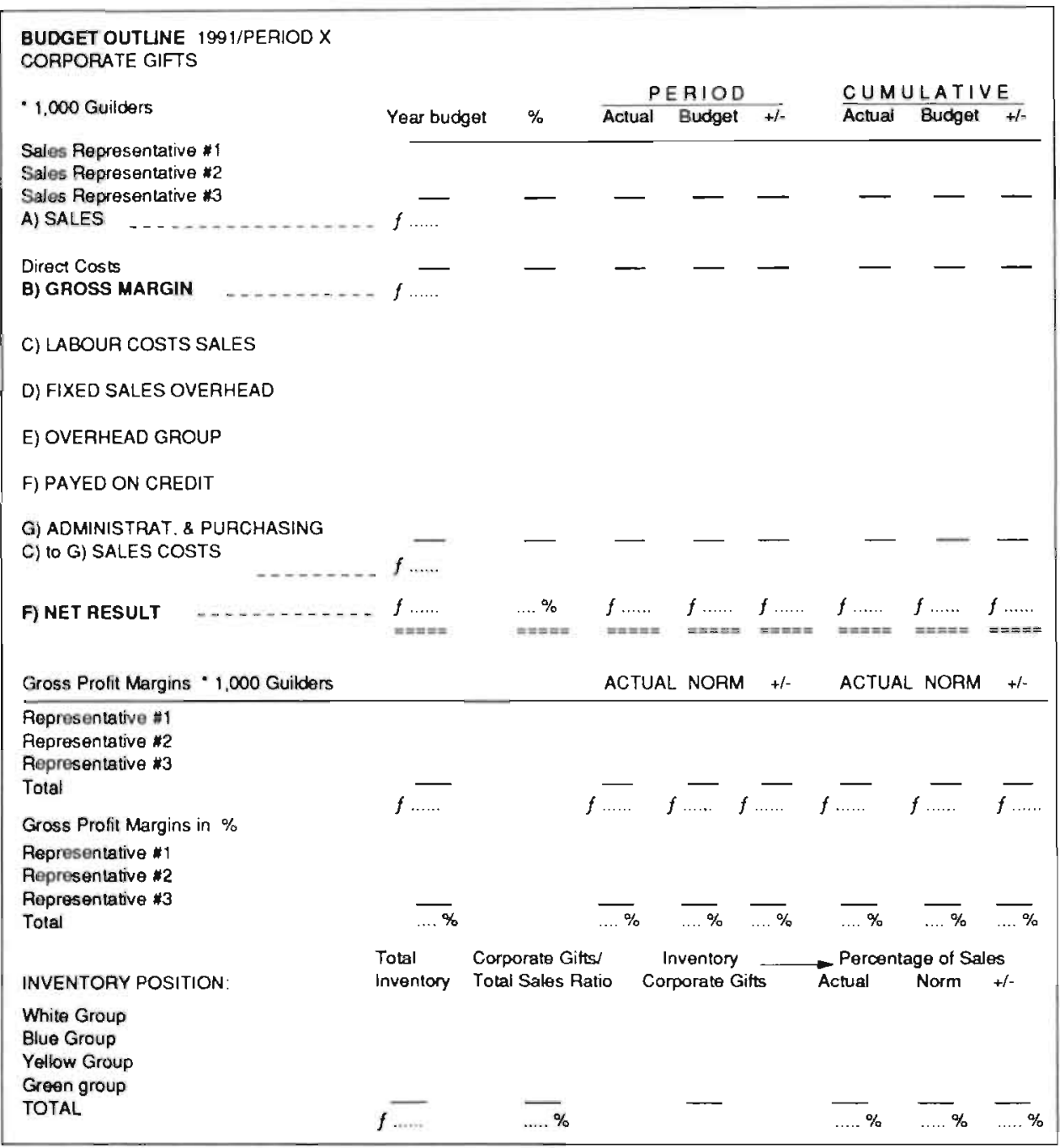

Figure 5.18 Sales group budget (Source: regular intemal report)

The internal failure costs in terms of reversed sales booking were analysed on what caused the failure. Eight categories are used to this extent: product quality, inventory mistakes, administrative mistakes, sales mistakes, invoices on samples 
and consignments-on-approval, service, factory mistakes, and miscellaneous. Norms to this nonfinancial information are not yet introduced nor will be because it is felt that a straight count of complaints is sufficient to steer on.

Quality is traditionally defined in terms of craftsmanship and materials used. Quality perceptions of customers, however, stand in sharp contrast with this craftsmanship's definition, which is the reason why an extensive use is made of samples and consignments-on-approval: To set product quality norms almost on a per customer order basis.

\section{Results of the Redesign}

As Sociotechnical redesign inherently links improving efficiency to the framework of a (more) effective and reshaped organisation, results are first and most clearly noticed at the efficiency level.

(Production executive) "There have been many results up until now. Of course, one cannot express a number of things in hard figures, for example the involvement of people, their attitudes. Still, I think that is the most important change, which results afterwards in figures."

Cost control and cost traceability have increased considerably. There is increased insight into product cost build-up and the causal factors driving costs, as the MAS design matches the organisational processes more closely. The relative simplicity of the design and the full participation of group members in designing it are mutually dependent factors. Responsibility in designing it seems to make it easier to have the responsibility accounted for.

In terms of hard numbers, Zilverstad improved its sales by $15 \%$ in 1989 , while at the same time experiencing a reduction in personnel of $5 \%$ (natural turnover). Inventory turnover in 1989 was 4.7 and 5.5 in 1990, with a norm of 4.0 for the industry. Absenteeism (sick leave) dropped to $6 \%$, which is below the Dutch average of $9.1 \%$ (1989). Furthermore, the number of complaints on product quality dropped considerably. Another indicator of quality is the number of orders delivered on time. In 1988, operating in the former organisation mode, delivery reliability was $40 \%$ (three out of five orders went wrong somewhere somehow). In 1989 it increased to $60 \%$ while in 1990 , it increased even more and is now reaching $85 \%$. This percentage relates to the busiest time of the year, i.e., the fourth quarter, which is the gifts season. A by-product of the improved delivery reliability was a reduction in orders that were delivered in different batch sizes; most orders are now being delivered in one single batch, thus saving extra shipping costs.

(Commercial executive) "It results in customers staying customers more easily. We get many repeat orders. So all the energy you put into customer acquisition you direct at getting new customers instead of replacing them. Price adaptations are hardly necessary since the organisation has improved and we are able to supply much better quality, service and delivery times for the same price. Our competitive position has markedly improved, also internationally. All segments have done well. The sales department has less internal problems to solve and, thus, can concentrate far more on its commercial activities. Of course, we've just been operating this way for nearly a year so the effects are still young. 
(Production executive) "Of course not everything can be accounted for by the organisational change. There are many other factors, for example the dollar exchange rate, the economic climate. Or one Saddam Hussein spoiling everything. You can be perfectly organised but if you don't get any orders ... On the other hand, it is also true that you can't get any orders if you don't have a well-organised company. It's a bit a question of which came first, the chicken or the egg."

No additional investments in assets were involved, apart from a one-time-only outlay for equipment to improve working conditions.

\begin{abstract}
(Head of Administration) "Yes, and for the rest: working conditions - we've spent a bit more on the costs for working conditions than we had the last couple of years. But those costs don't get any lower because for people to perform well they need a good PC, a good terminal, chair, etcetera. And that's of course a very natural thing because these are really legitimate demands and they spcak up far more easily when they take the initiative to purchase or replace something. But again, that's all right in itself but nevertheless it does lead to higher organisation costs."
\end{abstract}

A more structural increase in cost level is initiated, however, regarding personnel and human resources. The accentuation of group initiatives and the decentralisation of problem solving has made people aware of both their abilities and capacities and, consequently, of the value they represent for the organisation.

(Head of Administration) "Well, I think personnel costs tend to increase. Putting more demands on people or on groups is coupled to an overall performance target. By the end of the year, they know whether they've attained their group performance or not. And you try to steer it in that manner, which has consequences for your personnel policy. If you ask a bit more effort from your people, and if they perform accordingly, they'll demand more regarding salary conditions and payment. Also, people become more important for the organisation because if pcople drop out, if you end up with fewer puople, and certain key personnel in a group drop out, it can be quite harmful. So people, if they perform well, do become aware that they have gained importance for the company. But that has to do with the subject of personnel policy in the organisation. That's what we have picked up lately, putting up a job classification system and kevping appraisal interviews."

\title{
Projects Underway
}

At the time of study (September 1991) two main projects were put up and partly implemented: one regarding a job classification system and another regarding a sales information system. Both systems are the consequence of an increased effectiveness of the organisation: the accentuated role of human resources (e.g. local problem solving and multi-skilled personnel) requires proper management of jobs, rewards and personnel development (e.g., career planning, training). Also, enabling people to solve problems and structure their work themselves means they have to be supplied with the information necessary to do so. Information which crosses functional boundaries as do task groups: The sales information system therefore links Sales to Production and vice versa. Apart from it being necessitated by the redesign itself, putting up a sales information system was also a consequence of the Strategic Orientation Round (SOR): One of the outcomes was the awareness that very little information was available on the results of marketing and promotion efforts, sales performance and market conditions. 
(Head of Administration) "Well, our main bottleneck lay within the company. We were glad that we had the time to look outward for once since before we had no time at all. As a manner of speaking, of course, because Sales still passed on the signals what the market needed, they come up with proposals. Yes, we've always been a bit in a pioneer phase in which you look more at your internal problems than really at the possibilities in the market. You react to market signals, which of course makes you flexible."

The job classification system is adopted from the industries employers' organisation CWM. It distinguishes a number of ranks which are distributed across task groups and additional departments. Rank position is assessed using a score card for seven job elements constituting each job (education/skill, composition, organisational damage risk, interaction frequency, working conditions, nature of supervision and range of supervision); a high score indicates a high job class. Linked to job class are payment, secondary conditions such as study grants and study leave, and a development track for individual career management. On the other hand, if people did not want to go along with the general trend towards multi-skill and availability for various tasks, they would 'freeze' at their present job class level with all resulting payment consequences. Human resource management is embedded in a general social mentality and policy which is not officially formalised or written down. The family business character of the company is the main feeder of that mentality: The Pluut brothers maintain, however, more an executive than owner/employer role, which has led to a professionalisation of Zilverstad's social policy. For instance, at the very start of the reorganisation process it was decided that no one was to be fired, in fact it was one of the design requirements of the production structure.

The sales information system is in its operation a marketing system indicating which customers are the most profitable ones and which products are high-runners. Specifically, it is a database system providing the raw data for order-bidding information, customer profitability and the dye database used in production (it is important for Production to know whether a specific order will require the manufacturing of a new, customised dye, or if an existing dye can be used). However, as Production is fed by customer orders it establishes a link between Sales and Production based on sales information paralleling the order flow through the factory. And again, it provides a concrete basis for discussion between the two business functions; a market preference for a certain type of product leads directly to more work for the task group manufacturing those products. In other words, floworiented production has its equivalent in Sales, stated, however, in terms of product type. This 'pre- and past-production trajectory' is fed by the sales information system which links up with the sales orders used for production planning and job scheduling.

(Head of Administration) "In fact, it comes down to registering all sales actions in the sales information system, including everything that influences the customers' purchasing behaviour. And to take advantage by calculating and finding out which product offers are successful and which are typically not. You try to gain insight into how to bid for orders at a particular customer; which products score and which don't. All that has to be incorporated into some sort of sales information system, which the sales groups can use in their daily operations." 


\section{Case St. Antonius Vesselheads}

\section{Situational Background}

St. Antonius Vesselheads, Maasbracht, is the manufacturer of heads and specially formed parts for pressure vessels and pipelines. They are the subcontractor to Official Equipment Manufacturers (OEMs) in the petrochemical, energy, storage and food industries. The company's specialties are formed heads and cones for pressure vessels, manhole covers, expansion joints, reducers and bends for pipelines. Expansion joints and reducers are sold to the machine industry using installation companies as the intermediating channel. Of its production, $70 \%$ is being exported with the main markets being Belgium, Germany, France, the United Kingdom, and Scandinavia. All products are made to order, according to customer specification. The average order size is three products.

Since most products have to meet high-quality requirements - consider, for example, orders from the nuclear, off-shore and satellite industries - quality control and quality assurance are of prime importance (tolerances of 0-2 millimetres on diameters of 5 meters are quite usual). The large export volume further complicates quality management since St. Antonius has to comply with various construction design codes and regulations. This implies a quality assurance system that is able to handle and control many quality standards and national regulations. The quality assurance system is based on ISO $9002 / 9004$ and BS 5750 norms. The input variety is also heavily influenced by the high number of various materials used: $70 \%$ of St. Antonius' products are made of nonferro, duplex or stainless steel materials. Again, this poses specific demands on production methods such as the choice of the appropriate welding technique.

St. Antonius is a small-sized company employing 140 people with a net sales in 1989 of 20 million Dutch guilders and an added value of 63\% (1989, in percentages of net turnover). Added value is defined as labour cost turnover plus profit, excluding materials. Its EBIT in percentages of equity is about $36 \%$ (1989). From the 140 employees, 97 are working in production. Seventy-six people are direct personnel, which leaves an direct/indirect personnel ratio of almost one to one (76: 
64). St. Antonius' cost structure is mediated by the tariff system it uses: All overhead is allocated to subdepartmental work centres and their subsequent tariffs. This does not show up as separate cost figures to be assigned (see paragraph on management accounting system for a more detailed discussion). Reworking the figures results in a general, nonmanufacturing overhead of $7.6 \%$ of total planned costs.

St. Antonius is a family-owned and family-run company wherein engineer Jacques J.A. Houben took control of the company from his father in 1986. Previously, the culture of the company was one that was highly informal and where many things were improvised. The working method was based on individual craftsmanship and personal relationships, with the owner-president performing a central role in the social network. At present, this culture is being replaced with a more business-like one: the new culture disseminating top-down into the organisation. The change in control indicated a shift in management as well as in operating style since the need for change became more and more imminent: A clear business strategy was lacking, and ad hoc decision making and inadequate order planning caused many problems. Furthermore, its OEM market increasingly strengthened their demands for quality, timeliness and delivery reliability.

As a reaction, it was felt that 'more organisation' was needed. To start with, Houben jr. began to hire additional personnel who were to form a new and professional management team. This involved hiring a central planner for the Production department, a quality assurance engineer, and a financial controller who was also to establish a personnel policy. Included in this team was the production manager who was previously involved with introducing CAD/CAM to the firm, and the controller. These two later went on to become the STSD programme champions. The new management team consisted of relatively young people in their mid-thirties. Together with Houben jr., they were to take care of the day-today business and the development of company policies and standpoints on several areas of interest. This was not an easy job as a hotchpotch of affairs were all screaming for attention and, as a result, they had no idea where to begin.

Contact was made with the Dutch institute on Quality of Work and Organisation (NKWO), with the Dutch contact group for Employers in the Metal industry (CWM) functioning as an intermediary. The NKWO introduced SocioTechnical Systems Design ideas to the management team and middle management in two separate courses. The middle management course, called Partaking in Renewal, ran for nearly one year, from September 1988 until October 1989, and was joined by all middle management. Afterwards, it was concluded that this course came too early. It would have been more accommodating had it been scheduled after the design phase. People were now becoming anxious to start, although the strategic line had not yet been established. The timing was unsuccessful here because the information of the CWM was unclear and the management team of St. Antonius had no idea how big this change would be. It was only afterwards that they became aware that this was a full-scale reorganisation.

The second course was directed at the management team and was called Quality and Flexibility for Small and Medium-sized Enterprises, also by NKW(). As a result of these two courses, SocioTechnical Systems Design (STSD) was adopted as a 
leading concept. Later, middle management $(1991,1992)$ took part in several other training courses, whose main concerns were social skills such as presenting/speaking in public, chairing of a meeting and conducting personnel interviews.

The course for the management team was concluded by constituting a plan that clearly stated the subsequent phases of (see Figure 6.1 for chronological order):

0) the strategic orientation round plus preliminary discussion (January $1989+$ March 1989);

1) formulating functional redesign requirements, including process modelling and bottleneck categorisation (March - May 1989);

2) design and evaluation (June - September 1989);

3) elaborating the organisation model, including the presentation to the company (October - November 1989);

4) implementation process (December 1989 - present);

5) freezing process, directed at creative cooperation between and within groups, e.g., performance interviews, team management, effective leadership (last part of 1992).

The plan was drafted by both the management team and middle management and implied a strong commitment to the new organisation that was to be constructed.

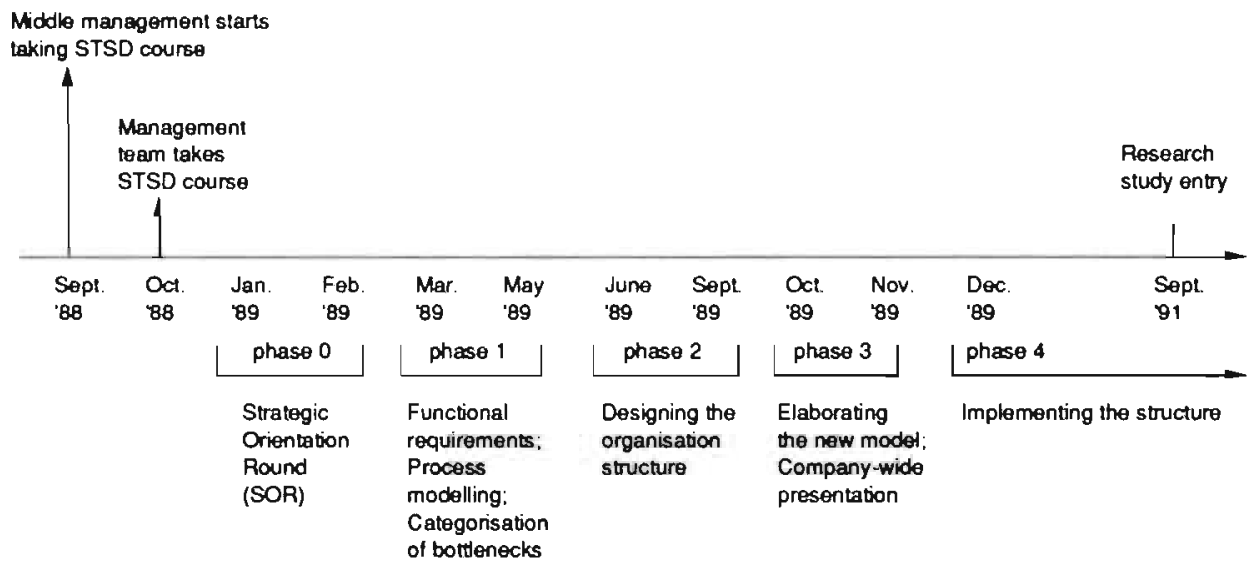

Figure 6.1 Time path (Source: project documentation)

The strategic orientation round (phase 0) was accomplished by performing a SWOT analysis (Strengths/Weaknesses - Opportunities/Threats) which made St. Antonius decide to start a process of organisation renewal. From the specifics of the SWOT analysis, a goal statement resulted, saying that the main characteristics of the organisational renewal were to be: 
- the formation of whole-task groups;

- to bring control to the shop floor;

- to actually control the organisation instead of 'fixing things';

- communication and information;

- 'knowing by measuring'.

Other aspects, such as quality, efficiency, environmental care, administrative organisation \& management information systems, flexibility and innovation, were to be considered in each of the above organisational renewal characteristics.

\section{Categorisation of Bottlenecks}

After following the strategic orientation came the listing and categorisation of existing bottlenecks. Context for categorisation was the planned redesign of the organisation, i.e., to specifically locate where improvements and structural renewal were needed. The bottleneck categorisation report was the main point of reference in setting up the final organisation design. It was structured into three parts:

1. formulating a model which represents the primary process of St. Antonius;

2. indicating bottlenecks within the modelled primary process;

3. indicating the correspondence between bottlenecks and the present organisational structure.

The categorisation report was drawn up by a work group (Work Group Design or WGD) composed of employees from each department in the primary process (production, planning, marketing, quality control \& engineering, general management) and one external consultant. The interdisciplinary character of the work group was deliberately put up in order to obtain input from as many experienced people as possible (see Figure 6.7).

The role of the consultant was restricted to that of facilitator in the change process. In the categorisation phase, his role consisted mainly of knowledge transfer on the modelling method as well as in supplying help in analysing the results of the method. His support was provided only when explicitly requested by the work group.

\section{Modelling the Primary Process}

The process model consisted of ten different submodels. Together they constituted the selling, preparing and manufacturing of vessel heads. Each submodel coincided with recognisable and 'old' existing departments (see Figure 6.2 for the process split-up).

The process analysis was based on a system-theoretical view of the organisation and consisted of classifying activities into four categories: inputs, outputs, resources and control information. This is called the IDEF methodology and its target is to model the function of a set of operations and the objects and information which pass through these operations ${ }^{7}$. Inside each category it was then indicated as to where the inputs and control information came from, or where the outputs 


\section{Chapter 6}

went. Also, the resources for that particular process part were indicated (see Figure 6.3).

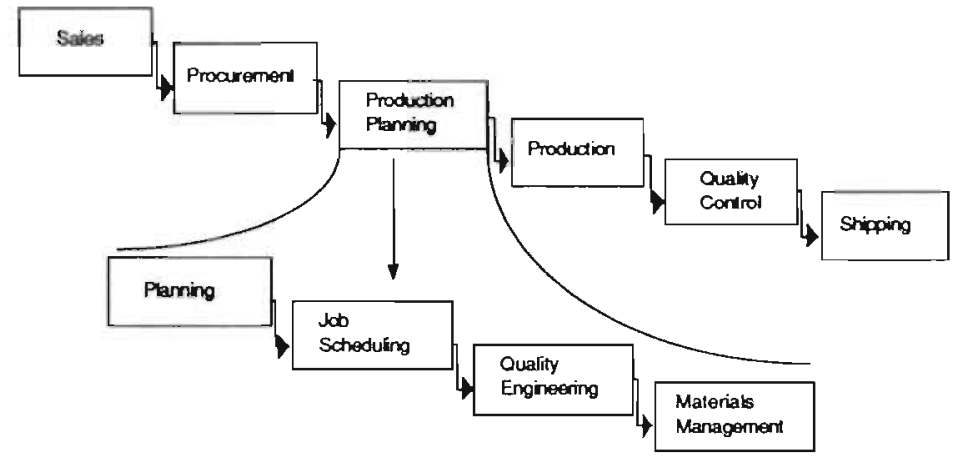

Figure 6.2 Production process modelling (Source: project documentation)

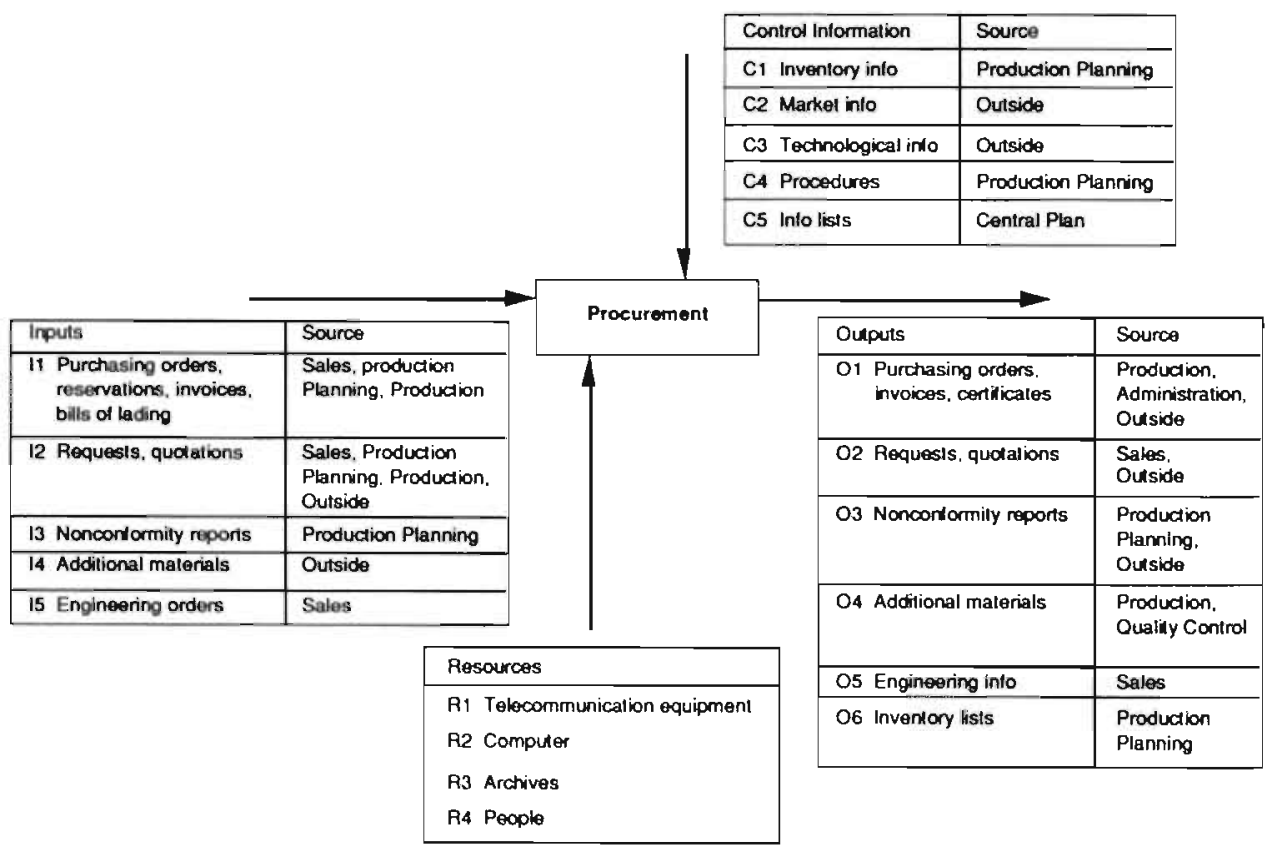

Figure 6.3 Example of the IDEF technique for the Procurement department (Source: project documentation) 
At a lower system level, this analysis resulted in clarifying not only control information bottlenecks but also operational constraints. Consequently, the relationship between activities and information became clear and improvements fell more or less into place by the depiction of this relationship. Consider, for instance, the press operation. Previously, the operation was completely controlled by the press operator, resulting in a clear planning but unreliable quality. Together with the press operators, the operation then was made transparent by working according to a new plan: Planning no longer took place on the basis of an operation, but rather a combination of operation plus the required dye (see Figure 6.4), resulting in a new planning based on effective time consumption. In addition, the new procedure made clear what precise craftmanship is required, which is subsequently normalised according to ISO 9002.
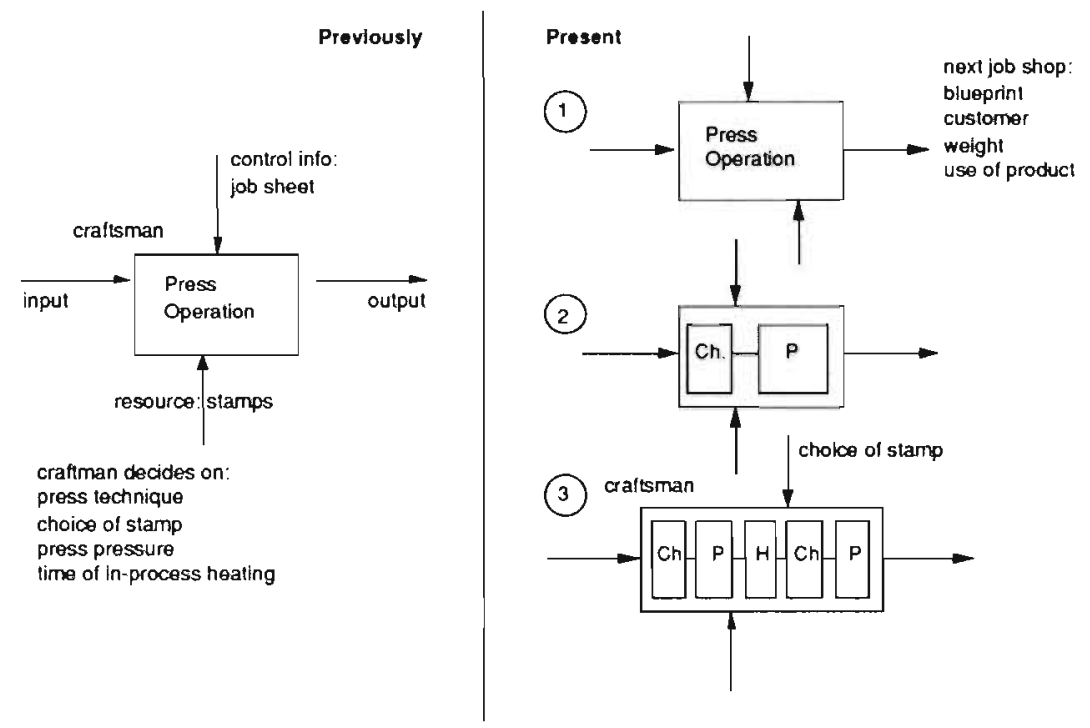

Figure 6.4 System-theoretical relationship between activities and information (Source: project documentation)

\section{Indicating Bottlenecks}

The main assumption was that bottlenecks can only be detected when the primary process is considered in its entirety. Consequently, the full process, from the initial order to shipment, was analysed according to the present bottlenecks. Once the bottlenecks were identified, they were separated into two categories: those having structural cause and those having nonstructural cause. This type of listing showed at what system level the bottlenecks occur and how much priority is given to resolving it. As a result, it became clear that $80 \%$ of the bottlenecks had a structural 
cause and $20 \%$ did not; therefore, the latter could be resolved with relative ease and on a short-term basis.

It took somewhere between three and six months to rectify those $20 \%$ of bottlenecks that did not require structural rearrangements. The top four nonbottleneck topics were assigned to a 'problem owner', who acted as chairman of a task force. It was up to him to take further action, including setting the time limit in which the problem should be resolved.

The remaining $80 \%$ was regrouped into general problem categories and analysed according to their respective structural implications. From the process modelling, it had already been made clear that the primary process was spread out across a multitude of departments: Closer scrutiny showed that each individual product order required the interference of approximately 15 separate departments.

This complexity was further aggravated by the crisscrossing of information flows between departments as well as within the departments themselves. This resulted in the side-effect that insight and understanding of one another's activities were lacking (compartmentalisation or 'pigeon-holing'). Consequently, the output of any one department was out of touch with the input needed by the next department. This created an atmosphere of irritability and reduced the incentive to team-up in much needed problem solving. The final result was a reduction of flexibility in the organisation, reflected by the need for 'fixing things', and improvised and unplanned expediting actions accompanied by relatively high costs. Moreover, the fact that each order/product is relatively unique, places additional emphasis on the importance of the (crisscrossing) information flow. Therefore, it became apparent that all activities, whether in terms of material or information, were interdependent within the product flow (see Figure 6.5). Thus, improvements had to be based on this flow interdependence, i.e., redesign should be based on flow-oriented production.

\section{Relating Bottlenecks to Organisation Structure}

Resolving these structural bottlenecks demanded a flow-oriented organisation design that met the following requirements:

1. Flexibility: The mixture of high quality and reliable delivery, at low cost, from a wide and customised product assortment required a very flexible organisation to adequately handle individual customer orders. The organisational design accommodating this requirement had to address all functions within the primary process.

2. Control of Quality, Delivery Time and Costs: Not only had the upstream activities such as procurement, planning, and materials management to be managed on their interdependence but they also had to tune into downstream activities in the order flow. This required short-circuited control cycles, bringing control levels as close to the process as possible. In other words, establishing the least possible amount of separation between activities in the production process.

3. Quality of Working Life: Accomplishment of the above-mentioned requirements only becomes possible when the commitment and subsequent participation of all personnel is high. From this point of view, an organisation having 
little departmentalisation is preferred. Simply speaking, this requirus a job design with little functional specialisation and a high availability of employees for different tasks.
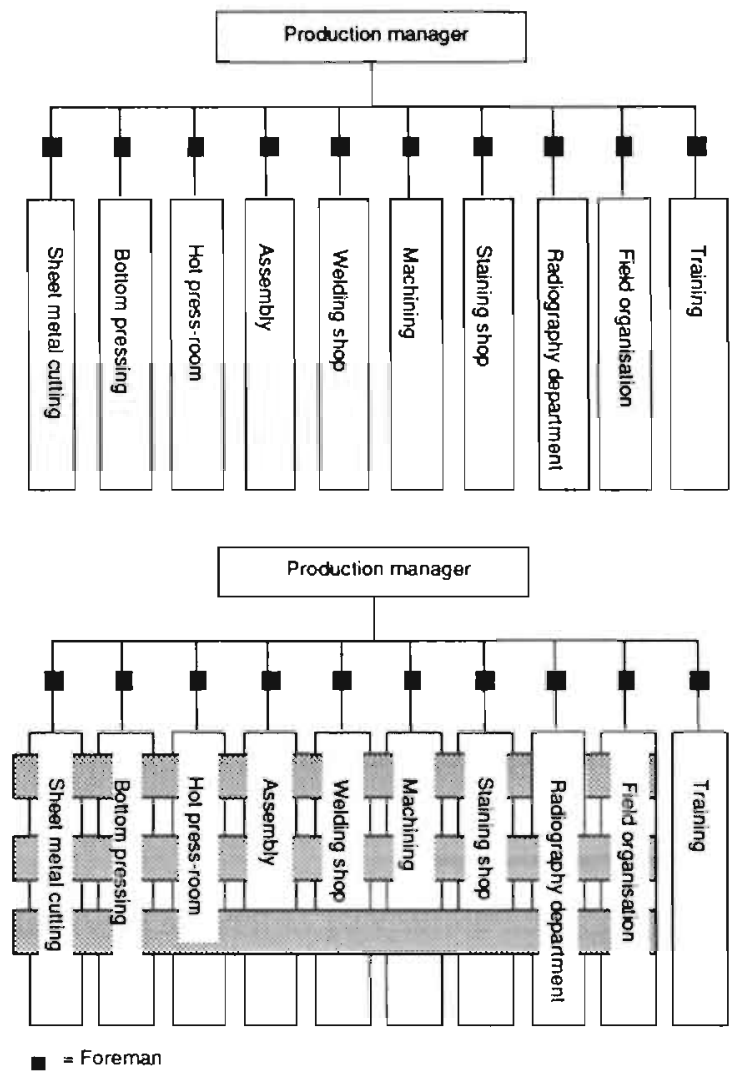

Figure 6.5 Product flow interdependency (Source: project documentation)

The overall conclusion of the categorisation phase was that the organisation should be restructured according to order flow. Initially, redesign of only the upstream functions was considered to do the job. After the bottleneck analysis, however, it became apparent that this would not be possible without redesigning the production function, and therefore the entire organisation. The close interdependencies of the various functions precluded a partial reorganisation, it was all or nothing. This led to adding the formation of whole-task groups to the strategic goal statement. 


\section{Designing the Organisation Structure}

Input for the design phase consisted of the results obtained from the bottleneck categorisation and the Strategic Orientation Round. The management team began this project chain by formulating the plan by which the design had to be accomplished (see Figure 6.6). Furthermore, since the Work group Design was comprised almost entirely from the management team, with the exception of Houben jr. and the Quality Assurance manager who had just entered the organisation, no formal top-down approval mechanism was deemed necessary.

\begin{tabular}{|c|c|}
\hline $\begin{array}{l}\text { Phase 1: Formulating Dosign Specifications } \\
\text { - Formulating design specifications and limiting conditions } \\
\text { - Nol too much detail } \\
\text { - Complete list: attention for all aspects regarding: } \\
\text { - flexibility/contollability } \\
\text { - producl quality } \\
\text { - quality of working life } \\
\text { - quality of work relations } \\
\text { - Take into consideration the outcomes of the SOR and the botteneck } \\
\text { calegonisation }\end{array}$ & $\begin{array}{l}\text { Throughput time: } \\
2 \text { weeks } \\
\text { Executed by: } \\
\text { Management team }\end{array}$ \\
\hline $\begin{array}{l}\text { Phase 2: Designing } \\
\text { - Look for paraliel flows in manulacturing } \\
\text { - Link flows in production preparation and production support as much } \\
\text { as possible to these parallel flows } \\
\text { - Develop several alternative production structure designs } \\
\text { - Develop several al ternative control designs } \\
\text { - Match production structure and control structure alternatives with the } \\
\text { - design specifications plus make a choice } \\
\text { - Presentation of the new organisation by the management team to the } \\
\text { entire company }\end{array}$ & $\begin{array}{l}\text { Throughput time: } \\
3 \text { months } \\
\text { Executed by: } \\
\text { Project work group }\end{array}$ \\
\hline $\begin{array}{l}\text { Phase 3: Worklng Out the Now Organisation Model } \\
\text { - Determine all operational and control activities of all groups and divisions } \\
\text { - Establish the factory and office lay-out } \\
\text { - Establish the adaptations to the technical resources } \\
\text { - Categorise the adaptations to the information supply } \\
\text { - Categorise the need for training } \\
\text { - Put up a training schedule and a construction schedule: phot all activities } \\
\text { on a network plan } \\
\text { Phase 4: Implementation } \\
\text { - Using the implementation plan, possible activities are: } \\
\text { - systematic problem solving during imptementation } \\
\text { - take up work counselling } \\
\text { - team building \& conficl management } \\
\text { - situational leadership } \\
\text { - formulating group goals } \\
\text { - pertormance appraisal } \\
\text { - project planning \& project control }\end{array}$ & \\
\hline
\end{tabular}

Figure 6.6 Redesign project targels (Source: project documentation)

The management team came up with the following functional requirements on the new organisational design in nonpriority order:

1. Controllable throughput times per order flow; 
2. Delivery reliability of less than five workdays, meaning that the spread of the actual delivery date should not deviate by more (or less) than five days from the agreed date;

3. Produce at the highest possible and necessary product quality levels;

4. Zero defects, both in attaining customer satisfaction and in the internal manufacturing process, where the rule is 'everything $100 \%$ the first time';

5. The product flow has to be clearly arranged and, therefore, must be able to be planned both in its upstream and in its various manufacturing and quality phases;

6. Overtime has to be minimised;

7. A flexible frame of mind for market demands, especially towards product customisation requests;

8. Self-contained group task descriptions moving responsibilities to the lowest level of the organisation;

9. Production task groups should consist of no more than twenty people (this was a figure obtained from practical experiences and as such taught in the earlier STSD course).

Formulating design specifications took approximately four weeks. The design requirements themselves were subjected to such limitations as compliance with the results of the bottleneck categorisation and the SOR. They should not be too detailed but remain as complete as possible in terms of flexibility and control, product quality and quality of both working life and internal labour relationships.

In phase 2, the Work group Design took over and started the actual design of the organisation structure. This work group consisted of six persons, representing all departments involved in the transition process, and was expected to attain the following targets in approximately three months:

* Look for parallel flows within manufacturing;

* Couple upstream flows as well as production support, as much as possible, to the parallel flows found in manufacturing;

* Develop several production structure alternatives to choose from;

* Develop several control structure alternatives to choose from;

* Test the production and control structure alternatives using the previously stated design requirements and make a choice;

* Present the new organisation design to all those involved, i.e., the entire company. The actual presentation is conducted by the management team.

The project planning took longer than expected: about seven months. The additional time was required because it was only realised midway into phase 2 , when designing the upstream activities, that the entire production process had to be redesigned as well.

The aim of having various alternatives made available stemmed from the wish to have a choice, i.e., not to be confronted with just one alternative which inevitably is labelled as the 'best'. Also, the presentation of the new organisation design by the management team displayed the commitment of the top to this new design. Since the management team almost equals the Work group Design, no ownership conflicts would arise. 


\section{Chapter 6}

In phase 3, redesign was first actuated in the Plate Material Supply (PMS) group and then moved downstream to the Formed Heads group and the Finishing and Shipping (F\&S) group (see Figure 6.8 for a layout of the production structure). Implementation (phase 4) was started by the main production group (Formed Heads), followed by its upstream supplier Plate Material Supply and its downstream consumer Finishing and Shipping. Once the main production flow was reorganised, the two remaining production groups followed suit (Hot $\mathcal{E}$ Cold Pressed Products and Assembled Products).

The project management itself was split up into four separate work groups with each work group having its own project responsibility (see Figures 6.6 and 6.7). In both the work groups for the office and plant design, a majority of 'owner-employee' groups participated. For example, in the 'Work group Office', two members of the overall 'Work group Design' were involved, complemented by six others that had been appointed by the office personnel. The 'Work group Plant' consisted of five people: One from the overall Work group Design, two permanent members and two rotating members. The rotating members also acted as the chairman and secretary of the work group, with both functions rotating with the production subdepartment which was next in line to be restructured.

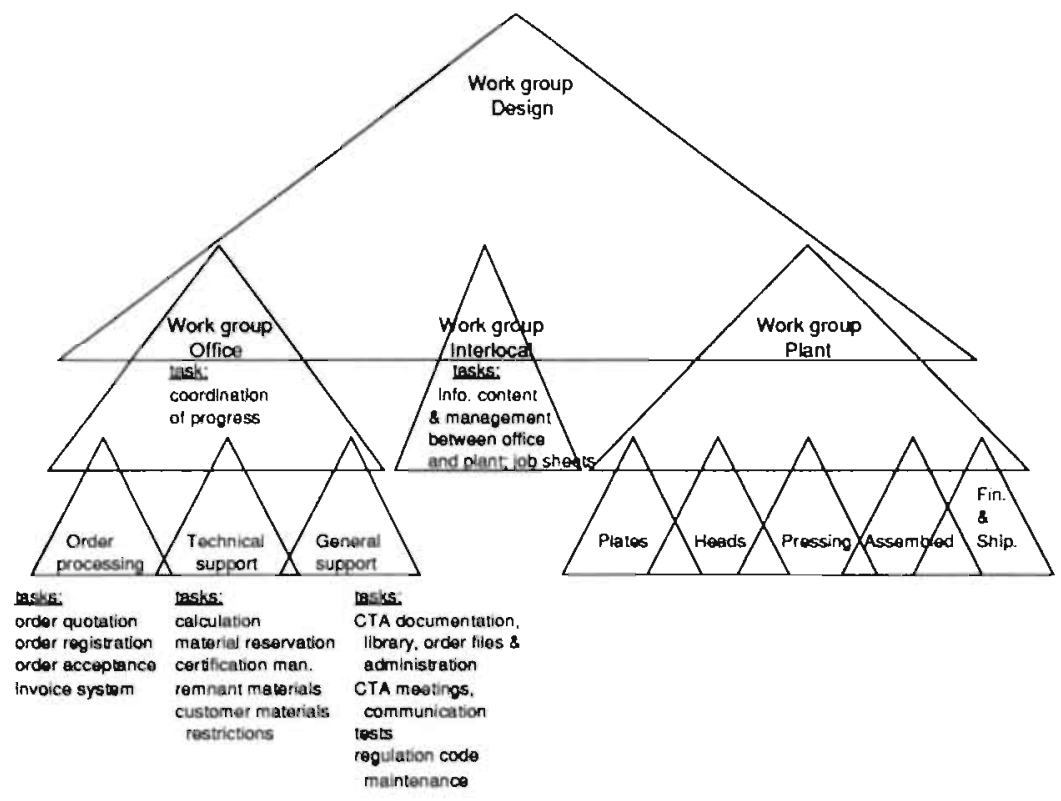

Figure 6.7 Linking pin structure of redesign work groups (Source: project documentation)

The central factor in designing the organisation structure was the linkage between Production and upstream/downstream activities. Clearly arranged production flows were considered the basis for the further design of preparatory and control- 
ling activities such as engineering, job scheduling, etc. Thus, the main redesign project was the improvement of the upstream trajectory, restructruring the information flow to and from the Production function. This was the project that triggered the conclusion that all of production had to be redesigned or there would never be an improved information flow.

Structural rearrangements in this information flow were twofold: First, the former job scheduler was assigned new tasks and his function was renamed Production Engineer. Second, the tasks of the Quality Engineer were also restructured and the Quality Engineers were integrated with sales personnel into one new department called Commercial Technical Activities (CTA). Quality Engineers were previously organised per construction design code category, much the same as the sales people were organised according to country. Five QEs are employed with one person fully responsible for giving advice to customers and the internal organisation. Production Engineers and Quality Engineers fulfil identical roles: They control the flow of production information as they possess the pertinent knowledge concerning product and production details. Similarly, their tasks require handling of an extensive and diverse information set.

The Quality Engineer is the person in the organisation who is most knowledgeable about the full production process. More specifically, he is knowledgeable about the production operations that are most critical to the product quality. He combines this knowledge with that of the various construction design codes and regulations required by each country being exported to. In turn, insight into the contents of the construction design codes requires a vast knowledge of the properties of all kinds of metals and press operations.

The main reason for the integration of Sales with QE was the role that technical information played in closing a sale. Essential technical information no longer bounces back and forth between two different departments but it is now concentrated into one department (see Figure 6.8). The CTA department is organised according to product-market combination instead of geographical area, and contains three CTA units. It required, however, that the QEs be retrained as they had to be familiar with all construction design codes applicable to their CTA unit. Nevertheless, each QE has retained his building code specialisation with which he backs up his colleagues. As a result of this coupling of expert information in one single department, the information flow in the upstream trajectory was considerably simplified: Order processing time, from the moment of sales agreement to the actual production stage, decreased from 11 to 3 days.

Restructuring the information flow equally involved reviving the administrative and reporting aspects of the 'new' information. This point is elaborated upon in the paragraph dedicated to Management Accounting Systems design.

The upstream information flow restructuring was complemented by an improvement in the customer ordering process. For example, to couple both the order and production flows, St. Antonius put together an order catalogue which helped the customer to define more exactly his product demands and establish the correct product specifications. 


\section{Chapter 6}

(Head of Central Planning) "Manufacturing a product is not much of a problem as long as there is adequate information. This starts already at the point where a quotation is drawn up. Previously, once an order was accepted, it went back and forth between production planning and sales, which led to delays. The order stayed too long at production planning. There was a misfit between time needed for scheduling and time needed for manufacturing. In the near future, there will only be techno-commercial employees. Delivery time has to be reduced by this from seven to eight weeks to three or four weeks."

Previous Departmental Organisation Structure

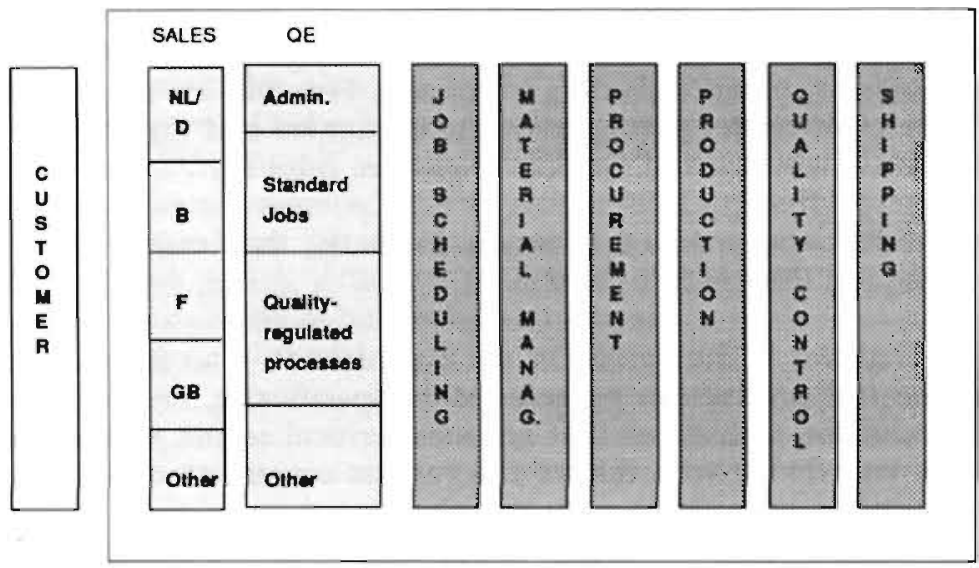

Presen Group Organisation Sinucaure

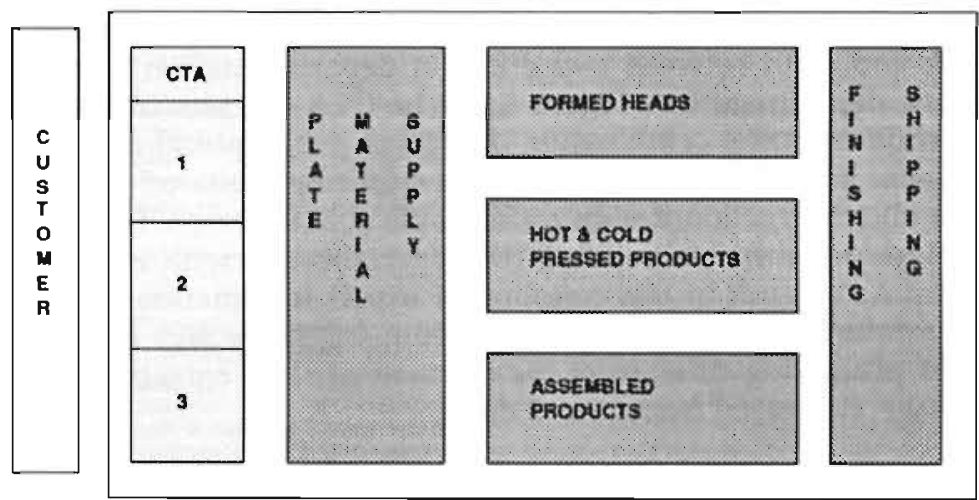

Figure 6.8 Restructuring the preproduction departments from functional concentration to flow concentration in a general design (Source: project documentation)

The original layout already indicates the crisscrossing of production flows. Manufacturing operations can be characterised by complex production flows, little controllability of order throughput times and the inspection of quality instead of the manufacturing of quality. Furthermore, in the previous situation a functional 
structure dominated. Manufacturing was organised according to similarity in operations, i.e., machines performing identical operations were grouped together.

In the new production structure, manufacturing is organised according to production flow. As many operations as possible are integrated into distinct process parts within the flow, i.e., there is little interdependence between the groups themselves, apart from the flow itself. It allowed the placing of scheduling and controlling activities into the groups, which then became 'autonomous' or 'composite'. As can be seen in Figures 6.8 and 6.9, manufacturing is split into three production groups: Formed Heads, Hot \& Cold Pressed Products and Assembled Products. These are also considered to be the three main production flows, because these product types dominate the manufacturing process. The Plate Material Supply group contains the former upstream operations such as cutting and certifying as well as the purchasing function. Its output has just one single denominator: metal discs. The output of the subsequent production groups has an equally simple output denominator, whether its output is delivered further downstream or sideways as semifinished product to parallel groups.

"OLD" PRODUCTION LAYOUT

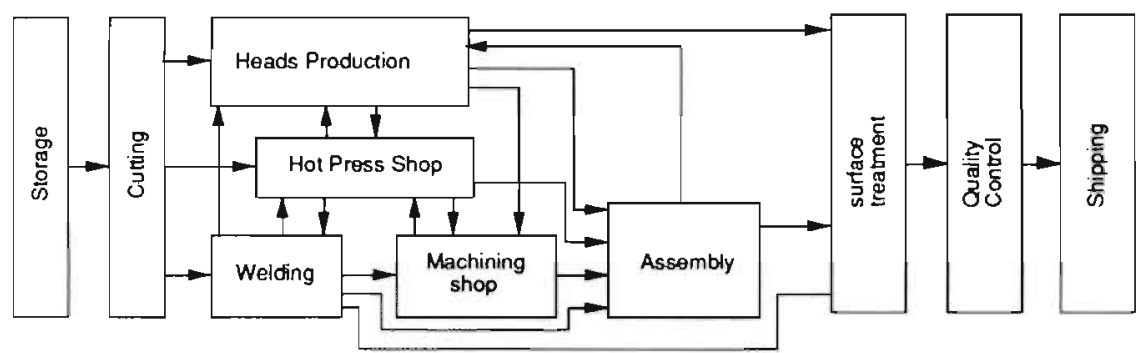

"NEW" PRODUCTION LAYOUT

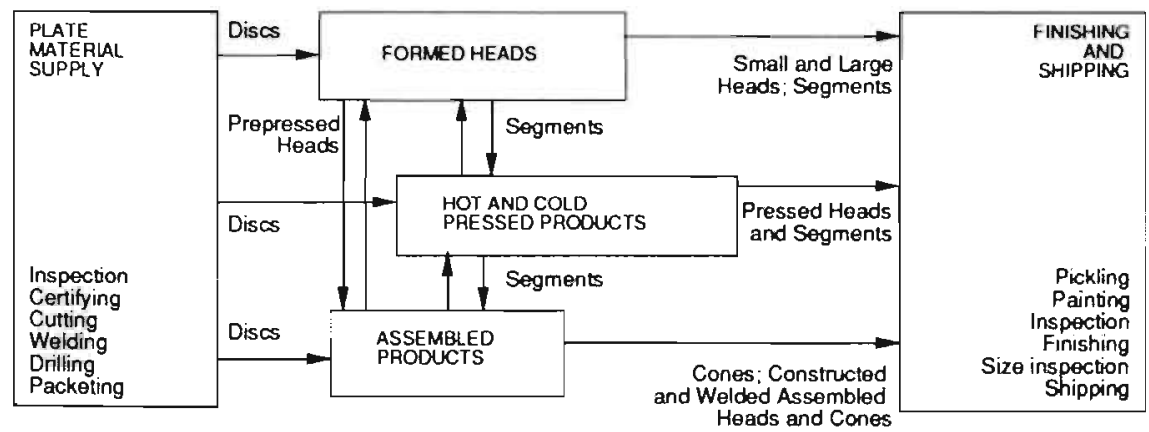

Figure 6.9 Production structure design (Source: company documentation) 
In the' new situation, the number of foremen can be limited to three: one for every production group. Also, the physical layout has been rearranged and adapted to the new production organisation structure.

To control and account for sideway movements, each group or division is split up into work centres. Work centre costs are assigned to the order passing through. For administration and clarification reasons, job sheet category codes coincide with work centre codes, thus planning the divisions the product passes. To indicate what the turnover relationships between divisions are, the turnover can be established per job sheet category. Work centre tariffs take over the role of transfer prices in financially mapping the flow (see paragraph on management accounting system for a discussion on the tariffs used).

The above-captioned production structure was not designed as being the only alternative available. In fact, three design options for restructuring production were discussed. When put to the test by the design requirements, the most satisfactory alternative emerged. The fact that this alternative also required the smallest amount of additional investments settled the matter (see Table 6.1 for argumentation used).

The next step was to design the control structure, i.e., the control tasks of departments and groups. Leading principles for this design phase were threefold:

- Bring as many control tasks as low in the organisation as possible, i.e., to the production groups;

- Couple preparatory and supporting activities to production groups as much as possible;

- Integrate related activities in the production and preproduction functions as much as possible.

For each department, its controlling activities were similarly modelled as in the preceding bottleneck categorisation phase: input, output, resources and control information. However, added to the process model were three other items: A further differentiation of resources into a technical and a human subcategory, a statement of operational requirements based on the specific technology for that part of the process, and a category called improvements/renewals. This last control category indicates the learning capacity requirements related to the various production groups. Examples are the new job sheet, called fabrication plan, which is designed by the employees of each division; the close involvement of division employees in designing several new machine manuals; and the full participation in deciding on the measurement criteria for performance measurement of each division.

A full-fledged control structure design as prescribed by STSD theory was not present, keeping in mind that the reorganisation was triggered as the only means of improving upstream activities was meant to be tackled. Much of the control design can therefore be considered to be included in improvements of the information flow and the administrative organisation. Consequently, these improvements made several structural rearrangements necessary, which, in turn, fitted in with the general organisation change. The main control redesigns, however, relate 
to normalisation and standard setting, for example, by means of quality systems, administrative organisation, performance measurement.

Table 6.1 Evaluation of design alternatives (Source: project documentation)

\begin{tabular}{|c|c|c|c|}
\hline $\begin{array}{l}\text { Design } \\
\text { Requirements }\end{array}$ & Altemative 1 & Alternative 2 & Altemative 3 \\
\hline \multirow[t]{2}{*}{$\begin{array}{l}\text { Control of } \\
\text { throughput time }\end{array}$} & $\begin{array}{l}\text { Difficult: during manulacturing } \\
\text { many interdependent local } \\
\text { product flows. } \\
\text { Transport lunction therelore } \\
\text { difficult to put on. }\end{array}$ & $\begin{array}{l}\text { All single hedges mostly dealt with within the } \\
\text { group. } \\
\text { Supply of prepressed by "HEDGES" to } \\
\text {-PRESSED PROOUCTS" } \\
\text { Supply of segments by both "HEDGES" and } \\
\text { "CONES'COMPOSITE PRODUCTS" } \\
\text { Transport function can be tully decentralized } \\
\text { to the separate groups }\end{array}$ & $\begin{array}{l}\text { Idem ait. 2, although Staining } \\
\text { Painting is the locus } \\
\text {-PLATES- and -FINISHING' } \\
\text { SHIPPING have own transpent. } \\
\text { Other groups are dependent on this. }\end{array}$ \\
\hline & $\cdot$ & + & + \\
\hline \multirow[t]{2}{*}{$\begin{array}{l}\text { Control of } \\
\text { product quality }\end{array}$} & No full products within groups. & Full products within groups. & $\begin{array}{l}\text { idem alt. 2, atthough less complete } \\
\text { because of separating out Staining. }\end{array}$ \\
\hline & $\cdot$ & ++ & + \\
\hline \multirow[t]{2}{*}{$\begin{array}{l}\text { Volume } \\
\text { flexibility }\end{array}$} & $\begin{array}{l}\text { Low. because of large } \\
\text { interdependent flows }\end{array}$ & $\begin{array}{l}\text { Reasonable. less for Staining because of } \\
\text { excentric position. }\end{array}$ & $\begin{array}{l}\text { High, better because of central } \\
\text { position of Siaining. }\end{array}$ \\
\hline & - & + & +4 \\
\hline \multirow[t]{2}{*}{$\begin{array}{l}\text { Control capaciry } \\
\text { buitt into a task } \\
\text { (Ouality of } \\
\text { Working Lite) }\end{array}$} & $\begin{array}{l}\text { No complele tasks: no full } \\
\text { overview ol product tlow. }\end{array}$ & $\begin{array}{l}\text { Production tasks reasonably complete. } \\
\text { Full product, incl. Staining, in one group. } \\
\propto C \text { and Fin!shing in one separate group. }\end{array}$ & $\begin{array}{l}\text { Production lasks reasonably } \\
\text { complete. Full product. exd. } \\
\text { Staining. in one group. } \\
\text { Staining. OC and Finishing in } \\
\text { one separate group. }\end{array}$ \\
\hline & - & + & +4 \\
\hline \multirow[t]{2}{*}{$\begin{array}{l}\text { Availability of } \\
\text { employees lor } \\
\text { different jobs } \\
\text { (Executive } \\
\text { tasks) }\end{array}$} & $\begin{array}{l}\text { Good. } \\
\text { More possibilities than in } \\
\text { fomer organisation. }\end{array}$ & $\begin{array}{l}\text { Good: theoretically also available for } \\
\text { Staining, but in practice not realisable } \\
\text { because of differences in know-how } \\
\text { and skills. }\end{array}$ & $\begin{array}{l}\text { Good. } \\
\text { More possibilities than in former } \\
\text { organisation }\end{array}$ \\
\hline & + & + & + \\
\hline
\end{tabular}

The STS redesign led to the following new (responsibility) organisation chart, where you can find at the bottom level, the five production groups and the three sales groups, and a simple, flat management structure (Figure 6.10). It shows the overall importance of quality as the quality standards of ISO 9004 are fully applied to the organisation, resulting in a matrix organisation. ISO 9002 is concerned with product quality and is the main function of Quality Engineering (CTA department), while ISO 9004 is concerned with the norms for a quality organisation. ISO 9004 is anchored in the organisation by establishing a management team level Quality Assurance department and by overlaying a quality control and engineering matrix over the organisation. Almost all of the ISO 9004 norms are realised by the STSD reorganisation, showing that the ISO 9004 concept, saying that good product quality is assured by a quality-organised company, is identical to the STSD concept of Quality of the Organisation. 


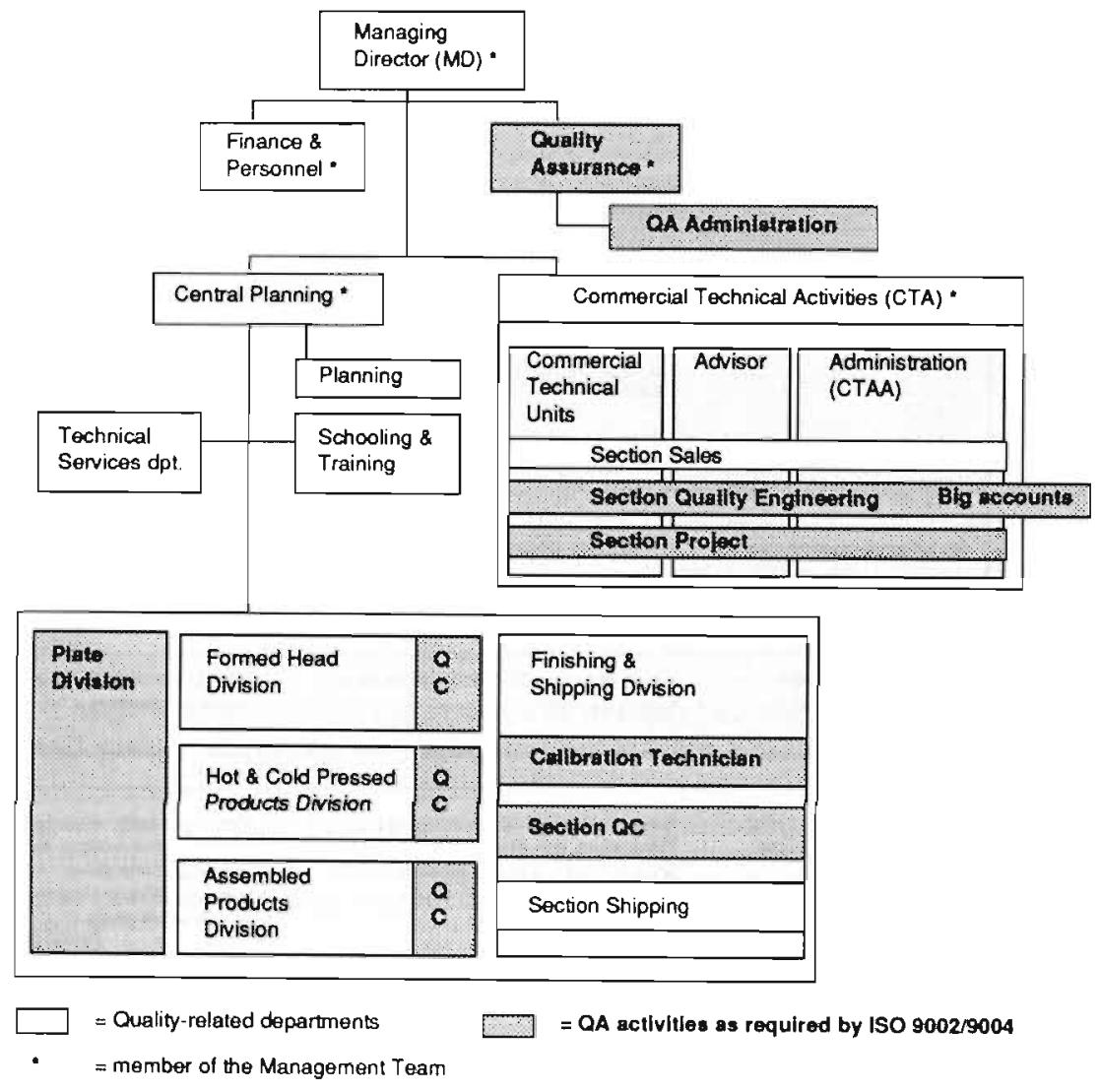

Figure 6.10 Present overall organisation structure of St. Antonius (Source: quality manual)

The following is an explanation of the new organisation chart: The Central Planning department in the new chart is responsible and takes care of overall production planning, automation and computerisation, R\&D, and overall production management. The manager of Central Planning is also in charge of the STSD change programme and its subsequent organisation policies and projects. Technical Services is a combination of inventory control \& management, and technical maintenance and support for the plant. Inventory management requires close attention because some customers supply their own materials which, depending on size/weight, delivery time and type of material, are difficult to handle and plan for. Schooling \& Training relates to both additional retraining and continuous education for employees as they acquire new tasks and responsibilities under the STS design, and to the apprentice job shop for junior employees. The special section of big accounts in CTA refers to projects requiring exceptional attention and regulation such as orders from the nuclear and space industries. 
With the redesign completed, it was now time to start preparing for the final implementation. Before that, however, the outcomes of the design phase were made clear to all employees by means of a role play in one of the production halls. Together with the employees it was enacted how the previous structure of the organisation made operations very difficult and how the new structure would change all this. Such a role play was repeated once more during the elaboration of the design (phase 3 ) to show what progress was made and what still had to be done.

The redesign work group finished its job by suggesting a series of steps for the implementation together with a proposal for the accompanying change management approach (see Table 6.2). As can be seen, it makes use of the already existent project management structure with the various work groups now involved in implementation issues.

Table 6.2 Implementation approach of the redesign proposal (Source: project documentation)

\begin{tabular}{|c|c|c|}
\hline Task: & & Under the responsibility of: \\
\hline $\begin{array}{l}\text { Setting up a stepwise } \\
\text { implementation plan } \\
\text { for both office and } \\
\text { plant, including a time path }\end{array}$ & Step 1 & Overall design work group \\
\hline $\begin{array}{l}\text { (1) Establishing the personnel } \\
\text { occupancy for both the office and plant } \\
\text { (2) Formulating training needs } \\
\text { and setting up a training plan }\end{array}$ & Step 2 & Management team \\
\hline $\begin{array}{l}\text { Setting up a communication } \\
\text { plan }\end{array}$ & Step 3 & Overall design work group \\
\hline $\begin{array}{l}\text { (1) Setting up the ideal office layout } \\
\text { (2) idem for the plant }\end{array}$ & $\operatorname{Step~} 4$ & $\begin{array}{l}\text { Otfice work group } \\
\text { Plant work group }\end{array}$ \\
\hline $\begin{array}{l}\text { (1) Setting up new technical affice } \\
\text { equipment descriptions } \\
\text { (2) idem for the plant }\end{array}$ & Step 5 & $\begin{array}{l}\text { Ottice work group } \\
\text { Plant work group }\end{array}$ \\
\hline $\begin{array}{l}\text { Checking of information needs and } \\
\text { setting up an information plan }\end{array}$ & Step 6 & Office and Plant work groups \\
\hline $\begin{array}{l}\text { Setting up job descriptions and } \\
\text { a job classification }\end{array}$ & Step 7 & Management team \\
\hline
\end{tabular}

The implementation was completed almost entirely on the basis of the proposed schedule. The involvement of the management team in steps 2 and 7 was based on a function classification project that was already running during the start-up of the redesign. This plan was abandoned later because the unions were opposed to it. 
The Work group Interlocal (Figure 6.7) disappeared from the above-captioned implementation plan. It proved unnecessary as the other work groups had already coordinated their plans in the Work group Design long before the Work group Interlocal became operational.

\section{Designing the Management Accounting System}

Development of the MAS design was a result of the general construction of a company-wide information system. This information system had two main starting points. First, it should generate the information necessary to steer the whole of the organisation: The general manager has to be provided quickly with information on the financial position of the firm, planning staff has to know real-time online where in the process a product was located, and the Quality Assurance department has to know where something went wrong. Second, the people on the shop floor had to be provided with proper information that would enable them to optimally manufacture products allowing them to influence financial position, planning and quality. Taken together, it requires a local information system that also serves the organisation on a higher level of aggregation.

To start with, it was decided to look at what information the job schedulers (the latter Production Engineers) really needed in order to determine the correct production method. Next, all tolerances in the entire process were normalised, using the strictest building code available. Surprisingly, this norm uniformity very quietly resulted in a reduction of the number of failures caused by deviations in measurements. Finally, one looked at the information needed by the Quality Engineers to determine the correct production process, welding method and heat treatment. It was from these three elements that the content format of a quotation was derived 8 .

The difference between the information needed by the PEs and the QEs is in the level of operations considered: The QE looks only at the process and the phases the product must complete, while the PE looks at the resources and instruments needed for each individual process phase. The PE, therefore, is the person who tries to come up with new work methods and, consequently, has closer contact with the shop floor.

Typically, these changes in information supply in the upstream quotation and order acceptance phases have turned out to be big improvements. Solid improvements have been generated in: Internal failure reduction; upstream order throughput time; delivery reliability; and, last but not least, the customers' perception of how the product is being manufactured. This, in turn, shows him or her what expertise ('value') is being offered for his money. Therefore, as a result of the earlier improvements in the upstream information flow, many elements of the accounting design were already present.

The general MAS design (or Management Information System as it is called at St. Antonius) is still in its construction phase. The main problem in developing an encompassing Management Information System (MIS) is that aggregation from parts to the whole is troublesome. This is due to the technological complexities 
involved. For example, each production group is compelled by its specific production technology to use its own unit of measurement. This can either be square metres, weight, diameter or thickness. Thus, transfers between production groups would also imply a transfer in the most basic information denominator. However, this problem was solved by creating work centre units: an alternative and uniform denominator which can be either hours, square metres, kilos or parts, relative to the production group involved.

Consequently, work centre units are used to calculate the production cost tariffs per production division. For this purpose, production groups were renamed divisions, each containing several work centres (i.e., having identical operational activities) which each has its own tariffs. Production tariffs are needed for determining manufacturing costs, product cost and, ultimately, the sales price (see Figure 6.12 for product cost information to be obtained from the accounting information system). Variance analysis is performed only on the basis of production hours, and not on a tariff or financial basis. However, the resulting utilisation rates are easily transformed into a financial numerator by multiplying the variance by the work centre tariff, thus obtaining a production volume variance.

It is this combination of work centres and tariffs that makes up the backbone of the MAS: They have an evaluative role regarding order performance (the job costing aspect) and a control role regarding the financial control of organisational performance (i.e., accountable work centre recovering costs). The textbook theory of tariff usage is their standard costing role for inventory valuation, especially regarding Work-In-Process (WIP). However, WIP is considered most significant for its throughput and delivery time indication, and far less significant for its balance sheet itemisation. Considering the intensive use of tariffs for this wide range of (financial) decisions, setting the tariffs is an important normalisation of financial behaviour, equal to the preceding normalisation of (product and organisation) quality, information flow and work processes.

Production tariffs are constructed using the cost pool method, i.e., a total cost estimate for the various work centres and subsequently divided by the estimated work centre units, explicitly taking into account mutual services rendered in the work centre cost estimate? 9 This results in the man hour rate and the machine hour rate adding up to one single average rate per work centre and per division. This rate is called a tariff. Technical Services, CTA and the Board, which are considered to be general overhead, are separate divisions each having an hourly rate. Production divisions also have indirect costs, but these are accounted for at the divisional level and are included in the divisional tariff.

Because of the cost structure at St. Antonius (few general overheads, itemised full production costs are termed as work centre tariffs), the control of singular overheads has little management attention. Its cost system is one typical of that of a jobber, having a great deal of tariffs available for operations, and work centres producing to recover costs and obtaining a sufficient capacity occupation. Nevertheless, it is leaving its preoccupation with 'capacity selling' to offer a full production service by its focus on product quality, timeliness and flexible production on order. 


\section{Chapter 6}

There are four different types of tariffs: (1) fiscal; (2) commercial; (3) business-administrative; and (4) sales. The commercial tariff is the tariff developed first, leading to the fiscal and business-administrative tariffs and, finally, to the sales tariff. The commercial tariff is related to the break-even capacity level when full available production hours, and their subsequent cost, are to be recovered by sales, i.e., it is based on the necessary sales turnover of the company. This break-even capacity level is the denominator for establishing the commercial tariff. With this tariff, the jobbing character of the cost system is most clearly shown.

The business-administrative tariff underpins the sales tariff. It explicitly includes machine depreciation based on replacement/current value, creating an accounting reservoir for both a technologically up-to-date machine park and the underabsorbed work centre man and machine hours.

Finally, the sales tariff is set by both the market and internal influences. If the market accepts the height of an individual production division tariff as being equivalent to the market price for a specific (number of) operations, then there is no need for subcontracting the work. If it does not accept these tariff levels as price equivalents, (parts of) orders should be subcontracted because St. Antonius cannot operate under its own production cost. The sales tariff equals the business-administrative tariff, with two exceptions: First, on the occasion that it has not been planned for the machines to have a 100\% occupancy; and, second, on those occasions when similar machines in separate divisions have different rates because of differences in division overhead. In both cases, it is accepted that the sales tariff is lower than the business-administrative tariff. Furthermore, the sales tariff requires authorisation and approval by the management team as it is the tariff used in day-to-day practice, i.e., for weekly WIP reporting. WIP valuation using the commercial tariff is performed during each monthly accounting period. The other three tariffs are used for WIP valuations at the year's end.

The importance of WIP is also shown in the regular reporting flow. It relates directly to its role as a throughput indicator. Typically, WIP can be broken down into the individual order level for detailed analysis (see Figures 6.14 and 6.17).

The administrative organisation of St. Antonius focuses primarily on the control of) the upstream order information flow between CTA and Production (see Figure 6.11). In the flow, the central position of the Quality Engineer and the Production Engineer is prominent. Also, the flow chart mirrors the production structure and the control structure in one diagram (task groups and Production Engineers). The administrative organisation 10 chart provides a map of the available financial information - where it is located/registered and what its original target of collecting is. This can be used, for example, to answer the question of whether or not a specific type of information can be used for a decision-making situation although it had not been originally designed for this.

For managerial purposes, the administration is considered to be able to provide cost information on the various product costs. The product cost itself is important because it is used as a basis for sales price setting, i.e., a cost-plus system is used (see Figure 6.12). 


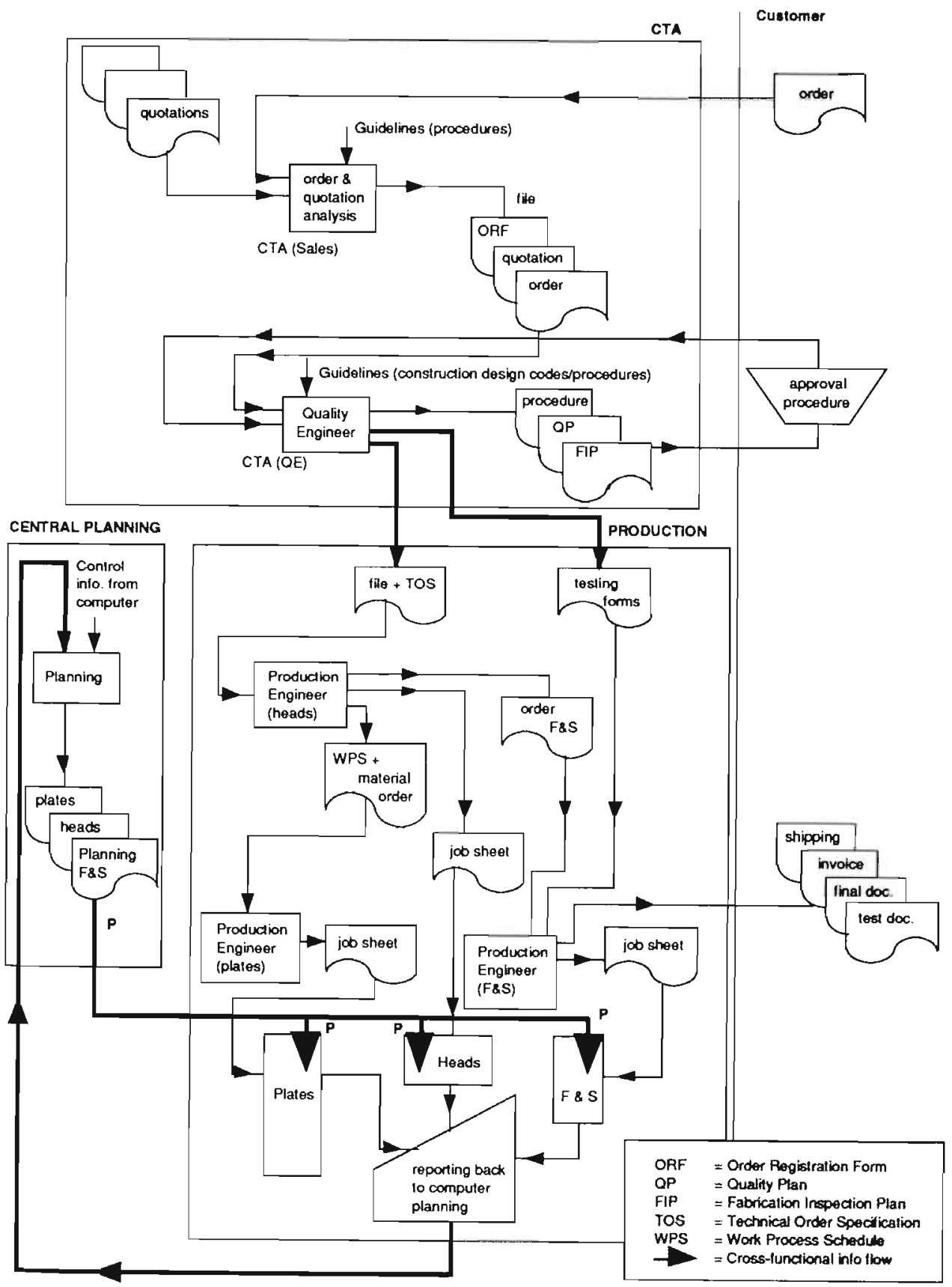

Figure 6.11 Administrative organisation of the upstream order flow (Source: project documentation) 


\section{Chapter 6}

Product cost build-up reflects the job order cost system: It is relatively detailed on material costs and shipping costs because of the size of the products and the provision of materials by the customer. The balance between tariff and market price costs is reflected by the item subcontracted work.

As mentioned above, once production process $(\mathrm{QE})$ and production process methods (PE) are integrated into one singular planning step, production cost standards are set at the same time because the work flow in the fabrication plan and work centre tariffs overlap: i.e., as soon as a product type is identified in its required operations, a product cost can be indicated to Sales (CTA) for further order negotiations.

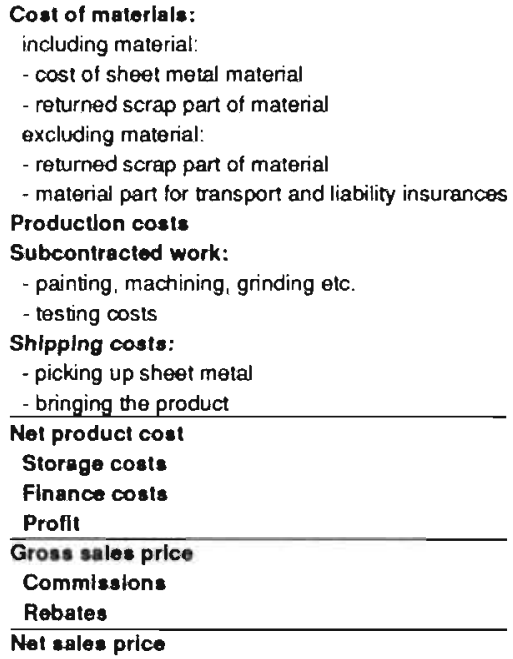

Figure 6.12 Product cost build-up and subsequent cost information requirements (Source: company documentation)

In order to construct a Management Information System, it was decided to build it bottom up, i.e., from the individual groups upwards. As in determining the tariff structure, the five production groups and the department of Commercial and Technical Activities (CTA) were renamed 'divisions'.

Each division had to develop its own performance measurements: After establishing what control tasks were involved, it was determined what the activity output of each division was (this was relatively easy because of the preceding STS design). For all divisions, the resulting list was split into four categories, relating to throughput time, quality, output volume and costs (these four items reappear on the various reports discussed later on). Further, it was specified what exactly was to be measured and what would be the priority order of this reduced number of items. Simultaneously, the performance range and the performance target were established. This performance modelling provides each division with a group per- 
formance standard that they developed themselves and apply to their group decisions. Throughput time is especially considered to be of prime importance because it is thought to be the best indicator of production process disturbances.

Typically, the MIS will have to accommodate the performance information from all divisions, with a strong accent on financial information. When this 'new' MIS becomes available, the aim is to have:

1) an information model representing the production process of the firm;

2) a linkage method for the chain of customer-CTA-Production, in such a fashion that the information flow starts at the customer rather than the CTA department (as already depicted in the administrative flow chart); and

3) a visual method for communication between the primary process level and organisational management.

A clear MAS design cannot yet be depicted. Nevertheless, the present reporting structure can be used as an indicator of such a management accounting design (see Figure 6.13).

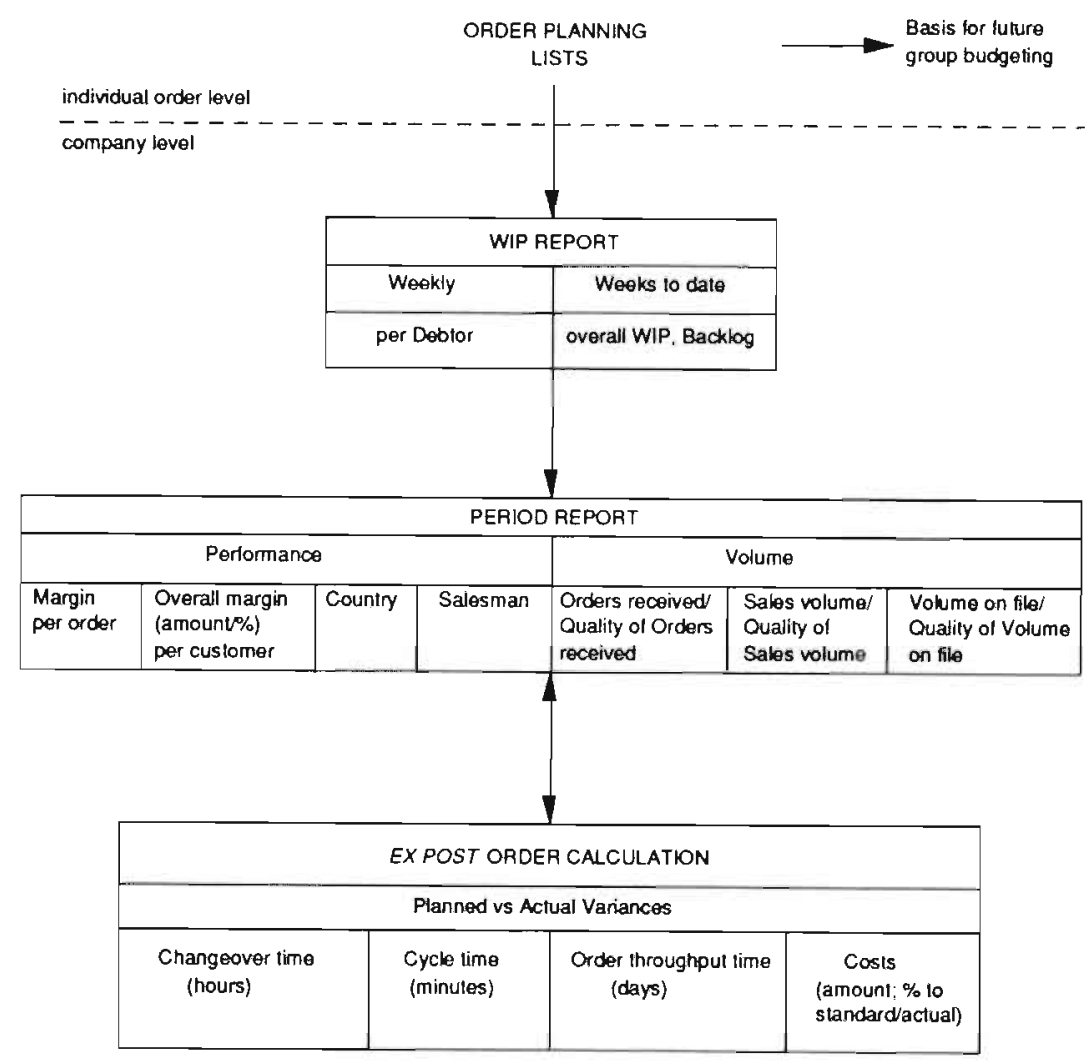

Figure 6.13 Management Accounting System design 


\section{Chapter 6}

The two main parameters for managerial control are order flow and (production) bottlenecks. Order flow is managed and controlled by the information on WorkIn-Process while production bottlenecks are indicated in the period report. The $e x$ post order calculation provides information on both order flow and production bottlenecks, disaggregate to order and individual operation (see discussion of individual reports).

From the order administration (see WP report, Figure 6.14) one should be able to follow exactly what division retains the main responsibility for each order and to what other divisions the order must be passed on next. As a result, a listing can be made as to what the product turnover per division is. Given the future insight into the specifics of product turnover per division, the intention is to use this information as a basis for group level planning and budgeting. That is, a budgeted result at the order level (sales according to invoice amount, minus actual product cost), a flexible budget variance per division and a static budget variance per cost category.

The weekly WIP report is based on production orders, and gives an insight into the WIP and the order backlog, both factors being indicative of throughput time. To explain: The WIP report is both aggregate and disaggregate. Disaggregate to individual customer (debtor) as to what the order status is, and aggregate as to what the total WIP volume and order backlog are per week. For the aggregate WIP position, the WIP (excluding materials) column is indicative, while for order backlog the balance (excluding materials) column is indicative. The material component of WIP is mentioned separately, because some customers provide their own materials and because it is indicative of the added value (defined as labour cost turnover) of the job on hand. Thus, it gives insight into the largest direct costs component of throughput time and order backlog. The category absent materials is further relevant to throughput time as it indicates a production slowdown on the particular order because materials are not delivered, i.e., a sort of production order on hold.

The next report is the period report. It is split into a volume part and a performance part (see Figures 6.15 and 6.16). The volume part provides insight into throughput volume, categorised by product size and the order portfolio. The financial position related to volume is indicated by the subcategory Sales, representing Sales turnover, main cost categories, overall planned costs, as well as the planned gross margin percentage. All other subcategories are concerned with order position in time: Completed until now, today, waiting, and in process. In other words, every time element of the product flow - whether upstream or downstream - is reported on.

The performance part of the period report is less aggregate (Figure 6.16). Instead of a technical grouping according to product diameter, it groups according to customer order position and relative (planned) profitability. Both volume and performance reports can be further split up into subcategories, providing information on, for example, monthly order volume or high-margin customers (see the appendix for examples of this split-up). 
Work-In-Process Report (current production orders)

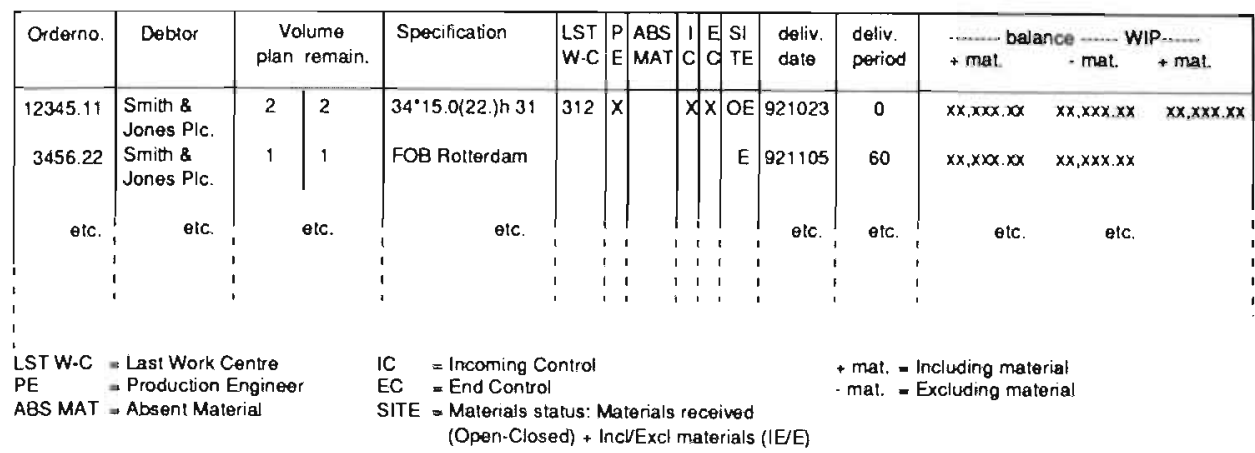

Work-In-Process report (weekly totals to date)

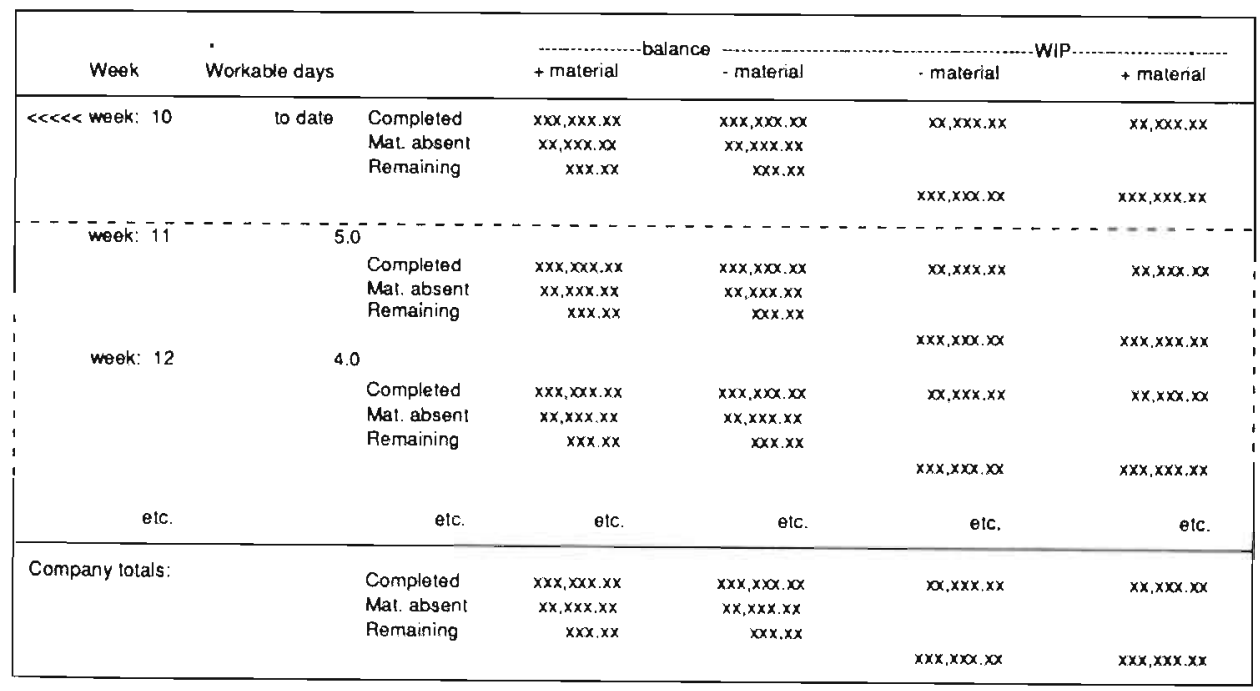

Figure 6.14 The Work-In-Process report (Source: regular company report)

The usefulness of the period report (especially the performance part) is further enhanced by having a regular ex post calculation per individual order two weeks after the period report, pinpointing the variances from plan (Figure 6.17).

The ex post order calculation provides detailed information on planned cycle time, manufacturing costs, changeover time, and order throughput time versus their various actuals (see Figure 6.17). In addition, it provides detailed information about the ex post gross margin per order and about how this difference occurred, up to and including the individual operation. 


\section{Chapter 6}

Period Report (wolume)

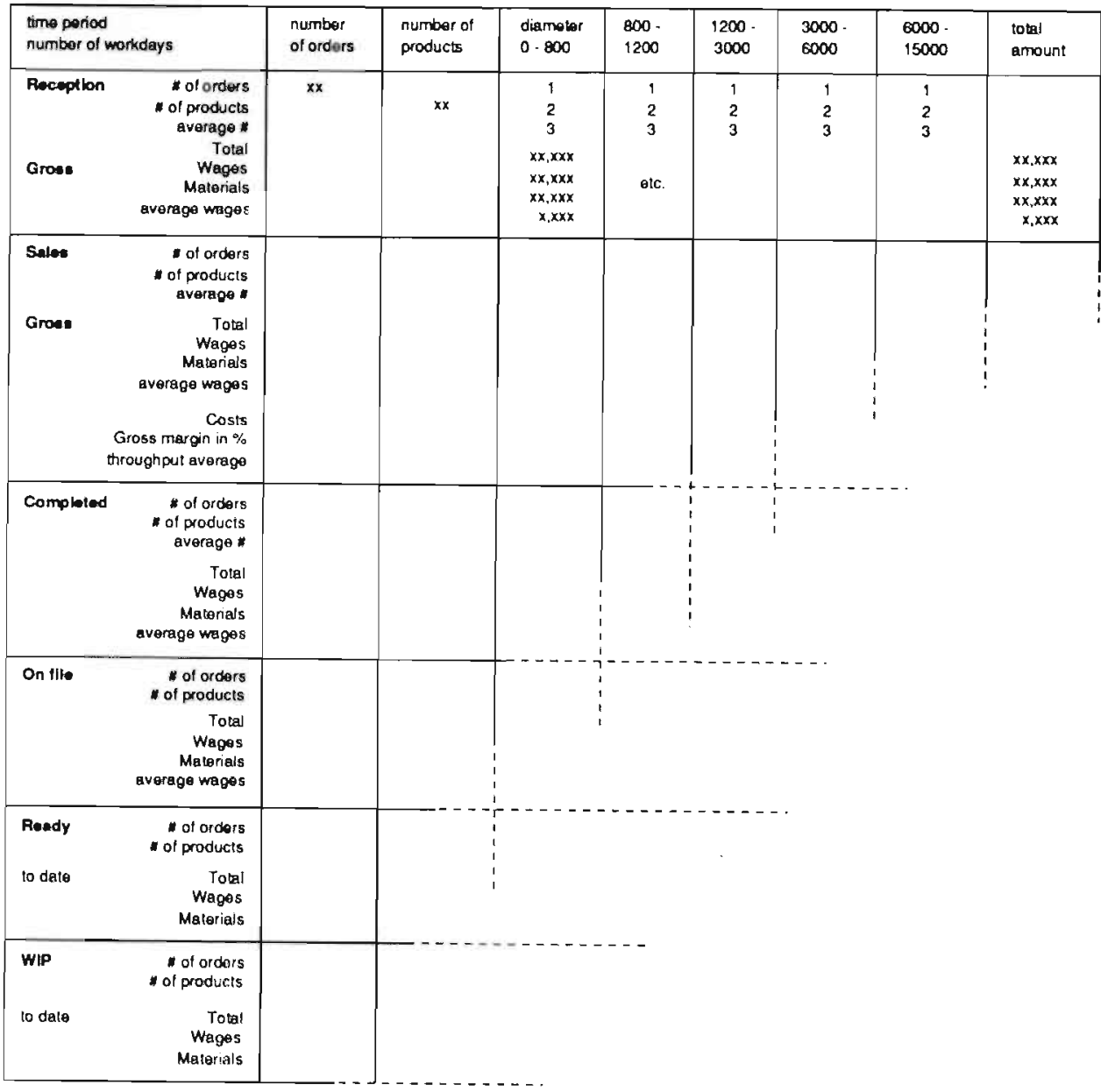

Figure 6.15 The period report regarding volume (Source: regular company report)

Period Report (pertormance per order)

\begin{tabular}{|c|c|c|c|c|c|c|c|c|}
\hline $\begin{array}{l}\text { Order } \\
\text { number }\end{array}$ & Customer & Specification & Price & $\begin{array}{l}\text { Credit - } \\
\text { note }\end{array}$ & Cosis & Margin & vs & Costs \\
\hline \multirow{4}{*}{$\begin{array}{r}12345.12 \\
.13 \\
.14\end{array}$} & \multirow{4}{*}{$\begin{array}{l}\text { Smith \& Jones Plc } \\
\text { Smith \& Jones Plc } \\
\text { Smith \& Jones Plc }\end{array}$} & \multirow{4}{*}{$\begin{array}{l}1 \mathrm{~KB} 1234.0 \mathrm{I}^{*} 12.0(12.0) \mathrm{h} 12.0 \\
\text { olc. } \\
\text { olc. } \\
\end{array}$} & $x \mathbf{x}, \mathbf{x x x}, \mathbf{x x}$ & $\cdot$ & $x, x \times x, x$ & $x x, x \times X X, x x$ & & $+x x \%$ \\
\hline & & & $x x, x x x, x x$ & . & $x, x \times x, 0 x$ & $x x, x \times x, x x$ & & $-x x \%$ \\
\hline & & & $x x, x \times x, x x$ & $\therefore$ & $x, 0 \times x, x$ & $x x, x, x, x x$ & & $+x \times \%_{0}$ \\
\hline & & & $\alpha, \infty x, x x$ & - & $x, x \times x, x x$ & $x x, x, x x, x x$ & & $+x x \%$ \\
\hline \multirow{3}{*}{$\begin{array}{r}23456.22 \\
.23\end{array}$} & \multirow{3}{*}{$\begin{array}{l}\text { Roberts Plc } \\
\text { Roberts Plc }\end{array}$} & \multirow{3}{*}{$\begin{array}{l}2 \text { HD } 1902.0^{\circ} \because-(3.0) \text { h } 13.0 \\
\text { olc. } \\
\end{array}$} & $x \alpha, x \times x, x x$ & 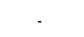 & $x, \operatorname{OXX}, \mathbf{X X}$ & $x x, x X X X X X$ & & $+x x \%$ \\
\hline & & & $x x, \infty x, x x$ & - & $x, x \times x, x x$ & $x x, x x x, x x$ & & $-x \times \%$ \\
\hline & & & $x x, x \alpha x \times x$ & $\cdot$ & $x, x \times x, x$ & $x x, x x x, x x$ & & $+x x^{2} \%$ \\
\hline etc. & otc. & otc. & elc. & & otc. & etc. & & elc. \\
\hline
\end{tabular}

Figure 6.16 The period report regarding performance (Source: regular company report) 


\begin{tabular}{|c|c|c|c|c|c|c|c|c|c|c|c|c|}
\hline \multicolumn{3}{|c|}{$\begin{array}{l}\text { Orderno: } 12345.11 \\
\text { Customer: Smith s Jones Plc } \\
\text { Completion date: } 23 / 1,192 \\
\text { Order active: } 19 \text { days }\end{array}$} & \multicolumn{5}{|c|}{$\begin{array}{l}\text { Specification: } 34 * 15.0 \text { (22)h } 31 \\
\text { Number: } 1 \\
\text { Material: } R \quad 1.4401\end{array}$} & \multicolumn{4}{|c|}{$\begin{array}{l}\text { Accounted amount exct, material s credit } \\
\text { Amount own transport } \\
\text { Amount subccntracted transport }\end{array}$} & \multirow[t]{2}{*}{$\begin{array}{r}950.00 \\
110.00 \\
0.00\end{array}$} \\
\hline \multirow[b]{2}{*}{ Oper. } & \multirow[b]{2}{*}{ Descriplion } & \multicolumn{3}{|c|}{ …........ Planning ……… } & \multirow[b]{2}{*}{$\begin{array}{l}\text { Plan } \\
\text { date }\end{array}$} & \multirow{2}{*}{ Cho:h\} } & \multirow{2}{*}{$\begin{array}{l}\text { Actual - } \\
\text { Prod(h) }\end{array}$} & \multirow[b]{2}{*}{$\operatorname{Cos} 1 \mathrm{~s}$} & \multirow[b]{2}{*}{$\begin{array}{l}\text { Dale } \\
\text { rady }\end{array}$} & \multirow{2}{*}{$\begin{array}{l}\text { Picking/ } \\
\text { Annealing/ } \\
\text { X-ray }\end{array}$} & \multirow[b]{2}{*}{$\begin{array}{l}\text { Subcontracted } \\
\text { work }\end{array}$} & \\
\hline & & Choo(h) & $\operatorname{Prod}(h)$ & $\cos t 5$ & & & & & & & & Pertormance \% \\
\hline 10 is & input controd & & & & 921023 & & & & 921023 & & & \\
\hline 206 & engraving ordem & & $16 . \infty$ & & 921024 & & 0.50 & 22.00 & 921024 & & & \\
\hline 6009 & wolding & & & & & 0.45 & 0.30 & 31.50 & 921030 & & & \\
\hline $6002 \mathrm{p}$ & prossing & & & & & 0.80 & 1.00 & 456.50 & 921101 & & & \\
\hline $6004 P$ & pickling & & & & & & 6.50 & & 921109 & 210.00 & & \\
\hline \multirow[t]{3}{*}{$\begin{array}{l}9400 \\
9500\end{array}$} & $\begin{array}{l}\text { int. } / \text { oxt. transfer } \\
\text { output controt }\end{array}$ & & & & $\begin{array}{l}921028 \\
921029\end{array}$ & & & & $\begin{array}{l}921111 \\
921111\end{array}$ & & & \\
\hline & & & $\overline{16.00}$ & & & $\overline{1.25}$ & $\overline{8.30}$ & $\overline{510.00}$ & & $\overline{210.00}$ & 0.0 & $230.00+15 \%$ \\
\hline & Throughpul 6 de & days & & & & & & & Porconta & ge over accour & 1 lod amount +2 & \\
\hline $\begin{array}{l}\text { Cho }(h) \\
\text { Prodin) } \\
\text { Opar. }\end{array}$ & $\begin{array}{l}=\text { Changeover } \\
=\text { Production in } \\
=\text { Operation nu }\end{array}$ & $\begin{array}{l}\text { in hours } \\
\text { In hours } \\
\text { umber }\end{array}$ & & & & & & & & & & \\
\hline
\end{tabular}

\begin{tabular}{|c|c|}
\hline PRODUCTION THROUGHPUT & $\begin{array}{l}\text { the difference botween the planned start date and the planned end date } \\
\rightarrow 29 \text { Oct. } 92 \cdot 23 \text { Oct. } 92=6 \text { days }\end{array}$ \\
\hline ORDER THROUGHPUT & $\begin{array}{l}\text { throughput days plus the diflerence between pianned and actual date ready } \\
\rightarrow 6 \text { deys }+13 \text { days }(20 / 10 / 92-11 / 11 / 92)=19 \text { days }\end{array}$ \\
\hline PERFORMANCE & $\begin{array}{l}\text { calculated as actual costs plus special operations pius supplies tess accounted emount } \\
\text { In absolule numbers: }[510+210+0)-950=230 \\
\text { in percentage over production costs: }(230+510)-100 \%=+45 \times \\
\text { in percentage over sales price: }(230+950)=100 \%=+24 \%\end{array}$ \\
\hline
\end{tabular}

Figure 6.17 The ex post calculation (Source: regular company report)

The operations of pickling, annealing and X-raying are mentioned separately because they are per unit operations instead of hourly process operations. The accounted amount is in fact the planned sales price. The two percentages calculated therefore refer to performance on the basis of production costs $(45 \%)$ and on the basis of sales price (24\%). The tariffs obtained from the cost pool method are used to calculate the actual cost per order; they function as a sort of standard unit price of input. Actual unit prices of operations input are not used in the cost pool method for setting tariffs.

Together with the period report on performance, the ex post report allows for control of time and financial resource consumption, as well as technical bottlenecks.

\section{A First Assessment}

In general, the insights into the connections between all phases in the process flow have increased. Typically, it has led to a strong incentive for Quality Assurance, and the use of norms and standards for all activities in general.

The cost-benefit analysis made by the head of Central Planning, occupied with the STSD project as well as being the production manager, showed the following assessment of the change venture: 


\section{Chapter 6}

\section{Costs}

\section{Quantitative}

* Takes up a lot of energy and man hours;

* Forming task groups requires investments in:

- additional tools and supplies to have task groups function without outside interference;

- training and coaching of top and middle management;

- appliances to generate information (St. Antonius spent 150,000 guilders on a laser printer and hardware and software to generate blueprints in the way production groups would have provided them);

* Introducing work counselling takes up manufacturing labour hours (in St. Antonius' case 4,800 hours a year, which amounted to 480,000 guilders);

* Reorganising the production layout is costly. For relocation of machinery, St. Antonius set aside 12 million guilders for a duration of three years. However, relocation offered the opportunity to direct their attention towards working conditions;

* Employees view the changes as a burden; at the beginning of the change process absenteeism dropped from $10 \%$ to $7.5 \%$, this was later followed by an increase to $20 \%$, which lasted for almost two months. It has now returned to $8 \%$;

* The actual design of the new organisation and subsequent training took about 8,000 man hours, 6,000 hours of which were accomplished by the employees during their personal time. The final costs to the firm amounted to 200,000 guilders.

\section{Qualitative}

* Increased pressure on people to attend courses and training programmes;

* Stress at various organisational levels; all managerial levels have to start thinking from the process upwards, forgetting about their disciplinary focus and training;

* Insecurity in many people as to what the reorganisation will hold in store for them.

\section{Benefits}

\section{Quantitative}

* More has become known by simply measuring things: More attention is paid to material knowledge, and throughput times can (now) be measured;

* Labour productivity has increased, to the extent that, despite the work counselling, $2 \%$ more output is produced ( $2 \%$ equals 295,000 guilders, considering that the work counselling costs of 480,000 guilders have already been made up for);

* Shorter throughput times:

- throughput time of the preparatory production stage (the office trajectory) decreased from 11 to 3 working days;

- full throughput time decreased from a 45-day average to a 24-day average. This led to an average decrease in WIP of 440,000 guilders;

- a decrease in sheet metal inventory holdings from 1400 tons to 400 tons is mainly due to an improved insight into throughput time and the subsequent arrangements with suppliers; 
- an increase in order position by $66 \%$ first led to an increase in throughput time of all products from 9 to 16 weeks. However, after a selective market approach introducing various market segments, it has again been reduced with 5 to 10 weeks, depending upon the specific market segment;

* Qualitative improvement in the documentation supplied to the customer;

* Costs are more traceable;

* Better information is available to the customer concerning the progress of their order;

* The amount of repair down-time hours in production has decreased from $5 \%$ to $2 \%$;

* The amount of actual hours worked has increased as a result of group initiatives. For example, a shift in lunch and coffee break schedules at the press operations, where bottlenecks are prevalent, led to an annual capacity increase of 233 production hours $(200,000$ guilders).

\section{Qualitative}

* Starting up an innovative, self-renewing organisation;

* An increase in knowledge of production, materials and construction codes as a result of recording procedures and norms. This saves a lot of planning and scheduling time;

* Task groups, with their internal job rotation systems, are less vulnerable to absenteeism. For example, during the $20 \%$ absenteeism period, production continued without disruption;

* The lines of communication have shortened and are less dependent upon the corridors of power;

* People have become more open;

* Everything is turned upside down. Many taboos have been broken and it is evident that many things can be done much better; craftsmanship is limited to 'real' craftsmanship.

IDEF is the abbreviation of Integrated DEFinition method and is the activity diagramming part of the commercial software package SADT (Structured Analysis and Design Technique). IDEF has IDEF 0, IDEF 1 and IDEF 2 type models working deeper into the dynamic modelling for systems simulation. Although mainly known to information system designers, IDEF can be used for any function and information analysis of a complex subject (e.g., van Koetsveld, 1984; Moravec and Yoemans, 1992).

8 Presently (Summer 1992), Central Planning is working on a method to establish the production process and, thus, product cost, only once.

9 The cost pool method, being of German origin, is not known to Anglo-Saxon accounting. However, it is widely used in Europe and part of the traditional body of knowledge of European accounting. See for a more detailed discussion A.N.A.M. Boons, H.J.E. Roberts and F.A. Roozen, Contrasting Activity-Based Costing with the German/Dutch Cost Pool method, in: Management Accounting Research, vol. 3, no. 2, 1992, pp. 97-117.

10 Typically, Administrative Organisation $(\mathrm{AO})$ is a separate subdiscipline in accountancy in The Netherlands, related to administrative control and information supply. The presence of an AO system is required by external auditors to allow for an unqualified opinion on the annual report. In other countries, it is unknown as a separate discipline and considered part of Accounting Information Systems (AIS) or Information Systems in general. 


\section{Appendix}

\section{Examples of the period report subcategories on volume and performance}

Period Feport (Orders receiverd)

\begin{tabular}{|c|c|c|c|c|c|c|c|c|}
\hline $\begin{array}{l}\text { Tirne period: } \\
x \times / \times x / 92-x \times / \times x / 92 \\
\text { Orders received }\end{array}$ & $\begin{array}{l}\text { Article } \\
\text { code }\end{array}$ & $\begin{array}{l}\text { Product } \\
\text { volume }\end{array}$ & $\begin{array}{l}\text { diameter } \\
0-800\end{array}$ & $\begin{array}{l}800- \\
1200\end{array}$ & $\begin{array}{l}1200 \\
3000\end{array}$ & $\begin{array}{l}3000 \\
6000\end{array}$ & $\begin{array}{l}6000 \\
15000\end{array}$ & $\begin{array}{l}\text { Total financial } \\
\text { amount }\end{array}$ \\
\hline & AA & $x x$ & $x$ & & $x x$ & & $x x$ & $x x, x \times x, x x$ \\
\hline & $A B$ & $x$ & & $x x$ & & $x$ & $x$ & $x, x x x, x x$ \\
\hline & $\mathrm{CO}$ & $x x$ & $x x$ & $x$ & & $x$ & & $x x, x x x, x x$ \\
\hline & $\mathrm{DE}$ & $x x$ & & $x$ & $x$ & $x$ & $x x$ & $x x, x x x, x x$ \\
\hline & $F G$ & $x$ & $x$ & $x x$ & & $x$ & $x$ & \\
\hline Total: & & $x x$ & $x x$ & $x x$ & $x x$ & $x$ & $x x$ & $x \times x, x x x, x x$ \\
\hline
\end{tabular}

Period Report (Quality of orders received)

\begin{tabular}{|c|c|c|c|c|c|c|c|c|}
\hline $\begin{array}{l}\text { Time period: } \\
x \times / x \times / 92-x \times / x \times / 92 \\
\text { Quality orders } \\
\text { received }\end{array}$ & $\begin{array}{l}\text { Level } \\
\text { code }\end{array}$ & $\begin{array}{l}\text { Product } \\
\text { volume }\end{array}$ & $\begin{array}{l}\text { diameter } \\
0.800\end{array}$ & $\begin{array}{l}800- \\
1200\end{array}$ & $\begin{array}{l}1200- \\
3000\end{array}$ & $\begin{array}{l}3000 \\
6000\end{array}$ & $\begin{array}{l}6000 \\
15000\end{array}$ & $\begin{array}{l}\text { Total linancial } \\
\text { amount }\end{array}$ \\
\hline NO code total & $\begin{array}{l}8.6 \\
9.3 \\
9.4 \\
9.5\end{array}$ & $\begin{array}{r}x x \\
x \\
x x \\
x x \\
x\end{array}$ & $\begin{array}{r}x x \\
x \\
\end{array}$ & $\begin{array}{l}x x \\
x \\
x \\
x x \\
\end{array}$ & $x$ & $\begin{array}{l}x \\
x \\
x \\
x \\
\end{array}$ & $\begin{array}{l}x x \\
x \\
x x \\
x\end{array}$ & $\begin{array}{r}x x, x x x, x x \\
x, x x x \times x x \\
x x, x x x, x x \\
x x, x x x \cdot x x \\
x, x x x, x x \\
\end{array}$ \\
\hline Totgl: & & $x \times x$ & $x x$ & $x x$ & $x x$ & $x$ & $x x$ & $x x x, x x x, x x$ \\
\hline
\end{tabular}

Period Report (Sales volume)

\begin{tabular}{|c|c|c|c|c|c|c|c|c|}
\hline $\begin{array}{l}\text { Time period: } \\
x \times / \times x / 92-x \times / x \times 192 \\
\text { Sales volume }\end{array}$ & $\begin{array}{l}\text { Article } \\
\text { code }\end{array}$ & $\begin{array}{l}\text { Producl } \\
\text { volume }\end{array}$ & $\begin{array}{l}\text { diameler } \\
0 \text { - Bo0 }\end{array}$ & $\begin{array}{l}800- \\
1200\end{array}$ & $\begin{array}{l}1200- \\
3000\end{array}$ & $\begin{array}{l}3000- \\
6000\end{array}$ & $\begin{array}{l}6000 \\
15000\end{array}$ & $\begin{array}{l}\text { Total financial } \\
\text { amount }\end{array}$ \\
\hline & $\begin{array}{l}A A \\
A B \\
C D \\
D E \\
F G\end{array}$ & $\begin{array}{l}x x \\
x \\
x x \\
x x \\
x\end{array}$ & $\begin{array}{l}x \\
x \\
x \\
x\end{array}$ & $\begin{array}{c}x x \\
x \\
x \\
x x\end{array}$ & $x x$ & $\begin{array}{l}x \\
x \\
x \\
x\end{array}$ & $\begin{array}{c}x x \\
x \\
x x \\
x \\
\end{array}$ & $\begin{array}{r}x x, x x x, x x \\
x, x x x, x x \\
x x, x x x, x x \\
x x, x x x, x x \\
x, x x x, x x\end{array}$ \\
\hline Totai: & & $x \times x$ & $x x$ & $x x$ & $x x$ & $x$ & $x x$ & $x \times x, x x x, x x$ \\
\hline
\end{tabular}

Penod Report (Quality of sales volume)

\begin{tabular}{|c|c|c|c|c|c|c|c|c|}
\hline $\begin{array}{l}\text { Time period: } \\
\times x / \times \times / 32-x \times / \times \times / 92 \\
\text { Quality of sales } \\
\text { volume }\end{array}$ & $\begin{array}{l}\text { Lovel } \\
\text { code }\end{array}$ & $\begin{array}{l}\text { Product } \\
\text { volume }\end{array}$ & $\begin{array}{l}\text { diameter } \\
0.800\end{array}$ & $\begin{array}{l}800= \\
1200\end{array}$ & $\begin{array}{l}1200- \\
3000\end{array}$ & $\begin{array}{l}3000 \\
6000\end{array}$ & $\begin{array}{l}6000 \\
15000\end{array}$ & $\begin{array}{l}\text { Total ftnancial } \\
\text { amount }\end{array}$ \\
\hline No ccde idal & $\begin{array}{l}3.6 \\
9.3 \\
9.4 \\
9.5\end{array}$ & $\begin{array}{r}\overline{x x} \\
x \\
x x \\
x x \\
x \\
\end{array}$ & $\begin{array}{r}x x \\
x \\
\end{array}$ & $\begin{array}{l}x x \\
x \\
x \\
x x\end{array}$ & $x$ & $\begin{array}{l}x \\
x \\
x \\
x\end{array}$ & $\begin{array}{l}x x \\
x \\
x x \\
x\end{array}$ & $\begin{array}{r}x x, x x x, x x \\
x, x x x, x x \\
x x, x x x, x x \\
x x, x x x, x x \\
x, x x x, x x\end{array}$ \\
\hline Total: & & $x \times x$ & $x x$ & $x x$ & $\overline{x x}$ & $x$ & $x x$ & $x \times x, x \times x, x x$ \\
\hline
\end{tabular}

Period Report (Quality of volume on file)

\begin{tabular}{|c|c|c|c|c|c|c|c|c|}
\hline $\begin{array}{l}\text { Time period: } \\
x \times 3 \times \times 92-x \times 1 \times x / 92 \\
\text { Ouality volume } \\
\text { on file }\end{array}$ & $\begin{array}{l}\text { Level } \\
\operatorname{cod} \theta\end{array}$ & $\begin{array}{l}\text { Product } \\
\text { volume }\end{array}$ & $\begin{array}{l}\text { diameter } \\
0.800\end{array}$ & $\begin{array}{l}800= \\
1200\end{array}$ & $\begin{array}{l}1200 \\
3000\end{array}$ & $\begin{array}{l}3000- \\
6000\end{array}$ & $\begin{array}{l}6000- \\
15000\end{array}$ & $\begin{array}{l}\text { Total financial } \\
\text { amount }\end{array}$ \\
\hline NO code total & & $x x$ & & & & & $x x$ & $x x, x 0 x, x x$ \\
\hline OP toral & 1.5 & $x$ & & $x x$ & & $x$ & $x$ & $x, \overline{x x x, x x}$ \\
\hline FIP total & $5 ?$ & $x x$ & $\times x$ & $x$ & & $x$ & & $x \times, x \times x, x x$ \\
\hline & $\begin{array}{l}8.3 \\
9.3 \\
\end{array}$ & $\begin{array}{r}x x \\
x\end{array}$ & $\underline{x}$ & $\begin{array}{l}x \\
x x \\
\end{array}$ & $x$ & $\begin{array}{l}x \\
x \\
\end{array}$ & $\begin{array}{r}30 x \\
\times \\
\end{array}$ & $\begin{array}{r}x x, x x x, x x \\
x, x x x, x x\end{array}$ \\
\hline FP rotal & & $x x x$ & $\overline{x x}$ & $x x$ & $x x$ & $x$ & $x x$ & $x \times x, x \in x, x x$ \\
\hline Total: & & $x \times x$ & $x x$ & $x x$ & $x$ & $x x$ & $x x$ & $x \times x, x \times x, x x$ \\
\hline
\end{tabular}

Figure 6.18 Period report - volume subcategories (Source: regular company report) 
Period Report (performance per customer - customer-aligned)

\begin{tabular}{|c|c|c|c|c|c|c|c|}
\hline $\begin{array}{l}\text { Customer } \\
\text { number }\end{array}$ & Customer & $\begin{array}{l}\text { Product } \\
\text { volume }\end{array}$ & Sales & Credil note & Cosis & Matrgin & vs Costs \\
\hline \multicolumn{8}{|c|}{ Aligned according to Sales (mumbers are fictional) } \\
\hline 1 & Smithe Jones Plc & 5 & $22,897.12$ & & $21,338.00$ & 1.558 .12 & $7.3 \%$ \\
\hline 2 & Robens Plc & 12 & 21.450 .00 & & $16,480.00$ & $4,970.00$ & $30.15 \%$ \\
\hline 3 & L1O Industries & 9 & $14,355.80$ & & $15,870.85$ & $-1,515.05$ & $.9 .5 \%$ \\
\hline 4 & DeFe consiructions & 2 & $12,250.90$ & & 11.150 .00 & 1.100 .90 & $9.8 \%$ \\
\hline 5 & Metallo Plc & 7 & $9,350.00$ & & 4.468 .95 & 4.881 .05 & $109.22 \%$ \\
\hline etc. & $\theta t c$ & elc. & otc. & & elc. & aic. & elc. \\
\hline \multicolumn{8}{|c|}{ Aligned according to Product Volume (numbers are lictional) } \\
\hline 1 & Roberts Plc & 12 & $21,450.00$ & & 16.480 .00 & $4,970.00$ & $30.15 \%$ \\
\hline 2 & LIO Industries & 9 & $14,355.80$ & & $15,870.85$ & $-1,515.05$ & $-9.5 \%$ \\
\hline 3 & Metallo Plc & 7 & $9,350.00$ & & $4,468.95$ & $4,881.05$ & $109.22 \%$ \\
\hline 4 & Smith\&Jones Plc & 5 & 22.897 .12 & & $21,338.00$ & 1.559 .12 & $7.3 \%$ \\
\hline 5 & Defe constructions & 2 & $12,250.90$ & & 11.150 .00 & $1,100.90$ & $9.8 \%$ \\
\hline etc. & elc. & & etc. & & elc. & elc. & elc. \\
\hline
\end{tabular}

Period Report (pertormance per customer - pertormance-aligned)

\begin{tabular}{|c|c|c|c|c|c|c|c|}
\hline Ranking & Custormer & $\begin{array}{l}\text { Product } \\
\text { volume }\end{array}$ & Sales & Credit nole & Cosis & Margin & us Cosis \\
\hline \multicolumn{8}{|c|}{ Aligned according to pertomance $\%$ tor sales $>15,000$} \\
\hline$\uparrow$ & Roberts Plc & 12 & $21,450.00$ & & 16.480 .00 & 4.970 .00 & $30.15 \%$ \\
\hline 2 & Smith\&Jones Plc & 5 & $22,897.12$ & & 21.338 .00 & $1,559.12$ & $7.3 \%$ \\
\hline elc. & elc. & elc. & etc. & & elc. & otc. & etc. \\
\hline \multicolumn{8}{|c|}{ Aligned according to performance $\%$ for sales $<15,000$} \\
\hline 1 & Melallo Plc & & 9.350 .00 & & 4.468 .95 & 4.881 .05 & $109.22 \%$ \\
\hline 2 & Defe consiructions & 7 & $12,250.90$ & & $11,150.00$ & 1.100 .90 & $9.8 \%$ \\
\hline 3 & L. Industries & 2 & 14.355 .80 & & $15,870.85$ & $-1,515.05$ & $-9.5 \%$ \\
\hline etc. & elc. & 9 & etc. & & etc. & elc. & elc. \\
\hline
\end{tabular}

Perlod Report (performance per country)

\begin{tabular}{|c|c|c|c|c|c|}
\hline Country & $\begin{array}{l}\text { Product } \\
\text { volume }\end{array}$ & Sales & Credit note & Margin vs & Cosis \\
\hline Belgium & $x x x$ & $x, x x x, x x x, x x$ & $x, x x x, x x x, x x$ & $x x, x x x, x x$ & $x x . x \times \%$ \\
\hline Germany & $x \times x$ & $x, x x x, x \times x, x x$ & $x \times x, x \times x, x x$ & $x x, x x x, x x$ & $x \times x \times \%$ \\
\hline France & $x x$ & $x \times x, x \times x, x x$ & $x x, x \times x, x x$ & $x x, x x x, x x$ & $x \times x \times \%$ \\
\hline Sweden & $x x$ & $x \times x, x \times x, x x$ & $x x, x x x, x x$ & $x x, x x x, x x$ & $x \times x \times \%$ \\
\hline \multirow[t]{2}{*}{ Nelherlands } & $x x$ & $x \times x \times x \times x$ & $x \times x \times x \times x$ & $x x, x x x, x x$ & $x \times x \times \%$ \\
\hline & Total: & $x, x \times X, X x x, x x$ & $x, x, x, x \times x, x x$ & $x \times x, x x x, x x$ & $x \times x \times \%$ \\
\hline
\end{tabular}

Period Repont (pertormance per salesman)

\begin{tabular}{|c|c|c|c|c|c|c|c|}
\hline Salesman Code & $\begin{array}{l}\text { Product } \\
\text { volume }\end{array}$ & Sales & Credín note & Costs & Margin & vs & Costs \\
\hline 1 & $x$ & $x x x, x x x . x x$ & & $x x, x, x x x, x x$ & $x x, x x x, x x$ & & $x \times \times x \%$ \\
\hline 2 & $x$ & $x \times x, x \times x, x x$ & & $x \times x, x \times x, x x$ & $x x, x x x, x x$ & & $x \times x \times \%$ \\
\hline 3 & $x$ & $x x x, x x x, x x$ & & $x x x, x x x, x x$ & $x x, x \times x \times x x$ & & $x x, x \times \%$ \\
\hline 4 & $x x$ & $x x x, x x x, x x$ & & $x \in X, x \in X, x x$ & $x x, x \mathbf{x x} x \mathbf{x x}$ & & $x \times x x \%$ \\
\hline \multirow[t]{2}{*}{5} & $x$ & $x x x . x x x, x x$ & & $x \times x \times x \times x \times x$ & $x x, x \times x \times x x$ & & $x \times x \times \%$ \\
\hline & Tolal: & $x, x x x, x x x, x x$ & & $\begin{array}{l}x, x \times x, x \times x, \times x \\
\% \text { over order amount }\end{array}$ & $\begin{array}{c}x \times x, x \times x, x \times \\
x \times, x \times \%\end{array}$ & & $x \times x \times \%$ \\
\hline
\end{tabular}

Figure 6.19 Period report - periormance subcategories (Source: regular company report) 


\section{Case Analysis and Cross-Case Comparison}

In this chapter, the three case studies are analysed based on grounded theory procedures as advocated by Strauss and Corbin. To explain the working of these procedures, the first case analysis of Van Nelle is used as an example, detailing the lines of argument and the specifics of each procedural step. Cases are analysed individually. After each case analysis, the axial pattern (i.e., the causal pattern of events and related characteristics) and the storyline (i.e., the summary line of argument) respectively are compared. It is concluded that organisational learning plays a major role in the change processes of organisation design and management accounting design. Key factor in setting up organisational learning is the STSDbased change management approach used. The strategic choice of a human resource-based vision of the organisation, flow-oriented production and simple accounting systems work together to maintain organisational learning and institute a process of continuous improvement.

The three case studies are analysed using the procedures of grounded theory (Strauss and Corbin, 1991). Grounded theory procedures are based on a data grouping and regrouping system called a coding process. It distinguishes three types of coding in a specific order: Open coding, axial coding and selective coding. Open coding is the first data-grouping step, by putting field observations into data categories. Next, these data categories are regrouped accordingly by using another axis, i.e., a core category overlapping all previous open-coded categories. This is called axial coding. The final coding step is selecting the phenomenon present in the core category which, consequently, is also present in all open-coded categories but did not 'shine through': This last stage is called selective coding. When the coding procedure is concluded, field observations are categorised and reduced in such a fashion that they tell the story of what happened during the period of observation. This 'storyline' is a causal narrative providing insight into the evolving nature of events. To put it another way, the storyline explains why and how things took shape. 
In the following chapter, coding procedures are used in the three separate case studies as described above. Input for open coding are, therefore, the full case descriptions, allowing the reader to trace back any inferences or analysis steps. The coding procedure is repeated for both the case studies and the cross-case analysis. The resulting cross-case storyline thus provides the basis for more formal, topicconstrained conclusions.

Each case study was described in chronological order, beginning with the felt need for change and how it was further articulated, to the situation where a preliminary assessment of completed changes is undertaken. Therefore, all open coding follows this initial chronological grouping of data. Furthermore, the three cases are specifically selected on the redesign of both their organisation and their management accounting system. In contrast, many situations are available where only one of the two is subject to change. For example, where only the management accounting design is changed but the organisation structure remains the same. Therefore, the selection of cases having consonance between the two design changes implies that lessons from cases where there was dissonance between the two designs (i.e., only one design was changed) are not considered. In other words, the selection of research sites influences the outcome of the conclusions. Second, and maybe this has to do with the consonance characteristic, these cases follow the normative prescriptions of STSD theory relatively closely. Weaknesses in STSD are consequently ignored due to their absence in the acquired data. A critical analysis of STSD in itself is therefore impossible, if based solely upon the research evidence presented here. For this reason, it is important to repeat the research question and ensure that it focuses on the influence of organisational redesign on management accounting systems design and not on the comparison or evaluation of STSD.

\section{Grounded Analysis of Van Nelle Tobacco/Rotterdam Plant}

Van Nelle Tobacco/Rotterdam plant (hereafter referred to as Van Nelle) maintains an exceptional position in the case study range. First of all, because it was used as the basis for the very first case: It functioned as a reference point for further observations. This project was started without any previous expectations as no prior cases or literature were available. To date, it is the case that boasts the largest amount of observations and data gathered. It also meant that the relative importance of open interviews was the greatest in all three case studies. As can be expected, this shows in itself both size and structure of the case description. In short, the full force of insecurity and uncertainty in doing grounded research was felt in this first case study.

This 'first case position' is maintained in the grounded theory approach as seen below. Per coding step in the Van Nelle case, each individual step is briefly explained in terms of the procedural techniques involved. This allows for an understanding of the outcome as well as the analysis procedure. The other reason for its exceptional position was its situational background. It is the only case regarding an organisation that became part of a larger functionally structured organisation, which is also of non-European origin. The other two cases concern fully independent organisations of Dutch origin. Therefore, the case description combines two major 
'externalities': It contains a takeover situation inclusive of all merging of activities and processes, and it contains national and managerial cultural factors. However, discussion of either of the two externalities is not attempted because both the research question and research design were not framed to do so.

\title{
Open Coding
}

The chronology of the case description equals the sequences in the time path of the change trajectory. Each sequence is described in a separate paragraph of the case description, leading to, for example, the distinction into: The Introduction Phase (1984-1986), The Analysis Phase (1986-April 1987) and The Learning Phase (April 1987-May 1988). Although neatly grouped as observations, they seem to be maintained at too abstract a level, because open coding requires that:

\begin{abstract}
"During open coding the data are broken down into discrete parts, closely examined, compared for similarities and differences, and questions are asked about the phenomena as reflected in the data. By breaking down and conceptualizing we mean taking apart an observation, a sentence, a paragraph, and giving each discrete incident, idea, or event, a name, something that stands for or represents a phenomenon." (Strauss and Corbin, 1991, pp. 62/63)
\end{abstract}

Therefore, the paragraphs are broken down into discrete incidents and listed together with the phenomenon and the incidents they represent (see Table 7.1). The analytical effort here is to find and couple phenomena to the incidents, as the case descriptions are incidence listings in themselves.

Table 7.1 Coupling phenomena to incidents in the case description of Van Nelle

\begin{tabular}{|c|c|c|}
\hline Paragraph in caseo description & Incldent: & Phenomena \\
\hline \multirow[t]{7}{*}{ The Introduction Phase } & lagging operating performance & pertormance sag \\
\hline & management buy-out & change of controf \\
\hline & restructuring policy statement & change assessment \\
\hline & product group organisation structure & change full organisation structure \\
\hline & management development plan & \multirow{3}{*}{ Human Resource Management } \\
\hline & relocation of personnel & \\
\hline & all-level training programmes & \\
\hline \multirow[t]{6}{*}{ The Analysis Phas $\theta$} & quality campaign & \multirow{2}{*}{ building involvement } \\
\hline & follow-up campaign & \\
\hline & redesign action plan & \multirow{3}{*}{ job design } \\
\hline & STAP analysis & \\
\hline & revision of job/rank classification & \\
\hline & IKZ report on task group structure & structural redesign statement \\
\hline \multirow[t]{11}{*}{ The Learning Phase } & appointment of task group leaders & \multirow{2}{*}{ change structure } \\
\hline & per task group implementation plans & \\
\hline & adapting budget structure & \multirow{3}{*}{ fitting the design } \\
\hline & task group training programmes & \\
\hline & surrounding deptartments informed & \\
\hline & task groups lunctioning & use \\
\hline & takeover & change of control \\
\hline & tunctional recentralisation of org. structure & \multirow{2}{*}{ fitting the mother } \\
\hline & company-rule reporting system & \\
\hline & freeze of change projects & \multirow{2}{*}{ legitimation } \\
\hline & A'dam plant continues task group structure & \\
\hline
\end{tabular}


The phenomena found after listing the incidents now provide an input to the conceptualisation phase. Again, this means regrouping and reducing case observations to an even more abstract level. Or, as Strauss and Corbin (1991, p. 65) put it:

"Once we have identified particular phenomena in data, we can begin to group our concepts around them. This is done to reduce the number of units with which we have to work. The process of grouping concepts that seem to pertain to the same phenomena is called categorizing. The phenomenon represented by a category is given a conceptual name, however, this name should be more abstract than that given to the concepts grouped under it."

Naming categories is an important step since it indicates the first move towards conceptualising raw data/observations. The advice given here by Strauss and Corbin is twofold: Be aware of using concepts from your own disciplinary background or theoretical literature as they bear commonly held meanings and associations with them and, second, name categories by phrases or words used by informants themselves, the so-called in vivo codes. In other words, go back to your transcribed interviews and look for catch words/phrases that brought on an Ahaerlebnis. In the case of Van Nelle, the following categories resulted:

Table 7.2 Open-coding categories and their dimensional profile the case description of Van Nelle

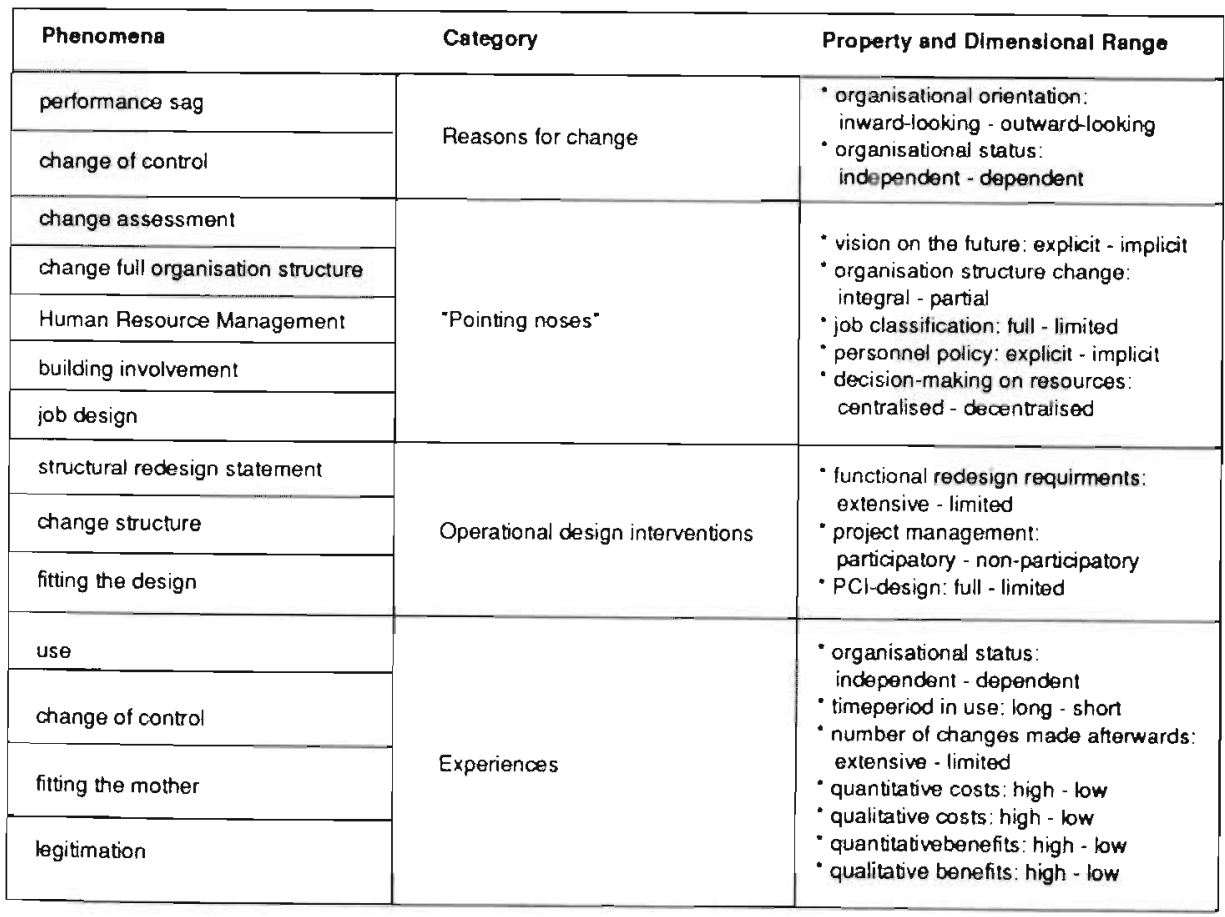

The final step in open coding is developing the categories, i.e., you blow up the one-dimensional concept by its characteristics. This is accomplished by distinguishing properties and dimensions. Properties are the characteristics of a conceptual category, while dimensions locate a property along a continuum, for example, 
an organisation has an inward- or outward-looking focus of orientation with inward-/outward-looking being a characteristic for the concept of change motivation. As a result, each conceptual category acquires several general properties with each property varying over a dimensional continuum; this is called a dimensional profile. A dimensional profile thus depicts the specific characteristics of a phenomenon under a given set of conditions (Strauss and Corbin, 1991, p. 70). In other words, it is a listing of the variables (the category) and their operationalisation (property and dimensional range).

The importance of this step is that properties and dimensions are the basis for building relationships between various categories, i.e., the causal order of events can be rebuilt in abstract terms. For example, the property and dimensions of inward/outward focus of orientation of the category Reasons for change can be used to link up with the property of functional redesign requirements of the Operational design interventions category. The focus of orientation property could then be linked to a redesign requirement that opposes it, such as the requirement to double the number of product variants in the future.

Open coding applied to Van Nelle thus far has fractured the observations, regrouped them into conceptual categories and provided the categories with distinctive properties. At this point, the chronology of the case description is still present in the listing of categories. This is due to both the case write-up and to the wellstructured approach enforced by the normative content of STSD.

The redesign of the MAS and its underlying logic are considered sufficiently important to be treated separately, i.e., to analyse it in a separate coding procedure. The subsequent two case studies maintained this separate analysis. There are three reasons for doing so. First, the research question was formulated in terms of the influence of organisational change on MAS change. In other words, the MAS is the main subject and organisational change in the context. Concretely, organisational change is expected to provide the change factors for MAS redesign; i.e., the research question focuses mainly on the 'then' part of the 'if-then' in the contingency relationship.

Second, organisational cues transpose to MAS cues, which can be phrased in a totally different manner. This is due to the different terminology and disciplinary focus. For example, managerial control is considered a problem in organisation theory and explored accordingly, while in accounting it is considered a solution. This leads to more elaborate control techniques. These standpoints are reflected in approach and language, necessitating a translation effort to keep the meaning of a cue as identical as possible in both disciplines.

Third, the organisational change is dominated by STSD theory. Subsequently, the resulting MAS design can be expected to bear upon STSD characteristics and constitute something like a sociotechnical accounting system. Stating the properties of such a system for both theory building and future empirical tests is considered a valuable side product of this research. Moreover, it would provide STSD research with an extension into the financial discipline, one that has been needed for some time. 
Open Coding - MAS Design

As in the above, case paragraphs are regrouped to their encompassing phenomena, which, in turn, are categorised into more conceptual terms. The resulting dimensional profiles are relatively elaborate, for the same reasons as mentioned above (study focus, disciplinary translation and first sketch of an STSD accounting system). The two tables allow tracing back a specific property to the element in the case description. Properties of all three cases form the basis for a broad outline of what a STSD accounting system would comprise, i.e., can be reformulated as testable propositions for the next research step.

Table 7.3 Open-coding categories of the MAS design of Van Nelle

\begin{tabular}{|c|c|c|}
\hline Paragreph in case description & Phenomens & Category \\
\hline \multirow[t]{4}{*}{ control and infomation structure } & task group siructure & organisation redesign \\
\hline & extension of existing MAS & \multirow{2}{*}{ inlormation supply } \\
\hline & Management Inlormation System & \\
\hline & reporting sequence & change chronology \\
\hline controi and informalion supply dete & \multirow{6}{*}{ soctorechnical reponing system } & \multirow{6}{*}{ MAS design } \\
\hline $\begin{array}{l}\text { - the capactifloccupancy calculali } \\
\text { and production budget }\end{array}$ & & \\
\hline - the period report & & \\
\hline - the machine efliciency report & & \\
\hline - the labour productiviny repon & & \\
\hline - the production report & & \\
\hline $\begin{array}{l}\text { the relationship with the } \\
\text { Management Accounting System } \\
\text { of Douwe Egberts/Sara Lee }\end{array}$ & use of the MAS & intormation parameters \\
\hline
\end{tabular}

Table 7.4 Open-coding properties of the MAS design of Van Nelle

\begin{tabular}{|c|c|}
\hline Caragory & Property and Dimensional Pange \\
\hline Organisention redesign & $\begin{array}{l}\text { - decision making on resounces: centralised - decentralised } \\
\text { - control build-up: by authority - by lunction level } \\
\text { - intormation system: aggregaled - desaggregated }\end{array}$ \\
\hline Information supply & $\begin{array}{l}\text { - intormation system: aggregated - desaggregaled } \\
\text { " operational control inlomation: aggregated - detailed } \\
\text { pertomance measurement to standards: extensive - limiled }\end{array}$ \\
\hline Change chronology & $\begin{array}{l}\text { - budgets standard developed: end of project - start ol project } \\
\text { " operalional control reports developed: } \\
\text { atier budget standards - belore budget standands } \\
\text { "periodic report developed: } \\
\text { atter operational control reports - belore operalional control reports } \\
\text { "variance reporting: end of project - stert of projed }\end{array}$ \\
\hline MAS design & 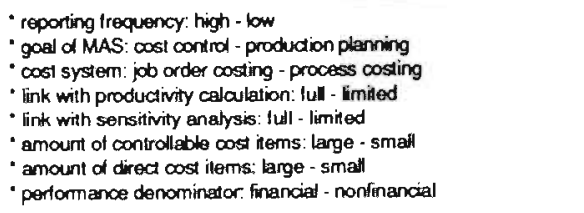 \\
\hline Indormation parameters & $\begin{array}{l}\text { - intomation basis: product bine - capacity } \\
\text { "amount of intomation parameters: large - small } \\
\text { "user level of generated inlormation: same level - higher level } \\
\text { " ongin of parameters: local - nonlocal }\end{array}$ \\
\hline
\end{tabular}


In the open-coding procedure regarding the MAS design, no use is made of the intermediary category of incidents. Events that have been inputs to the MAS design mainly took place before the actual design of the system itself. In other words, open coding here entails more of a description of a result rather than a description of the dynamic stream of incidents that lead up to that result.

\section{Axial Coding}

As open coding relates to fracturing data, axial coding refers to putting those data back together albeit in a different manner. The difference is in what you do with the categories: In open coding, they are further specified in terms of properties and their dimensions. In axial coding, categories are specified in terms of subcategories and, most important, what connects the two (the axis). As Strauss and Corbin state:

\footnotetext{
'In axial coding our focus is on specifying a category in terms of the conditions that give rise to it; the context (the specific set of propertics) in which it is embedded; the action/interactional strategies by which it is handled, managed, carried out; and the consequences of those strategies. These specifying features of a category give it precision, thus we refer to them as subcategories. In essence, they too are categories, but because we relate them to a category in some form of relationships, we add the prefix sub. (1991, p. 97)"
}

Every category, whether it is a subcategory or not, still has properties, so they do not disappear from sight in axial coding. Instead, they will reappear in the selective coding phase. The link or axis in relating between categories and subcategories is called a coding paradigm. It constitutes a set of relationships that are modelled in terms of:

A. causal conditions ---> B. phenomenon ---> C. context ---> D. intervening conditions --> E. action/interaction strategies ---> F. consequences

The following will briefly explain what is meant by the various terms (1991, pp. 100-107): Causal conditions refer to the incidents that lead to the occurrence of a phenomenon. For example, the incident of the management buy-out at Van Nelle's led to the phenomenon of control change. A phenomenon is the central event that is handled by the action set. For example, the control change phenomenon was handled by restructuring the organisation and its processes. Context has two meanings: First, it represents the dimensional profile (property plus dimensional range) related to a phenomenon. Second, it is more literally the context wherein actions are taken as a means to respond to a phenomenon. For example, the context of control change is reflected both by the property of an inward-looking focus of the organisation, as well as the American mother company of Standard Brands, which was unwilling to start up an organisational change process. Intervening conditions differ from causal conditions and context as they relate to the general conditions bearing upon action strategies. Such general conditions can be of an historic, economic and technological status, or cultural nature. For example, the intervening conditions related to control change at Van Nelle was of historical economic status because Van Nelle was one of the few Dutch rolling-tobacco producers. Action/interaction strategies are responses to a phenomenon. Action/interaction strategies themselves have four properties: They are processual, i.e., they can be studied in terms of sequences over time; they are purposeful, i.e., actions are undertaken for some reason; failed action is as important as actions ac- 
tually occurring; and, there are always intervening conditions facilitating or constraining actions. For example, the action strategies related to control change at Van Nelle are organisational restructuring, training and team building. Typically, action strategies show up as verbs in the field observations. Consequences are outcomes, both of actions taken and of failure to take action. Moreover, outcomes of actions can constitute the conditions for action in the future. For example, at Van Nelle the control change results in a change assessment of what needs to be done, which, in turn, is a condition to the organisation restructuring action.

Axial coding itself is performed by four analytical steps:

i. Hypothetically relating categories to subcategories by indicating the nature of the relationship between (sub)categories and the phenomenon, using the elements of the paradigm model. That is, is the relationship one of causal condition, context, intervening condition, etc?;

ii. Verification of these hypotheses against the field data;

iii. Further development of categories in terms of their dimensional profile;

iv. Exploring the variation in phenomena by linking categories at the dimensional level.

Axial coding for the Van Nelle case applies these four steps to the categories of reasons for change, pointing noses, operational design interventions and experiences. Labelling hypothetical relationships between phenomena and categories results in the listing below (see Figure 7.1).

\begin{tabular}{|c|c|c|}
\hline$\longrightarrow$ & Nature of roletionship & Catogory \\
\hline $\begin{array}{l}\text { performance sag } \\
\text { change of control }\end{array}$ & $\begin{array}{l}\text { causal condition } \\
\text { causal condibon; context; intervening conditions; action strategy }\end{array}$ & reasons for change \\
\hline $\begin{array}{l}\text { change assessment } \\
\text { relormatting the organisation } \\
\text { Human Ressource Managemen! } \\
\text { building involvement } \\
\text { job design }\end{array}$ & $\begin{array}{l}\text { Causal condition; conseguence } \\
\text { causa! condition; context; action strategy; consequence } \ldots \ldots \ldots \ldots \ldots \\
\text { causal condivon; context; intervening condicon; action strategy: consequence } \\
\text { causal conditon; context; acton strategy: consequence } \\
\text { causal conditon; context; intervening condition; action strategy: consequence }\end{array}$ & pointing nosas \\
\hline $\begin{array}{l}\text { stuctural redesign statement } \\
\text { change structure } \\
\text { fing the design }\end{array}$ & $\begin{array}{l}\text { causal condition; context, intervening condition: consequence } \\
\text { causal condition; context; action strategy: consequence } \\
\text { causal condition; context; action strategy; consequence }\end{array}$ & $\begin{array}{l}\text { operational } \\
\text { design } \\
\text { intorventions }\end{array}$ \\
\hline $\begin{array}{l}\text { use } \\
\text { change of control } \\
\text { consolidation } \\
\text { legitimation }\end{array}$ & $\begin{array}{l}\text { context; consequence } \\
\text { context; intervening condition } \\
\text { causal conditon; context; action strategy } \\
\text { context; consequance }\end{array}$ & axperiences \\
\hline
\end{tabular}

Figure 7.1 Axial coding of Van Nelle's case description-establishing hypothetical relationships

The next step is verification against field observations as described in the case report. Equally important are field observations that do not support the hypothesised relationships. Finding instances where these hypotheses do not hold up does not disprove these relationships or add variation and density because it triggers closer scrutiny. Verification, as proposed by Strauss and Corbin, means returning to your data and checking for supporting and/or refuting evidence. As we utilise case descriptions, data are already put together in the case write-up, which means that the basic input of observations is the case itself. That is, verification is confirmed against case descriptions. However, since the same case descriptions are used for creating the open-coding categories, prior verification has implicitly taken 
place. Therefore, the verification step is of little importance when using case descriptions as a data vehicle.

Furthermore, several observations regarding the nature of the relationships can be drawn. The most important of these is the relevance of causal condition and context, appearing 11 times on 14 phenomena, followed by action/interaction strategy, appearing 8 times on 14 phenomena. The first, tentative impression is that STSD design is strongly related to environmental factors. If we combine this idea with the relatively small number of appearances of the intervening conditions relationship, it seems that environmental factors are tied to STSD in discrete steps, i.e., sequential design and environmental input are combined factors. On a theoretical level, this is corroborated by STSD theory stating that a sequential design approach should be used, initiated by a strategic orientation round. Theoretical presumption is that strategic considerations are passed on along the line of increasingly specific design steps, and the above relationships seem to support this empirically.

Another line of thought connected to the intervening conditions relationship is that this label seems to indicate a boundary role in between action cycles. At Van Nelle's, two main ruptures coincide with the first and last intervening condition, each related to a change in managerial control and economic status. Within this cycle, there is another cycle related to a specific choice in approaching organisational behaviour, i.e., people are considered the main resource of the organisation and therefore the anchor point for managerial action.

The above-mentioned two analyses clearly show the iteration between observations and concepts, or in other words, between inductive and deductive thinking. This back and forth movement is one of the essential characteristics of grounded theory. Both the environmental importance and the cycle/metaphor concept are provisional and carry over to the next step in axial coding as well as to the next two case studies where they can be further supported, discarded or varied.

The third step is further development of categories in terms of their dimensional profile (property plus dimensional range). This step aims at improving specificity and developing conceptual density. Regarding the grounded analysis of the first case, this step is limited in its significance. Instead, it has considerable importance for cross-case comparison, when the properties of each case can be placed next to each other and conceptual specificity and variation can be more elaborately discussed. In other words, when performing grounded analysis on a series of case studies, this specific axial coding step has increasing significance from the second case onward.

The last axial coding step is linking categories at the dimensional level in order to explore variation in phenomena. Strauss and Corbin note that:

"But, it is here in axial coding that the process of linkage actually begins. While we do our analysis, we note patterns in our data in terms of dimensional locations of events, incidents pertaining to the property of a phenomenon (1991, p. 110)."

In the Van Nelle case, the idea of an event cycle or pattern is reflected by its properties. The main pattern is on the control change, which constitutes the link between the categories Reasons for change and Experiences. The other cycle falls in 
between those categories, linking the categories Pointing noses and Operational design interventions. Moreover, a third cycle can be distinguished within the Experiences category where the action strategy of consolidation is employed following the takeover of Van Nelle. This relationship is embedded by a preceding intervening condition and a successive consequence.

At the dimensional level, the patterns are supported by the properties of organisational status: At the start of the event cycle (management buy-out), the organisation is independent and at the end of the pattern (takeover) it becomes dependent. Linkage of the categories Pointing noses and Operational design interventions is supported by the dimensions of an explicit vision to the future and decentralised decision making on resources. The first one establishes the framework for further elaboration of that vision, which is a human resources type of vision, and the second elaborates the decentralised decision making into an Operational design intervention category. In other words, each one of the properties of the Operational design intervention category are elements of the STSD change management approach called Integral Organisational Renewal (IOR). Thus, properties become identical to instruments as a result of this approach. The two properties of project management and PCI design are theoretically restricted to take the dimensional positions of 'participatory' and 'full'. The property of functional redesign requirements is left open by the STSD theory; organisations are able to take any position in this dimension. Under this category, it may be possible to obtain the first input of the reasons responsible for unsuccessful STSD efforts, since organisations do not keep to the normative advice of the STSD toolkit and only partially redesign their organisation.

The above-named patterns and properties are the basis for replication in the following two case studies. They can either add support and variation to these patterns or they can refute them. They are able to replace them with different patterns which, in turn, need to be revised against observations from the other case studies.

\section{Axial Coding - MAS Design}

(An identical axial coding procedure is followed)

The relationships between phenomena and categories are established in terms of the coding paradigm, and the subseqent analytical axial coding steps are applied. Hypothetical relationships can be depicted as in Figure 7.2.

\begin{tabular}{|c|c|c|}
\hline Phenomene & Nature of relationshlp & Catogory \\
\hline lask group slructure $\ldots \ldots \ldots \ldots \ldots$ & $\begin{array}{l}\text { causal condition; conlext; intervening condition; } \ldots \ldots \ldots \ldots \\
\text { action strategy: consequence }\end{array}$ & Organisation design \\
\hline extension of exisding MAS $\ldots \ldots \ldots$ & causal condition; action stralegy; consequence $\ldots \ldots \ldots \ldots$ & Inlomalion supoly \\
\hline $\begin{array}{l}\text { Management information System } \\
\text { reporting sequence } \ldots . . . \ldots \ldots\end{array}$ & causal condition: action stralegy: consequence & Change chronology \\
\hline sociotechnical reporting system $\ldots$. & causal condition: context: action strategy: consequence $\ldots$ - & MAS design \\
\hline use of the MAS $\ldots \ldots \ldots \ldots \ldots$ & causal condition; context; consequence . . . . . . . . . & Informalion paramen $\theta$ \\
\hline
\end{tabular}

Figure 7.2 Axial coding of Van Nelle's MAS design 
Verification against field data is again of limited relevance because of the use of case descriptions as an intermediary data vehicle. However, a number of observations can be made. First of all, the combined appearance of causal condition and consequence at each category level indicates that this part of the design is a cumulative activity, moving from one phase to the next as completion is reached.

It is also interesting that this part of the design is determined by (the intervening condition of) the task group structure phenomenon; it relies strongly upon the further action strategies in the categories of information supply and MAS design itself. In other words, the task group structure, i.e., organisation redesign, constitutes the environment constraining and setting further MAS design activities.

The category of organisation design and the category of Pointing noses share an identical property in decision making on resources. When going back to the case description, it can be seen that the different coding elements result in being categorised in one identical category, although these elements do not have an indentical underlying phenomenon. More specifically, these phenomena are related to the incidents of the STAP analysis and to the bottom-up control design in the task group structure. However, it is important to note that both categories have something in common, i.e., all elements of the coding paradigm. This triggers the idea that those two categories (pointing noses and organisation design) are linking categories between the context part and the accounting part of the case study; they each cover a full coding paradigm and share an identical property.

Considering this idea of linkage, Table 7.4 shows that the information system property carries over to the next category which is that of information supply. In this category, the information system property is further exemplified by properties such as detail of control information and extensive performance measurement to standard; an extensive amount of control detail as well as extensive performance measures do not bear up well with an aggregated information system. Moreover, these subsequent properties (control detail and extensive measures), in turn, link up with the properties of the MAS goal (cost control), reporting frequency (high), amount of controllable and direct cost items (both large) and performance denominator (nonfinancial), all in the MAS design category. However, since the MAS goal property is preceded first by the centralised versus decentralised decisionmaking property and then by the information system property, the distinction centralisation versus decentralised seems to play an important role. This challenges the textbook idea that management accounting systems can be considered systems in themselves, which can have their own design argumentation. Instead, management accounting systems appear to be directly related to organisation design logic.

In the category of information parameters, the property of user level of generated information relates to the information system property in the previous categories. This relationship stems from the STSD balance equation between required control information and control information available, i.e., the control design in the task group structure as proposed by the law of requisite variety. The property of origin of parameter (local/nonlocal) is similarly related; control information is generated there where it is needed for control decisions in terms of best fitting the decision. Typically, these decisions are local (i.e., decentralised) and, according to the case 
study, related to nonfinancial decisions on machine efficiency and labour productivity. In this regard, the change in information supply and information parameters following the takeover by the Sara Lee corporation contours the pattern of relationships (see Figure 7.3). In terms of information system, it had to respond to the demand for control information on a centralised level, the point which led to the difficulties experienced by the users of the MAS design, once they were confronted with the 'company rule' aggregated reporting system of the Sara Lee corporation: The fit between decentralisation, desaggregation and local use is broken when such a vertical system is installed. Also, the information basis stressed most became that of capacity instead of articles: a change towards resource consumption rather than the previous resource utilisation.

After completing the axial coding, we have established a pattern of relationships which runs across categories and properties (see Figure 7.3) as well as some ideas to look for in subsequent case studies. The next coding step, called selective coding, is to organise this pattern.

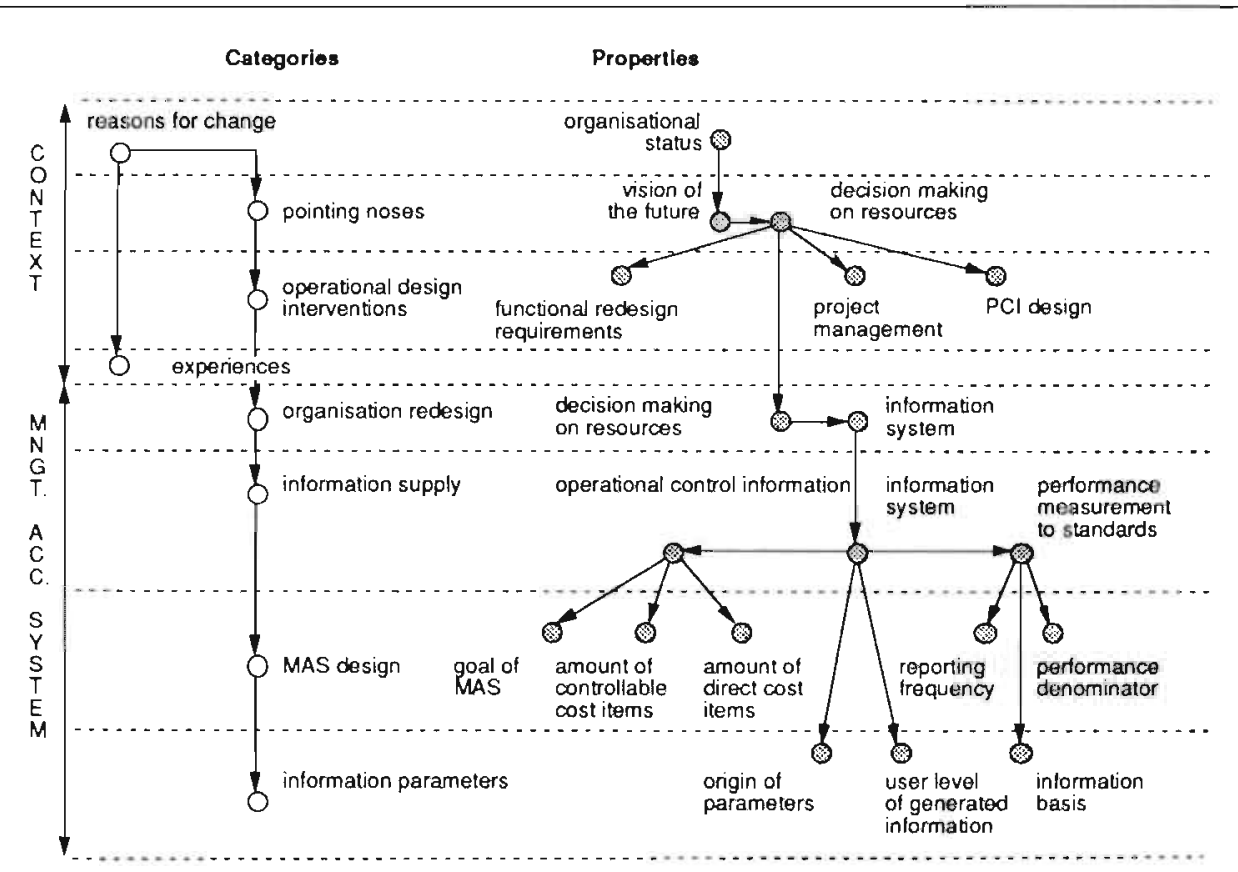

Figure 7.3 Pattern emerging after axial coding

\section{Selective Coding}

A final integration of the various categories and preliminary relationships is the job of selective coding. It involves selecting a core category wherein all other categories are conceptually related and can be integrated. It is considered the most difficult coding phase: 
"In axial coding you developed the basis for selective coding. You now have categories worked out in terms of their salient properties, dimensions, and associated paradigmatic relationships between major categories along the lines of their properties and dimensions. Furthermore, you have probably begun to formulate some conception of what your research is all about. After all, people have been asking you for some months: What is it that you are studying, and what are your findings? Surely, some conclusion has formed in your mind, if not on paper. The question is: How do you take that which is in a rough form, and hopefully in your diagrams and memos, and systematically develop it into a picture of reality that is conceptual, comprehensible, and above all, grounded?" (Strauss and Corbin, 1991, p. 117)

Again, there is a series of steps to guide this process. There are five and they are not sequential as much as iterative in their guidance. Also, a strong similarity with the axial coding process is present. The selective coding procedure involves:

* Explicating the storyline, which is a conceptualisation of the descriptive narrative about the central phenomenon (i.e., the core category) of the study;

* Relating subsidiary categories around the core category by means of the coding paradigm;

* Relating categories at the dimensional level;

* Validating those relationships against data;

* Filling in categories that may require further refinement and/or development (.i.Strauss and Corbin, 1991, p. 118).

The difference between a storyline and a case description is that the first is an analytical conceptualisation while the latter is merely a description of events, not using conceptual relationships but chronological event relationships: a story, rather than a storyline. The central part of the storyline is the core category: The one category or central phenomenon around which all other categories can be integrated. Choosing a core category is one of the most difficult things to achieve; one can either select an existing category that is abstract enough to encompass all concepts in the story, or one can select such a category by means of asking: What phenomena is repeated in all your data? What is the essential message in your research? In other words, developing the core category asks one to stand above the material and pinpoint the key subject. Ideally, if the previous coding steps are performed well, the core category presents itself almost naturally.

The storyline for Van Nelle revolves around the phenomenon of organisational change, which can be metaphorically labelled as the resurrection of the organisation. The firm went from a sleepy, inward-looking subsidiary organisation with a functional structure, to an active, market-oriented independent organisation with a highly decentralised, product group structure. Resurrection was accomplished through STSD insights and tools, and was consolidated by the changed information and control systems. The organisational change phenomenon was put in perspective by the takeover of a firm with an identical functional and centralised organisation structure as the one Van Nelle previously had. The resurrected organisation left the most robust parts untouched - the production, control and information structures at plant level. In short, this is the storyline at Van Nelle. 
Next, the core category is further identified by explicating its properties. Once the core category acquires its own dimensional profile, it can be used to relate the other categories to it, thereby making them subsidiary categories (Strauss and Corbin, 1991, p. 123). In the case of Van Nelle, the core category selected was organisational learning. The organisation learns how to become more open to its markets and changes itself accordingly. The learning process explicitly follows a route of structural changes, resurrecting the new organisation from the old one. The properties of this learning process can be tied to the three event cycles in the change process:

1) The control change between management buy-out and takeover within this cycle;

2) The change realisation, based on STSD; whereafter

3) The consolidated change trajectory is legitimised by its new 'school masters', i.e., those who set the new learning targets and try to stimulate learning towards them.

Properties of the organisational learning core category are, therefore, highly identical to properties of categories already found. Using Figure 7.3 to indicate those properties, the first event cycle of the organisational control change contains the main property organisational status, the second event cycle of the change realisation contains the properties vision on the future and decision making on resources, and the third event cycle that of the legitimation of the change, contains the properties costs and benefits.

Organisational learning, in terms of MAS design, also relates to the properties of information system, operational control information and performance measurement to standards apart from decision making on resources. The main reason is the boundary role of these categories: They link up with the organisational context and translate these organisational concepts into accounting instruments and concepts. For example, a decentralised organisation translates into allocating all operational controls to the lowest possible organisational level. This requires a decentralised information system encompassing all operational control information and, subsequently, the provision of a great number of operational targets and standards. In other words, a detailed system of standards, both financial and nonfinancial, will intervene in the construction of the management accounting system, as exemplified in the intervening condition relationship between the task group structure phenomenon and the Organisation design category (Figure 7.2).

We now have the core category of organisational learning, with the properties of organisational status (independent/dependent), decision making on resources (centralised/decentralised), information system (aggregated/desaggregated), operational control information (aggregated/detailed), performance measurement to standards (extensive/limited) and qualitative and quantitative cost (high/low) and benefits (high/low). Subsidiary categories are linked to the core category by means of the event cycle concept and the property pattern developed earlier (see Figure 7.4). 


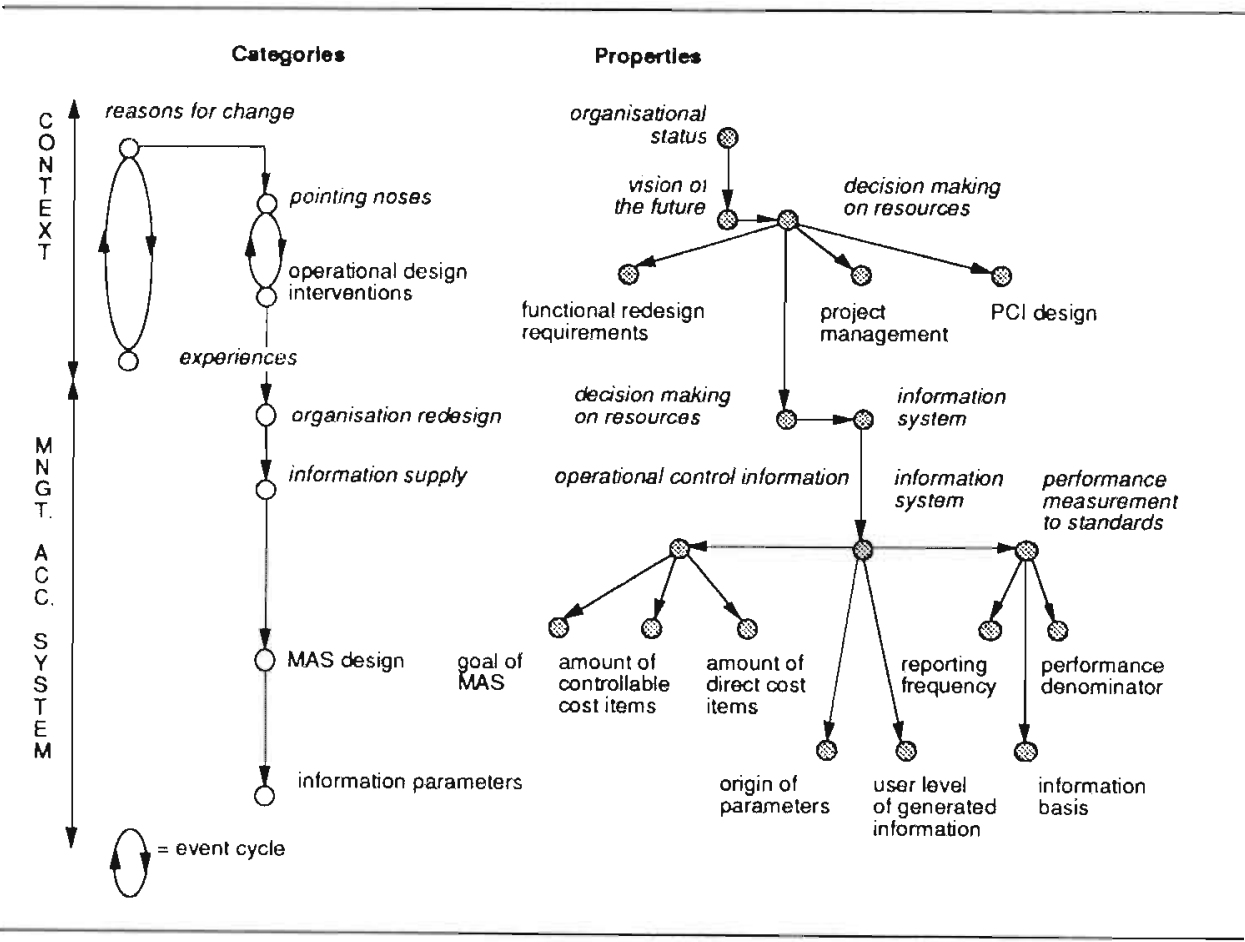

Figure 7.4 Subsidiary categories and propenties of the organisational learning core category

To further explicate the linkage between core and subsidiary categories, the terms of the coding paradigm are again used. According to the property pattern, subsidiary categories are: Reasons for change, Pointing noses, Organisation redesign, Information supply and Experiences. The nature of the relationships between subsidiary and core category is depicted in Figure 7.5. Causal condition and consequence relationships mark the presence of an events cycle while the presence of an intervening conditions relationship indicates that there are restrictions or boundaries on the choice of subsequent action strategies. The presence of a causal condition relationship to all subsidiary categories stresses the purposeful coherence in managerial action; resurrecting the organisation was a matter of policy decisions, not one of trial and error or good luck.

\begin{tabular}{|c|c|c|c|}
\hline Category & - & Nature of retationship $=$ & Core category \\
\hline Reasons for change & - & Causal conditions; context; intervening conditions & \\
\hline Pointing noses & - & Causal conditions; action strategy & \\
\hline Organisation redesign & - & Action strategy & Organisational leaming \\
\hline Information supply & - & Action strategy; consequence & \\
\hline Experiences & - & Causal conditions; consequence. & \\
\hline
\end{tabular}

Figure 7.5 Relating subsidiary categories to the core category 
The tentative theory that can now be developed, and the one that is to be replicated, specified and varied in subsequent cases, looks like this: In the condition that a firm wishes to survive as an independent organisation and finds itself not able to do so, it starts an organisational change process. When envisaging a change effort, based on its human resources and organisation design, it decides to create a learning organisation. Learning is initiated by pointing noses in terms of decentralising the decision making on resources. Subsequently, the organisation structure is redesigned using STSD-based interventions. The management accounting system, as part of the STSD intervention, has been redesigned to fit in the learning organisation context, by incorporating the same decentralisation decision making on resources as well as to redesign information supply. Typically, the information supply is redesigned to provide desaggregation information for detailed operational control and extensive performance measurements to standards. The experiences of having created a learning organisation in operation come forward distinctively when confronted with the loss of decentralised decision making. These experiences are consolidated into the management accounting system which is a stable entity, untouched by subsequent contextual changes in organisational status and decision making on resources.

\section{Grounded Analysis of Zilverstad Silversmithing}

The case of Zilverstad Silversmithing (hereafter referred to as Zilverstad) will be coded and analysed according to the procedures as described above. Since the Van Nelle case also provided an introduction to the content of the grounded theory techniques, further explanation of the procedures will be dismissed: Analysis contains the results and discussion of the results.

\section{Open Coding}

As in the Van Nelle case study, the case description is chronological; the time path and the sequence of events (Figure 5.5) therefore link up with the incidents underlying the phenomena. To further enhance tracing of the data grouping, the paragraphs in the case description relating to the various incidents are also mentioned.

In naming the open-coded categories, the use of jargon and standard accounting terminology has been avoided where possible, resulting in an almost conversational use of terms. It was unintended, however, to use verbs as a means of naming the categories; the change process seems to be best analysed in terms of dynamic expression. Unfortunately, no use could be made of in vivo codes as none were readily available from the interview transcriptions.

Properties are termed by using expressions or words obtained from the case study and the transcribed interviews. Again, where possible, it is refrained from using jargon or standard terminology from the accounting and organisation disciplines. 


\section{Chapter 7}

Table 7.5 Incidents in the Zilverstad case and their related phenomena

\begin{tabular}{|c|c|c|}
\hline Paragreph In cene description & Incidente & Phenomena \\
\hline \multirow[t]{14}{*}{ situational background } & situation of standardised mass production & \multirow{2}{*}{ single-operation company } \\
\hline & severe price competition from the Far East & \\
\hline & situation of product cuslomisation & \multirow{5}{*}{$\begin{array}{l}\text { changeover to customisation and } \\
\text { diversification }\end{array}$} \\
\hline & explosive sales growth & \\
\hline & increase in personnel & \\
\hline & extension of manulacturing capabilities & \\
\hline & increase in product diversity & \\
\hline & delivery time problems & \multirow{4}{*}{ problems with new strategy } \\
\hline & insufficient skilled personnel & \\
\hline & quality control problems & \\
\hline & manufacturing bottlenecks & \\
\hline & draw-up of business plan & \multirow{3}{*}{ looking for guidance } \\
\hline & help trom employers' association & \\
\hline & conlact with STSD consultancy & \\
\hline \multirow[t]{13}{*}{ the change trajectory } & introduction to STSD ideas & introduction to STSD \\
\hline & STSD execulive course followed & \multirow{3}{*}{ learning the language of redesign } \\
\hline & STSD middle management course tollowed & \\
\hline & entrance extemal consultant & \\
\hline & company-wide presentation & \multirow{2}{*}{ project set-up } \\
\hline & project group installed & \\
\hline & formulating the design requirements & design goal selting \\
\hline & listing of bottenecks & \multirow{2}{*}{ mapping the organisation } \\
\hline & primary process modelling & \\
\hline & start-up improvement projects & broadening the support base \\
\hline & preliminary production reorganisation plans & lesting ideas \\
\hline & Tormulation of general design & \multirow{2}{*}{ design decision-making } \\
\hline & decision of the Board & \\
\hline \multirow[t]{3}{*}{ production struchure redesign } & formation of tour kask groups & \multirow{2}{*}{ changing the work organisation } \\
\hline & delailed design per lask group & \\
\hline & new production organisation chart & allocating responsibility \\
\hline \multirow[t]{3}{*}{ control structure redesign } & meelings supporting the primary process & \multirow{3}{*}{$\begin{array}{l}\text { linking communication and } \\
\text { inlormation }\end{array}$} \\
\hline & reporting structure \& agenda setting & \\
\hline & evaluation of agenda selting reports & \\
\hline \multirow[t]{4}{*}{ the change trajectory (continuod) } & Strategic Orientation Round (SOR) & organisation goal serting \\
\hline & $\begin{array}{l}\text { presentation of new organisation design plus } \\
\text { global implementation plan }\end{array}$ & claritying the new organisation \\
\hline & detailed implementation pian & \\
\hline & carrying out implementation plan & Implementation trajectory \\
\hline \multirow[t]{3}{*}{ results of the redesign } & cosi control & \multirow{3}{*}{ cosi structure } \\
\hline & product cost build-up & \\
\hline & human resource costs & \\
\hline \multirow[t]{2}{*}{ projects underway } & job dassification system & \multirow{2}{*}{ control extensions } \\
\hline & sales information system & \\
\hline
\end{tabular}


Table 7.6 Open-coding categories and dimensional profile of Zilverstad

\begin{tabular}{|c|c|c|}
\hline Phonomene & Category & Property and Dimenslonal Range \\
\hline single-operation company & \multirow{2}{*}{ moving-up the organisation } & \multirow{2}{*}{$\begin{array}{l}\text { - implicit strategic competitive position: } \\
\text { price stralegy - focus stralegy } \\
\text { - implicit production strategy: } \\
\text { full-line producer - single-line producer } \\
\text { - technological competences: } \\
\text { extensive - limited }\end{array}$} \\
\hline $\begin{array}{l}\text { changeover to cuslomisation } \\
\text { and diversification }\end{array}$ & & \\
\hline problems with new stralegy & \multirow{2}{*}{ trying to come lo grips } & \multirow{2}{*}{$\begin{array}{l}\text { - human resource qualifications: } \\
\text { scarcely available - plenty available } \\
\text { control systems: } \\
\text { limitedly present - extensively present } \\
\text { planning systems: } \\
\text { limitedly present - extensively present }\end{array}$} \\
\hline looking for guidanco & & \\
\hline introduction to STSD & \multirow{2}{*}{ establishing an organisation view } & \multirow{2}{*}{$\begin{array}{l}\text { organisation solution wanted: } \\
\text { comprehensive solution - partial solution } \\
\text { - network memberships: extersive - limited } \\
\text { - type of assistance: } \\
\text { training courses - expert opinion } \\
\text { concepls introduced: } \\
\text { change instruments - change largels }\end{array}$} \\
\hline learning the language of redesign & & \\
\hline project selup & \multirow{2}{*}{ initiating change } & \multirow{2}{*}{$\begin{array}{l}\text { - tunctional redesign requirements: } \\
\text { extensive - limited } \\
\text { project management: } \\
\text { participatory - non-participatory }\end{array}$} \\
\hline design goal selting & & \\
\hline mapping the organisation & \multirow{4}{*}{ clearing the organisalion } & \multirow{4}{*}{$\begin{array}{l}\text { - analysis of the organisation: } \\
\text { extensive - limited } \\
\text { gaining credbility: } \\
\text { by aclual improvements - by rhetoric } \\
\text { selecting the production struclure: } \\
\text { in oulline - in delai }\end{array}$} \\
\hline broadening the support base & & \\
\hline lesting ideas & & \\
\hline design docision making & & \\
\hline changing the work organisation & \multirow{3}{*}{ structural interventions } & \multirow{3}{*}{$\begin{array}{l}\text { PCl-design: full - partial } \\
\text { sequence of production design: } \\
\text { work organisation firsi - responsibility first } \\
\text { meetings \& torms: } \\
\text { highly inleractive - little inleractive }\end{array}$} \\
\hline allocating responsibility & & \\
\hline $\begin{array}{l}\text { linking communication and } \\
\text { intormation }\end{array}$ & & \\
\hline organisation goal selting & selecting a direction & $\begin{array}{l}\text { strategy/redesign sequence: } \\
\text { redesign lirsi - stralegy firsl }\end{array}$ \\
\hline clarilying the new organisation & \multirow{2}{*}{ seltling in } & \multirow{2}{*}{$\begin{array}{l}\text { communicaling expectations: } \\
\text { to everyone - to a selecled group } \\
\text { change implementation: planned - not planned } \\
\text { cos! struclure: transparent - nonlransparent }\end{array}$} \\
\hline implementation trajectory & & \\
\hline cosi siructure & \multirow{2}{*}{ evaluating } & \multirow{2}{*}{$\begin{array}{l}\text { - human resource costs: } \\
\text { struclurally increased - struchurally decreased } \\
\text { - quantitative cosis: high - low } \\
\text { qualitative costs: high - low } \\
\text { quantilative benelits: high - low } \\
\text { qualitative benelits; high - low }\end{array}$} \\
\hline control exiensions & & \\
\hline
\end{tabular}

\section{Open Coding - MAS Design}

Separate discussion of this portion of the redesign process is warranted by the research question, stating that the management accounting system is expected to be influenced by changes in its organisational context. The discussion will maintain a similar format as in the case of Van Nelle: A depiction in logic diagrams of the phenomena found in Zilverstad's MAS, followed up by the open-coding procedures. 
A description of the MAS of Zilverstad can be found in a single paragraph of the case study. From this description, a listing of phenomena is compiled, followed by regrouping into more abstract categories and then separating these into properties and their dimensional ranges (see Table 7.7).

Table 7.7 Open coding of Zilverstad's MAS design

\begin{tabular}{|c|c|c|c|}
\hline $\begin{array}{l}\text { Paragraph in } \\
\text { case description }\end{array}$ & Phernomena & Category & Property and Dimenslonel Range \\
\hline \multirow{4}{*}{$\begin{array}{l}\text { Management } \\
\text { Accounting } \\
\text { System }\end{array}$} & use of meelings \& loms & Control siructure & $\begin{array}{l}\text { communicating perlomance: } \\
\text { belween groups - in group }\end{array}$ \\
\hline & sequence ol redesign & Change chronology & $\begin{array}{l}\text { - budgets esiablished: } \\
\text { production first - sales firs: } \\
\text { - transter pricing system: } \\
\text { afler budgeis - belore budgets }\end{array}$ \\
\hline & $\begin{array}{l}\text { previous intemal acoounting system } \\
\text { reporting format } \\
\text { task group central element } \\
\text { management intormation }\end{array}$ & Inlormation supply & $\begin{array}{l}\text { relative new redesign: } \\
\text { extension - new design } \\
\text { - steered on: gross margin - volume } \\
\text { central element: } \\
\text { task group - lunctional departmenl } \\
\text { - management information: } \\
\text { aggregated - desaggregated }\end{array}$ \\
\hline & $\begin{array}{l}\text { cost system } \\
\text { use ol cost pool method } \\
\text { larifl system } \\
\text { production/sales budgels } \\
\text { sales report } \\
\text { financial repon } \\
\text { nonfinancial operalional inlormation }\end{array}$ & MAS design & $\begin{array}{l}\text { "cost system: } \\
\text { job order costing - process costing } \\
\text { " use of cost poot method: } \\
\text { process conirot - overtiead allocation } \\
\text { ' tarift system: extensive - limiled } \\
\text { " use of budgeting: extensive - limiled } \\
\text { " use of budgels: cost control - planning } \\
\text { overall pertomance measurement: } \\
\text { control coherence - steer organisation } \\
\text { "nonfinanctal Intormation: } \\
\text { stand-alone - integrated }\end{array}$ \\
\hline
\end{tabular}

The category control structure is an example of an identical cue that is phrased differently in accounting than in organisation theory: The use of meetings and forms in the organisational open coding is focused on interaction of departments while in the accounting open coding, use of meetings and forms focuses more specifically on communicating performance information, i.e., interaction is specified in terms of performance information exchange. The subsequent discussion and possible action follow-up is, again, a matter of the organisational context and cannot be considered part of an accounting structural design but of the processes attuned to it.

\section{Axial Coding}

As categories and their characteristics are now available, linkage and causation can be analysed. Using the coding paradigm to find an axis/denominator for this linkage, we obtain an axial coding typification of the organisational redesign (Figure 7.6) and of the management accounting systems design (Figure 7.7). 


\begin{tabular}{|c|c|}
\hline $\begin{array}{l}\text { single-opefation company } \\
\text { changeover to customisation } \\
\text { and diversification }\end{array}$ & $\begin{array}{l}\text { context } \\
\text { context: intervening conditions; action strategy ..... moving-up the organisation }\end{array}$ \\
\hline $\begin{array}{l}\text { introduction to STSD } \\
\text { learning the language of redesign ..... }\end{array}$ & $\begin{array}{l}\text { causal condition } \\
\text { action stratogy: consequences } \quad \ldots \ldots \ldots \ldots \ldots \ldots \text { establishing an organisation view }\end{array}$ \\
\hline $\begin{array}{l}\text { project set-up } \\
\text { design goal setting } \quad \ldots \ldots \ldots \ldots \text {. }\end{array}$ & $\begin{array}{l}\text { context } \\
\text { action strategy }\end{array}$ \\
\hline $\begin{array}{l}\text { changing the work organisation } \\
\text { allocating responsibility } \\
\text { linking communication and } . . . . . . \\
\text { intormation }\end{array}$ & $\begin{array}{l}\text { causal condition; context; action strategy } \\
\text { action strategy } \\
\text { action strategy }\end{array}$ \\
\hline organisation goal setting $\ldots \ldots \ldots \ldots$ & intervening conditions; action strategy \\
\hline
\end{tabular}

Figure 7.6 Axial coding of Zilverstad's organisation redesign

When looking at the logic diagram in Figure 7.6, several observations can be made based on the nature of Zilverstad's unrolling change process. First, action strategies dominate the process, they appear in every category and occupy 12 of the 29 labels. Their omnipresence indicates the strong action orientation of the change process, which is further corroborated by the short time interval needed for the redesign: Eighteen months were necessary for acquiring a new vision of the organisation, initiating change as well as the actual redesign. Both action orientation and time interval seem to stress the transfer made by the organisation, from a pioneering family business towards a professionally managed organisation. The key word that springs to mind is that of the organisational constitution: The organisation is provided with a binding vision, company goals, a structure and targets for the near future, all elements that previously were absent, or only present in a limited manner.

Another notable point regarding the organisational transfer is the high level of attention that is paid to preparing the organisation prior to it being virtually redesigned. It takes up two categories (excluding the one on establishing an organisation view), eighteen months (from July 1989 until June 1990) and two companywide presentations before the detailed design is implemented. In other words, change management played a relatively important role in this process. Change management, in terms of the nature of relationships between phenomena and 
categories, is indicated by the presence of the 'context' label. At the start of the preparation categories Initiating change and Clearing the organisation, a 'context' label appears, indicating the amount of attention paid to preparing the mind for the next step. In turn, it leads (again) to the idea of event cycles, each cycle being a phase in the transfer process.

Second, the event cycle concept can be further exemplified by the appearance of the 'intervening conditions' label, each intervening condition marking the beginning and end of a cycle. Typically, the main event cycle of Zilverstad coincides with its transfer to the organisation stage. For instance, the phenomenon 'changeover to customisation and diversification' marked the beginning of a change in organisational processes, which was concluded by restructuring the organisation and starting up a new (and more explicit) selection of a future direction ('organisation goal setting' phenomenon). This can be considered as 'the big event'.

Several related event cycles that fit into 'the big event' can be subsequently distinguished: A cycle related to the awareness that something has to be changed, tying the categories Trying to come to grips and Establishing an organisation view together, in terms of 'causal conditions' and 'consequences'. A second subcycle related to preparing the organisation for change, as previously discussed, grouping together the categories Initiating change and Clearing the organisation by means of the 'context' and 'consequences' labels. A third subcycle related to structural interventions, including the MAS design, overlying the categories Structural interventions, Control structure, Change chronology, Information supply and MAS Design. This cycle also includes all the axial coding categories of the MAS design (see Figure 7.7), that will be discussed below. The fourth and final subcycle relates to the ex post condition of the transferred organisation (categories Settling in and Evaluating). It contains a relatively large number of 'consequences' labels and is initiated by a 'causal condition' label. It is, however, termed a subcycle and not a big event cycle' since the time interval allowed in the case description does not allow assessing if another 'big event cycle' has been initiated.

The 'intervening conditions' label at the end of the 'big cycle' marks a renewed strategic discussion. This time, however, it is more explicitly structured and formalised and departs from an improved starting position. The outcome of this strategic discussion can very well mean moving away from the diversification and customisation strategy (see case description). If this is the case, a subsequent big event cycle' inevitably begins, and follows the organisation stage in a step-function manner, i.e., building on to the newly acquired organisational capabilities.

\section{Axial Coding - MAS Design}

Similar to the organisation design, the MAS design of Zilverstad shows a strong presence of 'action strategies' in each category. This is also reflected in the MAS design, where one can see the considerable effort put into transferring the organisation from one stage to another. Moreover, the 'context' labels are repeatedly tied to the first phenomenon in each category, thereby embedding the 'action strategies' in each category. It suggests that the actions were preceded by setting the context in a planned effort, i.e., the important role of change management was maintained in the MAS redesign. 


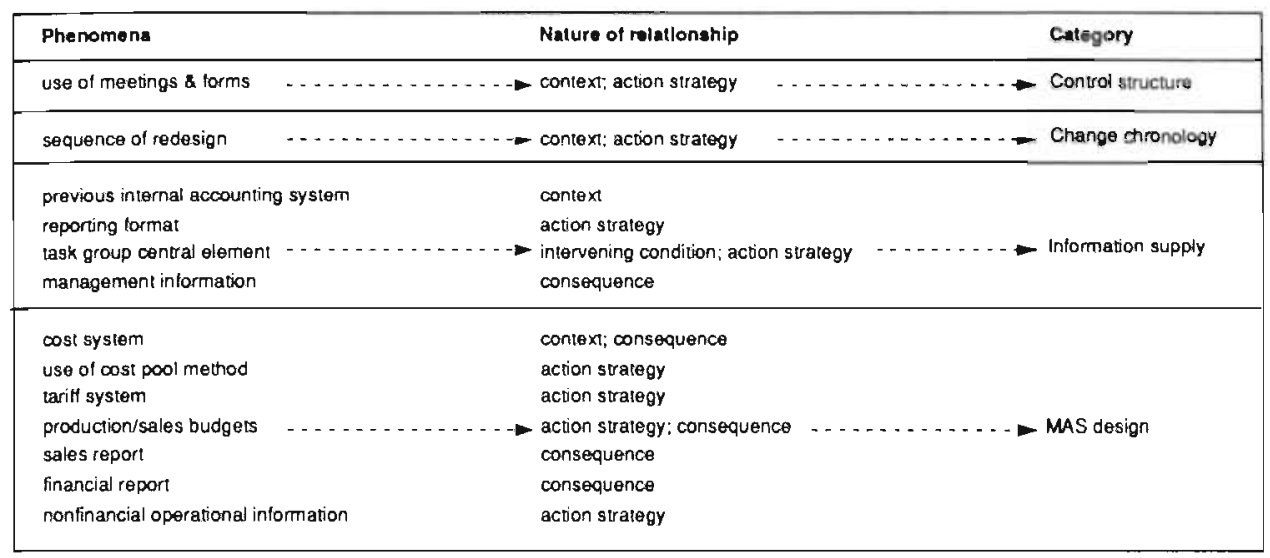

Figure 7.7 Axial coding of Zilverstad's management accounting systems design

Other labels also support the relational analysis of the organisational redesign. For instance, the 'intervening condition' label appears once in the MAS design, establishing the task group as a central element in the redesign. Basically, it intervenes in setting the MAS phenomena such as the budgeting and tariff systems, and their specific properties. In other words, the MAS Design category is a depiction of an STSD accounting system.

Next, the 'causal condition' label is not present at all. Instead, the 'context' label appears frequently, thus indicating that the MAS design (all four categories) is already including some other causal structure, i.e., the event cycles as discussed above. Linkage is provided by the control structure, especially the usage of meetings and agenda-setting forms. Causality then runs from control to communication, to reporting, to information and then to MAS design, showing the linkage with the PCI design sequence rule of STSD.

The explicit attention to communication is something which is added by Zilverstad. Communication itself was considered important, as the two incidents of company-wide presentations show, including the subsequent properties of participatory/nonparticipatory project management and communicating expectations to everyone/selected group (Tables 7.5 and 7.6). Therefore, the issue of communication is present throughout the change process and, perhaps, tied to the advance from the pioneering to the organisation stage.

Continuing the causal coherence issue, the categories of Control structure and Change chronology can be considered 'weave categories' in working down the PCI rule towards the MAS design. 


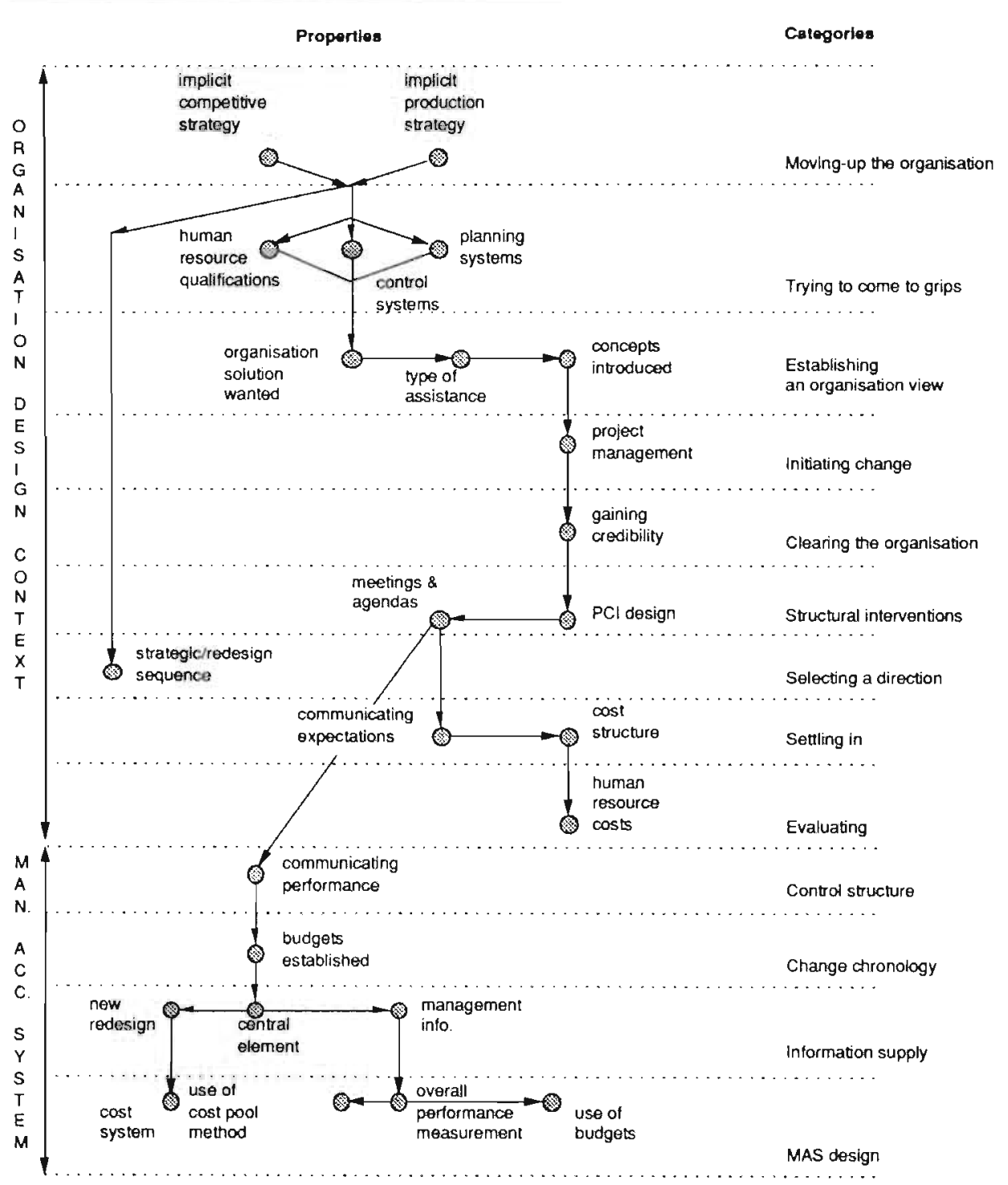

Figure 7.8 Axial pattern of Zilverstad

How this weaving is accomplished can be discussed by linking categories at the dimensional level, i.e., exploring the variation in phenomena, the last step in performing axial coding. The axial pattern that can be determined as a result of this process is linked by the dimensions of properties and not so much by the properties themselves. For instance, linkage between organisational context and MAS design is achieved by the properties of meetings and agendas (organisation design 
context) and communicating performance (MAS). Although they have different names, their dimensional profile is identical: In an organisational context, it is dimensionalised in terms of high and little interaction while in an MAS context, it is dimensionalised as between groups and in group, both exemplifying the linkage that is accomplished by the meetings and agendas. Categories also link up, because Structural interventions also contains the property 'PCI design'. The $\mathrm{C}$ in PCI design stands for control structure design. This is the starting category of the MAS design.

The order in the axial pattern is established by the previous axial coding of the nature of relationships between phenomena and categories and their 'properties'. For instance, consider the first top nodes in the axial pattern. 'Implicit competitive strategy' as well as 'implicit production strategy' are part of the changeover to the customisation and diversification phenomenon. It is related to Moving-up the organisation by means of establishing a context for the upcoming events, while at the same time providing an intervening condition, in order to set the tone for the reorganisation. In turn, the reorganisation brings events that are themselves action strategies, albeit implicit ones since the decision to changeover was not well thought-out. Consequently, the problems of the changeover were with 'human resource qualifications', and the 'control and planning systems' with which the organisation was Trying to come to grips. These problems directly caused (event cycle) the condition where a comprehensive 'organisation solution' was sought, resulting in an action to look for a certain 'type of assistance'. Consequently, this resulted in 'introducing concepts' that explicitly Establish an organisation view.

From the above example (coding paradigm categories in bold and open-coding categories in italic), you can already see that an axial pattern almost naturally rolls over into an abstract narrative of what happened. This narrative constitutes the storyline, i.e., the heart of selective coding.

\section{Selective Coding}

Again, the storyline revolves around the central phenomenon of organisational change, which can be, in the case of Zilverstad, metaphorically labelled as the constitution of the organisation. The firm went from a single-operation family business to a multi- operation, multi-product business with a focus on customised quality products. During this changeover, the firm professionalised its management as well as its organisational control by means of STSD instruments and the explicit human resource-based view on organisations that STSD endorses, and that neatly fitted together with the social responsibility felt by the owners. Once the organisation was constituted, it was used as a flexible and active entity for deliberate strategic management.

Since the central phenomenon is organisational change, the core category, once again selected, was that of organisational learning. Zilverstad learned quite literally how to lift itself up from a pioneering stage to an organisation stage. In the course of learning instruments and techniques, they also learned how to apply those instruments and work together, i.e., they learned a mode of behaviour previously unknown. Both structures, for which they learned how to build them, and the newly acquired behaviour, which was obtained by virtually building these structures, came together in an organisation now able to move as an entity. 
The first type of learning is single-loop learning (Argyris, 1977): It relates to the problems that were created by the implicit strategic choice of diversification and customisation (category Trying to come to grips) and the STSD instruments and views applied to resolving this problem. The 'concepts introduced' (final property in the Establishing an organisation view category) marked the end of that singleloop learning process and also of the first event of the subcycle. The second-loop learning process started shortly thereafter when the project management structure was initiated, getting people to work together. The project gained credibility and people rapidly became accustomed to the trust that was placed in them. It was at this stage, for example, that the case describes that the consultant was not involved and was only told at regular occasions what the state of affairs was. These two properties ('project management' and 'gaining credibility') also coincide with the second event subcycle. Subsequent participation in structural interventions (the third event subcycle) further increased the learning capacity. Notably, the detailed structural designs made by the organisation members were conceived in less than one year.

Moreover, the strong emphasis on communication (work groups, the central role of the meetings and agendas, company-wide presentations) indicated that considerable energy was generated and directed towards having people talk to one another and teach each other to work together (many action strategies). These newly learned capacities resulted in "... people do acquire an awareness they have gained importance for the company ...", thus leading to an increase of human resource costs (see case description) as well as the importance of a job classification system in Zilverstad's case (the final event subcycle).

The organisation, now perceived as one where people work together, has 'learned' on its way up. Its capacities, at present, involve behavioural routines that were not available at the onset of the change process. The next steps for the organisation, such as resetting its strategic course, are only possible once the organisation's structural and behavioural changes have taken place. In other words, deliberate strategy followed structure.

In terms of the MAS design, organisational learning is present in the decentralisation of financial control towards task groups ('central element' property). Accounting instruments are either directed at working together ('overall performance measurement' property) or providing the financial information for local control (properties of 'use of cost pool method' and 'use of budgets'). As local control is a matter of jobs and tasks, it is no surprise that the upgraded cost system has become a job order cost system, possessing characteristics such as products made to customer specification (samples!); direct material requisitions and direct labour costs carry the job (silver and skilled silversmiths); individual jobs identifiable in the production flow (STSD) and sales and administrative expenses are allocated to arrive at total cost (gross margin for Sales 'to live on'). Local cost control, clear processes and a simple cost system result in a highly transparent cost structure, built by people who learned how to create and think in terms of structures and now use these same structures to repeat the learning process, although this time, they concentrated on what behaviour is most profitable for their group. For example, this is achieved by paying full attention to sample requests from Sales or by manufacturing inventory orders in the same planning priority as the customer orders. 
Thus, organisational learning can be depicted by using the event cycles discussed above, the first subcycle relating to single-loop learning, while the other three subcycles relate to double-loop learning. The 'big event cycle', from the implicit strategic choice to the explicit consideration of resetting strategy, catches the learning process in general, while the subcycles catch the development process.

Organisational learning can be further explicated by showing the nature of relationships between categories and the core category, using the terminology of the coding paradigm (Figure 7.9).

\begin{tabular}{|c|c|c|}
\hline Catogory $\longrightarrow$ & Nature of relationship & Core category \\
\hline $\begin{array}{l}\text { Moving-up the organisation } \\
\text { Trying to come to grips } \\
\text { Establishing an organisation view } \\
\text { Initiating change } \\
\text { Clearing the organisation } \\
\text { Structural interventions } \\
\text { Control structure } \\
\text { Change chronology } \\
\text { Information supply } \\
\text { MAS design } \\
\text { Selecting a direction } \\
\text { Settling in } \\
\text { Evaluating }\end{array}$ & $\begin{array}{l}\text { context: intervening conditions; action strategy } \\
\text { action stralegy; consequences } \\
\text { causal condition; action strategy; consequences } \\
\text { context; action strategy } \\
\text { context; action strategy: consequences } \\
\text { causal conditions: context: action strategy } \\
\text { context } \\
\text { context; action strategy } \\
\text { context: action strategy; consequences } \\
\text { action strategy; consequences } \\
\text { intervening conditions; action strategy } \\
\text { action strategy: consequences } \\
\text { action strategy; consequences }\end{array}$ & Organisational Leaming \\
\hline
\end{tabular}

Figure 7.9 Selective coding of Zilverstad

A tentative theory based on the axial pattern and the selective coding would then look like this:

Under the condition that a firm informally changes over from a mono-product, single-operation price strategy to a multi-product, multi-operation strategy, it will find control, planning and staffing problems along the way. As it tries to come to grips with the situation, it will look for an organisational solution to answer these problems. Key personnel in the organisation will introduce STSD as the organisation solution desired, and start teaching middle management and themselves the STSD instruments. Once taught, the organisation will be mapped and credibility will be acquired for the upcoming change in structures and work processes. As part of the structural and process changes, the management accounting system will be addressed through the meetings and agendas on the cooperation in the firm. When people learn how to work together, they will learn how to use financial information, in the form of budgets and tariffs, for the local control of their performance. The acquired ability to work with each other as well as with financial information will result in an increased awareness of people's learning capacities and therefore in an increase in human resource costs. Furthermore, once the organisation is structured in work groups and flow-oriented manufacturing, it becomes transparent in terms of both production processes and cost structures and can manoeuvre as a flexible entity. A more deliberate strategy selection takes place once 
management and employees learn how to go about their work and understand the link between their work and the performance of the organisation.

\section{Comparison of Van Nelle and Zilverstad}

Comparison is based on matching both selective coding theories of Van Nelle and Zilverstad and their respective axial patterns, and tries to further develop matched categories in terms of their dimensional profile.

In general, both cases center on organisational change and organisational learning. Both change processes were initiated by a change in organisational status: Van Nelle became independent and Zilverstad departed from its long-term existence as a family business, metaphorically described as 'resurrection' and 'constitution' of the organisation. External market considerations seem to be less important: The tobacco market did not function as a change incentive to Van Nelle, although in Zilverstad's case, a market cue was indeed available: Price competition was no longer a viable strategy and was replaced with diversification.

Organisational status as a cue is followed up by the presence of a social vision on the part of top management. Van Nelle's new manager had a clear idea as to what image the firm must portray, key element being the human resources of the organisation. Zilverstad works somewhat the other way around: People were already the key element because of its longstanding family tradition, but their ideas regarding the outcome of the organisational change were less solid. The resulting learning organisations were, therefore, either consciously built upon the idea that people are the key asset (Van Nelle) or relatively less consciously generated as a byproduct of the longstanding family tradition (Zilverstad).

The central element in the change process is the change management approach. In both cases, change management introduced a number of important elements that guided all subsequent design efforts: participation, decentralised decision making, and local control.

The linking-pin project structure, controlled by a steering group and explicit functional design requirements, and the autonomy of work groups to take their own design decisions, resulted in credible designs and involved employees. Also, the high involvement in the design activity taught people how to cooperate, using one single STSD language. Further, decentralisation was made operational in terms of task groups and local information supply and control.

The newly acquired attribute of knowing how to work together in the design work groups transfers to how to work together in task groups. A capacity to learn from one another is also acquired. This is a side-effect of the concrete design skills. This 'working together' aspect of the change management approach constitutes the basis for double-loop learning: When people experience how other people work and cooperate, they reflect and question their own behavioural routines and how they pertain to this confrontation, that is, if permitted and encouraged by the context, i.e., the organisational design. Double-loop learning is just that: being able to take a 
double look at the situation by questioning the relevance of operating norms (Morgan, 1986, p. 88).

Both cases can be viewed in terms of cascading event cycles. The largest cycle depicts the primary motivation for change: The shock of the management buy-out for Van Nelle and organisational problem solving for Zilverstad. The event cycles within the main cycle can be considered learning loops. The first of these minor cycles is related to training: Employees follow courses where they are taught the design techniques and instruments of STSD, i.e., single-loop learning. Next, a start is made with a project management structure, preparing functional redesign requirements and a general organisation redesign. This first activity forms the basis for subsequent double-loop learning cycles. This becomes especially apparent in the case of Zilverstad: Working together in the design activity makes people aware of and allows them to question the mental picture of their work and the surrounding organisation. In the further development of the project, mutual interaction increases as management shows that they are serious about decentralised decision making and local control, either by improvement projects (Zilverstad) or STAP budgets (Van Nelle).

Double-loop learning is even more present in the considerable use of standards in the respective accounting systems. Standards can be considered implicit norms on how to perform although it just measures and controls performance output and not activity. When the organisation structure is decentralised and local control becomes the major element in the design, standard setting is completed by the groups. Thus, performance and performance standards are brought very closely together. So when the work of a group changes (i.e., you change the activities and tasks of an autonomous work group) the standards also change. In other words, challenging the job content is challenging the standards, which is a major aspect of double-loop learning. In terms of standard costs and standard cost systems, the normative standard aspect is more important than the financial cost aspect. Financial standards only differ at this stage in their provision of an alternative weighing factor in decision making, i.e., is the proposed action financially beneficial as well? When such financial weighing is lacking, other weighing factors such as delivery time (Zilverstad) or machine occupancy (Van Nelle) can take over because these factors are considered as being of strategic (Zilverstad) or control importance (Van Nelle). The main assumption, however, is that standards are used to direct behaviour to improve operations and processes, not to assure accomplishment of set targets and reward or punish accordingly by higher management.

Costs are standardised on the basis of job orders that are grouped into one single organisation unit, the task group. Job costs are, therefore, well matched and located, which in turn leads to a transparent cost behaviour where actions and costs can be traced simultaneously. Indirect costs are either made direct, once their underlying activity is revealed and allocated to a task group, or occur only at the company level, where they are highly distinguishable and can be allocated by some arbitrary measure open for managerial discretion.

Connectivity/coherence and timely feedback are also used in combination with standard setting and subsequent variance analysis. The reporting systems of both Van Nelle and Zilverstad are internally connected, aggregating detailed task group 
information to Production or company level. In the aggregation process, a systems jump in control level is explicitly made: Aggregated information addresses the company/plant as a whole and supplies input for full product line decision making. Aggregated and desaggregated information is also reported in different frequences: The more frequent, detailed and operational the information is, the less financial it is stated. The management accounting systems of van Nelle and Zilverstad, therefore, are strongly focused on operational control and local decision making.

Local control is further enabled by three issues that became clear in the Zilverstad case: the role of strategy, the role of communication and the use of the cost pool method. Zilverstad's climb in organisational status more or less replaces Van Nelle's fluctuation in economic status, within the larger context of the change process. The process was motivated by strategic arguments, although these differed in both cases. Van Nelle's larger goal was to get the organisation on the move, make it more open and flexible, therefore taking an organisational strategy point of view. Zilverstad's angle was also to set the organisation in motion, but its primary goal was to survive in the market place by solving all the organisational problems, i.e., its organisational strategy was linked to an implicit competitive strategy of differentiation and diversification. In Zilverstad's case, this strategy component becomes more evident as it relates to a full organisation instead of a plant organisation.

The follow-up to the structural redesign in both cases shows a causal chain: a more flexible production process, designed from autonomous modules leading to --> a more transparent organisation leading to $->$ better traceable costs and better organisational control which, finally, leads to --> improved input for strategic decision making. Again, Van Nelle is confronted with its economic status, the major policy maker is once again a very large multi-national: Sara Lee has its own strategic agenda and maintains only the plant level controls and flexibilities. On the other hand, Zilverstad uses its increased control and flexibility to reopen its strategic discussion - this time, in a more deliberate and conscious manner - and builds further upon its newly acquired capabilities.

To conclude, the interfaces of the strategy-structure-strategy chain are mediated by the economic or organisational status of the firm. For the resulting MAS design, the mediated strategy-structure relationship is important as well; what is strategically relevant reappears in the MAS structure. As far as strategy and organisational status means challenging set standards, in terms of costs and control information supply structures, the MAS design is an instrument to start up or improve doubleloop learning.

As a result of the Zilverstad case, the role of communication has been added to the list of differentiating factors. Communication is located at the boundary of the control structure and the administrative (financial and nonfinancial) information structure. What is meant by communication is the explicit use of meetings and agenda-setting forms to relate information to control decision making, i.e., structurally bringing supply and demand together. When comparing this to Van Nelle, the role of meetings is limited to internal task group meetings and discussions be- 
tween production manager and task group coordinators. Moreover, instead of a separate line of forms, the formal reports from the MAS are used.

The background of these differences can be either the different systems level (plant versus full organisation) and/or the type of production process (bulk versus customised). The production process of tobacco has a singular input and then is routed to one of three task groups (serial + parallel flows). In contrast, Zilverstad's production process maintains several inputs to the task groups and several outputs to inventory and customer (only parallel flows), requiring more coordinating effort between the task groups themselves, and between groups and other parts of the organisation. A more structured coordination, by way of meetings and agendas, then seems highly plausible.

Maybe a third basis for this difference is the attention Zilverstad pays to people working as a unity. Working together and coordinating and communicating it by means of a formalised meeting system furthers coherence in actions and operational behaviour. Again, a reference can be made to double-loop learning: Norms and standards such as how to handle sales orders, product development and production costs are exchanged and discussed. This is partly necessitated by the amount of customised products, and partly by the control and planning problems experienced before the STSD redesign, i.e., the importance of coherent and orchestrated action was well understood.

The final item added by Zilverstad is the use of the cost pool method. The cost pool method is primarily used to set tariffs, i.e., standard costs for operations: It is the pure accounting, calculative version of standard setting. Tariffs are used in product cost build-up, transfer pricing between groups as well as a minimal financial limit for make-or-buy decisions. The cost pool method at Van Nelle is used to allocate company level overhead across parts of the organisation, indicating that the cost pool method requires at least an outline of the full organisation in its calculative format. In both cases, cost allocation is performed by centralised staff, having this outline of the organisation chart.

The use of the cost pool method itself is a further detailing of standard setting. It hands over standards on individual operations, instead of handing over (budget) standards for the task group as a whole. Furthermore, tariff standards are less behaviour-restrictive than budgets since they are set less frequently (usually yearly) and relate to bookkeeping categories. These categories are inherently homogeneous to input, grouping identical costs together, and not to consumption (i.e., grouping costs on the basis of activities performed in the product flow). Therefore, tariffs relate to what is going in the organisation and what is going out of the organisation but not to what is done in between. In contrast, budgets are relatively better behavioural instruments as their unit of application relates to the task or activity of a section of the organisation and not to input/output registration. Therefore, the use of the cost pool method provides additional standards at the operational level. These standards have less behavioural and learning impact than the budget standards have.

The existence of a previous accounting system in some detail (Zilverstad) seems to add to the number of financial building stones required in the accounting system. 
For instance, Van Nelle was only provided with an elementary budget for Production and a number of general overhead expenses to absorb: the consequent redesign of the MAS seems to extend the previous budget type of control. New elements were added only in nonfinancial denominators. Similarly, Zilverstad's accounting redesign extends the elements already present to include the new organisational format (e.g., cost pool method allocation, budgets). New' accounting, therefore, are extensions of the existing elements. New, nevertheless, is the different use of the system and its explicit embedment in a larger reporting, communicating and information structure: Accounting is part of an encompassing management control design.

\section{Grounded Analysis of St. Antonius Vesselheads}

Table 7.8 Coupling phenomena to incidents in the case description of St. Antonius

\begin{tabular}{|c|c|c|}
\hline Paragraph In case descriplion & Incidents & Phenomena \\
\hline \multirow[t]{12}{*}{ Situational background } & new president & \multirow[t]{3}{*}{ change of control } \\
\hline & new management team & \\
\hline & clear strategy lacking & \\
\hline & ad hoc decision making & \multirow{3}{*}{ organisation problems } \\
\hline & inadequate order planning & \\
\hline & increasing market pressure & \\
\hline & much to do, where to start & looking for guidance \\
\hline & contact with STSD & \multirow{3}{*}{ STSD establishes itself } \\
\hline & courses followed & \\
\hline & STSD leading concept & \\
\hline & change plan constituted & overall change phases \\
\hline & SOA & change goals \\
\hline \multirow[t]{3}{*}{ Categorlsation of bottlenecks } & calegorisation bottlenecks & \multirow{3}{*}{ redesign reterence point } \\
\hline & Work Group Design installed & \\
\hline & entrance external consultant & \\
\hline Modelling the primary process & modelling the primary process & \multirow{3}{*}{ pinpointing change locations } \\
\hline Indicating bottienecks & indicating bottieneck causes & \\
\hline \multirow[t]{2}{*}{ Relating bottlenecks to org. structure } & relating bottlenecks to org. structure & \\
\hline & only upstream redesign impossibie & full reorganisation \\
\hline \multirow[t]{13}{*}{ Designing the organisation structure } & project planning & \multirow{3}{*}{ change management } \\
\hline & project management & \\
\hline & no formal approval machanism & \\
\hline & various alternatives available & \multirow{2}{*}{ design choice } \\
\hline & redesign chronotogy & \\
\hline & Production Engineers installed & \multirow{3}{*}{ information flow linkages } \\
\hline & Ouality Engineers merged with Sales & \\
\hline & improving ordering process & \\
\hline & formation of five production groups & production redesign \\
\hline & modelling controlling activities & \multirow{3}{*}{ control redesign } \\
\hline & normalisation and standard setting & \\
\hline & now organisation chart & \\
\hline & implementation plan & implementation trajectory \\
\hline A first assessment & cost-benefit analysis & evaluation \\
\hline
\end{tabular}


The case of St. Antonius Vesselheads (hereafter referred to as St. Antonius) is the case last described in the chronology of all three cases; it is the most recent one and it benefits from experiences gained in the previous two cases, both in terms of description and analysis.

Table 7.9 Open coding of St. Antonius' case description

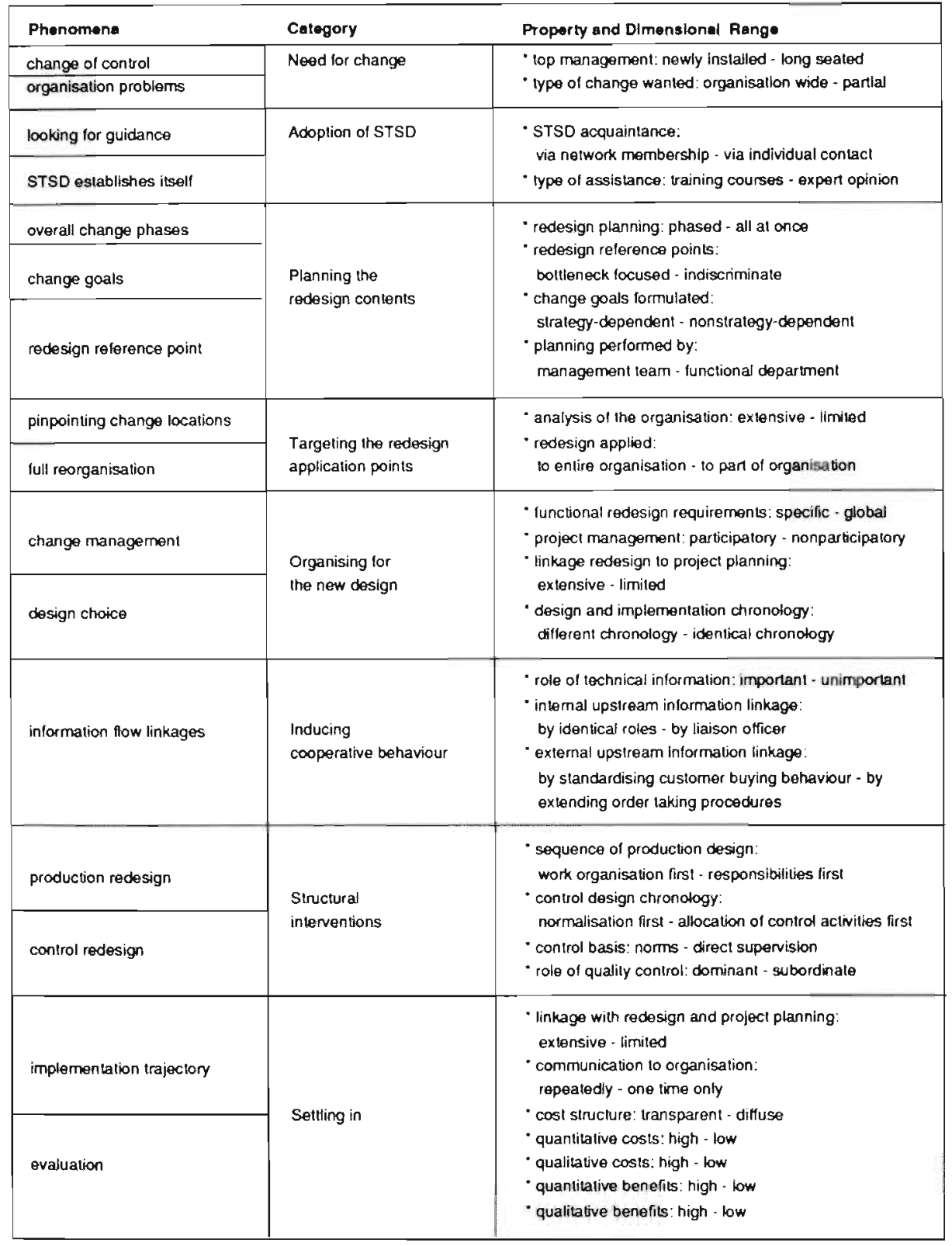




\section{Open Coding}

Similar to the previous cases, the case description is chronological. Incidents and underlying phenomena are, therefore, listed as they unfolded over certain time. Moreover, incidents and phenomena can be traced back to the case description as the matching paragraphs are also stated.

In labelling phenomena, terminology and words from the case description are used where possible. Next, phenomena are coded into categories, again using terminology and descriptions from the case study in order to avoid preliminary analytical interpretations. Both categories and dimensional profiles are closely stated to the text, although they try to obtain a higher conceptual content of terminology.

Open Coding - MAS Design

The phenomena in the management accounting system of St. Antonius are coupled to conceptual categories in Table 7.10. For these categories, the use of accounting jargon could not be avoided, particularly with the term valuating activities having a balance sheet connotation. Valuation in this case is used as a synonym for providing a financial dimension to processes, i.e., for translating one conceptual map (production activity) into another (cost behaviour).

Table 7.10 Open coding of the MAS design of St. Antonius

\begin{tabular}{|c|c|c|c|}
\hline $\begin{array}{l}\text { Peregraph in } \\
\text { ose description }\end{array}$ & Phenomona & Category & Property and Dimenaional Renge \\
\hline \multirow{19}{*}{$\begin{array}{l}\text { Designing the } \\
\text { Managemenl } \\
\text { Accounting } \\
\text { System }\end{array}$} & result of preceding company into system & \multirow{3}{*}{ Goets of the MAS } & \multirow{3}{*}{$\begin{array}{l}\text { posifion of MAS in information struciure: } \\
\text { technical into first - financlal info first } \\
\text { - MAS information flows: } \\
\text { accommodating horizontal \& vertical flow - } \\
\text { accommodating one fow only } \\
\text { - goel of MAS: production control - cost control }\end{array}$} \\
\hline & financial organisation level into & & \\
\hline & shop floor level info & & \\
\hline & work contre unlss croaled & \multirow{4}{*}{ Valuaring ectivilles } & \multirow{4}{*}{$\begin{array}{l}\text { "valuation besis: } \\
\text { work centres - responsibility conires } \\
\text { " valuation denominaror: } \\
\text { work centre units - product units } \\
\text { - activities cos led: } \\
\text { by tariffs - by percentual rates } \\
\text { - tariffs sel: } \\
\text { by cost pool mothod - by manegerial discretion }\end{array}$} \\
\hline & producilon cost terifts & & \\
\hline & four typos of tarlits & & \\
\hline & $\cos 1$ pool method & & \\
\hline & varlance analysis & \multirow{3}{*}{ Cost control } & \multirow{3}{*}{$\begin{array}{l}\text { cost control: } \\
\text { on nonfinancial besis - on financial besis } \\
\text { cosi sinucture: } \\
\text { fow indirect costs - many Indireci costs }\end{array}$} \\
\hline & $\cos 1$ structure & & \\
\hline & jab order cost system & & \\
\hline & WIP throughput indicator & \multirow{5}{*}{ Information supply } & \multirow{5}{*}{$\begin{array}{l}\text { - Work-tn-Process used as: } \\
\text { throughput indicalor - batance sheet Item } \\
\text { "role of administrative organisation: } \\
\text { depentmantal into linkage - extemal euditing device } \\
\text { - MIS: method for communicaton - method for contro } \\
\text { - MIS stnxcture: buitt bottom-up - built lop-down }\end{array}$} \\
\hline & adminis trative organisation & & \\
\hline & product cost & & \\
\hline & bottom-up bulit MIS & & \\
\hline & roles of MIS & & \\
\hline & management control parameters & \multirow{4}{*}{ MAS design } & \multirow{4}{*}{ 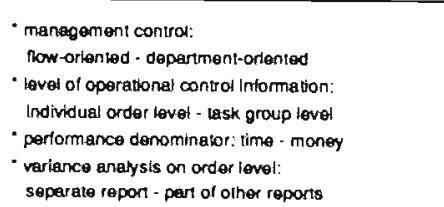 } \\
\hline & WiP roport & & \\
\hline & Portod report & & \\
\hline & Ex post catculation repon & & \\
\hline
\end{tabular}


Axial Coding

The basic input for establishing causal relationships between categories is now available in the above open-coding categories of St. Antonius. The denominator or axis for these relationships are depicted in Figure 7.10.

\begin{tabular}{|c|c|c|}
\hline Phenomenon & Nature of relationship & Category \\
\hline $\begin{array}{l}\text { change of control } \\
\text { organisation problemis } \ldots \ldots . . .\end{array}$ & $\begin{array}{l}\text { context; intervening conditions } \\
\text { causal condition; context }\end{array}$ & Need for change \\
\hline $\begin{array}{l}\text { looking for guidance } \\
\text { STSD establishes itself }\end{array}$ & $\begin{array}{l}\text { action strategy } \\
\text { context; consequence- }\end{array}$ & Adoption of STSD \\
\hline $\begin{array}{l}\text { overall change phases } \\
\text { change goals } \\
\text { redesign reference point }\end{array}$ & $\begin{array}{l}\text { context; action strategy } \\
\text { causal condition: context; action strategy . . } \\
\text { context; action strategy }\end{array}$ & $\begin{array}{l}\text { Planning the } \\
\text { redesign contents }\end{array}$ \\
\hline $\begin{array}{l}\text { pinpointing change locations } \\
\text { full reorganisation }\end{array}$ & $\begin{array}{l}\text { context; action strategy } \\
\text { causal condition; context; action strategy; consequence }\end{array}$ & $\begin{array}{l}\text { Targeting the redesign } \\
\text { application points }\end{array}$ \\
\hline $\begin{array}{l}\text { change management } \\
\text { design choice }\end{array}$ & $\begin{array}{l}\text { causal condition: contexl; action strategy } \\
\text { action strategy; consequence }\end{array}$ & $\begin{array}{l}\text { Organising for the } \\
\text { new design }\end{array}$ \\
\hline $\begin{array}{l}\text { information flow linkages ...... } \\
\text { production redesign } \\
\text { control redesign }\end{array}$ & $\begin{array}{l}\text { causal condition; action strategy ...... } \\
\text { context; action strategy; consequence } \\
\text { context; action strategy; consequence }\end{array}$ & $\begin{array}{l}\text { Inducing cooperative } \\
\text { behaviour } \\
\text { Structural interventions }\end{array}$ \\
\hline $\begin{array}{l}\text { implementation trajectory } \\
\text { evaluation }\end{array}$ & $\begin{array}{l}\text { context; action strategy } \\
\text { action strategy; consequence }\end{array}$ & Serti \\
\hline
\end{tabular}

Figure 7.10 Axial coding of St. Antonius

Several observations can be made concerning the organisation design category linkages. First of all, regarding the nature of relationships. Action strategies and context are the labels most frequently appearing. This indicates that St. Antonius' activities were embedded in a continuous sequence of newly shaped conditions. In other words, events were consciously directed and managed by an accumulative series of preparations, i.e., actions and context were tightly coupled, no action without a context that fitted that action. In terms of axial coding, a consequence code prepares the ground for a new cycle of events, which in turn are concluded by a consequence. For example, the establishment of STSD as leading concept for further redesign activities (a consequence of the preceding training courses) triggered various planning and targeting actions. Once these plans and locations were determined and clarified (a consequence), the next series of actions were started, regarding the change management approach and full organisational involvement.

The causal condition code has a similar boundary function, the difference being that it relates not to action cycles but rather to learning cycles. A causal condition code refers to the incidents that lead to the occurrence of a phenomenon; it makes something happen. This condition can be a preceding situation or a preceding insight into a situation. For instance, the causal condition of the organisational problems St. Antonius was experiencing led to problem-solving actions; they went outside to find help and found it in STSD. Once STSD was adopted as a leading concept, the situation not only changed (a consequence code) but also the ability to do something about it, i.e., they had learned something. The lessons learned were 
subsequently put down in the change goals, following the insights from a SWOT analysis and STSD (a causal condition code). Subsequent learning took place as a result of the extensive bottleneck analysis of the organisation and leading to the recognition that the full organisation needed to be redesigned, again indicated by a causal condition code. In short, learning cycles are indicated by a causal condition code and can extend across action cycles, indicated by context and action strategy codes.

A final observation that can be made, based upon the open-coding diagram, is that considerable effort is put into the preceding design phases: Four categories between the Adoption of STSD category and the Structural interventions category (i.e., the virtual design) indicate the importance placed by St. Antonius on the redesign preparations. Specifically, added by St. Antonius was the Inducing cooperative behaviour category which is concerned with establishing the information linkages previous to the structural redesign. Moreover, implementing the information design first, indicates that the production process and production structure are of a highly information dependent nature, up to the point that information controls the production. Consequently, the role of information design seems to be motivated by quality control and its exclusive attention for technical and normalised information (see axial pattern where this point is elaborated further). In short, St. Antonius' elaborate redesign preparations is related, presumably, to the presence of quality assurance normation. Comparison with the other case studies can give a more conclusive insight.

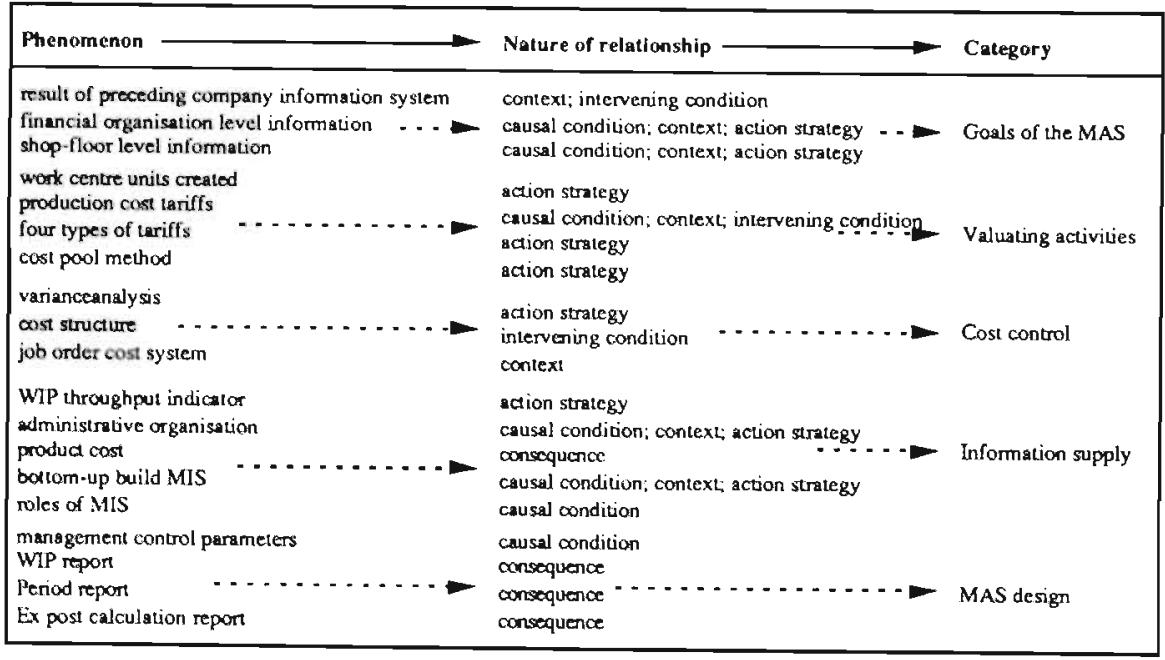

Figure 7.11 Axial coding of the MAS design of St. Antonius

\section{Axial Coding - MAS Design}

Observing the axial coding of the management accounting system of St. Antonius, in the first place, shows an almost identical frequency in the codes of context (7), action strategy (9) and causal condition (7). As in the axial coding of the organisational redesign, context and action strategy are related in terms of action cycles; 
what happened and in what order. For example, design of the accounting system is restricted by the preceding design of the company information system, which is both a context and intervening condition. Context because it has to reflect a twotier MAS: One for company-wide managerial purposes and one for local, operational purposes; and intervening condition, because it sets the goal for embedding the accounting part of the redesign trajectory in the overall organisation. Linking the two is achieved by creating work centre units, an action strategy mirroring the organisation structure (work centres, divisions) in the accounting map of the organisation (production cost tariffs). Basically, production tariffs were already familiar to St. Antonius but in the primitive form of specific labour and machine hour rates. Now, they include overheads and are more comprehensive, hence called tariffs instead of rates. Actions following the local purposes tier are the use of various nonfinancial variance analyses and the controlling reporting system itself. At a global company level, the distinction of several types of tariffs, each matching the company's capacity outlook (fiscal, break-even, replacement, and market value), as well as the role of WIP as a main throughput indicator, indicates how aggregate management information is supplied.

Causal conditions translate as restrictions on further design actions: Aggregate organisation level information as well as local information are required to be supplied, based on the preceding organisation design which matches a strong decentralisation with a flexible organisation. Use of work centre units, tariffs (local) and WIP as a throughput indicator (global) are the basic design follow ups. Moreover, causal conditions signal a step-up from the preceding actions: What was learned is used as input for the following action. For instance, building the MIS (an organisation level phenomenon) is done bottom-up. Thus, it was basing itself both on the previous positive experiences with employees designing their own task group in the project structure, and on the administrative organisation which was based on looking for the information Quality and Production Engineers actually needed for their work (i.e., endorsing a local perspective): Those lessons learned from the preceding design activities (the intervening condition code at the start of the MAS design).

Furthermore, the consequences codes in the diagram are located predominantly at the end of the design track. The reporting system and the production cost information supply are truly the final outcomes of preceding actions, also indicated by the absence of context and action strategy codes. Again, the importance of extensive preparations, also noted in the axial coding of the organisation design, is dominant: Preliminary and preparatory categories take up much of the event space three out of five categories. Intervening conditions codes have a historical flavour in that they relate to preceding events and circumstances. First of all, in the condition of the information system, where the accounting design has to fit in and, second, in the conditions where familiarity already exists with production rates as basis for the latter production tariffs and with a cost structure favouring direct over indirect costs. Both made good basic conditions for the subsequent creation of detailed and local cost information.

Linking categories at the dimensional level again indicates the relevance tothe overall and preceding information structure. The information structure itself is a reflection of several specific items: The redesign of the entire organisation, focus- 
ing on information linkages between departments and the importance of one type of information (technical). Information is used in the organisation design as a method of reinforcing the flow orientation of production, i.e., departments are required to cooperate with information supply because the technical process necessitates it. The accounting consequences are operationalised by the use of work centre units, detailed production cost tariffs, reporting at individual order and operation levels, variance analyses both in reports and as a separate ex post calculation report, a high level of nonfinancial information and a throughput indicator which is function nonspecific. In general, it can be questioned as to whether one can still speak of a management accounting system design because the financial/cost items are merely translations from operational and time dimensions of the global and local information demanded. Rephrasing linkages between categories and their properties, the axial pattern can be established as in Figure 7.12.

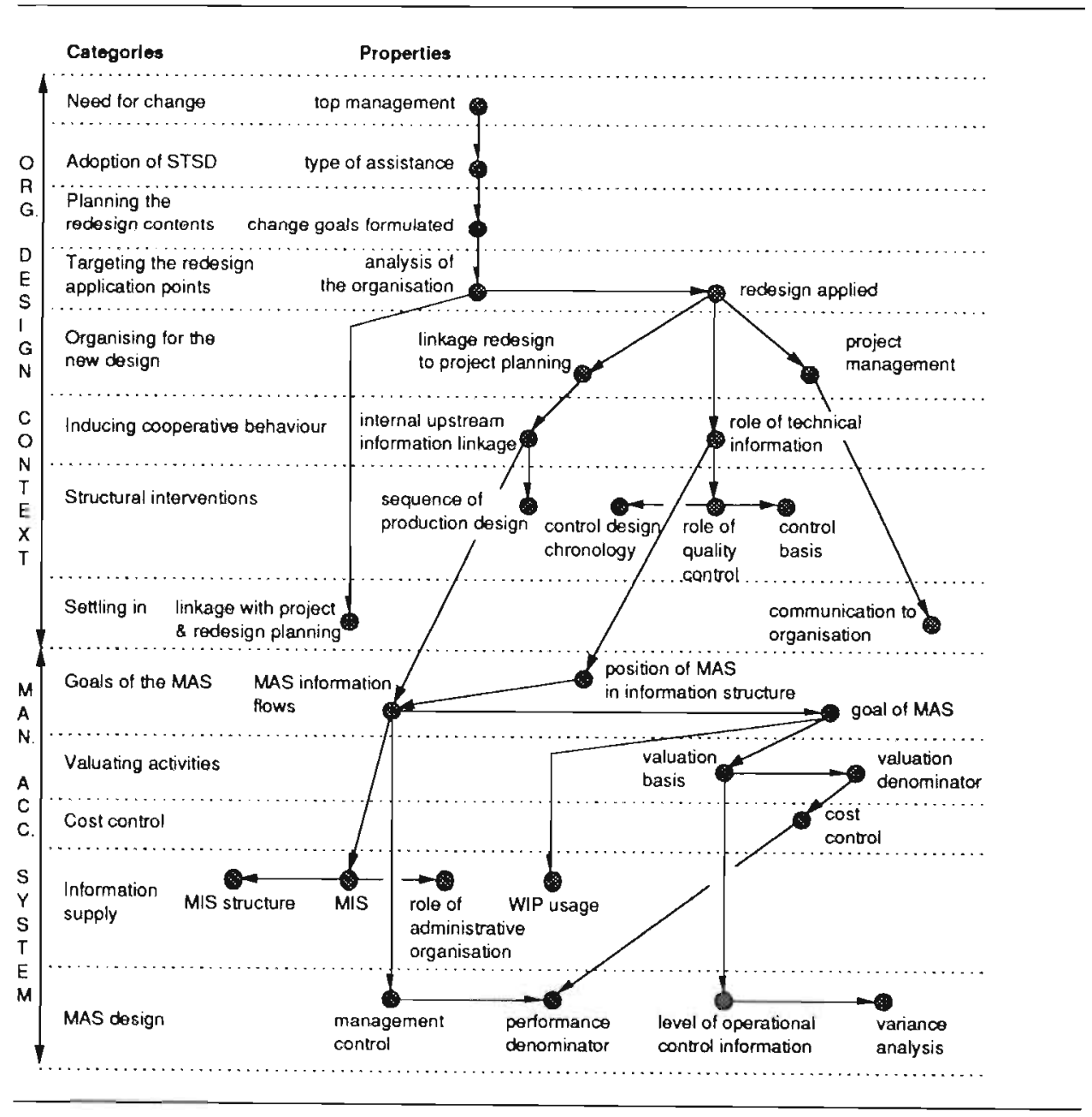

Figure 7.12 Axial pattern of St. Antonius 
Linkage between organisation design and MAS design is performed by the categories Inducing cooperative behaviour and Goals of the MAS. More specifically, the upstream information linkage between the Production and Sales functions of St. Antonius and the role of technical informationprovide the basic match. The latter property, however, links up indirectly as it is tied to the dimensional profile of the MAS property 'position of MAS in information structure' (technical info first versus financial info first). The reasons for the overall importance of technical information can be traced back to the 'change goals formulated' property in the Planning the redesign contents category. Change goals are dimensionalised as dependent on strategy, with the strategic goals of St. Antonius being related to high quality and short and controllable throughput times. More specifically, this is stated as 'communication \& information' and 'knowing by measuring'. In other words, St. Antonius strategic goals are highly nonfinancial and, therefore, are thought of as being nonfinancially transferred and operationalised in the redesign process.

Based on the above axial pattern, the nature of relationship between the various events can be stated as follows: The change in top management, as a result of Houben Jr. taking over control of the organisation and installing a professional management team, formed the organisational context for solving the organisational problems that St. Antonius experienced. Consequently, they took action by looking for guidance in their network of contacts. They came upon STSD, which assisted by training them in organisational redesign. Having adopted STSD as a leading concept, the management team formulated change goals and analysed the organisation as to locate the application points of their redesign effort. They discovered that redesigning only a part of the organisation was impossible and, as a result, the redesign content, redesign planning and project organisation was applied and communicated to the full organisation. A start was made with the upstream functions in the flow and, more specifically, with the integration of the technical information flow across the departments. The work organisation underlying the technical information demand was, in the first place, redesigned by normalising control standards and information requirements. This was much helped by the importance of quality control expressed in the change goals.

The management accounting system was preceded by the demand for technical information, both in the horizontal information flow to local users and to the vertical flow to managerial users. The structure of the information supply was built from the local users upwards, communicating to management rather than controlling actions by higher management. Linkage between the two flows was designed and visualised in the administrative organisation chart and in separate reporting on variances in time consumption and individual order performance. Cost control and managerial control were equally based on the work centres in the production flow. The accounting system, being primarily directed at production control, translated operations into financial values by creating work centres, having individual production cost tariffs.

\section{Selective Coding}

As with the two other case studies, the storyline of St. Antonius has revolved around organisational change, metaphorically expressed as the professionalisation of the organisation. The firm changed itself from a problem-ridden job shop or- 
ganisation into a quality-standardised, flexible subcontractor. Professionalisation is accomplished by a decentralised organisation structure, flow-oriented production and improved organisational control and information systems. STSD played a key role in attaining this status, and is still playing it in the ongoing improvements of information, managerial and work procedures.

Once again, the core category selected is that of organisational learning. St. Antonius learned how to change itself in full and, along the way, they have gained considerable insight into its own production operations, information flow and how to control the two. In other words, St. Antonius has learned to learn by questioning the relevance of operating norms or, in the many cases where there were no norms, ask itself what norms they think are relevant, thus questioning both the operational process and the larger strategic framework containing this process. The considerable effort of St. Antonius in normalising information (and work procedures, as the two are intrinsically tied) clearly shows that the question of 'what is relevant to what' has been asked many times.

Characteristics of the St. Antonius learning process can be gathered from the axial pattern. Learning began with the start of events, i.e., the changeover in managerial control by Houben Jr. and the newly engaged management team. Single-loop learning took place by attending the STSD courses, where the change skills and methods were literally learned. Single-loop learning is defined as "the ability to detect and correct error in relation to a given set of operating norms" (Morgan, 1986 , p. 88), hence, the strong normative content of STSD.

The first big lesson learned is that partial reorganisation, by linking up the upstream and production information flow, was not possible. Information was so deeply grounded in operational processes, that to engineer the information at the same time, meant to engineer the processes. This insight created not only a new action towards a reorganisation in full, but also made everyone aware that information was the crucial concept in the entire reorganisation; it was linked to every part of the production flow. It formed the first double-loop learning basis as it put the topic of what was relevant into the spotlight. Double-loop learning is defined as "being able to take 'a double look' at the situation by questioning the relevance of operating norms" (Morgan, 1986, p. 88). The lesson was immediately put into practice by linking redesign content, phases and planning to the linking-pin project organisation, thus interweaving the information knowledge of various employees with the required information and production redesign targets.

The second double-loop learning step was built from the first: The importance of information was structured into the jobs of Quality and Production Engineers, who have identical roles although at different levels (production processes and production methods respectively). Work procedures and information requirements were brought together in one individual, who, as a result, was able to set the specific control norm for subsequent operations on an order: Information and control brought together at one place, tightly coupled to production activities. Quality control considerations played an important role here as well. A high product and process quality was and is an explicit organisation goal, requiring that attention for normalisation and standardisation according to ISO was part of the redesign effort. The thorough analysis of the organisation preceding the design 
turned out to be usable for both; the process insights also made redesign as well as normalisation possible. In short, the second double-loop learning experience was that quality control information was an extension of the tight coupled informattion flow and production activities, up to the point that it set the control structure design by its elaborate supply of measurement standards.

The third double-loop learning experience carries over to the management accounting system design as it takes up the points of quality-normalised and nonfinancial information for organisational control. The goal of the MAS is production control which, as stated above, is mainly performed in nonfinancial terms. Control information is tied to quality standards as well as to production flow. Measurement of standard and variance analysis are, therefore, common ground. The learning part of the design, however, is located in the horizontal and vertical provision of information: Horizontal in terms of nonfinancial standards running parallel with order progress (i.e., WIP as throughput indicator) and vertical in terms of communicating the current state of affairs to higher management. Control actions are to be taken at the level where the information is generated and where the information system is built, and not by higher management. Unless, of course, it requires an action regarding the full organisation such as setting up a job classification system. The lessons learned by the preceding tight linkage between information and operations are reflected in the reporting structure. Detailed operational information, variances to standard, desaggregate to the order level and a separate report for checking on performance standards are the four items indicative for learning. Especially the check on the performance by the ex post calculation report is an evaluation device seldom encountered.

\begin{tabular}{|c|c|c|}
\hline Cotegory $\longrightarrow$ & Nalure of relationshlp & $\rightarrow$ Core cutegory \\
\hline Need tor change & Causal conoition: contexl; intervening condilion & \\
\hline Adoption ol STSD $\ldots . . . . . . . .$. & Conlext: action stralegy & \\
\hline Planning the redesign contents $\ldots . . . .$. & Contexl: action stralegy & \\
\hline Targeting the redesign application points ... & Causal condition; action strategy & \\
\hline Organising for the new design .......... & Causal condition; aclion strategy & \\
\hline Inducing cooperative behaviour- . . . . . . . - & Causal condition; action strategy & - Organisational \\
\hline Structural interventions $\ldots \ldots \ldots \ldots$ & Action strategy; consequence & \\
\hline Settling in $\ldots \ldots$ & Action siralegy: consequence & \\
\hline Goals of the MAS . . . . . . . . . . . & Causal condition: context; intervening condition & \\
\hline Valuating activitios $\ldots \ldots \ldots \ldots$ & Contexi: action strategy & \\
\hline Cos 1 control $\ldots \ldots \ldots \ldots \ldots$ & Action slralegy & \\
\hline Information supply & Causal condition: contexl; action strategy: $\infty$ nsequence & \\
\hline MAS design & Action strategy: consequence & \\
\hline
\end{tabular}

Figure 7.13 Selective coding of St. Antonius 
In explicating the linkage between core and subsidiairy categories, the coding paradigm is used for establishing the nature of the linkages. As can be derived from the diagram, learning can be tied to the appearance of the causal condition code. Interweaving of lessons learned with the next learning cycle is located in the three categories of Targeting the redesign application points, Organising for the new design and Inducing cooperative behaviour. The link of these lessons with the MAS design is located in the categories Goals of the MAS and Information supply, where the position and relationship of the MAS with the organisational context is explicated.

Next, a tentative theory regarding the reorganisation of St. Antonius would look as follows: On the condition that the top management of a firm determines that the organisation needs to be redesigned in order to solve the organisational problems it encounters, it can adopt STSD as leading redesign concept. Redesign is accomplished by employing STSD methodology. As a lesson of the targeting of redesign efforts, it is learned that partial redesign is impossible. Consequently, the organisation will extend the redesign effort as well as establish a close linkage between redesign content and planning, and project organisation. Redesign will focus on relating departments to each other, on the basis of the concurrent information flow. Since these information flows are technical in nature and are managed by creating identical information processing jobs in separate departments, control is based on the normalisation and passing of information to other function downstream in the work flow. Structural redesign is then performed by restructuring the work organisation, by first paying attention to the normalised control information. The management accounting system links up with the newly acquired insight into the horizontal and technical information flows of divisions and work centres, and is primarily directed at production control. Work centre financial performance is valuated by production cost tariffs and controlled on a variance basis. Financial information supply has a causal relation with the importance of the product flow and consequently reported on at the order level. The management accounting systems design resulted into a transparent cost structure, communicating performance to management and employees.

\section{Comparison of Van Nelle, Zilverstad and St. Antonius}

Comparison of the three case studies is based on the open-coding dimensional profile, axial patterns and the conclusions of the previous one-to-one comparison of Van Nelle and Zilverstad.

First, we compare at the open-coding level. All three cases revolve around organisational change and organisational learning. However, the need for change and the objective for entering the change process are different: Van Nelle wanted to resurrect the sleepy organisation and change it into a market-oriented flexible firm; Zilverstad wanted to constitute an organisation leaving the family business pioneering phase it had been in for a long time; and St. Antonius wanted to professionalise its current management and organisational control in order to become a quality-certified subcontractor. As different as their motivations may be, the routes they took were largely identical, following closely the STSD change management approach called Integral Organisational Renewal. Its elements of aware- 
ness for a need to change, strategic and structural orientation, training courses, structural redesign, project management and implementation can all be distinguished in each individual case (Table 7.11).

The first and last phases of each individual trajectory can be readily distinguished. Less clear are the phases preceding the interventions. Here, organisational differences become notable, depending on their economic or organisational status. For example, Zilverstad performed its strategic orientation in the structural redesign phase because of its wish to 'get organised' before setting its course. St. Antonius focused primarily on the information flow because it was here that they felt the largest contribution would be gained. In short, organisational differences can be found in the sequence or accentuation of elements along the change path, not in missing elements.

Table 7.11 Comparing change trajectories to STSD norm

\begin{tabular}{|lll|l|}
\hline Van Nelle & Zilverstad & St. Antonius & STSD \\
\hline Reasons for change & Moving-up the organisation & Need for change & $\begin{array}{l}\text { Awareness of need for } \\
\text { change }\end{array}$ \\
\cline { 2 - 4 } & Trying to come to grips & Adoption of STSD & Planning redesign contents \\
Pointing noses & $\begin{array}{l}\text { Establishing an organisation view } \\
\text { Initiating change } \\
\text { Clearing the organisation }\end{array}$ & $\begin{array}{l}\text { Targeting redesign applications } \\
\text { Organising for the new design }\end{array}$ & $\begin{array}{l}\text { Structural orientation } \\
\text { Training courses }\end{array}$ \\
\hline Operational design interventions & $\begin{array}{l}\text { Structural interventions } \\
\text { Selecting a direction }\end{array}$ & Inducing cooperative behaviour & Project management \\
\hline Experiences & Setting in & Structural interventions & Structural redesign \\
\hline
\end{tabular}

The open coding of all three management accounting systems design are less comparable to what STSD prescribes, simply because the subject is not covered by STSD. From the axial patterns, it shows that accounting design hangs somewhere in between the control structure design and the information structure design: A precise location in the STSD theoretical sequence cannot be given. For example, at Van Nelle, the internal accounting system is a financial extension of the information structure (i.e., the reports), at Zilverstad the accounting system is a natural exponent of the meeting \& agenda communication structure, and at St. Antonius, control and information are not easily separated because of their interweaving with production and quality control, and, before, the management accounting system. As a result, accounting submerges in the integral redesign process: Its information function integrating with the performance information and its calculative function integrating with the operational control. Furthermore, a clearly distinguishable change chronology as to when information design stopped and accounting design started is hard to give. The only chronology possible is, what report followed in what order in the redesign; in other words, it is an implementation chronology and not so much a design chronology.

To compare at axial coding level, we use the three axial patterns. When looking at the linkage between the organisational context and the management accounting systems design, we can see that there are eight properties performing this role: At 
Van Nelle, there exists decentralised decision making on resources and a desaggregated information system; at Zilverstad there are the highly interactive meetings \& forms and the communication of performance between groups; and at St. Antonius, there are the properties of the important role of technical information, the internal upstream information linkage by identical roles, the position of the MAS in the information structure and the accommodating of horizontal and vertical information flows in the MAS. To put into key words, we can identify the linkage to be made by the issue of decentralisation at Van Nelle, of communication by Zilverstad, and of information at St. Antonius. Each case then elaborates upon this issue and explores it as an organisation-specific MAS design. However, elaboration is always directed at control, be it managerial or local. In Van Nelle's case, cost control is explicitly addressed at the local task group level; in Zilverstad's case the control structure is designed around communication and cost control; and in St. Antonius' case, production control is addressed by tying information flows together.

Furthermore, linkage is established by the collaborating event and learning cycles in each case. Events are strongly mitigated by the use of both the Integral Organisational Renewal change management approach and the Production, Control and Information structure design rule of the STSD toolkit. Therefore, events are already prescribed in their causal order and attention is automatically drawn towards deviations from this order. Learning cycles, however, are less clearly determined. They are distinguished and discussed in terms of single and double-loop learning, with single-loop learning relating to "the ability to detect and correct error in relation to a given set of operating norms" and double-loop learning relating to "the ability to take a 'double look' at the situation by questioning the relevance of operating norms" (Morgan, 1986, p. 88).

Obviously, single-loop learning is tied to the training courses that each organisation puts its members through. The results fall into the 'how to' category. Once organisations are practising these lessons, double-loop learning begins. However, there seem to be two general double-loop learning bases in the case studies. The first basis is the one initiated by having a full overview of either the organisation or the problem situation, and the second basis is the one initiated by having people work together and get involved. For instance, the analysis of the organisation by means of process modelling and bottleneck categorisation provided St. Antonius with an overview that resulted in the insight that partial redesign would be impossible. Similarly, the many problems of Zilverstad were open to survey and, consequently, solutions obtained once the organisation was properly mapped.

Project and work groups and employee involvement are perhaps the strongest carriers of double-loop learning. The role of project management, bottom-up and top-down design and performance standards setting, are all contributing properties to double-loop learning, because they discuss and reflect upon (existing) norms. Learning is mainly based on the last type of characteristics of the design of the MAS. Performance and cost standards are set by the task groups. The conditions for participative, bottom-up MAS design are provided by the preceding control and information systems because of the attention they pay to local control and extensive information desaggregation. The overall flow-oriented production design prevents information and control conditions to be contained in functional de- 
partments and compartmentalised interests, i.e., performing together becomes a necessity through design.

When verifying the previous one-to-one comparison of Van Nelle and Zilverstad, we see that Zilverstad added the issues of strategy, communication and, for the MAS design, the cost pool method for standard setting to the issues of decentralisation \& desaggregation and event cycles, brought forward by the Van Nelle case. St. Antonius contains the items of decentralisation and desaggregation as well, although the reporting system desaggregates to the order level and not to task group level. However, the budgeting system to be implemented will probably be responsible for adding this level to the reporting system. St. Antonius also contains the issues of strategy and communication, but in a different fashion. Strategy is operationalised by the quality goal and the subsequent use of a large number of nonfinancial and technical norms. In other words, the quality strategy is implemented by transferring ISO 9002 and 9004 norms to the management process. Communication in the implementation stage has been similarly taken up by company-wide presentations but it is not addressed in a structural sense, for example, by a strict use of meetings and agendas. Instead, communication is considered to be integrated in the information and control structure.

The cost pool method is extensively used by St. Antonius as it is the basis for setting production cost tariffs. Tariffs are financial standards for operational control and for product costing (i.e., a basis for outsourcing as well as a criterion for order acceptation). St. Antonius thus adds the use of the tariff to the use of the cost pool method as being an important property of the MAS design. Specifically, what St. Antonius adds is the control of the information flow. Information is as critical a resource for operational activities as are inputs such as materials, money and machinery. To control this resource, St. Antonius adopted and implemented both a quality normalisation, and structured information by job design and administrative organisation. In comparison, the information flow at Van Nelle is literally controlled by the production manager, either asking divisional F\&A to format information in the way he can use it or by making the translation from 'company rule' production budget to internal reporting system himself. At Zilverstad, the information flow is controlled by the agenda-setting forms, which were designed by the design work group. Therefore, St. Antonius' accent is to structure information control explicitly, using the methods of a formal job and administrative design.

If we continue to use the coding procedures, we can state the open coding for the cross-case analysis as in Table 7.12. Categories follow STSD prescriptions in terms of the IOR trajectory and the PCI design sequence rule.

The MAS design reflects in its properties the basic principles of STSD: decentralisation of responsibility, control and group accountability. Management Accounting Systems design is closely tied in with the structural interventions and the simplification as set by STSD. The properties of the MAS design reflect this simplification. For instance, none of the organisations has expressed the need for 'new' or 'advanced' accounting instruments. Traditional textbook instruments such as budgets and variance analyses are found to be adequate. Their use, however, is far more different in a communicative sense, as it is directed at the need for control information at operational level. 
Table 7.12 Cross-case open coding

\begin{tabular}{|c|c|c|c|}
\hline CATEGORIES & \multicolumn{3}{|l|}{ PROPERTIES: } \\
\hline \multirow[t]{2}{*}{ Reasons for change } & Van $\mathrm{Ne}_{e} \mathrm{l}_{\theta}$ & Zilverslad & St. Antonius \\
\hline & $\begin{array}{l}\text { (a) Organisational independence } \\
\text { (b) Inward-looking organisation }\end{array}$ & $\begin{array}{l}\text { (c) Sales growth } \\
\text { (d) Organisation stage }\end{array}$ & $\begin{array}{l}\text { (e) Complexity } \\
\text { (f) Managerial prolessionalism }\end{array}$ \\
\hline Structural interventions & \multicolumn{2}{|l|}{ (1) Integral Organisational Renewal } & (2) $\mathrm{PCl}$ design sequence \\
\hline MAS design & \multicolumn{2}{|c|}{$\begin{array}{l}\text { (1) Desaggregated control information supply } \\
\text { (2) Textbook accounting instruments } \\
\text { (3) Communicative use of accounting }\end{array}$} & $\begin{array}{l}\text { (4) Nonfinancial dimensions } \\
\text { (5) Traceable cost behaviour } \\
\text { (6) Related to organisation design }\end{array}$ \\
\hline
\end{tabular}

The property of the communicative use of the accounting system, too, is largely influenced by the reorganised context. A simplified and transparent organisation, as a result of STSD-based reorganisation, makes it easier, for example, to trace costs. These costs can then be quickly accumulated for decision-making purposes. Consequently, more use is made of the accounting system because it fully represents process relationships. Another implication of this type of representative accounting system is that relatively more costs fall under the heading of 'direct costs'. Consequently, typical allocation-type problems lose some of their relevance. Instead, elements of responsibility accounting are more prone to increase in relevance. That is, organisational elements such as task groups can be rephrased as being (group) responsibility centres and provided with a subsequent performance and budget structure. This is already the case in Van Nelle (budget structure) and St. Antonius (performance structure).

Furthermore, a simple, 'direct costs' organisation makes different use of the concept of accountability (Roberts, J., 1991). The bottom-up design of the control structure in a sociotechnically redesigned organisation puts people in direct responsibility to their task domains. These are group domains which allow for shared responsibility and accountability. The mutual adjustment within groups and the lack of supervisionary control in contrast to internal control, allows the accountability to naturally transgress towards controllability: People that are in control of a certain task domain do not mind being held accountable if they are given the means for controlling their costs, i.e., in a group budget structure or a group standard cost system. The accountability-controllability overflow also has implications for cost behaviour. The amount of indirect costs relative to direct costs decreases, as more costs are assigned (designed) to work groups/the production flow.

Also, the flat organisation structure resulting from STSD reorganisation limits the aggregation levels of accounting information to three: order level, task group level and organisation level. The latter is where accounting information is most aggregate. Typically, it is mainly used for strategic decisions rather than operational decision making.

The storyline can now be formulated as follows: When a firm is faced with outside pressure to change, it can either change its structure, its activities, or both. If it makes the policy decision to change its structure, it can, for example, invest in cre- 
ating self-contained tasks (Galbraith, 1974). On the other hand, if the firm makes the policy decision to change its activities it can, for example, improve its accounting systems by introducing Activity-Based Costing (Cooper and Kaplan, 1991) or align organisational behaviour by implementing management techniques such as Total Quality Control (Martin, Schelb, Synder and Sparling, 1992).

There is a third policy option, which is to do both: change the structure of the organisation while changing its activities at the same time. Modern STSD provides the tools and system-theoretical view to accomplish this redesign. Once redesigned, the organisation is structured according to flow rather than operation. This, in turn, leads to simplified processes and simple structures which are flexible and can be better controlled. This combination results in a transparent organisation for all organisation members. 'Transparent' here means that it is visible to everyone what the results are of (group) actions undertaken and managerial policy decisions made.

Using the story as a guideline, the categories can be rearranged to provide an analytical version of the story. This is to identify the pattern which gives the theory specificity. Applying this step to the research study results in the following (as can also be read in the storyline):

Under the conditions that a firm (a) wants to change; (b) decides to change by integrally changing the organisation structure and its processes; (c) instruments this decision by using modern STSD, what happens is that the firm; (1) adopts a flow-oriented production; (2) simplifies its processes; (3) flattens its organisation structure; and (4) adopts an STSD-based accounting system.

The meaning of the latter is explained by the six properties in Table 7.12, and can be summarised as being a simple administration. On the other hand, a statement about what happens under alternative conditions cannot be made, due to the research design which only selected STSD cases in which both organisation design and management accounting design were collectively altered.

The next step is to group the cross-reference categories along the dimensional ranges of their properties. The main reason is that data should not only relate to the conceptual level, but also to the lower levels of properties and dimensions. In other words, the pattern should also hold for less conceptual levels. Applying this to the study results in a grouping of data as shown in Figure 7.14.

The final phase in generating a 'grounded theory' is validating one's theory against the data. It requires the theory to be laid out in memo format, either graphically or narratively, allowing one to make statements based upon relationships and thus validate these statements with data. This validating is already considered done: The memos are the diagrams and storylines of each case study, validated by the case reports they have been drawn from, and supplemented with a cross-case storyline and dimensional diagram. The layout of the theory (i.e., the syntaxis of the storyline) is identical in every case report and is described and documented in the above cross-case coding and dimensionalisation. 


\section{Chapter 7}

\begin{tabular}{|c|c|c|c|c|}
\hline \multirow[t]{2}{*}{ Reseons for change } & Ven Nelle & \multicolumn{2}{|c|}{ Zilverstad } & St. Antonius \\
\hline & $\begin{array}{l}\text { (a) Organisational independence } \\
\text { (b) Inward-looking organisation } \\
\text { low high }\end{array}$ & \multicolumn{2}{|c|}{$\begin{array}{l}\text { (c) Sales growth } \\
\text { low high } \\
\text { (d) Organisation stage }\end{array}$} & $\begin{array}{l}\text { (e) Complexity } \\
\text { (f) Managerial professionalism }\end{array}$ \\
\hline $\begin{array}{l}\text { Structural } \\
\text { Interventions }\end{array}$ & \multicolumn{3}{|l|}{ (1) Integral Organisational Renewal } & (2) $\mathrm{PCI}$ design sequence \\
\hline MAS dosign & $\begin{array}{l}\text { (1) Desaggregated control informati } \\
\text { (2) Textbook accounting instrument } \\
\text { low high } \\
\text { high }\end{array}$ & on supply & & $\begin{array}{l}\text { Nonfinancial dimensions } \\
\text { limited hill } \\
\text { Relaceable cost bethaviour }\end{array}$ \\
\hline
\end{tabular}

Figure 7.14 Cross-case dimensional grounding of the storyline 


\section{Conclusions and Discussion}

The conclusions pertain to the area of organisational change and the linkages between organisation design and management accounting systems design. To date, research has been limited to either organisational change and its structural and behavioural aspects, or the relationship of organisational design/management accounting systems with external and internal factors. This study attempts to explore two disciplines: organisation and accounting, in their design interface, with particular attention paid to the context of their mutual design. Research is inductive and based on such case evidence as project documentation, interview data and expert opinions. Analysis is performed by the coding procedures and techniques proposed by 'grounded theory', a sociological research methodology.

We found grounded theory particularly useful for our research study because grounded procedures provided stringent logic for reducing data and comparing case studies. Subsequently, data reduction was supported by using case descriptions, in other words, information was aligned in a chronological order of incidents, and aided by the strict order in which STSD interventions are to be constructed. The comparison of case studies benefited most from using the axial patterns and storylines. These two coding steps proved very effective in bringing arguments to the surface. Grounded procedures provide little help to enable exact comparison of these different patterns and result in deductions. It is at this point where discussions amongst colleagues and other researchers proved most useful.

Furthermore, the systematic build-up of the coding procedures opened the lines between the case elements and the larger conceptual categories. Consequently, the resulting conclusions and storylines are strictly linked to the case elements that are grounding them (i.e., internal validity is high). For example, in the Zilverstad case, the important role of communication can be retraced to the case description where the control structure redesign gives cause to linking up communication and information into a control mechanism.

The use of grounded theory itself is new in the accounting research field. Some grounded studies of innovation management, strategy decision making and or- 
ganisational change are available (Burgelman, 1983; Johnson, 1981; Turner, 1983), but these do not provide adequate direction on how to perform such a study in the area of accounting. As a result, the grounded analysis in this study is virtually preliminary in its methods and, therefore, open to improvements and adaptation in the field of accounting research. Such precise requisites being the rich amount of normative practices and concepts, its setting of a calculative regime and its omnipresence in every part of organisation life.

The case analysis and cross-case comparison resulted in a causal chronology for organisational and management accounting system to change. This causal chronology is detailed as to what properties are entailed and what makes the conditions conducive to the occurrence of these properties. Both are described by way of a diagram (see Table 7.12) and by way of conceptual narrative. Conclusions, therefore, are based upon the properties brought forward as well as the overall connection of properties.

The general outline ('storyline') of the cross-case comparison and the resulting 'grounded theory' is as follows:

When a firm enters an organisational change process guided by SocioTechnical Systems Design (STSD), it reorganises the full organisation according to product flow. Accordingly, control capacities are brought close to the primary process and staff functions are equally and closely allocated to the primary process. This leads to simplified processes and simple organisation structures, characterised by a task group work flow, flat organisation structures with decentralised control. Process and structure are flexible in their ability to cope with differing order sizes and contents and capable of improved control due to the decentralised mode of operation.

The control and information systems in these cases studies were supported by an STSD-based management accounting system that supplied desaggregated information for local control and decision making, utilised conventional accounting instruments and strongly related to the overall organisation design. Such a system places heavy accents upon the nonfinancial dimensions of information and control, and is primarily used to permit organisation elements the ability to communicate with one another. The cost behaviour in an STSDbased accounting system is related to the increased transparency of the organisation and, therefore, results in additional cost categories that are more direct and easier to trace back to their originating element.

\section{Conclusion 1: Organisation Design and Management Accounting Design - Equal Logics}

The properties included in the management accounting system design are all related to STSD, particularly the IOR trajectory and the PCI design sequence rule. These two instruments indicate the sequence in which the content of the change is to be implemented, i.e., the steps that should be made to obtain a redesigned organisation. Typically, it is the point of sequential order that creates the context for the MAS design, zooming in from strategy to overall organisation structure to 
control structure. The top-down sequence eliminates several structural factors and subsequently, eradicates the need to be addressed by the accounting design. These structural factors relate to the design of the control structure, allocating control to where activities take place, i.e., the task groups. Control information is, therefore, (designed to be) used locally and not translated into an aggregate number for more centralised control.

Management accounting is only limitedly involved in structural design. Where management accounting design indeed is involved, it is usually addressed in terms of normative information: What qualities should it possess (consistency, verifiability, etc.) and to what characteristics of decision making should it comply? Therefore, management accounting design is most explored in the area of information properties (Chenhall and Morris, 1986: Daft and Lengel, 1986; Hergert and Morris, 1989). Information properties that border on the design issue are, for example, timeliness, scope and media richness (Chenhall and Morris, 1986; Daft and Lengel, 1986). These factors relate to the structural characteristics of the organisation, because they cross organisational boundaries.

In an STSD-based accounting design, these structural characteristics are addressed by the specifics of the control cycle design; i.e., the design principles of unity in time, place and action to provide effective control information (see also Chapter 3). Timely information (i.e., reporting is frequent or speedy) is guaranteed because the control cycle can be found at the same location where the tasks are executed, i.e., in the task groups.

The scope of information relates to the use of external, nonfinancial and futureoriented (e.g., probabilistic) information. In all three case studies, we witness substantial usage of nonfinancial information. However, the external information present in the three case studies does not take the form of information on, for example, GNP or demographic factors but is related to the market performance of the organisation as a whole.

Again, future-oriented information is provided by the STSD-based accounting system. The transparency of processes allows for performing sensitivity analyses on production decisions. For example, in the Van Nelle case, the capacity calculation in the MAS design is also used to verify whether future demands on production such as for seasonal product promotion campaigns, can be adequately handled in terms of available man and machine capacities.

Media richness relates to the structural characteristics (the media) that can process rich information. Structural here means related to the organisational design as facilitator or blockade of information supply. Rich information is defined as: The ability of information to overcome different frames of reference or clarify ambiguous issues and, therefore, create understanding within a time interval (Daft and Lengel, 1986, p. 560). According to Daft and Lengel, these structural characteristics amount to seven, each one being found in the production and control structure designs of STSD. The structural characteristics are: group meetings, integrators, direct contact, planning, special reports, formal information systems and rules and regulations. They run on a continuum from rich (group meetings) to poor (rules and regulations). 


\section{Chapter 8}

In all three cases, group meetings are omnipresent. Zilverstad, in particular, has made group meetings its key control and accounting instrument. They tied the formal accounting information system to it by discussing each accounting report in a meeting specifically designed for this purpose. An example of this is the postcalculation meeting where discussion concerning the various calculation tickets of the three task groups are conducted together with Administration, Management and group leaders.

Integrators can be distinguished in the cases of St. Antonius and Van Nelle; integrators representing "... the assignment of an organisational position to a boundary spanning activity within the organisation" (Daft and Lengel, 1986, p. 561). At St. Antonius, integrators take the role of quality and production engineers, linking production processes and production methods between the Commercial \& Technical Activities (CTA) department and Production. At Van Nelle, the integrator role is performed by the Production Planning department which translate the plant level and task group reports into the Annual Operating Plan specifications that are required by the company rule reporting system. Also, they are the ones responsible for the processing of production performance information, i.e., machine efficiency, and for the task groups, providing them with control charts and graphs.

Direct contact is an inherently structural medium for information in any task group and,therefore, present in each individual case study. Planning is equally inherent in task groups as it functions as a control/performance measurement standard in the control cycles allocated to the various task groups. The role of planning is most prominent in the case of St. Antonius, where production control is extensively planned in terms of quality assurance, throughput time and bottleneck utilisation. Of equal importance is the large amount of quality control specifications as set out in the quality manuals of St. Antonius. These are examples of rules and regulations. Formal information systems provide the various accounting reporting systems for all three case studies. An example of a special report can be found in the way Zilverstad makes use of irregular reporting on delivery reliability of orders.

In short, the structural arrangements preceding the management accounting system design simplify the contents of the accounting design. Information characteristics brought into the structural organisation design result in the removal of certain elements from the management accounting system. What remains for the accounting design is a well-constrained organisational context, where the preceding design steps are to be completed by means of a concrete reporting structure.

Although it sounds as if only purely administrative considerations are involved, it is nevertheless necessary, according to the study, for such a reporting system to match calculative practices to the behavioural routines established in the control design. For example, the budgeting systems of Van Nelle and Zilverstad are groupbudgeting systems, compelling the task groups, as a whole, to be accountable for their production activities. They must cooperate in attaining the budget standards that they themselves set, i.e., as a group they are the only ones that can control the cost items in the budget. Furthermore, at St. Antonius, the press operations - a production bottleneck determining reported throughput time - can be planned in such a manner that dye changeover time is minimal, providing the press operator 
receives the required information from the production engineer. If there exists a lack of cooperation, the reported throughput time will not go according to plan and bottleneck utilisation will decrease, i.e., cost efficiency decreases.

The above-mentioned integration of organisation design, including information properties handled by the management accounting systems, was first signalled in the work of Galbraith (1973). He views the organisation as an information processing system, balancing the amount of information needed with the amount of information available. The amount of information required is a result of:

1) the diversity of outputs (e.g., products, services, clients);

2) the amount of different input resources utilised (e.g., departments, machine centres); and

3) the difficulty in the level of required performance (e.g., quality tolerance limits).

If the balance is disrupted, uncertainty is created. To resolve this uncertainty, several organisational design interventions can be undertaken such as: creating slack, investing in vertical information systems, establishing lateral relationships and creating self-contained tasks. Major strengths, according to Galbraith, are that information is considered a central factor in organisation design and a repertoire of organisational design responses are available for rectifying organisational problems.

In contrast to the various options Galbraith suggests to increase the effectiveness of an information, this study does not see these options as separate and distinguishable alternatives. Instead, there is a sequence of measures, each one following as a logical consequence from previous design choices. For example, an organisation can start by creating slack, rolling over to establishing self-contained units, which in turn, rolls over to establishing lateral relationship and is finalised by installing a vertical information system to maintain coherence between units. Each Galbraith type design option is then used, as a consequence of a previous design choice. Moreover, there is no general priority in this sequence. An organisation can start from either design option, but once a design choice is made, several other design choices will logically follow. Therefore, what is presented by Galbraith as a repertoire of individual instruments to choose from is in fact the start of a process of redesign: Once one instrument is employed, a sequence of choices is started. The choice open to organisations thus is not related to individual design instruments, but between sequences of choices. In other words, if an organisation starts by installing vertical information systems, a sequence is chosen. If it starts by creating slack, another sequence is chosen.

Many elements of Galbraith's model can be traced back to the case studies. For example, the amount of information due to output diversity is most visible in the Zilverstad case. When Zilverstad switched from being a low-cost single-product producer to being a producer of various high-quality products, it created an identical diversity. Simultaneously, Zilverstad retained a distinct number of production job shops (see the former production organisation chart, Figure 5.9), which, in turn, utilised a number of input resources. Furthermore, the difficulty of the level of required performance is clearly evident in the St. Antonius case. The ISO 
$9002 / 9004$ quality assurance and certification demand considerable tolerance limits of its products and processes.

The design strategies proposed by Galbraith are all included in the STSD interventions, with the exception of slack resources. The basic starting point is the creation of self-contained tasks that are central to STSD, followed by the creation of new lateral relationships. This final design strategy is most prominent in an STSD-based accounting system, because it moves the level of decision making to the point where the information is positioned, i.e., the shop floor/task group level. Galbraith sums up several means to create lateral relationships: liaison positions, task forces, dual reporting and matrix organisation. Liaison positions can be distinguished in the Van Nelle and St. Antonius cases as these positions coincide with the integrator roles of the Production Planning department and the quality and production engineers respectively. Dual reporting is present in the meeting structure of Zilverstad, and the task group meetings in each case study. The most obvious matrix organisation can be found at St. Antonius, where quality control and quality assurance are covered by the Production and Commercial departments (see Figure 6.10).

The creation of vertical information systems is the final step in the STSD process. Lateral relationships, together with the horizontal exchange of information, are primary design considerations. Once these are installed, a vertical information system is set up to provide top management with organisation level information. In all three cases, we can see that the task group level reporting is encompassed by a period report that provides financially aggregated information to the organisation level management. It is also at this point that we recognise the choice by STSD for one type of design sequence. STSD commences from self-contained tasks, installing a flow-oriented organisation placing an emphasis on lateral relationships. Slack resources are explicitly 'designed out', as in Just-In-Time systems, because they are not needed in organisations where control and execution are brought together in one location. The coordinative effort remaining is in maintaining overview on the primary process and ensuring that it stays within the control boundaries. For this purpose, a vertical information system is imperative. However, such a vertical system appears totally different than it did on the occassion where it was deemed necessary to start the design process by installing a vertical information system. In other words, the sequence included in STS design logic results in a different content of the design, even though all Galbraith-type elements are equally present.

Where Jönsson is concerned, the vertical and centralised accounting systems have been replaced by a more participative management accounting design, which emerged from the focal position of task groups in the organisation design. This is represented in all three cases by:

1) the central position of task groups in the accounting reports;

2) the provision of detailed nonfinancial control information; and

3) the extensive use of performance indicators that surpass functional departments (e.g., WIP at St. Antonius, gross margin at Zilverstad, and the simultaneous use of machine efficiency and utilisation rates as found in the period report at Van Nelle). 
In conclusion, all organisation design elements are removed from the management accounting system design. Consequently, the resulting accounting system is reduced to completing the information supply as set out by the control structure design. Therefore, if the control structure design emphasises decentralisation, local autonomy and participation, the management accounting system has to reflect these properties: The organisation design according to STSD defines 1:1 the management accounting design elements. The design sequence preceding the management accounting design is crucial to the content of the accounting design.

\section{Conclusion 2: Simple Organisations Make Simple Administrations}

The STSD-based focus on decentralisation promotes the design and use of an equally decentralised management accounting system. Previous research has stressed the point that a prerequisite for successful decentralisation and group autonomy is the redesign of information and control systems (Gordon and Miller, 1976; Den Hertog, 1978). The other way around, the message is equally true: Information and control systems do not improve if the organisation structures do not allow them to be redesigned. The organisation design is not a given condition for redesign efforts, but influences the content of the accounting (re)design, as previously discussed regarding the implementation of vertical information systems.

What, then, would such a decentralised and participative management accounting system look like? This question should be interpreted in a much larger context, as the accounting system is just one element from a larger control package (see Table 8.1).

Typically, such a control package consists of the management information system (MIS), the accounting information system (AIS), the organisation design and other control arrangements (Otley, 1980). Inside this comprehensive control package, control mechanisms can complement or substitute each other (Khandwalla, 1973; Mak, 1989).

The notion of an overall control package itself is fully present in the various case studies. For example, in the case of St. Antonius, the administrative organisation (the AIS), the organisation design (task groups), the management information system (the reporting system) and the job classification (other control arrangements) are all part of the control package. The other two cases have control packages that are balanced differently. For example, at Van Nelle the package consists of organisation design (task groups), information system (the reporting system) and the feedback of production charts by Production Planning to the task groups (other control arrangements).

The different control packages of the three cases are the result of different design choices that had been previously made. These design choices relate to strategic choices, market conditions and specific organisational circumstances. For example, the strategy of Van Nelle was to make the organisation more open to market sigrals and to create an internal dynamic. Subsequent design choices were: to reduce the number of organisation levels, install an Operational Team as business unit management, and begin with task groups. Similarly, the strategy of Zilverstad was 
to create a coherent organisation that could operate as a flexible unit. The traditional ties with the city, the family atmosphere of the organisation and the craftsmanship products influenced design choices; behavioural controls and cross-functional cooperation in meetings and task groups were natural extensions.

Table 8.1 Outline of case study characteristics

\begin{tabular}{|c|c|c|c|}
\hline & Van Nelle Tobacco - Rotterdem & Ziveratad Silversmthing & St. Amonius Veasealhoede \\
\hline $\begin{array}{l}\text { Type of } \\
\text { organisation }\end{array}$ & part of large US multinationel & mall farrily-owned business & modium-sized family-owned business \\
\hline Product range & $\begin{array}{l}\text { medum a large batch } \\
\text { production of rolting tobecco }\end{array}$ & $\begin{array}{l}\text { cratomanship products in small } 8 \\
\text { medum baich production; wholesale }\end{array}$ & $\begin{array}{l}\text { unit and small betch production of } \\
\text { vessatheads }\end{array}$ \\
\hline Market situation & $\begin{array}{l}\text { few competitors; mature } \\
\text { product; stable market }\end{array}$ & $\begin{array}{l}\text { many competitors; cusbmised } \\
\text { products; international market }\end{array}$ & $\begin{array}{l}\text { lew competitors; quality-certified products: } \\
\text { subcontractor to OEMs; international market }\end{array}$ \\
\hline $\begin{array}{l}\text { Organisation } \\
\text { struchure }\end{array}$ & $\begin{array}{l}\text { decentraliserd to Business } \\
\text { Units and production task } \\
\text { groups }\end{array}$ & $\begin{array}{l}\text { decentralised to productimarkel } \\
\text { combinations inherent in sales } \\
\text { and production task groups }\end{array}$ & $\begin{array}{l}\text { Decentralised to product/market } \\
\text { combinations and production task groups }\end{array}$ \\
\hline Organisation fevels & within plent: 2; within BU: 3 & 3 & 4 \\
\hline $\begin{array}{l}\text { Management } \\
\text { Accounding } \\
\text { Systern }\end{array}$ & $\begin{array}{l}\text { ask group budgets; accounting } \\
\text { into desaggregated to article } \\
\text { level }\end{array}$ & $\begin{array}{l}\text { lask group budgets: accounting } \\
\text { info desaggregated io order level }\end{array}$ & $\begin{array}{l}\text { planned cost based on work centres: } \\
\text { accounting info desaggregated to } \\
\text { order \& customer level; strong } \\
\text { inlituence hom quality certification }\end{array}$ \\
\hline Ousput controls & $\begin{array}{l}\text { budgeted vs actual labour cosls } \\
\text { per lask group; machine upbime }\end{array}$ & $\begin{array}{l}\text { budgeted ys actual gross margin } \\
\text { per task group }\end{array}$ & $\begin{array}{l}\text { planned vs actual gross margin pet order; } \\
\text { accordance to construction } \\
\text { codes; Work-in-Process }\end{array}$ \\
\hline $\begin{array}{l}\text { Behaviour } \\
\text { controls }\end{array}$ & $\begin{array}{l}\text { informal, with Production } \\
\text { Planning and in the task groups }\end{array}$ & $\begin{array}{l}\text { extensive meeting stucture with } \\
\text { concurrent agonda-setting forms }\end{array}$ & $\begin{array}{l}\text { ex post calculations; many standards } \\
\text { and normalised processes }\end{array}$ \\
\hline $\begin{array}{l}\text { Pontomence } \\
\text { masurement by }\end{array}$ & $\begin{array}{l}\text { labour productuity; machine } \\
\text { efficiency; budgei targets }\end{array}$ & $\begin{array}{l}\text { order gross margin; budgeted } \\
\text { results por task group }\end{array}$ & $\begin{array}{l}\text { order gross margin as \% of } \\
\text { planned costs }\end{array}$ \\
\hline $\begin{array}{l}\text { Accont of } \\
\text { accounting } \\
\text { systom }\end{array}$ & $\begin{array}{l}\text { production control } \\
\text { (efficiency) }\end{array}$ & $\begin{array}{l}\text { production control } \\
\text { (onder conformance) }\end{array}$ & $\begin{array}{l}\text { production control (quality } \\
\text { and timeliness conformance) }\end{array}$ \\
\hline
\end{tabular}

The common denominators, however, of all control packages are flexibility and process control. Autonomous task groups are provided in all three occasions with full responsibility, control and information over their tasks. Equally, the three organisations studied live close to the primary process and are able to correct or reroute it when the need arises. The case of St. Antonius is the most notable example of this common denominator. The administrative organisation, the many (quality-certified) norms in Production and the reporting on individual order and customers have led to considerable control of the primary process. Consequently, St. Antonius can operate flexibly on the quality-regulated original equipment manufacturer (OEM) market and, alternatively, can select its market approach because it has extensive information concerning ordering behaviour and customer profitability.

One major question of this study is to determine where organisation design and management design interface. To answer this question regarding the management accounting design, six elements are necessary to make up an STSD-based accounting system. Some of these elements overlap with the findings from alternate em- 
pirical research, mainly located in contingency studies of management accounting, and discussed accordingly.

The first element is that of textbook accounting instruments. The instruments used are:

- budgets (Van Nelle, Zilverstad);

- variance analysis, mostly related to variances to budget or plan (Van Nelle, Zilverstad and St. Antonius);

- the cost pool method of cost allocation and its concurrent tariffs per cost pool (Zilverstad, St. Antonius);

- standard costing/job order costing (Van Nelle, Zilverstad, St. Antonius).

All instruments are highly conventional in their calculative format. However, what is special is that they are used in a different way than had been originally intended. Each instrument relates to a norm - whether it is a budget norm, a tariff norm or a job cost standard - and it is the norm that is used. It is used in two ways: First, for local control by the responsible unit and, second, for involving the responsible unit. Feedback and judgement are traditional uses of standards. However, when feedback is used for local control of that process, it steers behaviour to activities; it instruments local control by providing task groups with techniques for measuring, judging and taking action. Traditionally, evaluating financial performance was the origin of these techniques, lining up the expected cost and profit contributions of each individual organisation element. In the case studies, this is turned 180 degrees and used for signalling to what degree the activities are controlled, for those that are in control.

The second different use of standards relates to involving the task group in setting the standard. They themselves set standards within a broader frame of general performance indicators. Therefore, they have to indicate what activities in their accountability area are crucial, measurable and controllable in relation to these performance indicators. In other words, the focus is again on the activities and not on conformity to financial expectations.

The difference with the conventional use of standards, therefore, is the heavy accent on activities rather than financial conformity. In other words, the norms are used to steer behaviour directly towards the process instead of steering behaviour to its (indirect) financial representation.

An identical approach has been adopted by Japanese management accounting. It also employs conventional instruments but uses a similar orientation to process, steering behaviour to continuously improving activities and processes. Financial standards take a similar role as reference points for actions onto the process, and not for aligning financial performance (Hiromoto, 1988; Makido, 1989).

The second element of an STSD-based management accounting system is the communicative use of accounting information. It follows from the behavioural use made of textbook accounting instruments, directing task groups to focus on the processes and activities in their accountability area. Communicative use then refers to the lateral exchange of activity information between task groups and, ver- 
tically, from task groups to organisation management. Characteristics of this communicative element are:

- the occurrence of work transfer between task groups at a transfer price or a work centre tariff (Zilverstad, St. Antonius);

- the formal meeting structure between task groups and other organisation elements (Zilverstad);

- the administrative organisation of St. Antonius;

- the setting and subsequent transfer of work standards by the specialist task group at Van Nelle;

- the integrator roles of quality and production engineers at St. Antonius; and

- the period reports summarising the performance of all task groups on a number of performance indicators (Van Nelle, Zilverstad and St. Antonius).

This communicative element is the vehicle for the differing application of textbook instruments, that is, the standards and norms are distributed amongst task groups by use of various means (formal meetings, integrators, period reports). Similarly, experiences with certain standards and norms are shared with other task groups so that they can also relate them to their own activities.

Communication amongst task groups is best noticed by their use of such a conventional instrument as Work-In-Process at St. Antonius. Rather than its conventional use as a financial reporting item, it is used as a throughput indicator, displaying at what exact location in the flow disturbances occur. These are then communicated to the relevant task group and/or to the production engineer to establish precautionary measures for future occurrences. The communicative element, of course, is equally served by a flat and simple organisation structure, precluding the use of extensive lateral and vertical distribution mechanisms.

The third element in an STSD-based management accounting system is the supply of desaggregated control information. Desaggregation refers to tuning the information supply to the required information for the various activities ('tasks') as performed by the group. This element is most apparent in:

- the regrouping of individual cost and budget items to a task group denominator (Van Nelle, Zilverstad, St. Antonius);

- taking cost items that are not controllable at task group level out of the budgets or task group planned costs (Van Nelle, Zilverstad, St. Antonius);

- assign former indirect manufacturing cost categories (e.g. maintenance, cleaning) to task group activities, thus increasing the share of direct costs and reducing the need for allocations (Van Nelle, Zilverstad, St. Antonius);

- detailing task group tariffs to several work centre tariffs for bottleneck planning and outsourcing evaluations (St. Antonius).

Management accounting conventionally elaborates on the side of information supply, i.e., the reporting on and inclusion of certain information items. In an STSD management accounting system, supply is for a large part generated by the task group itself; receiving feedback from the full control cycle contained in the task group. Typically, in conventional management accounting systems, information is supplied by specialised accounting staff and relates to management infor- 
mation regarding the financial performance of the full organisation, i.e., it is aggregate information. In other words, the full control cycle is assumed to be located at the organisation level and not at task group level. Desaggregate control information is not covered by the management accounting system, but set aside and maintained in a nonaccounting system such as a production planning system or a work scheduling database. In contrast, this type of desaggregated control information is an important aspect of an STSD-based accounting system.

Some similarity exists with the use of critical success factors in management accounting designs (Bossert and Van Nimwegen, 1991). These are broadly defined control criteria that apply to the primary process as a whole (e.g., product innovativeness or distribution channels). Usually, these factors are desaggregated topdown, i.e., derived from the organisation control level, and broken down into more specific performance targets for lower levels of control. Equally, control information supply follows this performance breakdown up to the level where performance norms and control standards are unified - at the task group level.

The fourth element in an STSD-based management accounting system is the inclusion of nonfinancial information. It relates closely to the supply of desaggregated control information as discussed above. This type of information is usually excluded from formal management accounting systems. Control at the organisation level is predominantly financial control. At the task group level, however, financial information plays an equal role aside from technical and quality- and time-based information. The importance of nonfinancial information is illustrated by the following:

- the machine efficiency report of Van Nelle, the standalone delivery reliability reports of Zilverstad, and the WIP volume report of St. Antonius;

- the construction codes and regulations, and the quality assurance maintained by St. Antonius;

- the capacity and occupancy calculation of Van Nelle;

- the product development meeting of Zilverstad;

- the changeover time, cycle time and throughput time of the ex post order calculation report of St. Antonius.

The equal status of nonfinancial information can be attributed to the role nonfinancial parameters play in performance measurement and process control. Each case study has strategic objectives stating their goals as being ones of flexibility, quality improvement and timeliness. Cost efficiency or cost reductions are equally valued goals, i.e., they do not stand out as the first and only goal. To acquire goals of flexibility, quality and timeliness, a well-controlled primary process is first required, allowing the possibility to adapt to the rate of change strategy or environment deemed necessary. It is in this element that Kaplan's question of lost relevance of management accounting can be most clearly signalled (1983, 1984a, 1984b). His statement that the concepts and techniques of management accounting are developed in and for a sellers market situation of low-priced mass production of standard products, attacks the use of financial and pure efficiency-directed performance parameters. A changed market situation (buyers market), the appearance of simultaneous competitive factors (price, quality, innovativeness, timeliness; Bolwijn, 1988) and the internationalisation of market places requires that firms 
monitor and steer a greater array of performance parameters. For a large extent, those parameters are nonfinancial.

The few field research studies available support this extensive use of nonfinancial information and performance parameters (Johnson and Kaplan, 1987; Bennett et al., 1987; Howell et al., 1987; Innes and Mitchell, 1988). Moreover, they also point out that well-controlled processes are the primary condition for allowing strategic mobility, i.e., to change strategies and tactics on short notice as competitive situation or strategic policy require.

The fifth element in an STSD-based management accounting system is that all accounting elements are related to the organisation design: The organisation design is not a given condition but rather an active tool for management accounting design. Examples of this design interdependence include:

- the coinciding of the various budget levels with the control levels (Van Nelle, Zilverstad);

- the coinciding of agenda-setting reporting forms with the interfaces between task groups and other organisation elements (Zilverstad);

- the triple coinciding of cost pools with accountability areas with organisation segments (Zilverstad, St. Antonius);

- tariffs representing work flow in the product cost structure instead of indirect cost allocation (Zilverstad, St. Antonius);

- task groups processing various batch sizes within one article group, allowing for sensitivity analyses of total volume flowing through the specific task group (Van Nelle) and sensitivity analyses of batch sizes within the article group mix (Zilverstad).

Control is the intermediary between organisation design and management accounting design. Organisation design sets the possibilities for control, while the need for control is defined by the activities performed. Therefore, the control design becomes the linkage between the two. The control structure is further set by the control possibilities on the one side, and by the need for control on the other side. Control possibilities are the result of a larger organisation design (the production structure, in STSD terminology), while the need for control is the result of activities performed (i.e., the 'tasks' of each task group; see Figure 8.1).

Controlling by designing, as proposed by STSD, leaves fewer activities ('tasks') that should be controlled on a conventional basis. The role of accounting in this perspective is extensive. Because the control and information needs reduce as a result of the organisation design (fewer tasks need to be controlled), more people will start to use management accounting information within their unit/task group, i.e., the number of users increases. Each task group uses controls (the above-discussed textbook standard instruments) and, therefore, management accounting is widespread; everyone is tinkering with it in order to have it fit its control needs.

However, it means that the role of accountancy is diverging: Supporting operational managers in improving their local control and information needs ('putting accounting in the line') versus supporting top management by providing strategic information for their strategic control and decision making (a continued staff 
role). Probably, the latter is more attractive to the present accounting professionals because this type of information and control support remains close to the traditional financial knowledge base of accounting. Either way, the accountant is required to possess additional expertise in the areas of: organisation design, production processes and information technology and on strategy decision making and analysis.

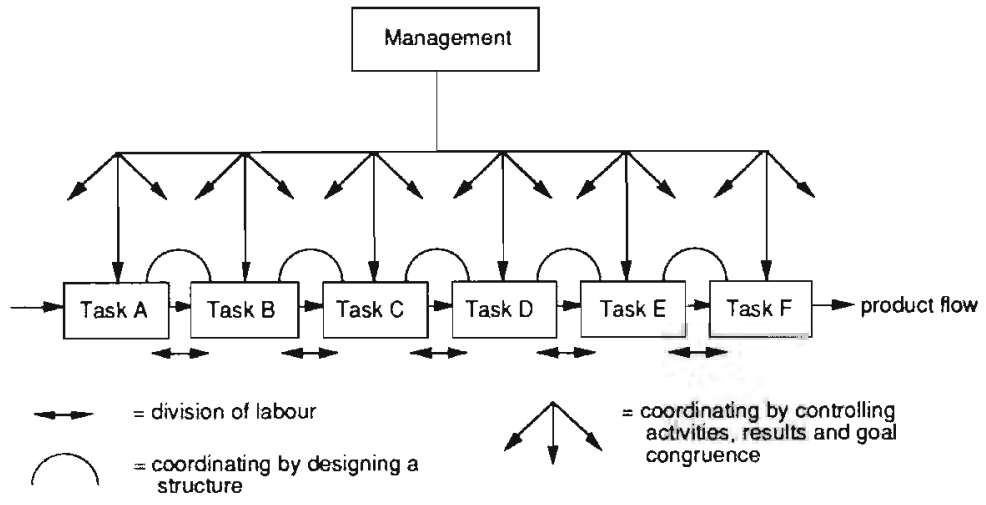

Figure 8.1 Structural design and control (cf, Kunst, Olie, Romme and Soeters, 1991)

The final and sixth element of an STSD-based management accounting system is the traceability of costs. In fact, traceable cost behaviour results from the five above-captioned elements. Traceable cost behaviour can be found in:

- the tariffs making up the product cost that are representations of the product flow across task groups and work centres instead of mere cost accounting allocations (Zilverstad, St. Antonius);

- the machine efficiencies and labour productivities per task group in the period report, which can be traced back to individual machines and orders (Van Nelle);

- the gross margin fluctuations per task group that can be traced by means of the post-calculation meeting (Zilverstad);

- the time performance variances in the ex post report that can be traced back to the individual work centres involved in each production order (St. Antonius);

- the small amount of allocated costs in production and sales group budgets (Van Nelle, Zilverstad);

- the reporting on order and article levels (Van Nelle, Zilverstad, St. Antonius).

The tracing of costs is clearly connected with the transparency of the organisation, the latter being translated by STSD as a simple organisation. Traceability and simplicity result from design interventions that go beyond accounting practices and methods. It is evident that they cannot be addressed by accounting alone. They require help from additional disciplines such as organisation theory, production 
management and management science. How to achieve traceability and simplicity can be found in the examples of STSD cases and the STSD theory in Chapters 3-6.

To date, field research has paid considerable attention to the concept of traceability, especially in relation to the accounting 'innovation' of Activity-Based Costing (Innes and Mitchell, 1990; Cooper and Kaplan, 1991; Boons, Roberts and Roozen, 1991). This technique groups costs into cost pools, according to their activity consumption instead of their resource consumption, i.e., the relationship with the production process replaces the traditional functional grouping of costs and responsibility cost pools. Cost are then tied to the process by using 'cost driver', causal factors that relate product/order flow to cost flow. Costs can now be traced by utilising these cost drivers, which can either be volume-oriented (as in conventional accounting practice), batch-sustaining activities (e.g., number of changeovers), product-sustaining activities (e.g., number of engineering change orders) and plant-sustaining activities (e.g., security). Therefore, cost drivers are traceability factors, opening up the production process for cost management, aptly referred to as Activity-Based Management.

Only recently has there been growing awareness that the alignment of activities, i.e., organisation design, is of prime importance for cost management (Womack, Jones and Roos, 1991). In other words, it is simpler to intervene directly into the process first, than to complete a more accurate accounting picture of this process and then intervene.

An STSD-based accounting system is made up of conventional textbook instruments that are used for decentralised control and lateral communication. Its relative simplicity closely follows the simplified organisation structure and the processes performed within that structure. Traceability of costs to responsible and accountable organisational units, having full control over the tasks contained in that unit, are an example of this close scrutiny. Its simplicity in instruments and design enhances its use by organisation members, thus adding to the decentralised perspective of a flexible organisation. In other words, an STSD-based accounting system clearly chooses for an operational, in-the-line function. Usage and role here are closely connected: When the accounting function is integrated with the accountability structure, as determined by the organisation design, little doubt can be casted on its relevance.

\section{Conclusion 3: Accounting and Learning Organisations}

In this section, we will discuss what role management accounting can play in promoting organisations to learn, and use the work of Morgan to exemplify this relationship.

The main body of knowledge of management accounting systems was developed in a time period when a standardised mass production, price competition and fragmented markets dominated (Johnson and Kaplan, 1987). The bureaucratic type of organisation provided the context for accounting instruments to be developed and perfected. 
Bureaucracies still dominate in management accounting thinking. Some of the principles of bureaucratic management such as centralisation, unity of command and efficiency maximisation are strongly present in management accounting. Centralisation is very prominent in various accounting concepts. For example, information should be consistent in order to have it aggregate up and down the line of command, calculative instruments focus on the organisation as a macro entity, and performance and control are tied to the organisational hierarchy. Unity of command states that there is one decision maker who should be supplied with all the required information, has the required perspective over goals and possible actions, makes the decision and feeds it back for execution. Efficiency is very prominent in management accounting, stating that a maximal use of resource should be made to have maximal returns on these invested resources. Concepts such as efficiency, yield and volume variances signal deviations form maximal returns, while break-even analyses, absorption and direct costing, and capacity calculations indicate the most efficient use of market conditions and internal cost structures. Moreover, the idea of one rational and efficient method of organising permeated into systems such as budgeting, Management By Objectives and cost allocation systems.

The organisational context of management accounting thus was one of rational and technically controllable set of problems with identically mechanistical solutions. In other words, the dominant metaphor of organisation was that of a machine. Limitations of this type of organisation are the lack of flexibility in adapting to changing circumstances, attitudes and outlooks that are limited to the specific area of responsibility, the use of the machine for personal purposes and the dehumanising effects on employees (Morgan, 1986, p. 35).

In all three cases studied, we can see that the reasons for the firms to change are rather similar to the above limitations. Van Nelle wanted to create an open and market-oriented organisation, changing attitudes and mentalities; Zilverstad was especially interested in creating a flexibile organisation that could not only handle but also initiate change; and St. Antonius was motivated by flexibility as well, being able to manage its ever increasing quality, timeliness technological market pressures. With the STSD-based changes they set the wheels in motion to transfer to another organisational metaphor, that of the organisation as a brain.

Morgan (1986) typifies such organisations as being holographically designed, using four interrelated principles: Redundancy of functions, requisite variety, minimal critical specification and learning to learn (see Figure 8.2). These four principles return in the management accounting design, with the principles of minimal critical specification and learning-to-learn being most clearly observable.

Requisite variety is a focal principle in STSD. Requisite variety indicates that any design should contain the critical parameters of the environment it has to deal with: It can then organise itself, and effectively and efficiently handle environmental demands. On a more generic level, such as the set of values maintained by the organisation, the principle of requisite variety applies as well. An open, active and rapidly changing environment identically requires an attitude from organisational participants that is equally open-minded, proactive and willing to handle the ambiguities presented to them. 


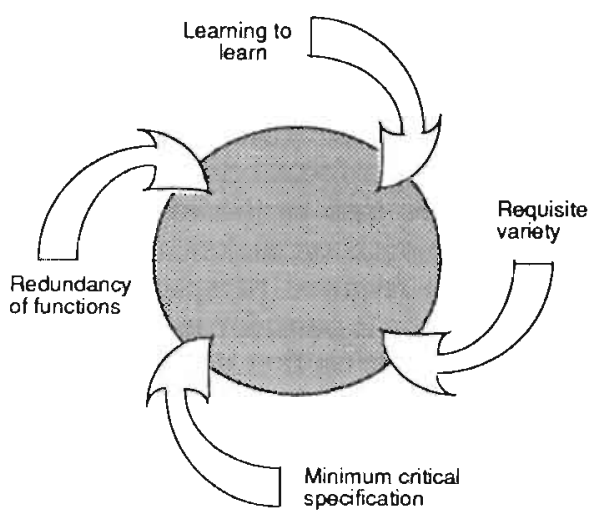

Figure 8.2 Principles of holographic design - a brain metaphor (Morgan, 1986, p. 99)

For a management accounting design, requisite variety means a proper reflection of organisation members' accountability by management accounting instruments and information denominators. Assigning accountability is a matter of overall organisation design (Scapens and Roberts, 1985; Roberts, J., 1991), hence the important role the control structure plays in the management accounting design. In terms of the case studies, the above-discussed element of desaggrageted control information supply is the best reflection of linking information to the control requirements. For example, by assigning costs (e.g., maintenance, cleaning) to the organisation level where they are indeed controllable (showing in the task group level or production level budgets), thus increasing the share of direct costs and reducing the need for allocations.

Redundancy of functions is related to the STSD concept of autonomous task groups. It states that the whole should be built into the parts, with every part being a reflection of the whole. As this is not a workable situation, the amount of redundancy is limited by the above principle of requisite variety: Only that amount of redundancy is built in that is directly required by the part. As a result, system boundaries between the whole and its parts become important in answering the question of what is directly required. This reflects the core idea of STSD as being an architectural theory of relations.

For a management accounting design, redundancy of functions focuses on local versus staff roles of accounting. Accounting for local control is required by the line, while accounting for encompassing organisational level control requires a staff role. In an STSD-based simple organisation, accounting's local role is accentuated. Most notably in the case of Van Nelle, where local accounting is provided by Production Planning, including budgeting and other cost information supply. In the other two cases, accounting (or administration as it is called at Zilverstad) assumes a facilitator role, explaining and helping task groups to implement the budget system (Zilverstad) or performance measurement and evaluation (St. Antonius). 
The characteristics of minimal critical specification and learning to learn are the two that are most closely related to the learning contents of a STSD-based accounting system ('accounting for a brain'). They are the principles that realise learning capacity and give it coherent direction (Morgan, 1986). Minimal critical specification is the reverse of trying to define and arrange activities as precisely as possible: Only a minimum is specified. The principle focuses on enabling or facilitating conditions in which activities can take place, i.e., are to be self-organised. In the three case studies, we saw this element return in how the overall design work group (minimally) steered the various other design work groups and, conversely, how the overall design work group was (minimally) steered by the owner-president (Zilverstad, St. Antonius). Also, the human resource type of vision held by all management in the case studies made them place trust in their people to organise themselves. Once the design was completed, minimal critical specification was maintained in setting the control standards: Performance requirements were formulated in broad terms and further filled in by the groups. In a sense, the use of textbook accounting techniques and reporting procedures is also prone to minimal critical specification: Task groups can organise the use of accounting techniques themselves.

An explanation of what happens when minimal becomes maximal can be found in the Van Nelle case. The incorporation of the plant into the accounting and reporting system of Sara Lee/Douwe Egberts enforces corporate beliefs and models upon an organisation holding entirely different beliefs: System boundaries ("... the limits placed on action ..." according to Morgan) and interdependencies were once again redefined. The plant was permitted to maintain its full STSD organisation, but had, when interfacing at its plant's system boundaries, to comply to 'company rule'. In terms of Morgan, the brain metaphor was replaced by the machine metaphor and the control system was replaced, concurrently (Kunst and Schreuder, 1991).

An alternative aspect of minimal critical specification is their implication concerning the distribution of power and control in the organisation. Autonomous work groups organising and controlling themselves usually indicate a power shift from staff expertise (e.g, accountants) to line functions. Lack of support from the upper echelons can then seriously block the distribution of information necessary for organisational learning to occur.

The learning to learn principle relates to single-loop and double-loop learning (see Figure 8.3). Single-loop learning relates to applying given knowledge onto a process, while double-loop learning refers to the process of learning to learn - questioning the appropriateness of what is being done.

Learning requires information for it to occur, i.e., for evaluation of the process at hand. This information, in turn, is acquired, processed and distributed by management accounting systems. For example, information regarding performance is acquired in terms of process outcomes, processed as to form budgets, costs and performance indicators and distributed to the ones needing that information for control, planning and decision-making purposes. 


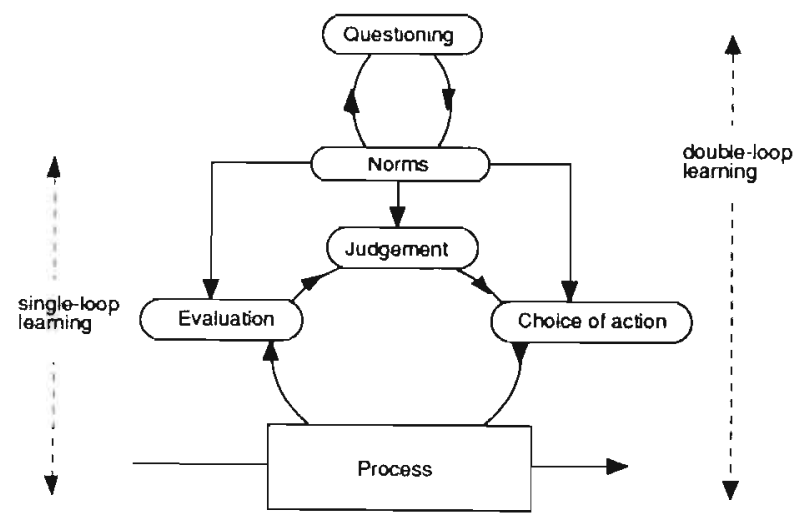

Figure 8.3 Single and double-loop control cycle

In other words, a management accounting system is in principle a learn system, used by decision makers to learn about the process they are accountable for. And, as in accounting, norms are used to evaluate and judge whether the process is in or out of control, control cycle elements such as measurement, evaluation and judgement usually being rephrased into information processing terms. However, an identical cycle is used for learning as well as for control.

A control cycle is depicted in Figure 8.3. It shows a situation in which there are stable norms. In conventional accounting practice, it is assumed that this is the normal situation. For example, for a cost centre to attain a budget norm, the manager responsible evaluates the results or the activities of the centre, judges them by the budget norm and takes action, if necessary. Evaluations can be performed by variance analyses to budget as set out in company procedures. If variances are significantly 'out of control' inquiries into the causes are started.

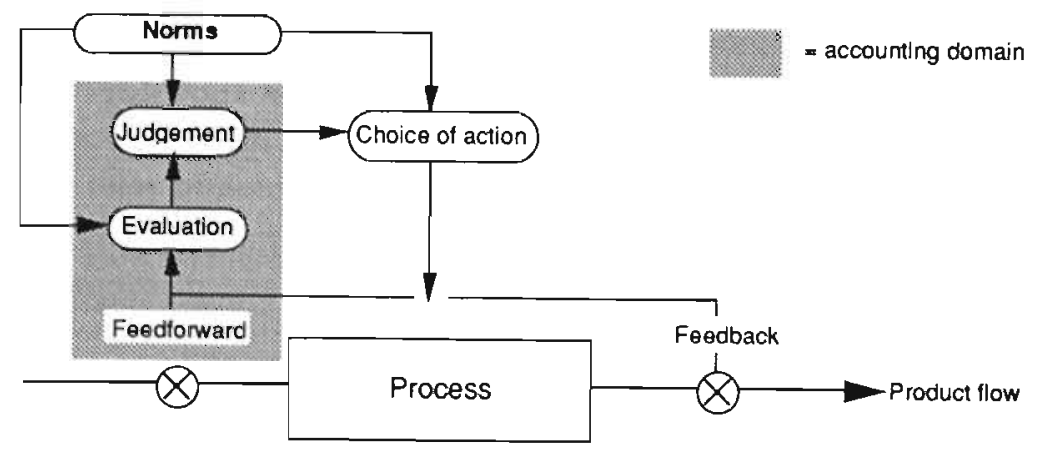

Figure 8.4 The accounting role in the control cycle concept 
It is in the evaluation and judgement parts that the role of accounting is traditionally located, albeit evaluation is usually called reporting. Judgement and subsequent control have led to a significant body of accounting research in the area of accounting information processing (Birnbergg et al., 1983; Birnberg and Sadhu, 1986). For example, by presenting financial evaluations in several reporting formats, accounting can shift the accentuation in evaluations, and consequently, manipulate judgements on the activities performed (Van de Poel, 1986, 1988).

The three cases studies correspond with Morgan's brain metaphor in their use of the four holographic design' principles of redundancy of functions, requisite variety, minimal critical specification and learning to learn. Still, the management accounting system, which maintains an inherent mechanical metaphor, serves as a vehicle to promote and enhance learning. The link between the two metaphors is the control cycle concept. The conditions for this linkage come from the case studies. They are related to:

1) the allocation of control, assigning learning to different levels in the organisation;

2) interaction and participation promoting local control, simplification and strong monitoring;

3) the excessive use of standards as a means to set a process of questioning and improvement in motion.

Control cycles are allocated at various levels of the organisation. When activities cannot be executed at one level, because of, for example, interdependencies, they raise to the next executive level, where these interdependencies are part of the responsibility and accountability. The final control cycle then spans the whole of the organisation and, consequently, leaves only the execution of activities ('tasks') that span the entire organisation, for example, a full reorganisation decision as taken by Van Nelle's top management.

Furthermore, one of the essential points is that control cycles need to be closed within the boundaries of one (sub)system. In other words, distributing information to a control cycle where it remains unclear as to what the relationship is between evaluation and action, blocks learning. For example, supplying task group leaders with order throughput information does not make sense, unless it is specified to the job shop in their accountability area. This involves redesign: Closing the control cycles (re)establishes the cause-and-effect relationship with the process.

As a result, control cycle (re)design necessitates reflection on what norms, evaluations, judgements and actions are relevant and are to be applied. This question is posed at every level a control cycle is allocated: At shop floor level, where machine efficiency is the norm, and machine downtime is classified into a number of categories to judge what action is appropriate (Van Nelle); and at organisation level, where quality conformance, throughput time and profitability are of equal importance, and WIP and actual costs are reported per work centre per order (St. Antonius). The information provided by the management accounting system in these cases represents the full cause-and-effect relationships of processes, and allows solving problems (single-loop learning) as well as improving existing situations (double-loop learning). 
In the three STSD-based accounting systems, performance monitoring is made part of the overall change process: Organisation members are asked to design their own performance measurement system, maintaining a highly participative focus. Moreover, the resulting performance systems require considerable interaction between task groups because they are related to each other in the flow. Interaction can be characterised as providing the distribution and sharing of information necessary for learning to occur.

The cross-functional cooperation, which is sought in order to keep the various autonomous task groups together, is explicitly addressed by the MAS design, for example, in the period reports of Van Nelle and St. Antonius, and the meetings \& agendas as set up by Zilverstad. St. Antonius even integrated structural cooperation arrangements (the CTA department and the liaison roles of the Quality and Production Engineers) with its MAS design, by monitoring quality and throughput performance as the results of these cross-functional interdependencies.

Self-appraisal does not stop at having the organisation members participate in the performance and accountability design. The resulting performance measurement system is owned by the designers, i.e., the task groups. Because task groups are also the control loci - responsibility, accountability and controllability are aligned at one organisational level - local autonomy and ownership coincide: Performance monitoring therefore is deprived of its top-down connotation and rebuilt to what can be literally called self-appraisal. Therefore, the learning process rests upon interaction and participation in the design. Accordingly, the resultant design is owned by the designers and made up of relatively simple accounting elements such as budgets and variances.

The final learning feature is the excessive use of standards, which can be observed in all three cases. Standards are norms for activities as well as reflections of the (cognitive map of the) cause-and-effect relationships in that activity. If activities change or are discussed regularly (i.e., task groups redesigning their work and discussing their performance), the underlying cause-and-effect relationships are regularly questioned. Consequently, norms are subject to continuous change. The autonomy task groups have in setting their own norms, then make it possible to obtain new insights into cause-and-effect relationships and to translate them directly into improved standards. In other words, a learning cycle effect arises because the provided accounting information leads continuously to looking for solutions and improvements. In turn, these show up again in the provided accounting information and serve a subsequent cycle.

In accounting terms, the use of conventional standard budgeting/costing techniques is of considerable relevance. However, the use and the accentuation of the technique are quite different from textbook treatments. Standards are not diluted versions of a top-down performance target, but bottom-up specifications of strategic goals. Standards do not serve so much a restrictive control purpose but, instead, a feedback and improvement purpose. Added to this, is the accent on the standard part instead of the cost part in standard costing: Nonfinancially expressed standards are deemed as important as financially expressed standards. 


\section{Help for Practice}

The above conclusions and discussions can be related to help for practice on two main topics:

- How to obtain cost insights that are relevant to the organisation;

- How to control and at the same time improve decentralised organisations.

From the case studies, we can observe that the shop floor defines what is relevant cost information: information that can be used to control processes. It resulted in simple systems of accounting and control. At organisation level, these simple systems where encountered with an equally simple control system, that of autonomous task groups that self appraise their control design. The key to these simple systems is to change the organisation design. Simplify the organisation design from bottom to top, starting from the production process upward. The instruments used to do this were discussed in Chapter 3 (design toolkit, change management approach, etc). It will result in a totally different organisation, as can be seen in the case studies.

However, it is not an easy managerial fix. What is crucial is the commitment to the primary resource of the organisation - people. Human resources need to be taken serious as the primary element of the organisation. People will direct themselves, as long as they are provided with the trust, goals, structures and instruments that will enable them to do so. Human resources are the main input for providing the requisite variety that a dynamic environment demands from an organisation. Trying to control this variety demands a management control system that indeed is critically specified at a minimum - critically here meaning what follows from the human resources vision employed.

The case studies indicate that we can control systems better, by controlling people less. Task groups are fully able to take responsibility and self-control their work. Their cumulative efforts at production system level make that little direct interference is needed. The criterion for leaving systems alone is whether they keep within their system boundaries, set by higher management in terms of organisation design and general performance targets. However, an important condition is that task groups are provided with the management accounting instruments to control themselves plus that they are provided with the information that tells them they indeed keep their system within the control and performance boundaries. Without such instruments and information, self-control is an empty word.

Of course, interdependence still exists, requiring interaction and hierarchic coordination. Equally, the need for vertical information system will not disappear, but their content will relate much more to controlling the coherence of local processes than to ensuring execution of set directives. Maintaining coherence will then be a mere matter of strategic choice and external conditions, as long as the organisation is carefully designed in terms of its internal system boundaries, including having the required management accounting instruments and information, what is required then being determined bottom up. 
Improvement relates to the possibilities for organisational learning as provided by task groups and decentralised organisation design. Self-control within system boundaries, whether they be task groups or business units, promotes questioning existing norms and procedures thus engaging in improvement management, somewhat similar to the Japanese approach of 'Kaizen'. The job of higher management is to assure that proposed improvements can be handled within the boundaries of each system.

\section{Limitations of the Study}

Research findings are constrained by several data-oriented factors. First of all, cases were selected as to best STSD practice, they are heterogeneous to core concept and to a successful event history (McPhee, 1990). Insights thus have a replicative nature, extending a grounded analysis base with subsequent factors from follow-up cases. In the design of this study, we consciously looked for the condition of consonant change between the organisation design and the management accounting systems design. Alternatively, a dissonant match was neglected, i.e., a research design in which only one design changed, or no design changed at all (see Figure 8.5).

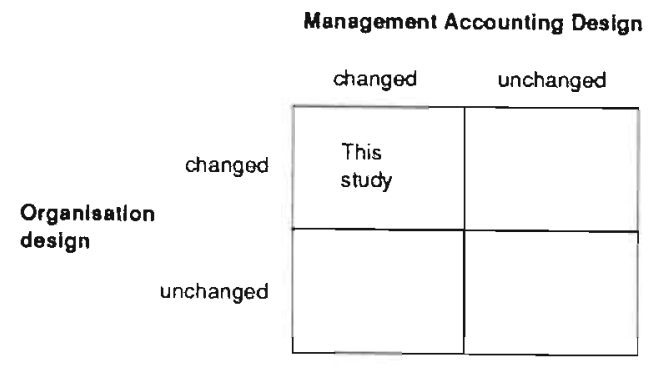

Figure 8.5 Researching the alternatives: dissonances organisation design and management accounting design

It is plausible that equally interesting evidence would have resulted. Consequently, research emphasis then would have shifted, for example, to the question why (STSD) organisational redesign change failed to take the management accounting design along. This type of 'dissonant match' research design can be found in the work of Den Hertog (1978) on task groups and vertical information systems, where a comparison was made between a simultaneous change and a nonsimultaneous change of the two design options.

Second, case descriptions were performed by 'robbing the window' at one limited period of time. In other words, evidence was gathered by taking a snapshot of events based on documents and extensive interviews with representative managers available at that time period. An action research type of data gathering, over 
a longer period of time, would probably have resulted in a closer look at the behavioural elements of the systems researched (attitudes, perceptions, changes in value and beliefs systems). For a first exploration, however, it was considered sufficient to rob the window because it was the first time this window was looked at.

The grounded theory coding procedures used for data reduction and analysis were directly applied from the textbook, i.e., without reference to other studies making use of these procedures. This may have resulted in procedural flaws that could have been avoided. However, the limited number of studies analysed by means of grounded theory available in management accounting were either conducted in highly dissimilar research areas or were designed to perform in one discipline only. A similar research study simultaneously addressing two disciplines (organisation theory and accountancy) as well as lacking any conceptual or empirical guidance was not available.

Furthermore, some of the dimensional profiles in grounded coding lack specificity. They run on a continuum of high versus low, which is an arbitrary scale. Given the presumption that properties resulting from the coding procedures can function as independent variables for statistical testing, operationalisation in terms of statistical modelling is limited. The few research studies attempting such modelling either focus on a limited number of variables or many variables in one single research site (Schuring, 1991). However, what is replicated in this study is not so much a number of factors or variables but a pattern of reasoning and action, i.e., an analytical replication in which contextual conditions are implicit in the analysis.

\section{Suggestions for Further Research}

Directions for future research can be considered opposites of the above-discussed limitations and therefore move in two directions: Improve the methodological aspects, and improve the results of the study.

Methodological aspects relate to site selection, and data gathering and analysis. Regarding site selection, it would involve STSD cases where the management accounting design was not taken along, in order to compare two contrasting clusters of evidence and replicate the study in a more ethnographic research design. Equally, the coding procedures could be improved and made more suitable to further studies involving management accounting systems. Essentially, these type of studies are basically unfamiliar to the management accounting discipline. Studying processes and establishing reasoning and action patterns that can be helpful to practice as well as to subsequent theory building, opens up many interdisciplinary research venues. At present, process studies in the accounting field are mainly located in auditing and auditing decision-making research (Hayes, 1989; Vaassen, 1992). Perhaps, the use of protocols in this area is a methodological example of how to model action \& reasoning patterns and how they perform in certain contexts (i.e., judgement and belief environments). Other fields - where process studies have been familiar for some time and led to a body of process research methodologies - are the fields of strategic decision making, innovation management and organisational change (Van de Ven, 1992; Van de Ven and Poole, 1990; 
Burgelman, 1983; Glick, Huber, Miller, Doty and Sutcliffe 1990; Barr, Stimpert and Huff, 1992). All make extensive use of case study research designs and have introduced several methodological approaches that can be useful to process research in management accounting. Particularly, the introduction of quantitative research methods to subportions of a case study seems worthwhile to consider for accounting research designs because of the many linkages between calculative practices and managerial discretion (McClintock, Brannon and Moody, 1979).

Finally, the research findings can be further developed and implemented in practice. Similarly, as in strategic/innovation management and in organisational development research, the results of the study should lead to improved policy decisions. Results stated in terms of reasoning and action patterns are then preferred to listings of correlated variables since they provide a map rather than cues. The move towards practice further implies additional verification and adaptation to various other real-life contexts. Consultants and researchers in this type of designoriented research perform equal roles: Applied sciences have to be applied to advance science. 


\section{References}

Adler, P. and D.U. Helleloid, Effective Implementation of Integrated CAD/CAM: A model, IEEE Transactions on Engineering Maragement, vol. EM-34, no. 2, May 1987, pp. 101107.

Adler, P., New Technologies, New Skills, California Management Review, vol. 29, no. 1, 1986, pp. 9-28.

Agurén, S., C. Bredbacka, R. Hansson, K. Ihregren and K.G. Karlsson, Volvo Kalmar revisited: Ten years of experience, Stockholm: Trykert Balder, 1984.

Allegro, J.T. and E. de Vries, Project 'Humanization and Participation' in Centraal Beheer, in: A. Alioth, J. Blake, M. Butteriss, M. Elden, O. Oortsman and R. van der Vlist (eds.), Working on the Quality of Working Life: Developments in Europe, Boston: Nijhoff, 1979, pp. 223-237.

Argyris, C., The Impact of Budgets on People, Ithaca NY: The Controllership Foundation, 1952.

Argyris, C., Organizational Learning and Management Information Systems, Accounting, Organizations and Society, vol. 2, 1977, pp. 113-123.

Argyris, C., Inner Contradictions of Rigorous Research, New York: Academic Press, 1980.

Armstrong, P., Changing Management Control Strategies: The role of competition between accountancy and other organisational professions, Accounting, Organizations and Society, vol. 10, no. 2, 1985, pp. 129-148.

Ashby, W.R., Design for a Brain, London: Chapman and Hall, 1956.

Auer, P. and C. Riegler, Post-Taylorism: The enterprise as a place of learning organizational change. A comprehensive study on work organization changes and its context at Volvo, Stockholm/Berlin: The Swedish Work Environment Fund/Wissenschaftszentrum für Sozialforschung, 1990.

Baiman, S., Agency Research in Managerial Accounting: A survey, Journal of Accounting Literature, vol. 1, Spring 1982, pp. 154-213.

Barr, P.S., J.L. Stimpert and A.S. Huff, Cognitive Change, Strategic Action, and Organizational Renewal, Strategic Management Journal, vol. 13, 1992, pp. 15-36.

Bennett, R.E., J.A. Hendricks, D.E. Keys and E.]. Rudnicki, Cost Accounting for Factory Automation, Montvale: National Association of Accountants, 1987.

Berg, P.O., Techno-culture: the symbolic framing of technology in a Volvo plant, Scandinavian Journal of Management Studies, vol. 1, no. 4, 1985, pp. 237-255.

Berliner, C. and J. Brimson (eds), Cost Management in Today's Advanced Manufacturing Environments: The CAM-I Conceptual Design, Boston: Harvard Business School Press, 1988.

Bertsch, H.B., Quality Management as a Strategic Learning Process, in: A.N.A.M. Boons en H.B. Bertsch (eds.), Organisatie effectiviteit en Management Accounting in industriële ondernemingen met geavanceerde produktietechnologie [Organisational Effectiveness and Management Accounting in industrial organisations using advanced production technologyl, rapport 8914/ACC/O, Rotterdam: Erasmus Universiteit - Centrum voor Bedrijfseconomisch Onderzoek, 1989, pp. 11-20. 
Birnberg, J.G. and K.K. Sadhu, The Contribution of Psychological and Cognitive Research to Managerial Accounting, in: M. Bromwich and A.G. Hopwood (eds.), Research \& Current Issues in Management Accounting, London: Pitman, 1986, pp. 116-142.

Bimberg, J.G., L. Turopolec and S.M. Young, The Organizational Context of Accounting, Accounting, Organizations and Society, no. 2/3, vol. 8, 1983, pp. 111-129.

Birnberg, J.G., M.D. Shields and S.M. Young, The Case for Multiple Methods in Empirical Management Accounting Research (With an Illustration from Budget Setting), Journal of Management Accounting Research, vol. 2, Fall 1990, pp. 33-66.

Bolweg, J.F., Job Design and Industrial Democracy: The Case of Norway. Leiden: Nijhoff, 1976.

Bolwijn, P.T., Continuiteit en Vernieuwing van Produktiebedrijven [Continuity and Renewal in Production Organisations], inaugural speech, Enschede: Technische Universiteit Twente, 1988.

Bolwijn, P.T. and S. Brinkman, Japanese Manufacturing: strategy and practice, Long Range Planning, vol. 20, no. 1, 1987, pp. 25-34.

Bolwijn, P.T. and T. Kumpe, Manufacturing in the 1990s - Productivity, Flexibility and Innovation, Long Range Planning, vol. 23, no. 4, 1990, pp. 44-57.

Boons, A.N.A.M. and H.J.E. Roberts, Cost Accounting in een JIT-omgeving, in: W.M. du Pon, J. Dijksma and C.D. Knoops (eds.), fMA kroniek 1990, Groningen: Wolters-Noordhoff, pp. $467-482$.

Boons, A.N.A.M, H.J.E. Roberts and F.A. Roozen, Activity-Based Costing: Strategisch cost management voor vernieuwende bedrijuen, Deventer: Kluwer Bedrijfswetenschappen, 1991.

Boons, A.N.A.M. and F.A. Roozen, Symptoms of Dysfunctional Cost Information Systems: Some preliminary empirical evidence from the Netherlands, paper presented at the European Accounting Association Conference, Madrid, 1992.

Bossert, J. and H. van Nimwegen, Ontwerpvariabelen voor Interme Berichtgevingssystemen (Design Variables for Management Accounting Systems), in: L. Traas and E. de With (eds.), Handboek Management Accounting, pp. E1100/16, 1991.

Bromwich, M., The Case for Strategic Management Accounting: The role of accounting information for strategy in competitive markets, Accounting, Organizations and Society, vol. 15, no. 1/2, 1990, pp. 27-46.

Bruns, W.J. and J.H. Waterhouse, Budgetary Control and Organization Structure, Journal of Accounting Research, vol. 13, 1975, pp. 177-203.

Buchanan, D.A., Job Enrichment is Dead: Long live high performance work design, Personnel Management, May 1987, pp. 40-43.

Buitelaar, W.L., B. Dankbaar and M. van Klaveren, Integrale Organisatievernieuwing en Arbeidsverhoudingen (Integral Organisational Renewal and Industrial Relations), Apeldoorn/Maastricht/Amsterdam: TAO position paper, 1990.

Burgelman, R.A., A Process Model of Internal Corporate Venturing in the Diversified Major Firm, Administrative Science Quarterly, vol. 28, 1983, pp. 223-244.

Capettini, R. and D.K. Clancy, Cost Accounting, Robotics, and the New Manufacturing Envirorment, Sarasota: American Accounting Association, 1987. 
Chenhall, R.H. and D. Morris, The Impact of Structure, Environment and Interdependence on the Perceived Usefulness of Management Accounting Systems, The Accounting Riview, vol. 61, no. 1, 1986, pp. 16-35.

Child, J., Information Technology, Organization and the Response to Strategic Challenges, California Management Review, vol. 30, no. 1, Fall 1987, pp. 33-50.

Cooper, R. and R.S. Kaplan, The Design of Cost Management Systems, Englewood Cliffs: Prentice-Hall, 1991.

Daft, R.L. and R.H. Lengel, Organizational Information Requirements, Media Richness and Structural Design, Management Science, vol. 32, no. 5, May 1986, pp. 554-571.

Dankbaar, B. and J.F. den Hertog, Labour Process Analysis and Sociotechnical Design: Living Apart Together?, Technology, Work and Employment, vol. 5, no. 2, 1990, pp. 122134.

De Sitter, L.U., Sociotechniek, Mens en Onderneming, vol. 28, no. 2, 1974, pp. 65-83.

De Sitter, L.U., Op Weg naar Nieuwe Fabrieken en Kantoren ISetting Out for New Plants and Offices], Deventer: Kluwer, 1981.

De Sitter, L.U., Integrale Produktievernieuwing: Sociale en economische achtergronden van het TAO-programma [Integral Production Renewal: Social and economic backgrounds of the TAO programme], Maastricht: MERIT, 1989a.

De Sitter, L.U., Modern Sociotechnical Systems Design, Maastricht/Den Bosch: MERIT/Koers, $1989 b$.

De Sitter, L.U. and J.F. den Hertog, Simple Organisations, Complex Jobs: The Dutch Sociotechnical Approach, Maastricht: MERIT Research Memorandum 90-012, 1990.

Den Hertog, J.F., The Role of Information and Control Systems in the Process of Organizational Renewal: Roadblock or Roadbridge?, Accounting, Organizations and Society, vol. 3 , no. 1, 1978, pp. 29-45.

Den Hertog, J.F., Interventiestrategieën in Organisaties: Cursusboek [Organisational Intervention Strategies: course reader], Heerlen: Open University, 1992.

Den Hertog, J.F. and H.J.E. Roberts, Learning Strategies for Management Accounting in Unprogrammable Contexts, Accounting, Management and Information Technology, vol. 2, no. 3, 1992, pp. 165-182.

Den Hertog, J.F. and P. Schröder, Social Research for Technological Change: Lessons from national programmes in Europe and North America, Maastricht: MERIT Research Memorandum 89-028, 1989.

Den Hertog, J.F. and L.U. de Sitter, Integrated Organisational Design: A structural and strategic framework, Maastricht: MERIT/University of Limburg, 1989.

Den Hertog, J.F., E. van Sluijs, B. van Diepen, and A. van Assen, Innovatie en personeelsbeleid: de beheersing van de kennishuishouding [Innovation and Personne] Policy: management of the knowledge enterprise], Bedriffskunde, vol. 63, no. 2, 1991, pp. 158-167.

Den Hertog, J.F. and Ph. Wester, Organizational Renewal in Engineering Works: A comparative process analysis, in: C.L. Cooper and E. Mumford (eds.), The Quality of Working Life: The European experiment, London: Associated Business Press, 1979. 
Den Hertog, J.F. and C. Wielinga, Control Systems in Dissonance: The computer as an inkblot, Accounting, Organizations and Society, vol. 17, no. 2, 1992, pp. 103-127.

Dent, J.F., Organizational Research in Accounting: Perspectives, issues and a commentary, in: M. Bromwich and A.G. Hopwood (eds.), Research \& Current Issues in Management Accounting, London: Pitman Publishing, 1986, pp. 147-178.

Dent, J.F., presentation held at the European Accounting Association's Doctoral Colloquium, Budapest, 1990.

Dermer, J.D. en R.G. Lucas, The Illusion of Managerial Control, Accounting, Organizations and Society, vol. 11, no. 6, 1986, pp. 471-482.

Eisenhardt, K.M., Building Theories from Case Study Research, Academy of Management Review, vol. 14, no. 4, 1989, pp. 532-550.

Eisenhardt, K.M., Better Stories and Better Constructs: The case for rigor and comparative logic, Academy of Management Review, vol. 16, no. 3, 1991, pp. 620-627.

Emery, F.E., Characteristics of Socio-Technical Systems, in: L.E. Davis and J.C. Taylor, Design of Jobs, Harmondsworth: Penguin Books, 1972, pp. 177-198.

Emery, F.E. and E. Thorsrud, Form and Content of Industrial Democracy: Some Experiments from Norway and other European Countries, Assen: Van Gorcum, 1969.

Emery, F.E. and E. Thorsrud, Democracy at Work: The Report of the Norwegian Industrial Democracy Program, Leiden: Martinus Nijhoff, 1976.

Emery, F.E. and E.L. Trist, Analytical Model for Sociotechnical Systems, in: W.A. Pasmore and J.J. Sherwood (eds.), Sociotechnical Systems: A sourcebook, La Jolla: University Associates, 1978, pp. 120-131.

Emmanuel, C.R., D.T. Otley and K.A. Merchant, Accounting for Management Control, London: Chapman and Hall, 2nd ed, 1990.

Engelstad, P.H., Socio-technical approach to problems of process control, in: L.E. Davis and J.C. Taylor (eds.), Design of Jobs, Harmondsworth: Penguin, 1972, pp. 328-356.

Ezzamel, M., K. Hoskin and R. Macve, Managing it All by Numbers: A review of Johnson \& Kaplan's "Relevance Lost", Accounting and Business Research, vol. 20, no. 78, 1990, pp. 153-166.

Ezzamel, M., The Impact of Environmental Uncertainty, Managerial Autonomy and Size on Budget Characteristics, Management Accounting Research, vol. 1, no. 3, 1990, pp. 181197.

Flamholtz, E.G., Accounting, Budgeting and Control Systems in their Organizational Context: Theoretical and Empirical Perspectives, Accounting, Organizations and Society, no. 2/3, vol. 8, 1983, pp. 153-169.

Flamholtz, E.G., T.K. Das and A.S. Tsui, Toward an Integrative Framework of Organizational Control, Accounting, Organizations and Society, no. 1, vol. 10, 1985, pp. 35-50.

Ford, J.D. and D.A. Schellenberg, Conceptual Linkages in Organizational Performance, Academy of Management Review, vol. 7, 1982, pp. 49-58.

Galbraith, J., Designing Complex Organisations, London: Addison-Wesley, 1974. 
Galbraith, J., Organization Design, Reading: Addison-Wesley, 1977.

Ginzberg, M.J., An Organizational Contingencies View of Accounting and Information Systems Implementation, Accounting, Organizations and Society, vol. 5, 1980, pp. 369-382.

Glaser, B. and A. Strauss, The Discovery of Grounded Theory: Strategies of qualitative research, London: Wiedenfeld and Nicholson, 1967.

Glick, W.H., G.P. Huber, C.C. Miller, D.H. Doty and K.M. Sutcliffe, Studying Changes in Organizational Design and Effectiveness: Retrospective Event Histories and Periodic Assessments, Organization Science, vol. 1, no. 3, 1990, pp. 293-312.

Gold, B., CAM Sets New Rules for Production, Harvard Business Review, vol. 60, no. 6, Nov.Dec. 1982 , pp. $88-94$.

Goldhar, J.D. and M. Jelinek, Plan for Economies of Scope, Harvard Business Review, vol. 61, no. 6, Nov.-Dec. 1983, pp. 141-148.

Gordon, L.A. and D. Miller, A Contingency Framework for the Design of Accounting Information Systems, Accounting, Organizations and Society, vol. 1, 1976, pp. 59-70.

Gordon, L.A. and V.K. Narayanan, Management Accounting Systems, Perceived Environmental Uncertainty and Organization Structure: An Empirical Investigation, Accounting, Organizations and Society, no. 1, vol. 9, 1984, pp. 33-48.

Govindarajan, V. and A.K. Gupta, Linking Control Systems to Business Unit Strategy: Impact on performance, Accounting, Organizations and Society, no. 1, vol. 10, 1985, pp. 5166.

Govindarajan, V. and J. Fisher, Strategy, Control Systems and Resource Sharing: Effects on business performance, Academy of Management Journal, no. 2, vol. 33, 1990, pp. 259-285.

Groep Sociotechniek, Het Flexibele Bedrijf: integrale aanpak van flexibiliteit, beheersbaarheid, kwaliteit van de arbeid en produktie-automatisering [The Flexibele Organisation: integral approach of flexibility, control, quality of work and production automation], Deventer: Kluwer Bedrijfswetenschappen, 1987.

Gutenberg, E., Grundlagen der Betriebswirtschaftslehre, Band I: Die Produktion, 1st. ed. Berlin: Springer Verlag, 1951.

Hammer, M., Reengineering Work: Don't Automate, Obliterate, Harvard Business Review, vol. 90, no. 4, July-August 1990, pp. 104-112.

Harrison, J.M., C.A. Holloway and J.M. Patell, Measuring Delivery Performance: A Case Study from the Semiconductor Industry, in: R.S. Kaplan (ed.), Measures for Manufacturing Excellence, Boston: Harvard Business School Press, pp. 309-351.

Hayes, R.H. en D.A. Garvin, Managing as if Tomorrow Mattered, Harvard Business Review, May-June 1982, pp. 71-79.

Hayes, R.H. and R. Jaikumar, Manufacturing's Crisis: New technologies, obsolete organizations, Harvard Business Review, vol. 66, no. 5, Sept.-Oct. 1988, pp. 77-85.

Hayes, R.H., S.C. Wheelright and K.B. Clark, Dynamic Manufacturing: Creating the learning organization, New York: The Free Press, 1988. 
Hayes, R.S., The Utilisation of Accounting Information by International Bank Loan Officers in their Loan Decisions: A Verbal Protocol-Based Expert System Stimulation, Ph.D. Dissertation, London: London School of Economics and Political Science, 1989.

Heinen, E., Betriebswirtschaftliche Kostenlehre; Kostentheorie und Kostenentscheidungen, 6th. rev. ed, Wiesbaden: Gabler Verlag, 1983.

Herbst, P.G., Task Structure and Work Relations, London: Tavistock Document 528, 1959.

Hiromoto, T., Another hidden edge - Japanese management accounting. Harvard Business Review, vol. 66, pp. 22-26, 1988.

Hofstede, G.H., The Game of Budget Control, Assen: Van Gorcum, 1967.

Hopwood, A.G., Accounting and Human Behaviour, Englewood Cliffs: Prentice-Hall, 1974.

Hopwood, A.G., Towards an Organizational Perspective for the Study of Accounting and Information Systems, Accounting, Organizations and Society, vol. 3, no. 1, 1978, pp. 3-13.

Hopwood, A.G., On Trying to Study Accounting in the Contexts in which it Operates, Accounting, Organizations and Society, vol. 8, no. 2/3, 1983, pp. 287-305.

Hopwood, A.G., The Growth of "Worrying" about Management Accounting, in: K.B. Clark, R.H. Hayes and C. Lorenz (eds.), The Uneasy Alliance: Managing the Productivity-Technology Dilemma, Boston: Harvard Business School Press, 1985, pp. 227-235.

Hopwood, A.G., Management Accounting and Organisational Action: An introduction, in: $M$. Bromwich and A.G. Hopwood (eds.), Research and Current Issues in Management Accounting, London: Pitman, 1986, pp. 9-30.

Hopwood, A.G., The Archaeology of Accounting Systems, Accounting, Organizations and Society, vol. 12, no. 3, 1987, pp. 207-234.

Hopwood, A.G., Accounting and Organisation Change, Accounting, Auditing \& Accountability Journal, vol. 3, no. 1, 1990, pp. 7-17.

Horngren, C.T. and G. Foster, Cost Accounting: A managerial emphasis, Englewood Cliffs: Prentice-Hall, 1991.

Howell, R.A., J.D. Brown, S. Soucy and A.H. Seed III, Management Accounting in the New Manufacturing Environment: Current Cost Management Practice in Automated (Advanced) Manufacturing Environments, Montvale: National Association of Accountants, 1987.

Innes, J. and F. Mitchell, Change in Management Accounting: Some case study evidence from the electronics sector, Workshop on Cost Management and Product Cost Analysis in Advanced Manufacturing Environments, Brussels: European Institute for Advanced Studies in Management (EIASM), 1988.

Jaikumar, R., Postindustrial Manufacturing, Harvard Business Review, vol. 64, no. 6, Nov.-Dec. 1986, pp. 69-76.

Jensen, M.C. and W.H. Meckling, Theory of the firm: Managerial behavior, agency costs and ownership structure, Journal of Financial Economics, no. 3, Oct. 1976, pp. 305-360.

Johnson, G., The Application of Grounded Theoy to a Study of Corporate Growth, working paper no. 212, Birmingham: University of Aston Management Centre, 1989. 
Johnson, H.T. and A.D. Loewe, How Weyerhauser manages corporate overhead costs, Management Accounting, August 1987, pp. 20-26.

Johnson, H.T. and R.S. Kaplan, Relevance Lost: The Rise and Fall of Management Accounting, Boston: Harvard Business School Press, 1987.

Jönsson, S., Budgetary Behavior in Local Government - A case study over three years, Accounting, Organizations and Society, vol. 7, 1982, pp. 287-304.

Jönsson, S., Limits of Information Technology for Facilitating Organizational Learning, in: J.M. Pennings and A. Buitendam (eds.), New Technologies as Organizational Innovation: The development and diffusion of micro-electronics, Cambridge: Ballinger, 1987, pp. 217 234.

Jönsson, S. and A. Grönlund, Life with a Sub-Contractor: New technology and management accounting, Accounting, Organizations and Society, vol. 13, no. 5, 1988, pp. 512-532.

Jönsson, S. and A. Grönlund, Managing for Cost Improvement in Automated Production, in: R.S. Kaplan (ed.), Measures for Manufacturing Excellence, Boston: Harvard Business School Press, 1990, pp. 163-191.

Kaplan, R.S., Measuring Manufacturing Performance: A new challenge for managerial accounting research, The Accounting Review, vol. 58, no. 4, 1983, pp. 686-705.

Kaplan, R.S., The Evolution of Management Accounting, The Accounting Review, vol. 59, no. 3, 1984a, pp. 690-718.

Kaplan, R.S., Yesterday's Accounting Undermines Production, Harvard Business Review, JulyAugust 1984b, pp. 95-101.

Kaplan, R.S., Accounting Lag: The obsolescence of cost accounting systems, in: K.B. Clark, R.H. Hayes and C. Lorenz (eds.), The Uneasy Alliance: Managing the Productivity-Technology Dilemma, Boston: Harvard Business School Press, 1985, pp. 195-226.

Kaplan, R.S., The Role for Empirical Research in Management Accounting, Accounting, Organizations and Society, vol. 11, no. 4/5, 1986a, pp. 429-452.

Kaplan, R.S., Must CIM be Justified by Faith Alone?, Harvard Business Review, March-April 1986b, pp. 87-95.

Kaplan, R.S., One Cost System Isn't Enough, Harvard Business Review, Jan.-Feb. 1988, pp. 6166.

Khandwalla, P.N., Viable and Effective Organizational Design of Frim, Academy of Management Journal, vol. 16, 1973, pp. 481-495.

Kirk, J. and M.L. Miller, Reliability and Validity in Qualitative Research, Sage University Paper Series on Qualitative Research Methods, vol. 1, Beverly Hills: Sage Publications, 1986.

KOERS, Principles of Integrative Organizational Design, Den Bosch: KOERS Consultants, 1989.

Kunst, P.E.J. and H. Schreuder, Opening Up the Concept of Control, working paper 91-06, Brussels: European Institute for Advanced Studies in Management, 1991.

Kunst, P.E.J., R.L. Olie, A.G.L. Romme and J.L. Soeters, Organisatie, deel 1, Leiden: SMD, 1991. 
Lawler III, E.E., High Involvement Management: Participative strategies for improving organizational performance, San Francisco: Jossey-Bass, 1986.

Lawrence, P.R. and J.W. Lorsch, Organization and Environment: Managing Differentiation and Integration, Homewood: Irwin, 1969.

Libby, R. and B.L. Lewis, Human Information Processing Research and Accounting: The state of the art in 1982, Accounting, Organizations and Society, vol. 7, no. 3, 1982, pp. 231-285.

Madden, D., Empirical Research in Management Accounting: An unlimited potential for progress, Management Accounting News \& Views, vol. 8, no. 2, 1990, pp. 5-7.

Majchrzak, A., Methods for Policy Research, Applied Social Research Methods Series, vol. 3, Beverly Hills: Sage Publications, 1984.

Makido, T., Recent Trends in Japan's Cost Management Practices, in: Y. Monden and M. Sakurai (eds.), Japanese Management Accounting: A World Class Approach to Profit Management, Cambridge: Productivity Press, 1989, pp. 3-14.

Martin, J.R., W.K. Schelb, R.S. Synder and J.S. Sparling, Comparing U.S. and Japanese Companies: Implications for Management Accounting, Journal of Cost Management, vol. 6, no. 1, 1992, pp. 6-15.

McClintock, C.C., D. Brannon and S.M. Moody, Applying the Logic of Sample Surveys to Qualitative Case Studies: The Case Cluster Method, Administrative Science Quarterly, vol. 24, 1979, pp. 612-629.

McNair, C.J., W. Mosconi and T. Norris, Meeting the Technology Challenge: Cost Accounting in a ITT Environment, Montvale: National Association of Accountants, 1988.

McPhee, R.D., Alternate Approaches to Integrating Longitudinal Case Studies, Organization Science, vol. 1, no. 4, 1990, 393-405.

Merchant, K.A., Control in Business Organizations, Cambridge: Ballinger, 1985.

Merchant, K.A. and R. Simons, Research and Control in Complex Organisations: An overview, Journal of Accounting Literature, 1986, pp. 465-476.

Merchant, K.A., Rewarding Results: Effectively motivating profit center managers, Boston: Harvard Business School Press, 1989.

Miles, M. and A.M. Huberman, Qualitative Data Analysis, Beverly Hills: Sage Publications, 1984.

Miles, R.E. and C.C. Snow, Organizations: New Concepts for New Forms, California Management Review, vol. 28, no. 3, 1986, pp. 62-73.

Mintzberg, H., An Emerging Strategy of "Direct" Research, Administrative Science Quarterly, vol. 24, Dec. 1979, pp. 582-589.

Mintzberg, H., The Structuring of Organizations, Englewood Cliffs: Prentice Hall, 1979.

Mintzberg, H., The Effective Organization: Forces and forms, Sloan Management Review, vol. 32, no. 2, 1990, pp. 54-67.

Moch, M.K. and J.M. Bartunek, Creating Alternative Realities at Work: The Quality of Work Life Experiment of FoodCom, New York: Harper \& Row, 1990. 
Monden, Y. and K. Hamada, Target Costing and Kaizen Costing in Japanese Automobile Companies, Journal of Management Accounting Research, vol. 3, Fall 1991, pp. 16-34.

Morgan, G., Images of Organization, Beverly Hills: Sage Publications, 1986.

Nachmias, D. and C. Nachmias, Research Methods in the Social Sciences, New York: St. Martin's, 1976.

Nadler, D.A., Concepts for the Management of Organization Change, in: M.L. Tushman, C. O'Reilly and D.A. Nadler (eds.), The Management of Organizations, New York: Harper \& Row, 1987, pp. 490-504.

Otley, D.T., The Contingency Theory of Management Accounting: Achievement and Prognosis, Accounting, Organizations and Society, vol. 5, 1980, pp. 413-428.

Pasmore, W.A., Designing Effective Organizations: The sociotechnical systems perspective, New York: Wiley, 1988.

Polimeni, R.S., F.J. Fabozzi and A.H. Adelberg, Cost Accounting: Concepts and applications for managerial decision making, New York: McGraw-Hill, 3rd ed., 1991.

Porter, M.E., Competitive Advantage: creating and sustaining superior performance, New York: The Free Press, 1985.

Porter, M.E., Competitive Strategy: techniques for analyzing industries and competitors, New York: Free Press, 1980.

Ratnatunga, J., R. Pike and G.J. Hooley, The Application of Management Accounting Techniques to Marketing, Accounting and Business Review, vol. 18, no. 72, 1988, pp. 363-370.

Reisman, A., On Alternative Strategies for Doing Research in the Management and Social Sciences, IEEE Transactions on Engineering Management, vol. 35, no. 4, 1988, pp. 215-220.

Roberts, H.J.E., New Production Technology and Management Accounting, in: A.N.A.M Boons en H.B. Bertsch (eds.), Organisatie effectiviteit en Management Accounting in industriële ondernemingen met geavanceerde produktietechnologie [Organisational Effectiveness and Management Accounting in industrial organisations using advanced production technology], rapport 8914/ACC/O, Rotterdam: Erasmus Universiteit - Centrum voor Bedrijfseconomisch Onderzoek, 1989a, pp. 21-56.

Roberts, H.J.E., Organizational Change and Management Accounting Systems: A case study, Conference on Accounting in its Organizational and Social Contexts, Brussels: European Institute for Advanced Studies in Management (ELASM), 1989b.

Roberts, H.J.E., Management Accounting en Innovatie [Management Accounting and Innovation], in: J.F. den Hertog en F.M. van Eijnatten (eds.), Management van Technologische Vernieuwing [Management of Technological Renewal], Assen: Van Gorcum, 1990, pp. 154-177.

Roberts, J., The Possibilities of Accountability, Accounting, Organizations and Society, vol. 16, no. 4, 1991, pp. 355-368.

Roberts, J. and R. Scapens, Accounting Systems and Systems of Accountability: Understanding Accounting Practices in their Organisational Contexts, Accounting, Organizations and Society, vol. 10, no. 4, 1985, pp. 443-456.

Safizadeh, M.H., The Case of Workgroups in Manufacturing Operations, California Management Review, vol. 33, no. 4, Summer 1991, pp. 61-82. 
Scapens, R.W., Closing the gap between Theory and Practice, Management Accounting (UK), Jan. 1983, pp. 34-36.

Scapens, R.W., Research into Management Accounting Practice, Management Accounting (UK), Dec. 1988, pp. 26-28.

Schoenfeld, H.M.W., The Development of Cost Theory in Germany: A Historical Survey, Management Accounting Research, vol. 1, no. 4, 1990, pp. 265-280.

Schonberger, R.J., Frugal Manufacturing, Harvard Business Review, vol. 65, no. 5, Sept.-Oct. 1987, pp. 95-100.

Schuring, R.W., Produktie-organisatie met autonome groepen: De combinatie van maatregelen brengt het gewenste strategische resultaat (Production Organisation using Autonomous Groups: The combination of measures brings the desired strategic result, paper presented at the NOBO-onderzoeksdag 1991.

Simon, H.A., Administrative Behavior, New York: Macmillan, 1947.

Stalk, G., Time - The next source of competitive advantage, Harvard Business Review, July-August 1988, pp 41-51.

Staubus, G.J., Activity Costing and Input-Output Accounting, Homewood: Irwin, 1971.

Staubus, G.J., Activity Costing: Twenty years on, Management Accounting Research, vol. 1, no. 4, 1990, pp. 249-264.

Strauss, A. and J. Corbin, Basics of Qualitative Research: Grounded theory procedures and techniques, Newbury Park: Sage, 1990.

Takeuchi, H. and I. Nonaka, The New New Product Development Game, Harvard Business Review, vol. 64, no. 1, Jan.-Feb. 1986, pp. 137-146.

Tanaka, M., Cost Planning and Control Systems in the Design Phase of a New Product, in: $Y$. Monden and M. Sakurai (eds.), Japanese Management Accounting: A World Class Approach to Profit Management, Cambridge: Productivity Press, 1989, pp. 49-72.

Taylor, J.C., Two decades of Socio-technical Systems in North-America, Los Angeles: University of Southern California/Institute of Safety and Systems Mangement, paper presented at the 1990 National Academy of Management Meeting, San Francisco, August 1990.

Theeuwes, J.A.M., Bedrijfskundige Heroriëntatie van de Bedrijfseconomie [A Managerial Reorientation of Business Administration], Bedrijfskunde, jrg. 60, no. 1, 1988a, pp. 39-49.

Theeuwes, J.A.M., Logistiek Management en Budgettering [Logistics Management and Budgeting], Bedrijfskunde, jrg. 60, no. 1, 1988b, pp. 31-38.

Theunisse, H., M. Kerremans, D. Dyck and C. van Overloop, Impact of Automation on Cost Accounting; Some evidence from empirical research in Belgium, Workshop on Cost Management and Product Cost Analysis in Advanced Manufacturing Environments, Brussels: European Institute for Advanced Studies in Management (EIASM), 1988.

Thompson, J.D., Organizations in Action, New York: MacGraw-Hill, 1967.

Trist, E.L., The Evolution of Socio-Technical Systems: A conceptual framework and an action research program, in: A.H. van de Ven and W.F. Joyce (eds.), Perspectives on Organization Design and Behavior, New York: Wiley, 1981, pp. 19-75. 
Trist, E.L. and K.W. Bamforth, Some Social and Psychological Consequences of the Longwall Method of Coal-getting, Human Relations, vol. 4, no. 1, 1951, pp. 3.38.

Turner, B.A., The Use of Grounded Theory for the Qualitative Analysis of Organizational Behaviour, Journal of Management Studies, vol. 20, no. 3, 1983, pp. 333-348.

Vaassen, E.H.J., Auditor's Decision Processes in Audit Planning, Stage Materinlity and Risk ludgments, Maastricht: University Press Maastricht, forthcoming.

Vaill, P.B., The Purposing of High-Performing Systems, Organizational Dynamics, Autumn 1982, pp. 23-39.

Van Aken, J.E., On the Control of Complex Industrial Organizations, Leiden: Martinus Nijhoff, 1978.

Van Amelsfoort, P., Het Vergroten van de Bestuurbaarheid van Produktie-Organisaties (Enlarging the Managerial Control of Production Organisations), Oss: ST-Groep, 1992.

Van Assen, A. and J.F. den Hertog, From Job Rotation to Organisation Design, in: P.J.D. Drenth, H. Thierry, P.J. Willems and Ch. de Wolff (eds.), Handbook of Work and Organisation Psychology, London: Wiley, 1984.

Van Assen, A., Technologie en Personeelsbeleid: De draad van Ariadne in het technisch labyrint [Technology and Personnel Policy: Ariadne's thread in the technological labyrint], inaugural speech, Nijmegen: Catholic University، 1990.

Van Beinum, H.J.J., Veldexperimentele ervaringen in een bedrijfssituatie [Field experimental experiences in a business context], in: M. Mulder (red.), Mensen, Groepen, Organisaties [People, Groups, Organisations], Assen: Van Gorcum, 1963.

Van de Poel, J.H.R., Judgment and Control: Individual and Organizational Aspects of Performance Evaluation, Groningen: Wolters-Noordhoff, 1986.

Van de Poel, J.H.R., Als de tekenen bedriegen ... (If the evidence is nothing to go by ...), Inaugural speech, Groningen: Wolters-Noordhoff, 1988.

Van de Ven, A.H., Suggestions for Studying Strategy Process: A Research Note, Strategic Management Journal, vol. 13, 1992, pp. 169-188.

Van de Ven, A.H. and R. Drazin, The Concept of Fit in Contingency Theory, in: L.L. Cumimings and B.M. Staw, Research in Organizational Behavior, vol. 7, London: JAI Press, 1985, pp. 333-365.

Van de Ven, A.H. and M.S. Poole, Methods for Studying Innovation Development in the Minnesota Innovation Research Program, Organization Science, vol. 1, no. 3, 1990, pp. 313-335.

Van Eijnatten, F.M., From Autonomous Work Groups to Democratic Dailogue and Integral Organizational Renewal: 40 Years of Development and Expansion of the SocioTechnical Systems Design Paradigm, Maastricht: MERIT, University of Limburg, Research Memorandum 91-015.

Van Maanen, J., The Fact of Fiction in Organizational Ethnography, in: J. van Maanen (ed.), Qualitative Methodology, Beverly Hills: Sage, 1983.

Van Reeken, A.J., Naar een andere aanpak in de systemering [Towards another approach in systemisation], in: J.F. den Hertog en F.M. van Eijnatten (eds.), Management van Techno- 
logische Vernieuwing [Management of Technological Renewal], Assen: van Gorcum, 1991, pp. 129-153.

Van Sluijs, E., A. van Assen and J.F. den Hertog, Personnel Management and Organizational Change: A Sociotechnical Perspective, European Work and Organizational Psychologist, vol. 1, no. 1, 1991, pp. 27-51.

Van Terwisga, H.B. and E. van Sluijs, Opleiden voor de toekomst: onderdeel van bedrijfsbeleid [Educating for the Future: Part of Company Policy], Stichting Toekomstbeeld der Techniek; 50, Alphen aan den Rijn: Samsom, 1990.

Whitsett, D.A. and L. Yorks, Looking Back at Topeka: General Foods and the Quality-ofWork-Life experiment, California Management Review, vol. 25, no. 4, Summer 1983, pp. 93-109.

Wildavsky, A., Budgeting: A Comparative Theory of Budgetary Processes, Boston: Little and Brown, 1975.

Wildavsky, A., The Art and Craft of Policy Analysis, London: The Macmillan Press, 1979.

Womack, J.P., D.T. Jones and D. Roos, The Machine that Changed the World: The Story of Lean Production, New York: Harper Collins, 1990.

Yin, R.K., The Case Study Crisis: Some Answers, Administrative Science Quarterly, vol. 26, no. 1, 1981, pp. 58-65.

Yin, R.K., Case Study Research: Design and Methods, Applied Social Research Methods Series, vol. 5, Beverly Hills: Sage Publications, 1984.

Yoshikawa, T., J. Innes and F. Mitchell, Cost Management through Functional Analysis, Journal of Cost Management, vol. 3, no. 1, 1989, pp. 14-19.

Yoshikawa, T., J. Innes and F. Mitchell, Cost tables: A Foundation of Japanese Cost Management, Journal of Cost Management, vol. 4, no. 3, 1990, pp. 30-36. 


\section{Authors Index}

Adler and Helleloid; 4

Adler; 4

Agurén, Bredbacka, Hansson, Ihregren and Karlsson; 44

Allegro and De Vries; 44

Argyris; $13 ; 26 ; 182$

Ashby; 39; 40

Auer and Rigeler; 44

Baiman; 24

Barr, Stimpert and Huff; 228

Bennett, Hendricks, Keys and Rudnicki; 7; 216

Berg; 54

Berliner and Brimson; 7

Bertsch; 3

Birnberg and Sadhu; 223

Birnberg, Turopolec and Young; 13; 24; 223

Bolweg; $41 ; 42$

Bolwijn and Kumpe; 2

Bolwijn; 2; 215

Boons and Roberts; 3

Boons and Roozen; 8

Boons, Roberts and Roozen; 218

Bossert and Van Nimwegen; 215

Bruns and Waterhouse; 11

Buchanan; 44

Buitelaar, Dankbaar and Van Klaveren; 38

Burgelman; 206; 228

Capettini and Clancy; 7

Chenhall and Morris; 207

Cooper and Kaplan; 203; 218

Daft and Lengel; 207; 208

Dankbaar and Den Hertog; 38

De Sitter and Den Hertog; 39; 44; 46; 47; $48 ; 54 ; 55$

De Sitter; $45 ; 37 ; 44 ; 45 ; 46 ; 53$

Den Hertog and De Sitter; 53; 54

Den Hertog and Roberts; 14

Den Hertog and Van Assen; 26

Den Hertog and Wester; 44; 53

Den Hertog and Wielinga; 53

Den Hertog; 36; $41 ; 43 ; 53 ; 211 ; 226$

Dent; $9 ; 10 ; 12 ; 13 ; 15 ; 18$

Dermer and Lucas; 15

Emery and Thorsrud; 41; 44; 52

Emery and Trist; 43

Emery; 41

Emmanuel, Otley and Merchant; $6 ; 14$

Engelstad; 43

Ezzamel, Hoskin and Macve; 7; 15

Flamholtz, Das and Tsui; 11

Flamholtz; 11
Ford and Schellenberg; 12

Galbraith; 12; 40; 203; 209; 210

Ginzberg; 11

Glaser and Strauss; 26

Glick, Huber, Miller, Doty and Sutcliffe; 228

Gordon and Miller; $11 ; 211$

Gordon and Narayanan; 11

Govindarajan and Fisher; 11

Govindarajan and Gupta; 11

Groep Sociotechniek; 37; 44

Gutenberg; 19

Harrison, Holloway and Patell; 8

Hayes and Garvin; 6

Hayes; 227

Heinen; 19

Herbst; 43

Hergert and Morris; 207

Hiromoto; 213

Hofstede; 13

Hopwood; $13 ; 15 ; 16 ; 17$

Horngren and Foster; 6

Howell, Brown, Soucy and Seed III; 7; 22; 216

Innes and Mitchell; 22; 216; 218

Jaikumar; $4 ; 8$

Johnson and Kaplan; 4; 5; 17; 18; 216; 218

Johnson and Loewe; 8

Johnson; 206

Jönsson; 13; 18; 210

Kaplan; 5; 7; 18; 22; 215

Khand walla; 211

KOERS; 51

Kunst and Schreuder; 221

Kunst, Olie, Romme and Soeters; 217

Lawler; 44

Lawrence and Lorsch; 11

Libby and Lewis; 24

Majchrzak; 26

Makido; 213

Martin, Schelb, Synder and Sparling; 203

McClintock, Brannon and Moody; 228

McNair, Mosconi and Norris; 8

McPhee; 226

Merchant; $13 ; 14$

Miles and Snow; 8

Mintzberg; 3; 9; 11

Moch and Bartunek; 44

Morgan; 26; 53; 185; 196; 200; 219; 220; 221

Otley; 211

Pasmore; 54 
Polimeni, Fabozzi and Adelberg; 13

Porter; $1 ; 11$

Reisman; 24; 25

Roberts, J.; 202; 220

Roberts, J. and Scapens; 220

Roberts; 2

Roethlisberger; 30

Safizadeh; 44

Schoenfeld; 19

Schuring; 227

Simon; 40

Stalk; $2 ; 8$

Staubus; 19

Strauss and Corbin; $27 ; 28 ; 158 ; 160 ; 161$; $162 ; 164 ; 166 ; 170 ; 171$

Tanaka; 5

Taylor; 44

Theeuwes; 16

Theunisse, Kerremans, Dyck and Van Overloop; 7; 22

Thompson; 40

Trist; 40

Turner; 206

Vaassen; 227

Vaill; 44

Van Aken; 13

Van Amelsvoort; 49

Van Assen and Den Hertog; 53

Van Beinum; 44

Van de Poel; 10; 223

Van de Ven and Drazin; 11

Van de Ven and Poole; 228

Van de Ven; 228

Van Eijnatten; $40 ; 41 ; 42 ; 44 ; 45$

Van Maanen; 26

Van Reeken; 43

Van Sluijs, Van Assen and Den Hertog; 38

Whitsett and York; 44

Wildavsky; 13

Womack, Jones and Roos; 218

Yin; 28; 29; 30

Yoshikawa, Innes and Mitchell; 5 


\section{Nederlandse samenvatting - Summary in Dutch}

Dit proefschrift behandelt de samenhang tussen (veranderingen in) het organisatie-ontwerp en (de daarmee gepaard gaande veranderingen in) het management accounting-systeem. De achterliggende gedachtengang is dat het functionele organisatiemodel waarop de management accounting is gebaseerd, niet tegemoet komt aan de markteisen van flexibiliteit, kwaliteit, tijdigheid en innovativiteit. Als alternatief voor dit functionele model word het stroomsgerichte organisatiemodel van De Sitter gehanteerd, het zogeheten Moderne Sociotechniek, dat een sterke nadruk legt op de order-/werkstroom die de diverse organisatiefuncties verbindt. Vervolgens is bekeken hoe dit andere organisatiemodel van invloed is op het management accounting-systeemontwerp c.q. welke wijzigingen zich voordeden in het eerdere, functioneel georiënteerde management accounting-systeemontwerp. Geconcludeerd werd: (1) dat een groot aantal van de problemen die voorheen door de management accounting-functie werden beantwoordt, nu beantwoord worden door het verbeterde organisatieontwerp waarbij het management accounting-systeemontwerp sterk complementair functioneert; van groot belang bleek hier vooral de volgorde van de diverse ontwerpstappen; (2) dat de elementen waaruit een stroomsgericht management accounting-systeemontwerp bestaat (het 'alternatieve' ontwerp), worden gekenmerkt door hun relatieve eenvoud en conventionele tekstboekkarakter; zowel gebruik en rol van deze elementen zijn duidelijk gebaseerd op de beheersings- en verantwoordelijkheidsstructuur die ingebracht is door het organisatieontwerp; (3) dat een stroomsgericht management accounting-systeemontwerp het ontstaan van een lerende organisatie aanmoedigt, waarbij dit leren slaat op continue verbetering van produktieactiviteiten en procesbeheersing met behulp van decentralisatie van beheersing en verantwoordelijkheden, participatie en normering van activiteiten.

In hoofdstuk 1 wordt de probleemstelling gedefinieerd en gepositioneerd: achtergrond van de probleemstelling en de plaats van de probleemstelling binnen het bestaande veld van organisatieonderzoek in management accounting. Er wordt aandacht besteed aan de opkomst van additionele concurrentiefactoren zoals flexibiliteit, kwaliteit en tijdigheid en de claim dat deze nieuwe concurrentiefactoren een verlies aan relevantie van bestaande management accounting-concepten en -methoden inhoudt. Vervolgens wordt aangegeven wat de theoretische karakteristieken van een competitief meer relevant management accounting zouden moeten zijn, hierbij gebruik wordt gemaakt van de laatste, van toepassing zijnde theoretische en empirische inzichten. Besloten wordt met de opmerking dat een mogelijke verbetering van de bestaande management accounting-systemen, een andersoortig onderzoek vereist - praktijkgericht en gebaseerd op veldonderzoek.

Hoofdstuk 2 neemt de draad op bij het andersoortig onderzoek dat vereist is en werkt dit uit in termen van het gehanteerde onderzoeksontwerp en de gehanteerde methodologie. Het onderzoeksontwerp is gebaseerd op een combinatie van gevalsstudies en 'grounded theory'-analyseprocedures. Dit omwille van de feiten dat het onderzoek gebaseerd is op veldonderzoek en -observatie en op het grensvlak ligt van organisatietheorie en management accounting terwijl er geen sprake is van een uitgebreide theoretische en empirische basis voor onderzoek met dit 
soort kenmerken. Drie gevalsstudies worden beschreven van drie Nederlandse bedrijven (Van Nelle Tabak/Rotterdam, Zilverstad zilversmeden en St. Antonius metaalconstructies) die alle hun bedrijfsstructuur en -voering radicaal hebben veranderd in een stroomsgewijs ontwerp. De grounded theory-analyseprocedures, ontwikkeld vanuit sociologisch veldonderzoek en sterk gestructureerd in hun analyseproces, zijn vervolgens toegepast, daarbij een aantal gebruikelijke bezwaren met betrekking tot gevalsstudies omzeilend. In hoofdstuk 7 wordt de werking van deze procedures expliciet en uitvoerig aangetoond aan de hand van de analyse van de Van Nelle Tabak/ Rotterdam case.

In hoofdstuk 3 worden beknopt de basisgedachtengang alsmede de concepten en methoden van stroomsgewijze produktie volgens de Moderne Sociotechniek besproken. Dit hoofdstuk is volledig gebaseerd op het werk van De Sitter. Centraal in de Modern Sociotechniek staat de analyse van relaties tussen interne subsystemen waarbij een onderscheid wordt gemaakt naar produktie-, besturings- en beheersingsstructuur. Voorts staat de order-/werksstroom binnen de organisatie voorop in de integratie van de diverse bedrijfsfuncties, hetgeen leidt tot een sterk decentraal en multifunctioneel ingerichte organisatie. De benadering als zodanig is een Nederlandse voortzetting van eerdere, en beperktere, sociotechnische experimenten elders in Europa, en vereist een integrale verandering van zowel alle organisatieprocessen als de bijbehorende organisatiestructuur.

De hoofdstukken 4 tot en met 6 bevatten de drie genoemde gevalsstudies. Deze studies zijn verricht in de volgorde waarin ze opgenomen zijn. Tevens is elke gevalsstudie in chronologische volgorde van gebeurtenissen beschreven. De gevalsstudie van Van Nelle Tabak/Rotterdam omvat het herontwerp van de organisatie in de periode kort ná de verzelfstandiging door een management 'buyout' en vóór de overname door Sare Lee/Douwe Egberts. Het betreft hier vooral een organisatieverandering geinitieerd door de wil als zelfstandig bedrijf te overleven ('wederopstanding' van de organisatie). De gevalsstudie van Zilverstad betreft een klein tot middelgroot familiebedrijf dat in een sterk competitieve markt het eigen organisatievermogen als concurrentiefactor ontwikkelt ('oprichting' van de organisatie). St. Antonius ten slotte is eveneens een middelgroot familiebedrijf dat op een Europese markt tegemoet moet komen aan hoge eisen met betrekking tot kwaliteit en levertijd, waartoe de bestaande procesbeheersing en bedrijfsvoering sterk geprofessionaliseerd dient te worden ('professionalisering' van de organisatie).

Hoofdstuk 7 bevat de uitgebreide analyse van deze drie gevalsstudies. De gehanteerde grounded theory-analyseprocedures leggen daarbij een dwingende en grondige analysevolgorde op; de beschikbare gegevens worden binnen een netwerk van gerelateerde gebeurtenissen gebracht (een 'axiaal patroon') door middel van een iteratief proces van classificatie, rangschikking en betekenisgeving. De grounded theory-analyse per geval worden vervolgens vergeleken waarna er een aantal omvattende conclusies getrokken worden. De grounded theory-analysemethode als zodanig is nooit eerder binnen accounting-veldonderzoek toegepast.

Het slothoofdstuk 8 bevat de conclusies en hun bespreking, hulp voor de praktijk, de beperkingen van de studie en de suggesties voor vervolgonderzoek. Een drietal conclusies worden getrokken: Ten eerste, de concepten en algemene gedachten- 
gang van Moderne Sociotechniek zijn overdraagbaar naar management accounting-systeemontwerp. Zij resulteren in een complementaire aansluiting waarbij het resulterende management accounting-systeemontwerp, vanwege de gehanteerde volgorde van veranderingsstappen, een sterk vereenvoudigde ondersteunende functie heeft - iedereen beheerst en beoefent management accounting.

Ten tweede, de karakteristieken van een sociotechnisch management accountingsysteemontwerp, waar dus een ander organisatiemodel dan het functionalistische aan ten grondslag ligt, luiden: (1) accounting-methodieken en -technieken zijn van een conventionele tekstboekaard; (2) het ontwerp is gericht op de gedragsaspecten van accounting informatie, d.w.z. signaleren van verbeteringsmogelijkheden in de procesbeheersing binnen en tussen taakgroepen; (3) het voorziet voornamelijk in gedesaggregeerde informatie op lokaal taakgroepniveau, d.w.z. het informatiesysteem is sterk bottom-up' ontworpen; (4) het ontwerp maakt intensief gebruik van niet-financiële informatie die enerzijds relateert aan het sterk lokale karakter van het ontwerp (zie 3. hierboven) en anderzijds aan het belang van concurrentiefactoren die niet-financieel van aard zijn, zoals kwaliteit, levertijd en flexibiliteit; (5) het management accounting-systeemontwerp is een integraal deel van het organisatieontwerp, met andere woorden het organisatieontwerp is géén gegeven ontwerpconditie, maar een actief bestanddeel van het management accounting-systeemontwerp; en (6) het organisatieontwerp leidt to een transparente organisatie waarbinnen kostengedragingen eenvoudig en snel zijn na te speuren, d.w.z. 'traceability' staat voorop.

Ten derde, de hantering van Moderne Sociotechnische concepten als het onderliggende organisatiemodel stimuleert het ontstaan van een lerende organisatie. Het management accounting-systeemontwerp speelt hierin een duidelijke rol door middel van de karakteristieken van 'minimale kritische specificatie' (prestatiemaatstaven zijn richtinggevend geformuleerd) en 'leren te leren' (de norm van een beheersingsregelkring wordt continu ter discussie gesteld door de taakgroepen). Het is vooral het regelkringconcept dat het management accountingaandeel in de lerende organisatie betreft: Regelkringen worden 'bottom-up', zonder uitzondering, op elk organisatieniveau gealloceerd; op lokaal niveau wordt de regelkring gehanteerd om procesbeheersing te vereenvoudigen en onderlinge samenwerking in normbepaling en procesbewaking aan te moedigen; en de normen in regelkringen worden vooral gehanteerd als verbeteringsinstrument. 


\section{Curriculum Vitae}

Henri Johan Eduard (Hanno) Roberts werd op 8 november 1959 geboren te Pretoria, Zuid-Afrika. In 1979 slaagde hij voor het eindexamen Atheneum, waarna hij economie ging studeren aan de Erasmusuniversiteit Rotterdam. Na het behalen van zijn kandidaatsexamen in 1983 studeerde hij vervolgens bedrijfskunde aan de toenmalige Interfaculteit Bedrijfskunde te Delft. In 1986 behaalde hij zijn doctoraaldiploma Bedrijfskunde aan de Faculteit Bedrijfskunde van de Erasmusuniversiteit Rotterdam, waarna hij als Wetenschappelijk Assistent in dienst trad van de sectie Berichtgeving en Accountancy van de Rijksuniversiteit Limburg. Na vier jaar werd hij als Toegevoegd Onderzoeker verbonden aan zowel de sectie Berichtgeving en Accountancy als het Technologie, Arbeid en Organisatie (TAO) programma, ondergebracht in het Maastricht Economic Research institute on Innovation and Technology (MERIT). Van 1991 tot 1992 was hij aan beide groepen verbonden als Universitair Docent.

Binnen het TAO-programma is hij verantwoordelijk voor de onderzoeklijn Management Accounting. Zijn onderzoekbelangstelling ligt op het grensgebied van de Management Accounting en de Organisatietheorie, en betreft met name de relatie tussen organisatie-/accountingsysteemontwerp en organisatiegedrag.

Vanaf 1992 is hij als Visiting Professor verbonden aan de Universidad Carlos III de Madrid, Spanje.

Henri Johan Eduard (Hanno) Roberts was born on November 8th, 1959, in Pretoria, South-Africa. In 1983, he obtained his Bachelors degree in Economics and Business Administration from the Erasmus University of Rotterdam, after which he graduated in 1986 from the Rotterdam School of Management with a Master's degree in Business Administration. From 1986 onwards, he worked consecutively as a research assistant, research fellow and assistant professor at both the Department of Accounting and the Maastricht Research institute on Innovation and Technology (MERIT) of the University of Limburg, The Netherlands. At MERIT he participates in the Technology, Work and Organisation programme in which he is responsible for the Accounting research line. His research interests are located at the interface of Management Accounting and Organisation Theory, and focus mainly on the relationship between Organisation Design/Management Accounting Design and Organisational Behaviour. As of 1992, Hanno has been a Visiting Professor at the Universidad Carlos III de Madrid, Spain. 


\section{Accountability and Responsibility}

The rapid increase in technological advancement, the extension of competition with elements such as quality, timeliness, flexibility and innovativeness, together with the effects of the business cycle, resulted in structural changes inside the organisational model underlying management accounting. Management accounting has to re-establish the links between organisational management and the design of the internal accounting system.

This study looks at the role that the design of the organisation plays in the redesigning of the management accounting system. It describes how three firms completely reorganised their organisation. The new design is highly decentralised and flow-oriented, placing responsibilities as low in the organisation as possible.

Concurrently, the management accounting system was redesigned, and local responsibilities were matched with the new accountabilities that arose.

It was found that the resulting management accounting system was one of a conventional, textbook nature. However, accounting instruments were distinctively applied, turning their focus towards the behavioural implications and actively encouraging organisational learning and continuous improvement efforts.

The case study descriptions were analysed by use of grounded theory procedures, a methodology that has never before been applied to managerial accounting research. 